\title{
Stress Analysis of High-Level Waste Canisters: Methods, Applications, and Design Data
}

F. A. Simonen

S. C. Slate

October 1979

Prepared for the U.S. Department of Energy under Contract EY-76-C-06-1830

Pacific Northwest Laboratory Operated for the U.S. Department of Energy by Battelle Memorial Institute 


\title{
NOTICE
}

This report was prepared as an account of work sponsored by the United States Government. Neither the United States nor the Department of Energy, nor any of their employees, nor any of their contractors, subcontractors, or their employees, makes any warranty, express or implied, or assumes any legal liability or responsibility for the accuracy, completeness or usefulness af any information, apparatus, product or process disclosed, or represents that its use would not infringe privately owned rights.

The views, opinions and conclusions contained in this report are those of the contractor and do not necessarily represent those of the United States Government or the United States Department of Energy.

\author{
PACIFIC NORTHWEST LABORATORY \\ operated by \\ BATTELLE \\ for the \\ UNITED STATES DEPARTMENT OF ENERGY \\ Under Contract EY-76-C-06-7830
}
Printed in the United States of America
Avallable from
National Technical Information Service
United Stater Department of Cornmerce
5245 Part Royal Road
Spriogfield, Virginia 22151

Price: Printed Copy 5

$\therefore$ Mierotiche 5200

NTIS

-Pages Selling frice

$001-025 \quad 34.00$

$026-050 \quad 5450$

$051-075 \quad 55.25$

$076-100 \quad \$ 6.00$

$101.125 \quad 56.50$

$126.150 \quad \$ 7.25$

151.175 58.00

$176-200 \quad 59.00$

$201.225 \quad \$ 9.25$

$225.250 \quad 59.50$

$251.275 \quad 510.75$

$276 \cdot 300 \quad \$ 11.00$ 
PNL-3036

UC-70

\section{4}

STRESS ANALYSIS OF HIGH-LEVEL WASTE CANISTERS:

METHODS, APPLICATIONS, AND DESIGN DATA

F. A. Simonen

S. C. Slate

October 1979

Prepared for

the U.S. Department of Energy

under Contract EY-76-C-06-1830

Pacific Northwest Laboratory

Richland, Washington 99352 


$$
\begin{gathered}
\cdot \\
: \\
:
\end{gathered}
$$$$
+
$$
2 
The Pacific Northwest Laboratory (PNL) is conducting research and development studies on technology for immobilization of nuclear wastes. In this report, an overview of stress analysis methods, structural design procedures, and design data is presented for canisters used to package solidified wastes, particularly borosilicate glass. In addition, waste processing, canister materials, fabrication and inspection methods, and performance testing are summarized.

Sources of stress in canisters are lifting and handling loads, internal pressure, hightemperature filling operations, transient heating and cooling, differential thermal expansions of canisters and glass, and impact loadings from low-probability accidents. Results of case studies that illustrate applicable methods of stress analyses are presented for these sources of stress.

Existing sections of the American Society of Mechanical Engineers (ASME) Boiler and Pressure Vessel Code are reviewed and found to be applicable to canister fabrication, but the code does not cover many aspects of canister service loadings. Specialized criteria for minimum wall thicknesses to sustain filling stresses are proposed in this report. Results of a test program to measure the creep strength of candidate canister materials are described.

Methods to predict residual stresses in the walls of waste canisters are described; predicted residual stress levels agree with measured stress levels. The consequences of these residual stresses are reviewed, and stress-corrosion cracking is identified as the mode of canister failure affected by residual stresses.

Canister-closure design is covered in detail, particularly the welding and inspection of the final closure seal-weld. It is shown that the methods of fracture mechanics and fatiguecrack-growth analyses are valuable tools for evaluating the performance of closure welds in the presence of crack-like defects.

Canister performance in process trials at PNL shows the ability of canisters to survive high temperatures and loadings during processing. The results of impact tests at PNL show that a suitably designed canister can sustain severe impacts without loss of integrity. 


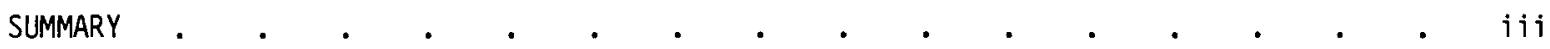

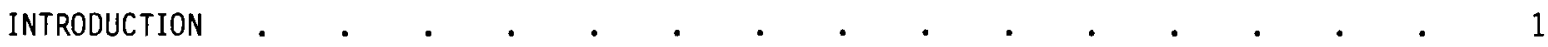

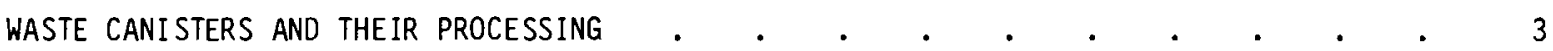

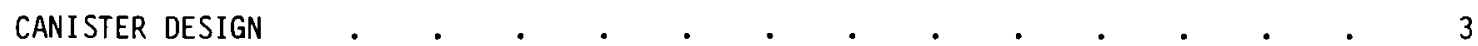

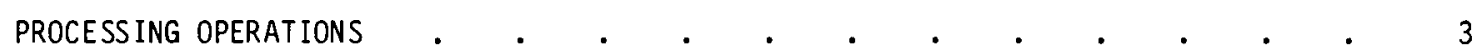

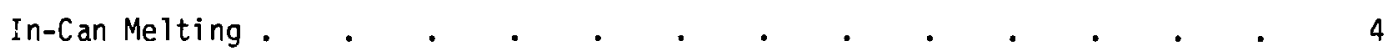

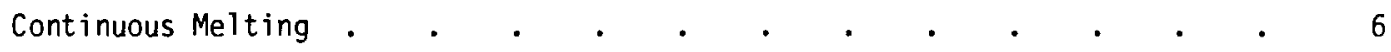

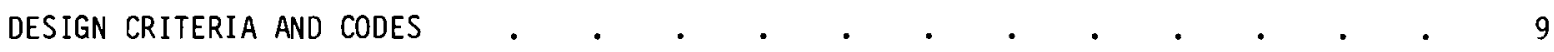

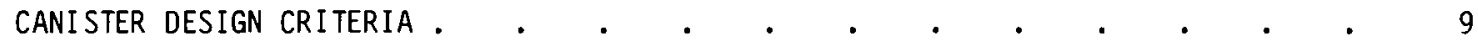

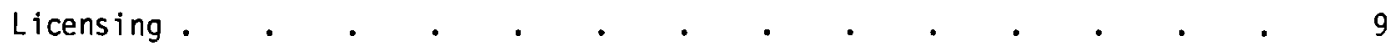

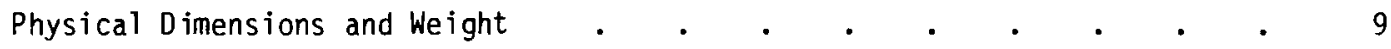

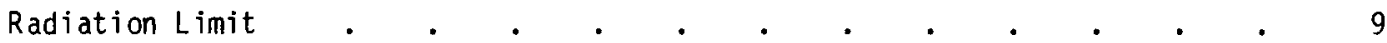

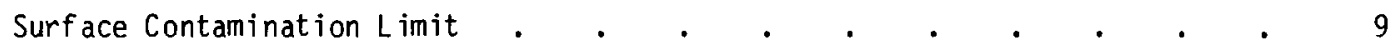

Design and Fabrication . . . . . . . . . . . . . . . 10

Canister Operations . . . . . . . . . . . . . . 10

Waste and Canister Documentation . . . . . . . . . . . . 10

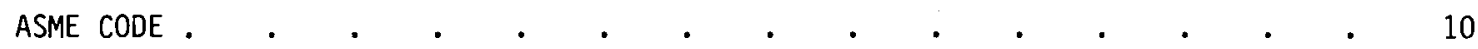

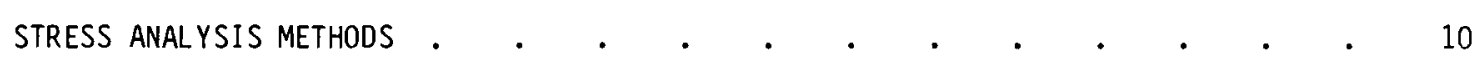

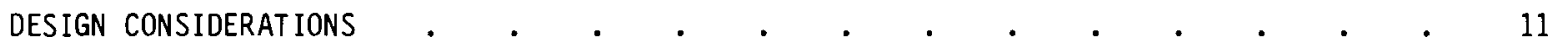

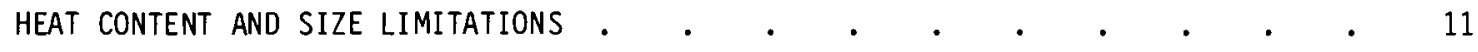

CLOSURE DESIGN •

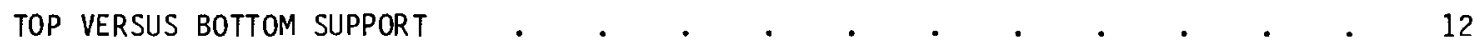

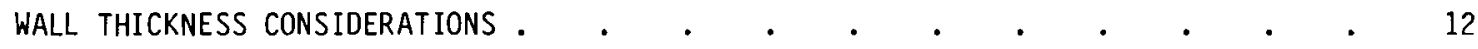

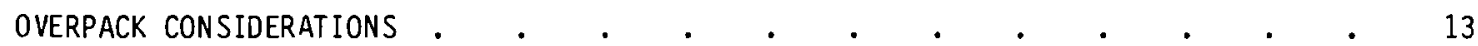

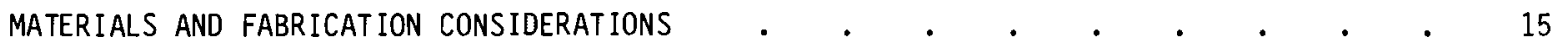

MATERIALS SELECTION •

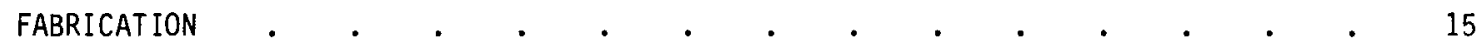

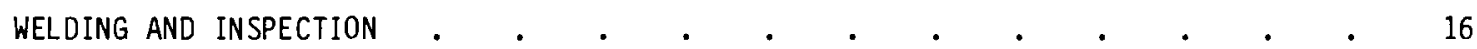

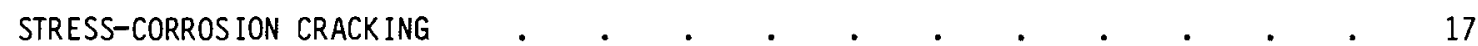

CREEP STRENGTH •

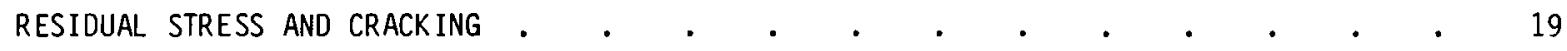


RESIDUAL STRESSES $\quad$ •

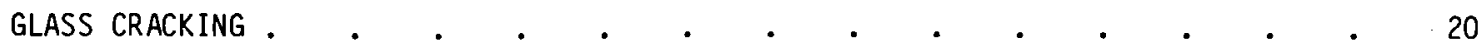

PERFORMANCE TESTING AND ACCIDENT EVALUATION

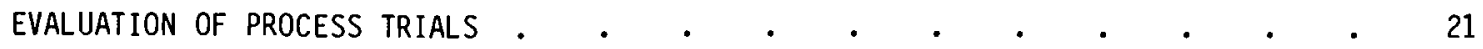

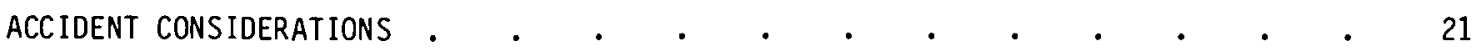

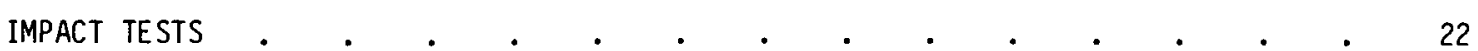

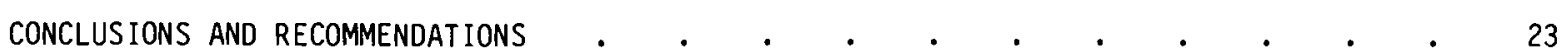

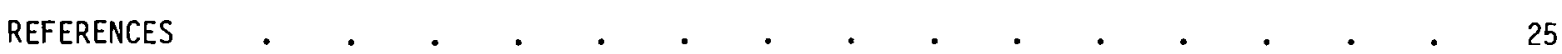

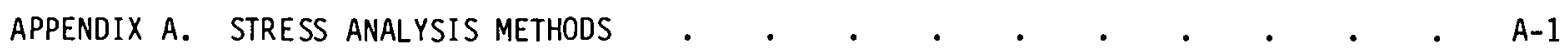

APPENDIX B. APPLICATION OF ASME CODE

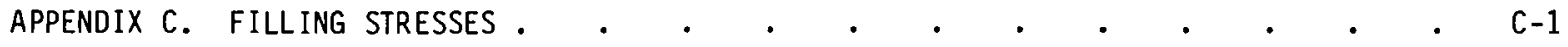

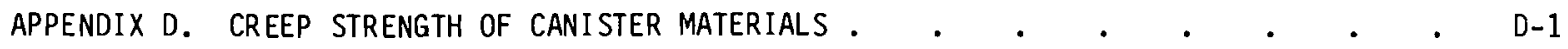

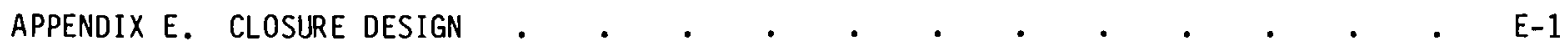

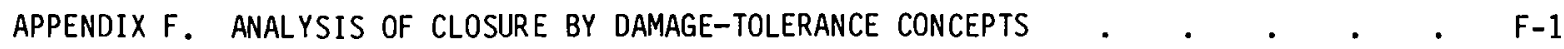

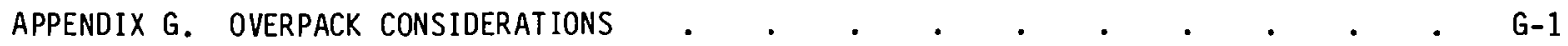

APPENDIX H. ACCIDENT PERFORMANCE . . . . . . . . . . . . . . . . . . . . H-1

APPENDIX I. RESIDUAL STRESSES AND GLASS FRACTURING 


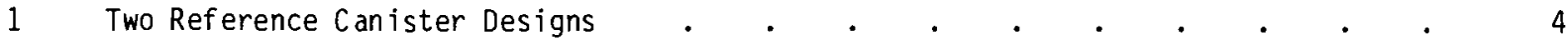

2 Schematic of the ICM Furnace Connected to the Spray Calciner . . . . 5

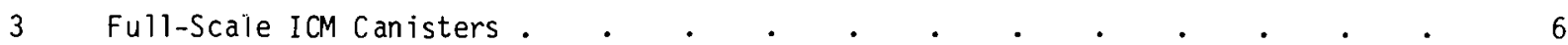

4 Schematic of the Joule-Heated Ceramic Melter for the CM Process . . . . 7

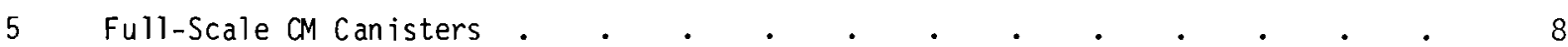

A.1 Dimensions of Short Top-Supported Canister . . . . . . . . . . . A-4

A.2 Isochronous Stress-Strain Curves Used in Stress Analyses of
Canister at $1050^{\circ} \mathrm{C}\left(1922^{\circ} \mathrm{F}\right)$

A.3 Comparison of Predicted Bottom Deflections from Small and

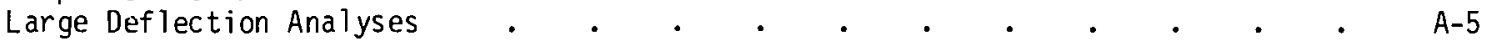

A.4 Predicted Bottom Deformation in Canister at $1100^{\circ} \mathrm{C}\left(2012^{\circ} \mathrm{F}\right.$ )

for $32 \mathrm{~h}$ with 8-f Glass Fill Height $\quad . \quad$. . . . . . . . . . . . A-6

A.5 Factor to be Applied to Small Deflection Solution for Bottom of Canister to Correct for Geometric Nonlinear Effect - Based on Isochronous Analyses of Canister at $1100^{\circ} \mathrm{C}\left(2012^{\circ} \mathrm{F}\right)$

A.6 Predicted Bottom Deformation in Canister at $1050^{\circ} \mathrm{C}\left(1922^{\circ} \mathrm{F}\right.$ ) for $24 \mathrm{~h}$ with $3-f$ Glass Fill Height

A.7 Predicted Bottom Surface Stress in Canister at $1050^{\circ} \mathrm{C}\left(1922^{\circ} \mathrm{F}\right)$ for $24 \mathrm{~h}$ with $3-f$ Glass Fill Height

C.1 Design Strength of 304L Stainless Steel Based on Stress to Produce $1 \%$ Strain in a Specified Time Period . . . . . . . . . . C-2

C.2 Design Strength of Inconel Alloy 601 Based on Stress to Produce $1 \%$ Strain in a Specified Time Period

C.3 Strength of $304 \mathrm{~L}$ Stainless Steel vs Temperature . . . . . . . . . C -6

C.4 Comparison of 4000-h Rupture Strength of Various Alloys . . . . . . . C-7

C.5 Canister Creep Test Configuration 304L Stainless Steel . . . . . . . C-9

\begin{tabular}{l} 
C.6 Isochronous Stress-Strain Curves Used in Calculation of \\
Canister Creep Deformation \\
\hline
\end{tabular}

C.7 Comparison of Predicted and Measured Canister Bottom Deformation

C.8 Comparison of Predicted and Measured Canister Bottom Deformation
for Assumed Bottom Temperature of $1060^{\circ} \mathrm{C}\left(1940^{\circ} \mathrm{F}\right) \quad . \quad . \quad . \quad . \quad$. $\quad .10$

C.9 Effect of Pressure History and Fill Rate on Bottom Deflection of a Canister $\quad$ C-14

C.10 Joint Stresses for Bottom-Supported Canister with Flat Bottom

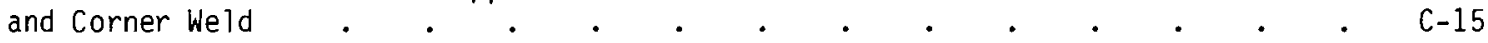
\begin{tabular}{l} 
C.11 Joint Stresses for Bottom-Supported Canister with Flat Bottom \\
and Turned Corner \\
\hline
\end{tabular} 
C.12 Canister Thermal Stresses in Region of Zone Separation in Zone Melting

Furnace, 16-in.-Dia Canister with 6.35-mm- (0.25-in.-) Thick Wall

C.13 Estimated Permanent Deformation of Canister Wall at Zone Separation Points of Zone Melting Furnace, 16-in.-Dia Canister with 6.35-mm- (0.025-in.-) Thick Wall

C.14 Model for Analysis of Banana Mode of Canister Thermal Distortion . . . . . C-18

C.15 Predicted Thermal Distortion of Canister for Banana Mode . . . . . . C-19

D.1 Microstructures of Materials Before Testing Glyceregia Etch, Magnified 100X

D.2 Test Specimens After Exposure.

D.3 Creep Curves for 304L Stainless Steel Plate (1/2 in.) Tested at $950^{\circ}, 1000^{\circ}$ and $1050^{\circ} \mathrm{C}$ and $13.8 \mathrm{MN} / \mathrm{m}^{2}$ (20 ksi) in Air

D.4 Creep Curves for 304L Stainless Steel Plate (1/2 in.) Tested in Air at $1000^{\circ} \mathrm{C}-17.7 \mathrm{MN} / \mathrm{m}^{2}(3.0 \mathrm{ksi})$ and $1100^{\circ} \mathrm{C}-10.3 \mathrm{MN} / \mathrm{m}^{2}(1.5 \mathrm{ksi})$

Creep Curves for 304L Stainless Steel Plate (1/2 in.) Tested in Air at $1050^{\circ}$ and $1100^{\circ} \mathrm{C}$

D.6 Creep Curves for 304L Stainless Steel Plate (1/2 in.) Tested in Air at $950^{\circ}, 1000^{\circ}, 1050^{\circ}$ and $1100^{\circ} \mathrm{C}$ and $6.9 \mathrm{MN} / \mathrm{m}^{2}(1.0 \mathrm{ksi})$

D.7 Creep Curves for $304 \mathrm{~L}$ Stainless Steel Plate (1/2 in.) Tested in Air at $950^{\circ}, 1000^{\circ}, 1050^{\circ}$ and $1100^{\circ} \mathrm{C}$ and $1.38 \mathrm{MN} / \mathrm{m}^{2}(0.2 \mathrm{ksi})$ and $3.45 \mathrm{MN} / \mathrm{m}^{2}(0.5 \mathrm{ksi})$

D. 8 Relative Creep Strengths of 1/4-in. and 1/2-in. 304L Stainless Steel Plate Tested in Air at $1050^{\circ} \mathrm{C}$ and $10.3 \mathrm{MN} / \mathrm{m}^{2}(1.5 \mathrm{ksi})$

D.9 Effect of Plate Thickness (1/4 vs. 1/2 in.) on the Creep Strength of $304 \mathrm{~L}$ Stainless Steel at $1050^{\circ} \mathrm{C}$ and $6.9 \mathrm{MN} / \mathrm{m}^{2}(1.0 \mathrm{ksi})$

D.10 Effect of Vacuum Versus Air Environment on the Creep Strength of 304L Stainless Steel Plate $(1 / 2 \mathrm{in.})$ at $1050^{\circ} \mathrm{C}$ and $10.3 \mathrm{MN} / \mathrm{m}^{2}(1.5 \mathrm{ksi})$

D.11 Effect of Vacuum Versus Air Environment on the Creep Strength of $304 \mathrm{~L}$ Stainless Steel Plate (1/2 in.) at $1050^{\circ} \mathrm{C}$ and $6.9 \mathrm{MN} / \mathrm{m}^{2}(1.0 \mathrm{ksi})$

D.12 Effect of Vacuum Versus Air Environment on the Creep Strength of $304 \mathrm{~L}$ Stainless Steel Plate $\left(1 / 2\right.$ in.) at $1100^{\circ} \mathrm{C}$ Creep Curves for Inconel $601 \mathrm{Plate}(1 / 4$ in.) Tested in Air at $1050^{\circ} \mathrm{C}$ and $1100^{\circ} \mathrm{C}$

D.14 Creep Curves for Inconel $601 \mathrm{Plate}\left(1 / 4 \mathrm{in.)}\right.$ Tested at $1050^{\circ}$ and $1150^{\circ} \mathrm{C}$ in Air.

D.15 Creep Curves for Inconel 601 Plate ( $1 / 4$ in.) Tested in Air at $1050^{\circ}, 1100^{\circ}$ and $1150^{\circ} \mathrm{C}$ and $6.9 \mathrm{MN} / \mathrm{m}^{2}(1.0 \mathrm{ksi})$

D.16 Creep Curves for Inconel $601 \mathrm{Plate}(1 / 4 \mathrm{in.})$ Tested in Air at $1050^{\circ}, 1100^{\circ}$ and $1150^{\circ} \mathrm{C}$

D.17 Creep Curves for Inconel 601 Plate (1/4 in.) Tested in Air at $1100^{\circ}$ and $1150^{\circ} \mathrm{C}$ 
0.18 Creep Curves for Inconel 601 Plate (1/4 in.) Tested in Air at $1050^{\circ}, 1100^{\circ}$ and $1150^{\circ} \mathrm{C}$

D.19 Larson-Miller Plot of Rupture Strengths for Type 304L Stainless Steel and Inconel 601

D.20 Design Curves for 304L Stainless Steel Plate (1/2 in.) in Air . . . . D-14

D.21 Design Curves for 304L Stainless Steel Plate (1/2 in.) in Air . . . . D-15

D.22 Design Curves for Inconel $601 \mathrm{Plate}(1 / 4 \mathrm{in.})$ at $1050^{\circ}, 1100^{\circ}$ and $1150^{\circ} \mathrm{C} \quad$ D-15

D.23 Isochronous Stress-Strain Curves for 304L Stainless Steel at $950^{\circ} \mathrm{C}$. . . D-16

D.24 Isochronous Stress-Strain Curves for $304 \mathrm{~L}$ Stainless Steel at $1000^{\circ} \mathrm{C}$. . . D-17

D.25 Isochronous Stress-Strain Curves for 304L Stainless Steel at $1050^{\circ} \mathrm{C}$. . . D-17

D.26 Isochronous Stress-Strain Curves for $304 \mathrm{~L}$ Stainless Steel at $1100^{\circ} \mathrm{C}$. . . D-18

D.27 Isochronous Stress-Strain Curves for Inconel Alloy 601 at $1050^{\circ} \mathrm{C}$. . . D-18

D.28 Isochronous Stress-Strain Curves for Inconel Alloy 601 at $1100^{\circ} \mathrm{C} \quad$ • . . D-19

D.29 Isochronous Stress-Strain Curves for Inconel Alloy 601 at $1150^{\circ} \mathrm{C}$. . . D-19

E.1 Schematic Drawing of the Twist-Lock Closure . . . . . . . . . E-2

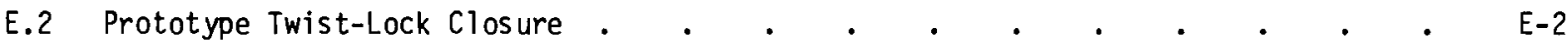

E.3 PNL Prototype Canister Closure Welder Using the GTA Welding Process . • . E-3

E.4 Schematic Diagram of the Equipment for Helium-Leak-Checking a Canister • • E-4

E.5 Schematic Diagram Showing Transducers and Instrumentation for Ultrasonic Inspection . . . . . . . . . . . $\quad$. E-5

E.6 Shell Segment Model of Twist-Lock Closure . . . . . . . . . . . E-6

E.7 Dimensions and Lifting Stresses for Twist-Lock Closure for 12-in.-Dia Canister . E-7

E.8 Dimensions and Lifting Stresses for Twist-Lock Closure for 16-in.-Dia Canister . E-8

E.9 Dimensions and Lifting Stresses for Twist-Lock Closure for 20-in.-Dia Canister . E-9

E.10 Dimensions and Lifting Stresses for Twist-Lock Closure for 24-in.-Dia Canister of Flat-Ended Configuration . . . . . . . E-10

E.11 Dimensions and Lifting Stresses for Twist-Lock Closure for
24-in.-Dia Canister of Contoured-Ended Configuration . . . . . . . . . E-10

E.12 Finite-Element Model of Twist-Lock Canister Lid . . . . . . . . E-11

E.13 Calculated Rim Displacement for Canister Lid . . . . . . . . . . . E-11

E.14 Calculated Stress Contours (2x Max. Shear) on Lower Surface of Lid . . - E-12

E.15 Calculated Stress Contours (2x Max. Shear) on Midplane of Lid . . . . E-12

E.16 Calculated Stress Contours (2x Max. Shear) on Upper Surface of Lid . . . E-13

E.17 Schematic Drawing of Flange Closure . . . . . . . . . . . E-13

E.18 Dimensions of Flange Closure and Stress Output Locations . . . . . . E-14 
F.1 Full-Scale Canister . . . . . . . . . . . . . . . . . . F-1

F.2 Finite-Element Model for Thermal Structural Analysis . . . . . . . F F-2

F.3 Temperature Distribution at $4.6 \mathrm{~s}$ into Water Quench . . . . . . F-3

F.4 Transient Thermal Stress in Seal Plates Adjacent to Closure Weld . . . . . F-4

F.5 Postulated Weld Defects . . . . . . . . . . . . . . F-4

F.6 Detailed Finite-Element Model for Fracture Mechanics Analysis . . . . F-5

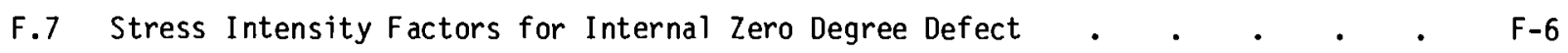

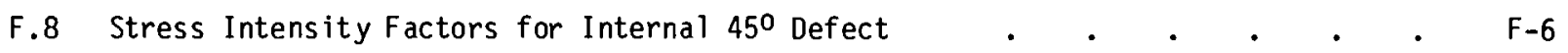

F.9 Stress Intensity Factors for Internal $90^{\circ}$ Defect $\quad$. . . . . . . . . . F-7

F.10 Stress Intensity Factors for External Zero Degree Defect . . . • . F-7

F.11 Stress Intensity Factors for External $45^{\circ}$ Defect _ . . . . . . F-8

F.12 Stress Intensity Factors for External $90^{\circ}$ Defect . . . . . . F 8

F.13 Fatigue Crack Growth for Internal Defects . . . . . . . . . F-9

F.14 Fatigue Crack Growth for External Defects . . . . . . . . F-10

F.15 Metalographic Section of Closure Weld . . . . . . . . . . . F-11

F.16 Finite-Element Model Based on Metalographic Section of Weld Bead . • . . F-11

F.17 Stress Intensity Factors for Internal Defects in Weld Bead

F.18 Fatigue Crack Growth for Internal Defects in Weld Bead . . . . . . F-12
of Metalographic Section. . . . . . . . . F

G.1 Schematic Drawing of a Canister in an Overpack . . . . . . . . . . G-1

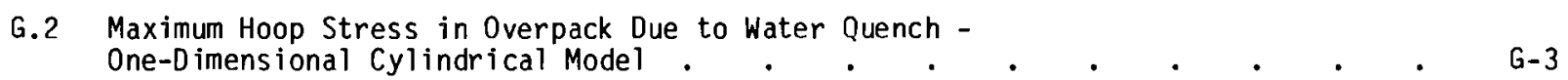

G.3 Predicted Outer Surface Stress in Canister Overpack Due
to Rapid Cooling in Water . . . . . . . . . . G-4

H.1 Mobile Crane and Canisters in Position for Impact Testing . . . . . H-3

H.2 View of Impact Pad with Canister Number 5 About to Impact . . . . . . H-3

H.3 Canister 45 Showing Bottom Deformation Following 31.7-m (104-f)
Drop onto Corner . . . . . . . . . H-6

H.4 Top of Canister Number 30 Following Drop from $6.1 \mathrm{~m}(20 \mathrm{f})$. . . . . H-6

H.5 Calculated Stresses in Canister Closure System for Internal

I.1 Thermal Analys is Model for ANSYS Finite-Element Code . . . . . . . I-3

I.2 Stress Analysis Model for Finite-Element Code AXISOL . . . . . . . . . I-4

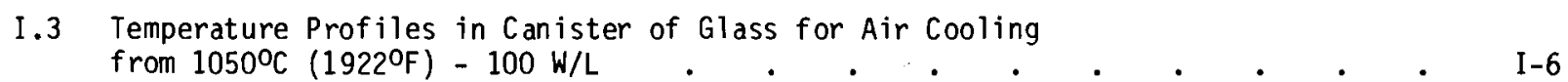


I.4 Stress in Wall of Canister Showing Effect of Heat Generation . . . . I-7

I.5 Stress in Canister Wall Showing Effect of Thermal Cycling . . . . . I-8

I.6 Effect of Water Quench on Stress in Canister Wall . . . . . . . . . I-9

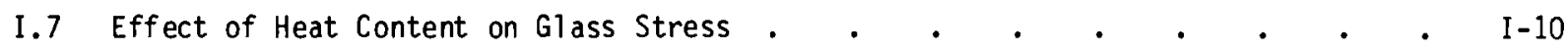

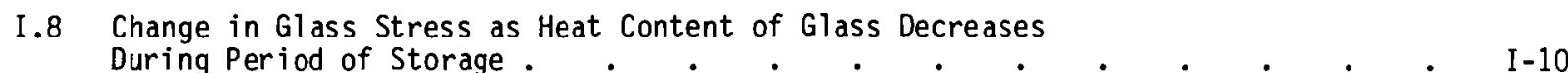

I.9 Effect of Cooling Rate on Glass Stress (Zero Heat-Generation Glass) . . . . I-11

I.10 Glass Filled 8-in.-Dia Canister with 8 Internal Fins . . . . . . I-12

I.11 Stress Analysis Model for Glass Fracturing . . . . . . . . . . . I-12

I.12 Calculated Contours of Maximum Tensile Stresses in Glass Due to
Differential Thermal Expansion Coefficients of Glass and Metal . . . . . I-13

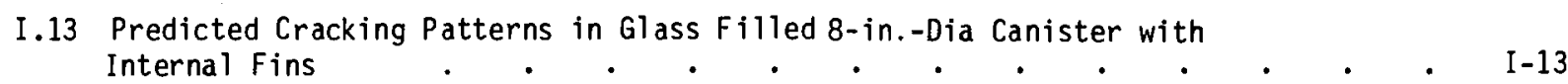

I.14 G1ass Cracking Pattern as Seen in Sectioned Canister Outside Diameter $=219 \mathrm{~mm}$ (8.625 in.), Wall Thickness $=8.18 \mathrm{~mm}(0.322 \mathrm{in.})$ 


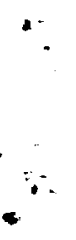

$-$ 


\section{$\underline{\text { TABLES }}$}

1 Surface Contamination Limits of Canisters (49 CFR 173.397) . . . . . . 9

A.1 Computer Codes Used in Canister Studies . . . . . . . . . . . . A-2

C.1 Minimum Wall Thickness - 304L Stainless Steel - To Avoid Excessive
Creep Deformation During Filling by ICM. . . . . . C-4

C.2 Minimum Wall Thickness - Inconel 601 - To Avoid Excessive

C.3 Estimate of Safety Factors in Design of Canisters for ICM . . . . . . . C-5

C.4 Minimum Thickness of Low-Carbon Steel Canister Wall to Sustain
Stresses During Filling with the CM

C.5 Minimum Thickness of $304 \mathrm{~L}$ Stainless Steel Canister Wall to Sustain Stresses During Filling with the CM-Design Stress of $25.5 \mathrm{MN} / \mathrm{m}^{2}(3700 \mathrm{psi}) \cdot{ }^{2}$. $\quad \mathrm{C}-8$

C.6 Canister Parameters and Loading Cycle Definition . . . . . . . C-12

C.7 Calculated and Measured Diametrical Expansions of Canisters . . . . . C-13

C.8 Calculated and Measured Bottom Deflection of Canisters . . . . . . C-13

D.1 Chemical Composition of Materials Tested (wt\%) . . . . . . . . . D-2

D.2 Summary of Data on Creep and Rupture Properties for $304 \mathrm{~L}$

D.3 Summary of Data on Creep and Rupture Properties of

E.1 Results of Stress Analyses for Various Design Parameters . . . . . E-14

H.1 Description of Canisters Impacted in 1977 Series Drop Tests . . . . . . H-4

H.2 Results of 1977 Series of Canister Impact Tests . . . . . . . . . H-5

H.3 Pressure Ratings of Canister Top . . . . . . . . . . . . . . H-8

I.1 Thermal and Physical Properties of Glass [Density $=3.2 \mathrm{gm} / \mathrm{cc}\left(0.115 \mathrm{lb} / \mathrm{in} .{ }^{3}\right)$ ] . I-3

I.2 Thermal and Physical Properties of $304 \mathrm{~L}$ Stainless Stee1
$[$ Density $=7.8 \mathrm{gm} / \mathrm{cc}(0.28 \mathrm{lb} / \mathrm{in} .3)]$

I.3 Mechanical Properties of Glass . . . . . . . . . . . . . . I-5

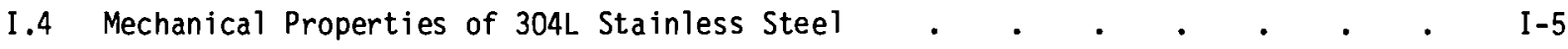




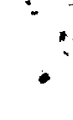

$+$

. 
STRESS ANALYSIS OF HIGH-LEVEL WASTE CANISTERS: METHODS, APPLICATIONS, AND DESIGN DATA

\section{INTRODUCTION}

Through the High-Level Waste (HLW) Immobilization Program, the Pacific Northwest Laboratory (PNL), operated by Battelle Memorial Institute for the U.S. Department of Energy, is developing process technology for the immobilization of high-level liquid wastes. These wastes are the radioactive by-products of various nuclear operations. This work is part of the overall waste management program whose objective is to control and isolate these wastes. To do this a system of multiple barriers is being developed. The first barrier is waste that is solidified into a stable durable form; borosilicate glass (Mendel 1978) is a leading candidate waste form. The second level of containment is an engineered barrier, of which the storage canister may be an important part. The final barrier is a stable geologic formation, where the waste will be placed for permanent disposal.

The subject of this report is the structural integrity of waste canisters during processing, handling, transportation, and interim storage before their ultimate geologic disposal. Consideration of canister durability in the geologic formation is beyond the scope of this report.

Most of the work discussed in this report was done on canisters designed for vitrified waste. However, much of the information is applicable to canisters containing alternative waste forms.

In support of the Waste Immobilization Program, PNL has conducted research to analyze stresses in canisters and to evaluate canister integrity under projected service loadings. This report describes case studies that illustrate applicable stress analys is methods, show preferred design approaches, and provide useful engineering design data. The report is divided into two major parts. The first part, the body of the report, summarizes the principal features of canisters and their processing, design criteria, materials and fabrication considerations, results of process trials, and accident evaluations. The second part, Appendices A through I, details the specific investigations and case studies. 


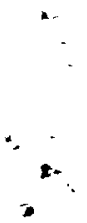

.

ง 


\section{WASTE CANISTERS AND THEIR PROCESSING}

An important part of the Waste Immobilization program at PNL is the task of developing the primary glass storage canister. The objective of this work is to develop a flexible canister system that will provide high-integrity containment for HLW glass, from processing to final disposal. In this report we consider the functions of the primary canister during processing. The canister prevents any direct contact between the glass and the immediate environment, protects the glass from physical damage, and provides a means for handling the glass. The canister must be designed to be compatible with the variety of environments it encounters during the many processing operations. The purpose of this section is to describe basic canister designs and the processing operations for filling and storing the canister. We do not consider the role of the canister during disposal.

\section{CANISTER DESIGN}

The design of a waste canister is based on safety considerations, government regulations, facility requirements, and economics. There is currently no accepted set of criteria on waste canisters. A preliminary draft of acceptance criteria has been proposed by Moore (1978), and is briefly reviewed in the next section. These criteria have been combined with processing requirements established at PNL to form a basis for the current PNL canister designs.

Reference canister designs have been developed for both the in-can melting (ICM) and continuous-melting (CM) processes that are under development at PNL. The basic design consists of a standard, single-wall pipe with flanged-only tank heads welded to both ends. The top may also be a standard, dished head on large-diameter canisters. The top has an opening that is carefully designed to couple to the vitrification equipment and to be reliably closed and sealed.

The dia of the canisters range from $12 \mathrm{in.}$ to $36 \mathrm{in.}$ and their length is about $10 \mathrm{f}$. The construction material is stainless or carbon steel, depending on the process and service requirements. The current reference alloys are $304 \mathrm{~L}$ stainless steel and Inconel 601 for ICM canisters and carbon steel for CM canisters. Other alloys are also being studied to meet new requirements. Figure 1 shows two possible canister designs. The first is an ICM canister. The internal fins are necessary to achieve the high melting rates desirable for large-scale production and for improved heat transfer through the glass during storage, if the glass has a high heat-generation rate. The second canister is for use with the CM process.
The selection of a specific optimal design for a storage canister (i.e., diameter, length, wall thickness, material, etc.) depends on the requirements of the overall waste management system. The design of an optimal canister for most systems is technically feasible. Some of the various aspects of canister design are discussed by Slate and Ross (1977).

\section{PROCESSING OPERATIONS}

A major part of the work on canisters at PNL is directed towards studying all the processing steps a canister goes through, from fabrication to final disposal. Initial results from this work served as the basis for the calculations of the service loads used in this document. Fourteen major processing operations have been identified. From these fourteen operations, seven were selected for specific study. These areas are:

- fabrication and quality assurance

- glass filling

- cooldown

- final closure

- decontamination

- interim storage

- transportation.

The processing step that has the greatest effect on the canister is the glass-filling operation. At PNL we are developing two processes for converting HLW into glass. The first is the ICM process, where calcine and glass-forming materials are melted in the canister. The second technique is the CM process, in which liquid or calcined waste is combined with glass formers and is melted continuously in a glass melter. Both these processes produce high-quality waste 


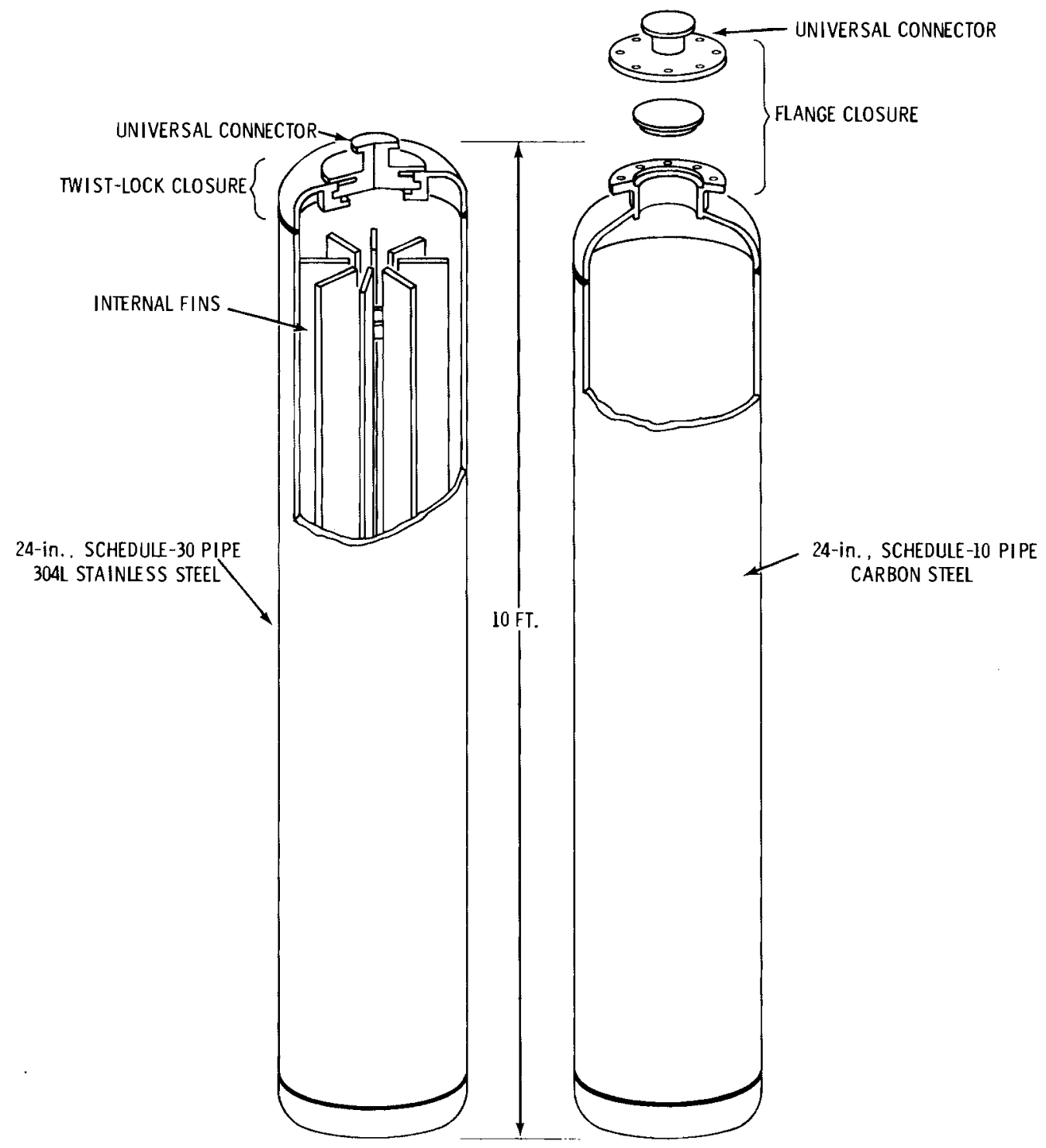

FIGURE 1. Two Reference Canister Designs

glass and are well developed. However, there are significant differences between the processes that affect the structural requirements for the canister. These two processes provide the reference operating conditions that are used in this report for the canisters during filling.

\section{In-Can Melting}

The ICM process uses the storage canister as the melting crucible for the glass (Blair 1976 and 1978). Figure 2 shows the
ICM furnace connected to a spray calciner. The spray calciner is coupled to both the ICM and CM process equipment. The calciner converts liquid wastes to a fine powder of waste oxides by spray drying (Mikols 1978).

The canister is placed on the bottom of the furnace and is covered by an insulated top. It is then connected to the calciner through a hole in the furnace top and is preheated to $1050^{\circ} \mathrm{C}\left(1922^{\circ} \mathrm{F}\right)$ before feeding is started. As the waste oxides fall into the canister, they mix with glass-forming 


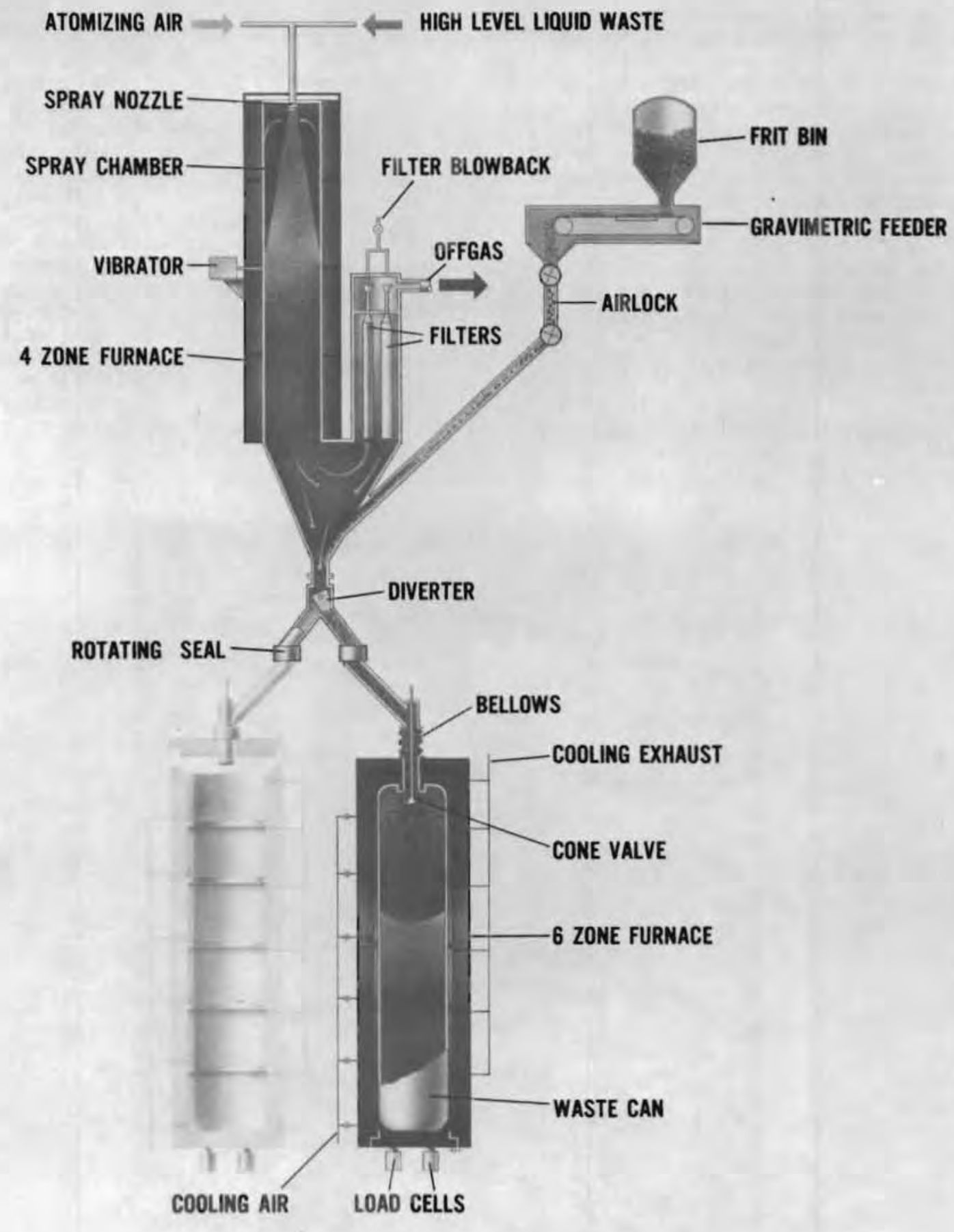

FIGURE 2. Schematic of the ICM Furnace Connected to the Snray Calciner 
additives that are metered in. At $1050^{\circ} \mathrm{C}$ $\left(1922^{\circ} \mathrm{F}\right)$ this mixture melts and radionuclides react with the glass additives, chemically bonding the waste in the glass. When the canister is filled and feeding has stopped, its temperature is held at $1050^{\circ} \mathrm{C}$ (19220 F) for $2 \mathrm{~h}$ so that the glass formers can completely react with the waste and so that bubbles can escape. The canister is cooled to $700^{\circ} \mathrm{C}\left(1292^{\circ} \mathrm{F}\right)$ while it is still in the furnace and then it is removed. The canister is then cooled until it reaches its steady-state temperature for storage.

The ICM process has been under development at PNL for about nine years. To date, 20 full-scale canisters of nonradioactive glass have been produced. These canisters, like those shown in Figure 3 , have ranged from 12 in. to $28 \mathrm{in.}$ in dia. During 1979, two 8-in.-dia canisters were filled by the ICM process with actual HLW from a power reactor.

\section{Continuous Me1ting}

A schematic drawing of a CM melter is shown in Figure 4. The waste and glass formers are fed onto the surface of a pool of glass that is contained in a ceramiclined cavity. To date, most studies have used calcined waste (Chapman and Buelt 1977); however, liquid waste can also be fed directly to the melter (Chapman and Buelt 1978). Energy for vitrification is supplied by joule heating. At high temperatures glass becomes an electrical conductor. Electricity is passed through the glass between immersed electrodes. Waste glass is continuously drained from the bottom of the melter and poured into a storage canister. During filling, the canister is contained in an enclosure that maintains its temperature near $600^{\circ} \mathrm{C}\left(1112^{\circ} \mathrm{F}\right)$ and monitors the filling process. When the canister is ful1, it is removed and cooled.

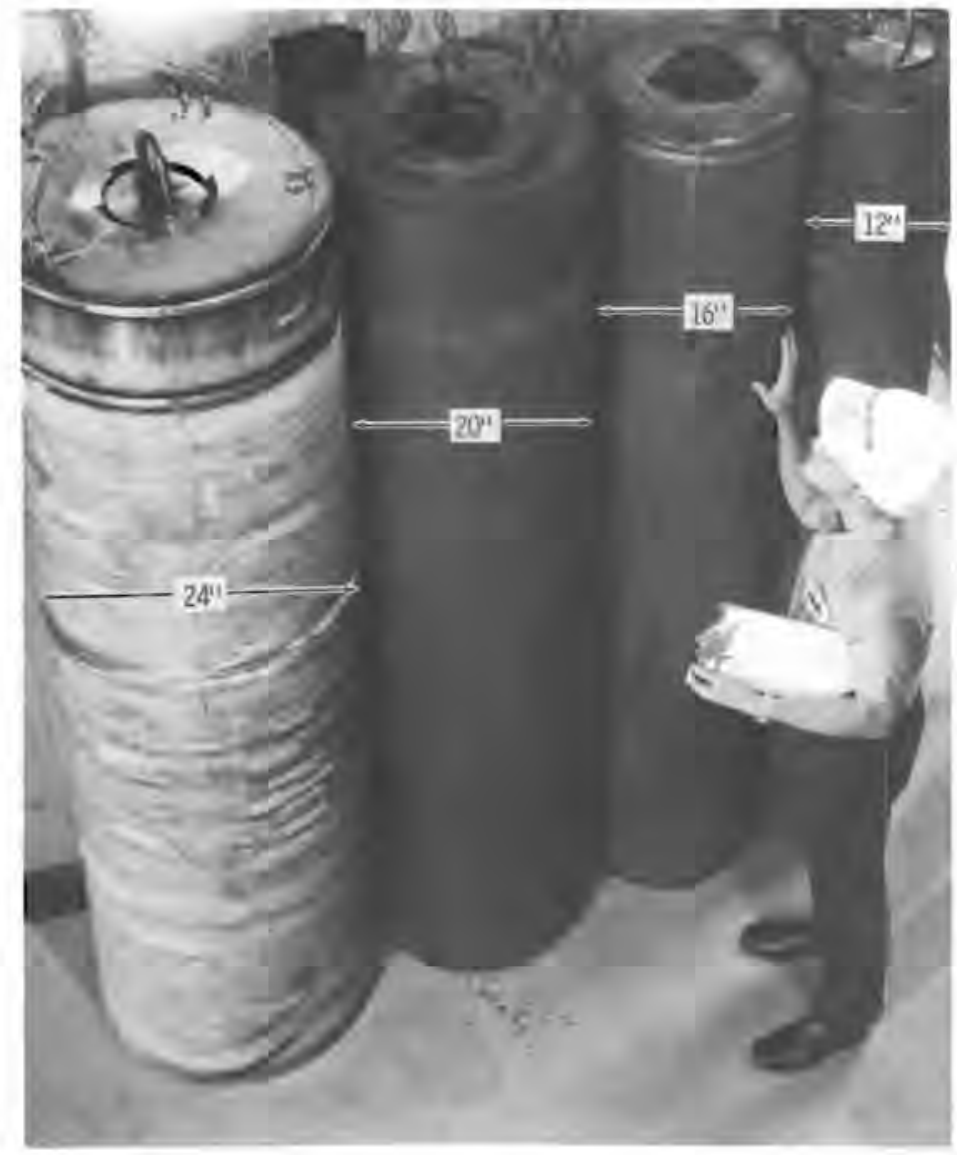

FIGURE 3. Full-Scale ICM Canisters 


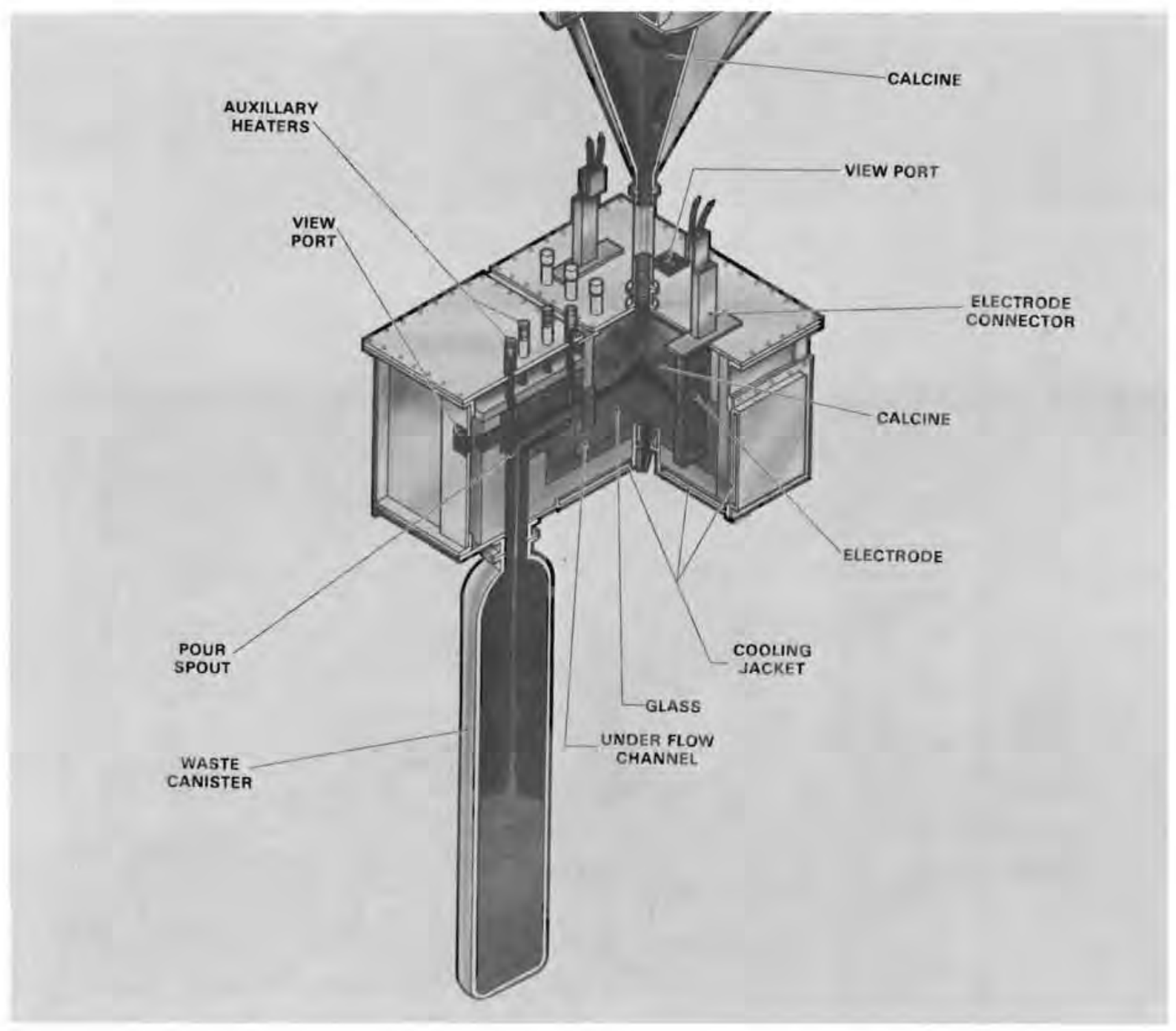

FIGURE 4. Schematic of the Joule-Heated Ceramic Melter for the CM Process

The ceramic melter has been under development for about five years at PNL. Two plant-scale melters, currently in operation, have filled 50 canisters like those shown in
Figure 5, which range from 12 in. to 36 in. in dia. The majority of canisters produced are $24 \mathrm{in}$. in dia, which is the reference size for defense waste solidification. 


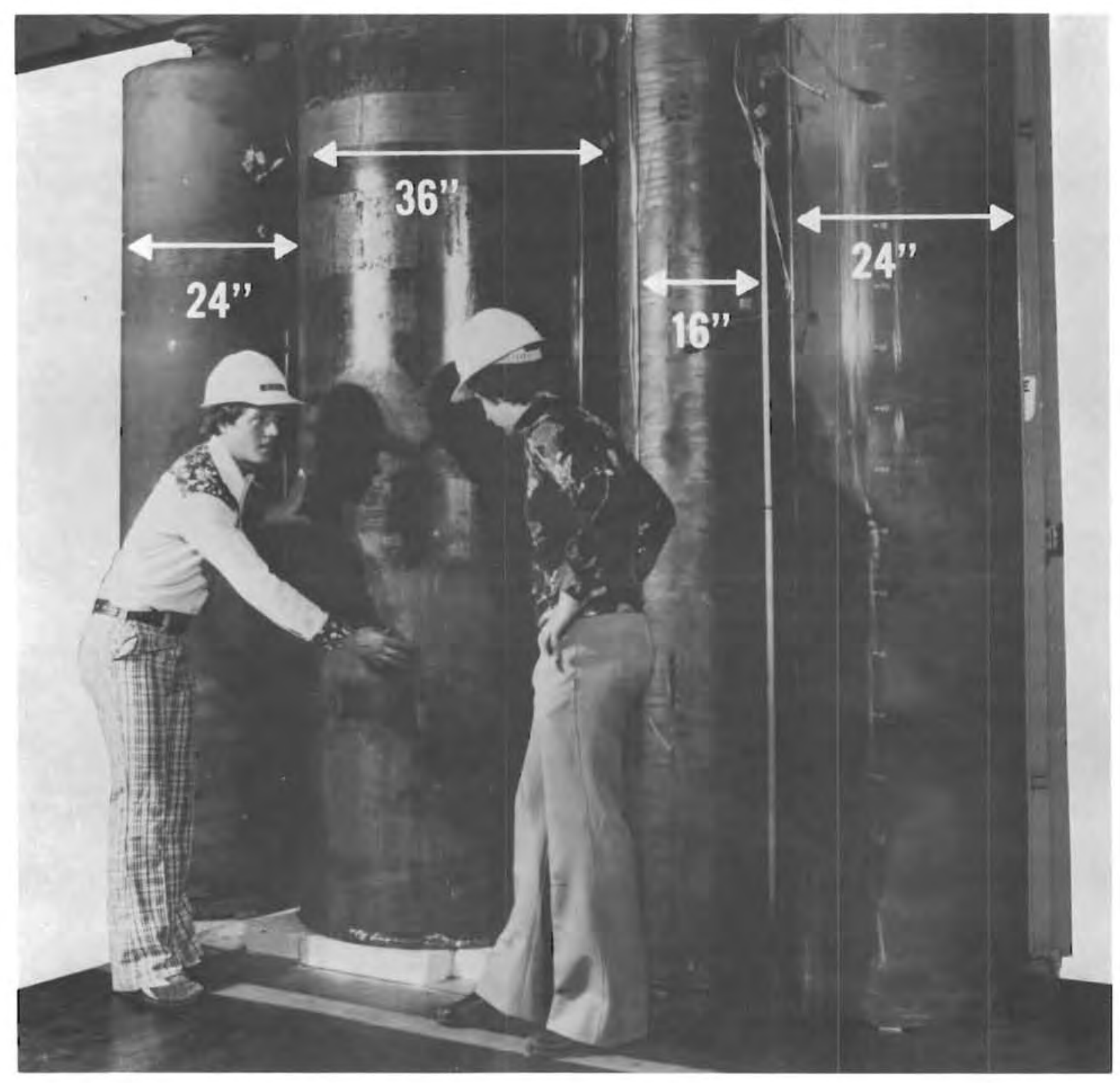

FIGURE 5. Full-Scale CM Canisters 


\section{DESIGN CRITERIA AND CODES}

Designing a canister that is compatible with all phases of processing, transportation, and disposal requires a set of performance criteria. These criteria must be based on processing needs, government regulations, and storage site requirements. This section summarizes performance and design criteria for HLW canisters. The relevance of the ASME Boiler and Pressure Vessel Code as it applies to the fabrication and design criteria is then reviewed. Finally, available stress-analysis methods and computer codes are assessed. Specific design rules to ensure structural integrity are recommended elsewhere in this report.

\section{CANISTER DESIGN CRITERIA}

A preliminary draft of acceptance criteria for HLW canisters has been developed and is presented by Moore (1978). This document is the basis of many of the working criteria used in this report. In addition to acceptance criteria, we have considered the anticipated requirements of processing, storage, transportation, and disposal.

While all HLW canisters will be required to meet general performance criteria as outlined here, the specific application will dictate details of the canister design. The main variables are the melting process and the heat-generation rate of the waste glass from radioactive decay processes. The melting process determines the maximum canister wall temperatures during filling, as described in Appendix $C$ of this report. Heatgeneration rates can be as high as $150 \mathrm{~W} / \mathrm{L}$ glass, depending on the age and source of the waste. Higher heat-generation rates place greater demands on canister integrity. High-heat glasses, which increase the risk of corrosion damage to canisters, will dictate an interim-storage period in water basins. Also, thermal stresses from heating and cooling transients increase with heatgeneration rate. The heat-generation rates of concern vary from an extreme of nearly $150 \mathrm{~W} / \mathrm{L}$ to essentially no heat generation at all $(0.01$ to $0.1 \mathrm{~W} / \mathrm{L})$. For purposes of this report, we will define these extremes as high-heat and low-heat glass, respectively. The general canister criteria from Moore's document are summarized below.

\section{Licensing}

The canister and overpack must meet the requirements of the operating licenses of the waste facility, transportation system, and the Federal repository.

\section{Physical Dimensions and Weight}

For canisters containing high-heat glass waste, the maximum dimensions will be $457 \mathrm{~mm}$ (18 in.) in OD and $4.9 \mathrm{~m}$ (16 f) long, with a maximum weight of $3630 \mathrm{~kg}(8000 \mathrm{lb})$. For low-heat waste, the maximum dimensions are $610 \mathrm{~mm}$ (24 in.) in 00 and $4.8 \mathrm{~m}(16 \mathrm{f}$ ) long, with a maximum weight of $5450 \mathrm{~kg}(12,000 \mathrm{lb})$. These values include an overpack if it is used. Final limits will be established once a repository has been designed.

Radiation Limit

The maximum radiation level, $0.3 \mathrm{~m}(1 \mathrm{f})$ from the canister midpoint, must not exceed $1 \times 10^{5} \mathrm{rem} / \mathrm{h}$ total dose rate.

\section{Surface Contamination Limit}

There must be no significant removable contamination on the exterior surface of the canister. Significant levels are those levels, when averaged over any $300 \mathrm{~cm}^{2}$ of surface, that exceed any of the values in Table 1. These limits are based on

TABLE 1. Surface Contamination Limits of Canisters (49 CFR 173.397)

Source $\quad$ Li/cm $\underline{\mathrm{dpm} / \mathrm{cm}}$

Natural or depleted uranium and natural thorium:

$$
\text { Beta-gamma }
$$

Alpha

All other beta-gamma emitting radionuclides

All other alpha-emitting radionuclides
$10^{-3}$

$10^{-4}$

2200 220

$10^{-4}$ 220

$10-5$ 22 
49 CFR 173.397, which specifies contamination levels for shipping casks. The values are conservative and may be revised when facility designs are complete and operational requirements are known.

\section{Design and Fabrication}

The canister will be designed and fabricated to meet applicable standards of the ASME Boiler and Pressure Vessel Code, Section III, Division I. When an overpack is required, it shall meet the same requirements.

\section{Canister Operations}

The canister must be compatible with the requirements of remotely operated waste management facilities. It will be handled by a single, central handling device on the top.

The canister must protect and contain the waste glass during normal and accident conditions. The necessary canister operations must not adversely affect the glass. The canister must be compatible with a suitable overpack if one is required. An overpack may be used if the canister does not meet quality specifications, or if added protection is needed during disposal.

\section{Waste and Canister Documentation}

Each canister and its contents must be adequately documented during fabrication, processing, storage, transportation, and disposal. A permanent record is necessary to assure that the canister and glass meet all the requirements of the waste system.

\section{ASME CODE}

The application of the ASME Boiler and Pressure Vessel Code to waste canister fabrication and design has been studied by PNL researchers, as we 11 as by others (Kaiser Engineers 1978, Mecham 1976, and Nuclear Services Corporation 1978). Appendix B of this report summarizes the results of these studies.
It has been concluded that for waste canisters, of the various parts of the code, ASME Section III, Division I, Class 3 provides the most appropriate set of rules. These rules ensure quality fabrication of the canister. However, many aspects of canister service loadings and environments fall outside the scope of the code. Evaluation of waste canister designs requires additional rules. We expect that verification testing will also play a major role in the licensing of HLW canisters. These additional rules and data from developmental tests could eventually lead to a new subsection of the ASME Code, directed specifically to HLW canisters.

\section{STRESS ANALYSIS METHODS}

Studies at PNL on the structural integrity of canisters have used several computer codes and stress analysis techniques. The applica$t i o n$ of these methods is illustrated by the various case studies described in appendices to this report.

Appendix A specifically addresses stress analysis methods. In general, we found that the extensive analytical methods for pressure vessel technology are equally applicable to canister evaluation. Finite-element computer codes have proven invaluable in evaluating canister stresses; specific codes that have been used at PNL are listed in Appendix $A$.

The calculation of creep deformation that can occur in canisters at elevated temperatures during filling is a particular challenge to the canister designer. This calculation generally has required computer-based methods. However, routine application of such methods has not proven cost effective at PNL. Instead, isochronous stress-strain curves (ASME 1972) and the reference stress technique (Kraus 1977) have been valuable analytical tools. The basic features and advantages of both methods are described in Appendix $A$. 


\section{DESIGN CONSIDERATIONS}

Designing of a canister for a particular application requires creative, yet sound engineering. In each case the selection of a specific, optimal design for a storage canister (i.e., diameter, length, wall thickness, material, closure system, etc.) depends on the total processing and waste management system. However, the design of an optimal canister for a given system is technically feasible. Studies at PNL and elsewhere have identified no insurmountable problems of engineering and design for hardware, materials, and transport systems.

This section summarizes basic considerations that govern canister design, and highlights PNL design approaches. The key factors, canister wall thickness and closure design, are emphasized. Advantages of bottom-supported canisters in contrast to top-supported canisters are reviewed. Finally, the advantages and disadvantages of using an overpack with primary canisters are discussed.

\section{HEAT CONTENT AND SIZE LIMITATIONS}

The nature of the nuclear waste, as well as the type of process selected for vitrification, governs the design of the canisters. The radioactive decay heat-generation rate is perhaps the most important characteristic of the waste product in relation to canister design. For high-heat wastes, the heat content of the waste form can limit canister size. For low-heat waste, canister size will be largely governed by shipping and handling considerations. However, for very large canisters of low-heat waste, cooling rates after filling may be so slow that the temperature of the glass in the central portion of the canister may stay within the devitrification temperature range too long. For low-heat waste, a canister with a dia of $24 \mathrm{in.}$ is considered a reasonable size. However, studies are being conducted to evaluate the feasibility of using 36-in.-dia canisters for some waste.

For purposes of this report, it was assumed that peak centerline temperatures during storage would be lower than devitrification temperatures. This limits the canister diameter, since a large canister of waste may not be able to transfer internal heat away from the central portion of the canister rapidly enough. Very high-heat wastes, with power levels as high as $150 \mathrm{~W} / \mathrm{L}$, will limit canister diameters to between 12 and $16 \mathrm{in}$.

The total heat-generation rate of each canister may be further limited at the time it is placed in the geologic repository. During the period of interim storage, the total rate of heat output of the canister must decrease to a specified level consistent with stability considerations for the geologic repository site. It appears that for reasonable durations of interim water storage the requirements on canister heat output during disposal will be the limiting factor, rather than the centerline temperature during storage.

Heat content also affects the choice of the interim storage method. For high-heat waste, water-basin storage will be desirable because of its large cooling capacity. Water-basin storage, in turn, has a profound impact on the selection of canister materials. For the water environment, generalcorrosion and stress-corrosion cracking must be carefully considered. Low-heat waste can be suitably stored in air, and the selection of materials for such canisters is less critical. Low-carbon and low-alloy steels are the prime candidates for such applications. For water-basin storage, stainless steels and nickel-chromium-iron alloys are the prime candidates. If stainless steels are to be used, care must be exercised so that the combined effects of alloy composition, material sensitization, residual stresses, and water chemistry do not lead to stresscorrosion cracking during storage.

\section{CLOSURE DESIGN}

The final closure of a canister seals the glass inside the canister, and thus must be a durable, reliable barrier to any interaction of the glass with the external environment. Appendix $E$ provides details of two closure designs. Special design and inspection criteria developed at PNL are described, particularly for the twist-lock closure, which is for canisters used in the ICM process. A flange type of closure for the CM canisters is also described. 
The twist-lock closure is the result of a systematic application of the following design criteria for closures. Besides providing a reliable barrier, the closure must connect with remotely operable process equipment for filling. Seal-welding of the closure, as well as its inspection, must be performed remotely. Design criteria have required that the connecting device for lifting be an integral part of the closure. 0ther criteria for closures include ease of decontamination and allowance for overpacking (e.g., no undersirable projections).

PNL has been developing a two-fold inspection of the twist-lock closure weld, involving both a helium leak check and an ultrasonic scan for weld defects. Studies have indicated that a helium leak rate in the range of $10^{-5}$ to $10^{-6} \mathrm{~atm} \mathrm{cc} / \mathrm{s}$ is suitable for leak-tightness. Ultrasonic inspection will detect internal defects in the weld. A detailed fracture mechanics study, described in Appendix $F$, shows that the proposed ultrasonic inspection will detect any defect that could grow to a critical size because of fatigue.

Closure systems can be stressed from the pressure of gases in the void space at the top of the canister. Appendix $H$ discusses the origin and consequences of such pressure. It is concluded that pressure due to normal heating of gases should be of little concern. The presence of large quantities of water in the void space could, however, under extreme heating (as in a fire) result in pressures that are not feasible to contain.

The impact strength of closures, as evaluated in drop tests, requires further study. The limited results of the drop tests described in Appendix $H$ indicate that optimal weld joint designs in canister fabrication are important to the impact strength. Further design studies and impact testing are recommended so that the ability of closures to sustain hypothetical impact accidents can be evaluated.

\section{TOP VERSUS BOTTOM SUPPORT}

While early work at PNL with the ICM process used top-supported canisters, subsequent tests have used bottom-supported ones. In the top-support design for ICM, the canisters had a projecting neck that extended outside the furnace. The canister was supported or hung outside the furnace from lug-type attachments to this neck. Bottom support allows the canister design to be greatly simplified, since the canister is supported within the furnace on its flat bottom. A connecting section extends with in the furnace and is remotely attached to the canister for filling.

Results described in Appendices $A$ and $C$ show that the bottom of a top-supported canister is subject to high levels of bending stress and to bulging during filling at high temperatures. Stresses in the bottom greatly exceed those in the canister wall. Bottom support eliminates the high bottom stresses.

Bottom support also eliminates problems from cool temperatures in the neck of topsupported canisters. With the canister entirely in the furnace, all the contents of the canister can completely vitrify since all internal surfaces are at melting temperatures (Blair 1978). The cool regions of the neck of a top-supported canister are also subject to sensitization. This adverse metallurgical condition can contribute to canister failure during water storage because of stress-corrosion cracking.

\section{WALL THICKNESS CONSIDERATONS}

Numerous factors have a bearing on the required wall thickness of canisters for high-level nuclear wastes. The wall thickness must be sufficient so that the canister will withstand conditions during filling with molten glass and subsequent stresses during handling and storage. Appendix $C$ of this report reviews general considerations that govern wall thickness and outlines detailed procedures for evaluating stresses during filling.

During filling, the wall of the canister must contain the molten glass. At the processing temperatures, both creep deformation from diametric expansion and corrosion attack of the canister wall must be considered. Slate and Maness (1978) have reported data on both the internal corrosive attack of glass and the oxidation of the furnace environment. Our experience has shown negligible corrosion for canisters filled by the continuous melter. Corrosion rates are significantly higher for canisters used with in-can melters. In most cases, a total corrosion allowance of $0.50 \mathrm{~mm}(0.020 \mathrm{in.})$ for canister wall thicknesses should be adequate. However, we recommend that specific corrosion tests be performed for new combinations of glass compositions and canister materials.

The design procedure described in Appendix $C$ addresses creep deformation of the 
canister during filling. This procedure allows for possible overheating, variations in material strength, and filling rates. As a result, the canister is protected from rupture during filling. Safety factors as high as 17 on wall thickness have been est imated. The validity of the stress analysis procedure has been verified by comparison with deformation data taken from ICM trials and a controlled canister creep test (described in Appendix C).

Wall thicknesses of prototype designs at PNL have been in the range of 6.3 to $12.7 \mathrm{~mm}$ $(0.25$ to $0.50 \mathrm{in.})$, depending on the canister diameter. The greater wall thicknesses correspond to canisters in the 600-mm- (24-in.-) dia range. In general, the specified wall thickness has exceeded the established minimum thickness required to sustain filling stresses. The additional thickness has been provided to sustain normal lifting and handling loads (as discussed in Appendix $E$ ) and low-probability impact loads (Appendix H).

\section{OVERPACK CONSIDERATIONS}

An overpack refers to any second container into which the primary canister is placed any time after filling with the waste glass. Appendix $G$ of this report describes some of the important considerations that will govern decisions on if and when to overpack a primary canister.

One thrust of current work at PNL is to demonstrate that a single canister will be able to meet all necessary requirements. This approach agrees with an evaluation by the Nuclear Services Corporation (1978) that an overpack is undesirable both from a design and economical standpoint. If possible, overpacks would be used only for defective canisters that did not meet acceptance criteria for shipping or disposal.

One of the main arguments against overpacking in the case of high-heat wastes is the degradation of heat removal. An overpack may dictate an undesirably small canister size.

The main arguments in favor of routine overpacking center on increasing the level of containment. Overpacks should have less severe residual stresses than primary canisters, which should decrease their susceptibility to stress-corrosion cracking in water storage environments. 0ther potential benefits of routine overpack usage are reductions in quality verification requirements, ease of leak checking, and ease of decontamination.

The argument for routine overpack use for a second level of containment does not seem to be justified. All processing and interim storage facilities, as well as shipping containers, will contain any releases from failed canisters. However, the scope of this report does not include ultimate disposal in a geologic repository, for which an overpack may be used as a barrier in the design of the disposal system. 
$\because$
$\therefore$
$\therefore$ 


\section{MATERIALS AND FABRICATION CONSIDERATIONS}

In order to design a canister and predict its structural integrity, the performance of materials and methods of fabrication must be carefully considered. This section reviews materials, fabrication, and inspection considerations as they affect the design and stress analysis of canisters.

\section{MATERIALS SELECTION}

The selection of a material for a given canister application will be based on many, and often conflicting, performance criteria, as outlined in a preceding section of this report. While canister materials require mechanical strength and ductility, stresses imposed on canisters in handling and storage after filling are not unusual. The strength requirements can be met by most commercial alloys.

Filling temperatures are higher than normal service temperatures for the materials of interest, so PNL has emphasized evaluation of high-temperature strength. Creep-strength data are presented in Appendices $C$ and $D$. We found that a number of common commercial alloys can meet high-temperature strength requirements (e.g., low-carbon and low-alloy steels for CM canisters and austenitic stainless steels for ICM canisters). Corrosion and melting point considerations, rather than strength per se, probably affect upper temperature limits for potential canister materials.

Ductility and toughness are required of canister materials so that they meet the impact performance requirements described in Appendix $H$. In general, austenitic alloys and ferritic alloys should meet the ductility and toughness requirements of canisters for temperatures above their ductile-brittle transition range.

The corrosion performance of potential canister alloys has been reviewed by slate and Maness (1978). Both general-corrosion and stress-corrosion cracking must be considered. General corrosion can be both by attack of the inside canister surface by glass and by oxidation of the outside canister surface from the furnace environment. External oxidation can be a problem even if the loss of cross section is minimal, since the accumulation of spalled oxides in processing facilities can be unacceptable. We have reviewed questions on corrosion and it appears that existing commercial alloys can meet canister requirements. Selection of materials for corrosion will, however, be based on cost, fabrication, and other performance criteria. Performance requirements of materials should be balanced against material cost, fabrication ease, suitability for welding, and availability of acceptable product forms. It should be recognized that the cost of materials for canisters will no doubt be small in comparison with the total cost of building and operating the waste processing system. Thus, higher material cost will probably be justified if canister performance can be clearly improved, or if processing operations can be simplified or made more reliable.

The thermal expansion coefficient of the canister material and internal heat-transfer fins have been evaluated at PNL. As discussed in Appendix I, a low-expansion canister fin material will tend to reduce canister residual stress and result in less cracking of the waste glass in the canister. Ferritic stainless steels (in particular the E-Brite 26-1 alloy) have been considered for this reason. However, the desirable lowexpansion coefficients and favorable corrosion properties of these materials are balanced by relatively low strengths at ICM temperatures and poor impact properties at ambient temperatures.

\section{FABRICATION}

Canisters must provide the desired level of containment of the waste glass. Thus, the strict fabrication and quality assurance requirements for nuclear components will, in general, apply to canisters.

While to date no specific rules or regulations for the fabrication of canisters have been formally adopted, there are several reasons for adopting existing standard codes. Such codes have both governmental and public acceptance because of their demonstrated reliability. Also, potential vendors are accustomed to working with the standard codes, and this will expedite procurement and decrease costs of canister fabrication and inspection. Fabrication of a well characterized, reproducible, high-quality canister will also greatly assist quality 
verification of the packaged HLW. Such quality verification will be necessary to meet criteria for acceptance of the packaged waste at the geologic repository.

The rules of the ASME Boiler and Pressure Vessel Code, Section III, Nuclear Power Plant Components (as discussed in Appendix B), are considered appropriate to the fabrication and quality assurance aspects of waste canisters. Although it is recognized that the service stresses and functional requirements of canisters are, in many respects, different than those addressed by the ASME Code, waste canisters are generally within the scope of the ASME Code. Low-carbon steel, low-alloy steel, stainless steels, and nickel-based alloys are all recognized and approved for coded vessels. Canister designs and fabrication methods are also within the scope of the code, although it may be desirable to amend existing code requirements, where such changes will further improve canister integrity.

Specific fabrication and quality assurance measures will apply to the general areas listed below:

\section{- material specifications and certification}

- specifications concerning welding procedures, welding materials, and qualification of welding personnel

- heat treatment

- inspection of welds by approved methods, such as radiography

- documentation.

Documentation begins at the time of canister fabrication and continues through the life cycle of the canister.

In research programs at PNL, many canisters have been procured for packaging of simulated waste. The extent of fabrication and quality assurance measures applied to these canisters has varied according to need. In many cases, canisters have been fabricated on very short notice to meet the immediate needs of laboratory melting trials. In other instances, standards have been imposed for prototype canisters typical of those that might be used in a productionscale waste processing plant. While the resulting canister quality has no doubt been quite varied, the performance of all canisters has been satisfactory. The only possible deficiencies have been in drop tests, which evaluate canister performance under severe impact conditions. As described in
Appendix $\mathrm{H}$, some welds have cracked in corner impacts. Here, the failures are believed to be caused by specific joint-design and welding deficiencies, rather than inherent material problems.

\section{WELDING AND INSPECTION}

Our work in the areas of welding and inspection (as discussed in Appendix E) have been directed to the final closure, which is welded after the canister has been filled with waste glass. Welds performed in the fabrication of canisters, as well as the inspection of these welds, should require no advances in existing technology. The practices and codes used for nuclear pressure vessels and piping should be suitable for waste canister fabrication and inspection.

The welding requirements and preferred methods will be similar for most closure designs. Closures must be welded remotely and preferably without filler metal. The gas-tungsten-arc (GTA) process was used by the prototype welder demonstrated at PNL, since this process closely matches proposed acceptance criteria and is the most common method used today for welding nuclear equipment. The welding device was designed for ease of maintenance and operations.

Before a closure is welded, contaminants such as oxidation must be removed. Various procedures have been considered at PNL, but further research is required to develop and demonstrate a preferred method.

Closure-weld inspection methods being developed at PNL include a helium leak check and an ultrasonic inspection for internal defects. Further work on inspection methods is required, including demonstration of the proposed methods under remote conditions.

No regulations have yet been established as to the need for verification of canister integrity after a period of interim water storage. If inspections of such canisters are to be required, much developmental work will be needed to establish the feasibility and reliability of inspection methods. Not only will the final closure weld need to be inspected, the integrity of the canister body will also need to be checked. This may be a difficult task. For example, in a helium leak check, one would need to be assured that the helium had access to the bottom portion of the glass-filled canister. One proposed alternative involves placing canisters in a special water-filled pod and monitoring the pod for leakage from the canister. We conclude that methods for interim inspection of 
canisters will require major developmental work; this work has been postponed until the need for such inspections has been clearly established.

\section{STRESS-CORROSION CRACKING}

The possibility of stress-corrosion cracking should be carefully evaluated for canisters that will be subject to interim waterbasin storage. Boyd and Hall (1977) have reviewed the potential causes of stresscorrosion cracking in canisters. Material selection, processing conditions, and the storage environment must be controlled if stress-corrosion cracking of canisters is to be prevented. While it is clear that cracking can be prevented, the exact thresholds for cracking are not known.

For stress-corrosion cracking to occur, a sustained tensile stress, typically from residual stresses, must be present. Appendix I of this report summarizes PNL studies on residual stresses and presents data that shows tensile residual stresses in the walls of typical canisters at or near the yield strength of the canister materials. However, cracking will not result unless the canister material is susceptible to cracking (e.g., sensitized 304 stainless steel). In addition, the material must be exposed to specific corrosive conditions.

Stress-corrosion cracking of a stored glass canister has occurred in one instance at PNL (Bradley 1977). A particularly adverse combination of stress, material characteristics, and corrosive media were present during the storage period.

The use of a nickel-based alloy, such as Inconel Alloy 601, is recommended as one practical means of preventing stresscorrosion cracking. However, such alloys are more costly and may be more difficult to fabricate and weld. Therefore, efforts have been directed toward demonstrating that stainless steels, such as 304L, can be used with confidence if the processing and storage environments are suitably controlled.

A test pod facility has been designed and built at PNL to subject glass filled canisters to simulated water-storage environments. Water chemistry is carefully controlled so that canister performance can be evaluated under various service environments. Tests are currently underway, and data on canister performance will be available in the near future.

Another proposed solution to the stresscorrosion-cracking problem is to overpack canisters, before they are stored in water. The main advantage of an overpack in this context is that residual stresses are lower in an overpack than in a primary canister. (Disadvantages of using overpacks are described in Appendix G.)

In summary, the potential for stresscorrosion cracking is greatest for stainlesssteel canisters subject to water-basin storage. The potential for cracking is essentially nonexistent for low-carbon and low-alloy steel canisters and for stainlesssteel canisters stored in an air environment. We believe that for water-basin storage, cracking can be eliminated by a combination of alloy selection, residual stress reduction, control of processing conditions, and control of water chemistry of the storage basin.

\section{CREEP STRENGTH}

During the filling process, canisters must contain molten glass and must not show creep deformation at the high filling temperatures. Canister-wall temperatures during filling exceed normal design temperatures for the materials of interest. Design data, such as those given in the ASME Boiler and Pressure Vessel Code, have not been applicable. In addition, creep-strength data reported in the literature are very limited. Therefore, a series of creep tests at ICM temperatures were conducted at Battelle-Columbus Laboratories at the request of PNL. Two alloys were tested, 304L stainless steel and Inconel Alloy 601; the results of those tests are reported in Appendix $D$. These two alloys were selected since they are representative of high- and low-performance alloys that have been considered for ICM canisters.

Extensive creep- and creep-rupturestrength data, ranging from $950^{\circ}$ to $1150^{\circ} \mathrm{C}$ $\left(1742^{8}\right.$ to $\left.2102^{\circ} \mathrm{F}\right)$, were generated. The creep strength of $304 \mathrm{~L}$ stainless steel was found to be about $60 \%$ that of Inconel Alloy 601 , up to about $1050^{\circ} \mathrm{C}\left(1922^{\circ} \mathrm{F}\right)$. This temperature is a practical upper limit for $304 \mathrm{~L}$ stainless steel, due primarily to excessive oxidation and glass corrosion that occurs at higher temperatures. 
Creep strength is not a factor in the design of canisters for the CM process when austenitic alloys, such as 304L stainless steel, are used. However, the potential for creep deformation must be evaluated when low-carbon or low-alloy steels are used. (Representative creep-strength data for these alloys are presented in Appendix C.) Although canister wall temperatures during filling exceed usual design temperatures for these alloys, studies at PNL show that excessive creep deformation will not occur during filling.

The advantages of bottom-supported over top-supported canisters in minimizing creep deformation have been previously discussed. One of the main advantages is a reduction in stress levels during filling. Stress analyses show high levels of bottom stress during the filling of a top-supported canister by ICM.

Each of the process development trials of canisters filled at PNL is, in a sense, a creep test of the material involved. Data in Appendix $C$ shows that canister creep deformation observed in process trials has been minimal.

In summary, the available data on creep strengths of selected canister alloys indicates that canisters can sustain stresses without difficulty at the high temperatures during filling. However, creep-strength data in the temperature ranges of interest are limited. We recommend that further creep tests be performed once a specific alloy or alloys are selected for particular waste processing applications. 
RESIDUAL STRESS AND CRACKING

Cooling canisters of waste glass after processing produces residual stresses in both the canisters and the contained glass. The discussion below sumarizes analyses of residual stresses and also addresses the nature and causes of cracking of waste glasses.

\section{RESIDUAL STRESSES}

Residual stresses in the walls of canisters and their consequences on canister integrity have been important concerns in our work at PNL. Appendix I of this report assesses the effect of these stresses and describes two analytical models developed to predict the levels of these stresses.

Residual stresses mainly affect canister failure by stress-corrosion cracking. It is believed, however, that the potential contribution of residual stress to stresscorrosion cracking can be reduced, if suitable restrictions are placed on canister materials and usage. Furthermore, the potential for stress-corrosion cracking is essentially nonexistent for low-carbon and low-alloy steel canisters stored in an air environment. On the other hand, stainlesssteel canisters subject to water-basin storage have the greatest potential for stress-corrosion cracking.

The primary source of residual stress in canisters is the higher thermal expansion coefficient of the canister relative to the contained glass. In cooling below the temperature at which the molten glass hardens, the canister tends to shrink tightly around the glass. Because the canister is constrained by the solid glass, tensile stresses build up in the walls. These stresses can readily reach and exceed the yield strength of the canister material. Residual stresses have been measured on selected canisters filled by both the ICM and CM processes at PNL. These measurements have confirmed the expected high levels of tensile residual stress.

In Appendix I, finite-element computer predictions of canister residual stresses are described in detail. The effects of various canister cooling and heating sequences are evaluated, as well as the effect of internal heat generation in the glass. The analyses of rapid cooling of canisters of glass, especially of heat-generating glass, indicate that residual stresses in canisters will be significantly reduced from the high levels measured to date for nonheating glasses.
Numerous procedures have been tested for reducing residual stresses in canisters. Thermal treatments include quenching and subcooling. In quenching trials at PNL, a hot canister was rapidly cooled in water. Thermal stresses resulting from the quench were expected to deform the canister and relieve residual stresses. However, the measured reduction in stresses was marginal, much less than anticipated, for reasons not yet explained. In subcooling tests at PNL, subscale canisters of glass were cooled below room temperature in a cold bath. Reductions in measured residual stress were observed that were almost as predicted. However, the bath temperature was not cold enough to entirely eliminate the tensile residual stresses. Although thermal treatments show promise of reducing canister residual stresses, they may have detrimental effects on glass quality. The extent of cracking in the glass is likely to increase because of shock-type thermal stressing of the glass.

Changes in the design of the canister and packaging system can also be used to reduce residual stresses. Ferritic stainless steels have thermal expansion coefficients that more closely match expansion coefficients of waste glasses. The alloy E-Brite 26-1 has been considered for this reason and also because of its good corrosion characteristics. However, ferritic stainless steels can have low impact toughness at room temperature and poor creep strengths (relative to austenitic materials) at ICM temperatures.

Compliant liners have been evaluated at PNL as a means of reducing canister residual stresses. In this concept, the liner will crush with little resistance as the canisters tend to shrink around the glass. Porous metal materials have been considered for this purpose. However, these materials have not been considered particularly desirable. They tend to be attacked by the molten glass and also seriously impede the removal of heat from the glass.

Overpacks have been evaluated as a means of achieving an outer containment that is relatively free of residual stresses. We 
conclude that residual stresses in overpacks will be much less severe than in primary canisters, although stresses from final closure welding will no doubt still be present in overpacks.

\section{GLASS CRACKING}

In order to analyze residual stresses in canisters, it is necessary to consider the stresses and cracking that occur in the contained glass. This glass-canister interaction is discussed in Appendix I of this report, where glass response data are reported along with predictions of canister residual stresses.

The causes and consequences of glass crackina have been addressed in detail at PNL (Slate et al. 1979). We have concluded that thermal and residual stresses are the major causes of cracking in waste glass. The major consequences of cracking are the increase in surface area, which may result in enhanced release rates during a leaching event, and the production of respirable-size particles. The amount of cracking in canisters ranging from 150 to $900 \mathrm{~mm}$ ( 6 to 36 in.) has been between 0.5 to $1.0 \mathrm{~cm}^{2} / \mathrm{g}$. Most of the surface area is from the very small particles, with about 1 wt\% of the glass having $50 \%$ of the surface area. Surface area increases from severe impacts have also been measured (Smith and Ross 1975). For a standard 9-m (30-f) drop, the surface area of the glass will increase by a factor of 4 to 10 , depending on the size of the canister and the original state of the glass.

Residual stresses and thus cracking arise from two sources: 1) stresses from the differential thermal expansion coeff $i-$ cients of the canister and glass, and
2) stresses that develop in the glass monolith itself from temperature gradients in the glass as it hardens from a molten state. For glass with internal heat generation, superimposed on these locked-in stresses are thermal stresses from decay cooling.

The objective of the glass-cracking analyses was to identify the causes of observed cracking in experimental canisters. In this way, changes in processing that can minimize cracking could be evaluated. In general, the extent of cracking can be reduced if thermal gradients during cooling are reduced (ideally, cooling at rates approaching $1^{\circ} \mathrm{C} / \mathrm{h}$ ) and if interaction between the glass and canister is minimized. The extent of this interaction can be reduced with a better thermal expansion match between the canister and glass and by elimination of bonding between the canister and the glass.

Predictions of cracking in glass have been consistent with the types of cracking observed in experimental canisters. A longterm goal is to predict the extent of glass cracking in a quantitative manner (e.g., net increase in surface area and particle size). However, present analytical methods do not permit realistic quantitative predictions.

In summary, thermal and residual stresses are believed to be the major causes of cracking in waste glasses. However, the amount of cracking can be controlled within acceptable limits (Slate et al. 1979). In most situations, the amount of cracking typically observed in simulated waste glasses should have no significant effects on the safety of surface operations. Also, recent work on glass behavior in disposal environments does not indicate that cracking causes any significant adverse effects. 


\section{PERFORMANCE TESTING AND ACCIDENT EVALUATION}

The evaluation of canister stresses and structural integrity, both for design and licensing purposes, will be partly based on validation of canister performance by structural testing. The discussion below summarizes efforts at PNL to evaluate canister performance under normal operating conditions and hypothetical accident conditions.

\section{EVALUATION OF PROCESS TRIALS}

Over 20 full-scale canisters have been filled by the ICM process at PNL (Blair 1976 and 1978), and about 50 canisters have been filled using CM (Chapman and Buelt 1977 and 1978). In addition, two nearly full-scale canisters of radioactive waste glass were produced in Waste Solidification Engineering Prototype Program at PNL in 1970, and two more were filled in the Nuclear Waste Vitrification Program in 1979. These canisters have provided data on canister performance, under both filling and storage conditions, which support the stress analysis and structural integrity evaluations.

In this report, we have emphasized ICM canisters, because the service conditions are more severe than those for CM. Measured diameter increases have been relatively small and have not exceeded about $1.27 \mathrm{~mm}$ $(0.050 \mathrm{in.})$. Most of this change is attributed to the differential thermal expansion coefficients of the canister and glass, rather than stress-induced creep. There have been no instances at PNL of canister structural failure that resulted in released glass during filling.

The long-term integrity of canisters in storage environments is less certain, particularly for water-basin storage. Bradley (1977) reports the stress-corrosion cracking in one of the canisters filled in 1970 with radioactive waste. This canister developed a crack in the water environment of a test pod. The canister material was determined to be extremely sensitized by an adverse thermal history; the combination of residual stress and water chemistry was particularly conducive to stress-corrosion cracking. The conditions for this canister were not typical of anticipated canister conditions. Nevertheless, further tests of canisters in water-storage environments are currently in progress at PNL. Canisters filled with simulated wastes have been placed in test pods, where the water chemistry is carefully controlled. Results of these tests will provide service-type experience and will indicate how extensive preventive measures need to be to eliminate stress-corrosion cracking of canisters.

\section{ACCIDENT CONSIDERATIONS}

Various hypothetical accidents have been studied for canisters during processing, handling, storage, and transportation. In general, the accidents involve either impacts or overheating.

In evaluating the consequences of accidents, it should be recognized that the canister will never be the sole or final barrier to the release of radioactive material. In addition, the solid form of the waste glass will greatly minimize the amount of release in accidents. Radiation-shielding requirements will dictate that canisters be confined at all times in either a shielded facility (i.e., processing cell) or a shielded container (i.e., transportation cask). Such facilities by themselves will be capable of containing any release of material from the canister. Nevertheless, an objective in canister design has been to maximize the performance of the canister itself and to demonstrate the ability of the primary canister to meet accident criteria. Accident-resistant canisters will provide additional margins of safety and, perhaps, ease requirements on processing, storage, and transportation facilities.

Impact performance has received the greatest emphasis in work at PNL. The results of impact tests are summarized below and in Appendix H. Lacking specific design criteria for HLW canisters, research at PNL and elsewhere (Kaiser Engineers 1977 and 1978, Nuclear Services Corporation 1978) has used the Federal Regulations from 10 CFR 71.64. These criteria define test requirements for fire, impact, and submersion in water. The submersion requirement is essentially trivial for glass in canisters and will not be discussed further here.

One of the standard criteria imposed on containers for shipment of radioactive materials is its ability to survive a fire of $800^{\circ} \mathrm{C}\left(1475^{\circ} \mathrm{F}\right)$ for $0.5 \mathrm{~h}$ (10 CFR 71.64). Such a temperature is not high enough for a canister to fail by overheating (melting or oxidation). The primary concern is pressure that may build up from the heating of gases or water that may be in the void space at 
the top of the canister. (Such internal pressure stresses are evaluated in Appendix $H$ for PNL twist-lock closure design). We believe that the canister will not lose integrity unless a substantial quantity of water is present in the canister top void because of leakage during water storage. We also believe that it is impractical to design canisters to sustain the very high pressures of such rapid heating of entrapped water.

The other mode of overheating failure is that of an uncontrolled temperature excursion during processing. Hypothetical causes of such an excursion could be a malfunction of an ICM furnace, or a high-heat generating glass placed in an insulated enclosure that does not allow adequate cooling of the canister.

Process overheating has been studied at PNL in a canister-overheat test. In this test, glass in a canister was heated by electrical resistance heating of fins imbedded in the glass. The glass and canister were heated to temperatures above normal ICM temperatures (i.e., $1050^{\circ} \mathrm{C}$ or $1922^{\circ} \mathrm{F}$ ). Melting of the resistance-heated fins terminated the test before any noticeable damage occurred to the canister. Further testing of canisters under overheating conditions is needed to establish the temperature and failure mode for catastrophic failure of a canister during processing. Possible failure modes are stress-induced creep rupture, catastrophic corrosion of the canister wall, and melting of the canister wal1. We anticipate the ultimate failure will not occur until temperatures at or near the canister melting temperature are reached.

\section{IMPACT TESTS}

Specific design criteria for impact accident conditions have not yet been adopted for waste canisters. However, it is expected that future criteria will be similar to the well-developed rules presently in force for the transportation of radioactive materials. These criteria include qualification tests of a 9-m (30-f) drop onto a flat surface and a $102-\mathrm{cm}(40-\mathrm{in}$.) drop onto a puncture probe. Other specific accidents have been hypothesized based on projected canister handling conditions (Kaiser Engineers, 1978). The most severe of these is a drop of a canister several thousand feet down a mine shaft at the geological disposal site.

The approach at PNL to the design of canisters for impact loadings has been to follow, as much as possible, design practices recommended for shipping containers for radioactive materials. The specific practices cover materials selection, joint design, welding techniques, and quality assurance. Stress calculations for impact loadings have not been emphasized, because of the inherent difficulty of predicting structural response and failure thresholds under impact conditions. Full-scale drop tests have been used to evaluate designs. Canister test-specimens for such tests have been readily available as a result of process-development trials at PNL.

Two series of impact tests, in 1975 and 1977, have been conducted at PNL. The main objective of the 1975 series was to evaluate the extent of glass fracturing as a result of impact (Smith and Ross 1975). In the more recent 1977 series, the focus was on canister integrity. The results of these tests are described in Appendix $\mathrm{H}$ of this report.

In the 1977 series, 18 drop tests were performed from heights ranging from 6 to $32 \mathrm{~m}$ ( 20 to $104 \mathrm{f}$ ). Both bottom- and topdrops were performed. The test results show that HLW canisters can sustain severe bottom impacts, when accepted design and fabrica$t$ ion rules are followed. The consequences of top impact were found to be more severe since the void at the top of the canister does not provide the restraining effect that glass provides at the filled bottom of the canister. We believe that an optimal top and closure design, particularly in weldjoint configurations, can result in impactresistant canister tops. Further impact testing of canister tops is recommended.

We have not evaluated canister puncture resistance as defined in 10 CFR 71.64. It is recommended that puncture resistance be established. Puncture resistance criteria will probably impose limits on minimum canister-wall thickness. 


\section{CONCLUSIONS AND RECOMMENDATIONS}

Many conclusions and recommendations have been incorporated in the body of this report and in its appendices. A summary of the major conclusions and recommendations that will advance the state of canister stress analyses are included below:

1) No formal and comprehensive criteria or codes have been adopted for the design and fabrication of waste canisters, although a number of existing codes and regulations provide valuable guidance. The ASME Boiler and Pressure Vessel Code is suitable for canister fabrication and quality assurance, but important aspects of canister processing and loadings fall outside the scope of the ASME code. Methods proposed in this report provide preliminary design rules for processing conditions, and existing federal regulations on transportation of nuclear materials provide guidance on handling and transportation stresses. We recommend that systematic criteria and design rules for waste canisters be developed. These rules should include performance and qualification tests to demonstrate the adequacy of specific canister designs.

2) Well-developed methods, particularly computer-based methods using finiteelement codes, are available to calculate stresses in waste canisters. These methods have been extensively developed for pressure vessel and aerospace applications, but are well suited for waste canister applications, as well. We recommend that effective use be made of this available technology, as illustrated by numerous case studies described in this report.

3) A number of canister-design concepts have been developed and demonstrated at PNL. The use of bottom-supported canisters and the twist-lock closure have been emphasized in this report. It is recommended that the features of these designs be incorporated into canisters developed in the future for particular process applications.

4) The factors of materials performance, fabrication methods, and nondestructive inspection methods cannot be separated from stress analysis and structural design. In particular, the requirements for remote welding and inspection of the final seal weld will largely dictate canister closure configurations. The development of remote welding and inspection equipment should be pursued, so that canister designers can focus on realistic closure concepts.

5) The methods of fracture mechanics and damage-tolerance analys is allow realistic evaluation of the consequences of cracklike defects in closure welds. It is recommended that application of these methods be an integral part of research to develop nondestructive inspection methods.

6) The high temperatures experienced by canisters, along with the requirement to contain molten glass during filling, falls outside the scope of conventional engineering practice. However, PNL studies have shown that canisters can be designed for the extreme conditions encountered during filling. We recommend, however, that additional creep strength and corrosion data be generated for design and licensing purposes, after specific canister alloys and process conditions have been selected.

7) Stress-corrosion cracking is the aspect of materials performance that demands the highest priority for further research. The feasibility of interim storage of canisters in water-basin environments is not in question, provided suitable measures are taken to preclude cracking (i.e., alloy selection, metallurgical controls, water chemistry control, and residual stress reduction). Rather, uncertainty exists as to what trade-offs and compromises can be made to minimize costs and to simplify processing.

8) The use of canister overpacks on a routine basis is not advocated by PNL. The emphasis should be to develop primary canisters that can contain the waste form through processing, interim storage, and transportation. While the durability of canisters following geologic disposal is outside the scope of this report, we recommend that overpack studies emphasize corrosion performance in geologic environments.

9) The evaluation of canister impact strength should be based on full-scale drop tests rather than on stress calculations. Tests at PNL have shown that canisters can sustain severe bottom impacts without releasing contained waste. it is recommended that future testing focus on the impact performance of closures and 
the puncture resistance of canisters.

Canister impact performance should be evaluated and improved whenever possible. However, impact performance should not be achieved at the expense of perhaps more important considerations, such as corrosion performance. In large measure, safety in transportation and handling accidents will be ensured by transportation casks and processing facilities. 


\section{REFERENCES}

ASME. 1972. The Generation of I sochronous Stress-Strain Curves. New York, New York.

Blair, H. T, 1976. Vitrification of Nuclear Waste Calcines by In-Can Melting. BNWL-2061, Pac if ic Northwest Laboratory, Richland, Washington.

Blair, H. T. 1978. Full-Scale In-Can Melting for Vitrification of Nuclear Waste. PNL-SA-6768A, Pac if ic Northwest Laboratory, Richland, Washington.

Boyd, W. K., and A. M. Hall. 1977. Topical Report on Analys is of the Factors That Impact the Reliability of High Level Waste Canister Materials. $\mathrm{RHO}-\mathrm{C}-7$, Battelle Columbus Laboratories for Rockwell Hanford Operations, Columbus, Ohio.

Bradley, D. G. 1977. History of Prototype High-Level Waste Canister SS-9 While in Air and Water Storage. PNL-2278, Pac if ic Northwest Laboratory, Richland, Washington.

Code of Federal Regulations, Title 10, part 71, section 64, Appendix B.

Chapman, C. C., and J. L. Buelt. 1977. Vitrification of High-Level Waste in a Joule-Heated Ceramic Melter. BNWL-SA-6375, Pacific Northwest Laboratory, Richl and, Washington.

Chapman, C. C., and J. L. Buelt. 1978. The Use of a Continuous Glass Melter in ImmobiTization of Radioactive Defense Waste. PNL-SA-6867, Pacific Northwest Laboratory, Richland, Washington.

Kaiser Engineers. 1977. High-Level Waste Canister Envelope Study Structural Analysis. RHO-C-8, Rockwe11 Hanford Operations, $\overline{\mathrm{Rich}}$ land, Washington.

Kaiser Engineers. 1978. Classification of Fuel Element Canisters with Respect to ASME Boiler and Pressure Vessel Code for Use in Spent Fuel Handling Studies. By Kaiser Engineers, for Rockwe11 Hanford Operations, Oakland, California.

Kraus, H. 1977. Reference Stress Concepts for Creep Analysis. Welding Research Council Bulletin Number 227, New York, New York.
Mecham, W. J., W. B. Seefeldt, and M. J. Steindler. 1976. An Analys is of Factors Influencing the Reliability of Retrievable Storage Canisters for Containment of Solid High-Level Radioactive Waste. ANL-76-82, Argonne National Laboratory, Argonne, Illinois.

Mende 1, J. E. 1978. The Storage and Disposal of Radioactive Waste as Glass in Canister. PNL-2764, Pacific Northwest Laboratory, Richland, Washington.

Mikols, W. J., L. S. Romero, and W. F. Bonner. 1978. Recent Advances in Spray Calcination of Nuclear Wastes. PNL-SA-6719, Pacific Northwest Laboratory, Richland, Washington.

Moore, E. L. 1978. Inter im Report: Commercial Waste Packaging Studies, Task w, High-Level Waste Package Acceptance Criteria Study. RH0-ST-10, Atomics International Division, Rockwell Hanford Operations, Richland, Washington.

Nuclear Services Corporation. 1978. Recommendations for Codes and Standards to be Used for Design and Fabrication of High-Leve1 Waste Canister. NSC-1-78-004, by Nuclear Services Corporation, for Rockwell Hanford Operations (Rockwell report $\mathrm{RHO}-\mathrm{C}-13)$, Campbe11, Cal ifornia.

Slate, S. C., and R. F. Maness. 1978. "Corrosion Experience in Nuclear Waste Processing at Battelle-Northwest," Materials Performance 17(6):13-21.

Slate, S. C., et al. 1979. "Stresses and Cracking in High-Level Waste Glass." Proceedings of the Conference on High-Level Radioactive Solid Waste Forms. NUREG/CP-0005, Nuclear ReguTatory Commission, Washington, D.C.

Slate, S. C. and W. A. Ross. 1977. HighLevel Radioactive Waste Glass and Storage Canister Design. BNWL-SA-6379, Pacific Northwest Laboratory, Richland, Washington.

Smith, T. H., and W. A. Ross. 1975. Impact Testing of Vitreous Simulated High-Level Waste in Canisters. BNWL-1903, Pacif ic Northwest Laboratory, Richland, Washington. 
APPENDIX A 


\section{STRESS ANALYSIS METHODS}

Various computer programs and stress analysis techniques have proven useful in canister structural integrity studies at PNL. The application of these codes and techniques to particular canister design problems are illustrated in subsequent appendices to this report. This appendix summarizes and highlights some of these methods. Computer codes used in PNL work are listed and areas of application are identified. Isochronous stress-strain curves and the reference stress technique have proven to be valuable analytical tools for predicting canister performance at elevated temperatures. The basic features and advantages of both methods are described. Finally, the importance of large deflection effects and methods of treating these effects by using appropriate computer codes are discussed.

\section{COMPUTER PROGRAMS}

In recent years, the use of digital computer programs for stress and heat-transfer analyses has become commonplace. Such codes have proven invaluable in the evaluation of canister stresses. Table A.1 lists specific computer programs that have been used at PNL. Program capabilities and areas of application to canister technology are noted. Some of the codes were available at PNI. from in-house developments, some were acquired from outside sources, and some were proprietary codes accessed by commercial timesharing arrangements. The list is not intended to be an endorsement of particular codes, nor to suggest that other codes are not equally applicable. Rather, the list is intended to indicate the types of computer codes that are likely to apply to the area of canister technology. The analysis of creep deformation during canister filling presented a particular challenge. A number of the codes included in Table A.1 were evaluated for this application.

\section{ISOCHRONOUS STRESS-STRAIN CURVES}

At the temperatures associated with vitrification processes, canister materials no longer behave in a linear elastic fashion. Stress analyses are complicated by deformation that occurs by the creep mechanism. At PNL, isochronous stress-strain curves have been found to be particularly suitable for the analysis of creep deformation in canisters filled by the ICM process. For the conditions of canister analys is, isochronous stress-strain curves allow efficient solutions for time-dependent creep deformation, while avoiding severe numerical-stability problems encountered with forward timeintegration schemes.

An isochronous stress-strain curve allows a time-dependent creep analys is to be treated as a succession of time-independent elastic-plastic analyses. Constant-stress, constant-temperature creep curves from conventional uniaxial creep tests are used to generate an equivalent time-independent stress-strain curve for each period for which a solution is desired. These isochronous curves incorporate the combined effects of primary and secondary stage creep, and the difficult task of fitting equations to families of creep curves is circumvented. Isochronous stress-strain curves for some materials of interest to canister design are given in Appendix D. Examples of stress analyses based on such curves are described in Appendix $\mathrm{C}$.

Attempts at PNL to use forward integration schemes in canister creep studies have encountered numerical difficulties. Such schemes partition the strain state into elastic and inelastic contributions. Numerical stability requires that the change in inelastic strain during each time step not exceed the elastic strain corresponding to the prevailing stress level (Greenbaum and Rubinstein 1968). At the temperatures of interest, significant creep can occur at stresses as low as 1000 psi. This trend introduces an unstable character to the numerical integration process and can require an excessively large number of time steps to generate a creep solution for the time periods of interest. 
TABLE A.1. Computer Codes Used in Canister Studies

\begin{tabular}{|c|c|c|c|c|}
\hline $\begin{array}{l}\text { Name of } \\
\text { Code }\end{array}$ & Reference & Source of Code & Code Capability & Area of Application in Canister Studies \\
\hline ANSYS & $\begin{array}{l}\text { DeSaivo and } \\
\text { Swanson } \\
1975\end{array}$ & $\begin{array}{l}\text { Proprietary - Swanson } \\
\text { Analysis Systems, } \\
\text { Elizabeth, PA }\end{array}$ & $\begin{array}{l}\text { General purpose finite- } \\
\text { element code for stress } \\
\text { and heat transfer }\end{array}$ & $\begin{array}{l}\text { - Heat transfer and thermal stress } \\
\text { analysis of closures } \\
\text { - Heat transfer analysis of canister } \\
\text { and glass residual stresses }\end{array}$ \\
\hline MARC & $\begin{array}{l}\text { MARC -CDC } \\
1974\end{array}$ & $\begin{array}{l}\text { Proprietary, Marc } \\
\text { Analys is Research } \\
\text { Corp., Palo Alto, CA }\end{array}$ & $\begin{array}{l}\text { General purpose finite- } \\
\text { element code for stress } \\
\text { and heat-transfer } \\
\text { analysis }\end{array}$ & $\begin{array}{l}\text { - Creep analys is for in-can melting } \\
\text { conditions }\end{array}$ \\
\hline HEAT ING-4 & $\begin{array}{l}\text { Turner and } \\
\text { Simon-Tov } \\
1971\end{array}$ & $\begin{array}{l}\text { Oak Ridge National } \\
\text { Laboratory }\end{array}$ & $\begin{array}{l}\text { Finite-difference heat } \\
\text { transfer }\end{array}$ & - Heat transfer of canister closures \\
\hline MONSAST IFF & $\begin{array}{l}\text { Lestingi } \\
1969\end{array}$ & $\begin{array}{l}\text { Dr. J. F. Lestingi, } \\
\text { Univ. of Akron }\end{array}$ & $\begin{array}{l}\text { Multi-segment numerical } \\
\text { integration of elastic } \\
\text { shells of revolution }\end{array}$ & $\begin{array}{l}\text { - Lifting stresses in closure } \\
\text { - Discontinuity stresses in bottom } \\
\text { and sidewall of canister }\end{array}$ \\
\hline AXICRP & $\begin{array}{l}\text { Suther land } \\
1969\end{array}$ & $\begin{array}{l}\text { Battelle, Pacific } \\
\text { Northwest Laboratory }\end{array}$ & $\begin{array}{l}\text { Finite-element } 20 \text { solid } \\
\text { for creep andysis }\end{array}$ & - Canister creep during filling by ICM \\
\hline CRPSOL & -- & Battelle Columbus Lab & $\begin{array}{l}\text { Finite-element } 20 \text { solid } \\
\text { for elastic-plastic } \\
\text { analysis }\end{array}$ & - Canister creep during filling by ICM \\
\hline AXISOL & $\begin{array}{l}\text { Wilson and } \\
\text { Jones } \\
1967\end{array}$ & $\begin{array}{l}\text { Battelle, Pacific } \\
\text { Northwest Laboratory }\end{array}$ & $\begin{array}{l}\text { Finite-element } 20 \text { solid } \\
\text { for elastic-plastic } \\
\text { analysis }\end{array}$ & $\begin{array}{l}\text { - Canister creep during filling by ICM } \\
\text { - Analysis of glass canister residual } \\
\text { - Antresses } \\
\text { - Calysis of glass fracturing } \\
\text { - faluclation of stress intensity } \\
\text { factors for weld defects }\end{array}$ \\
\hline NONLEP & $\begin{array}{l}\text { Gerdeen, } \\
\text { Simonen and } \\
\text { Hunter } \\
1971\end{array}$ & Battelle Columbus Lab & $\begin{array}{l}\text { Mult isegment numerical } \\
\text { integration of elastic- } \\
\text { plastic shells of } \\
\text { revolution }\end{array}$ & - Canister creep during filling by $\mathrm{ICM}$ \\
\hline WERCO & $\begin{array}{l}\text { Hichman, } \\
\text { Hopper and } \\
\text { Mershon } \\
1972\end{array}$ & $\begin{array}{l}\text { Proprietary, AAA } \\
\text { Technology \& Special- } \\
\text { ties, Co., Inc., } \\
\text { Houston, Tx }\end{array}$ & $\begin{array}{l}\text { Local stresses in shell } \\
\text { structures from local- } \\
\text { ized external loadings }\end{array}$ & $\begin{array}{l}\text { - Analysis of stresses at locations } \\
\text { of canister lifting ears }\end{array}$ \\
\hline
\end{tabular}

Time integration schemes for creep analyses are effectively used in situations where the total creep strain is comparable to the elastic strain level (say within one or two orders of magnitude). In these integration schemes, material behavior is represented by a so-called equation of state, which allows cyclic changes in loading and temperature to be readily treated. On the other hand, isochronous curves imply monotonic loadings and temperatures. Fortunately, the loadings of interest to canister filling at very high temperatures can be reasonably treated as monotonic, and one can without difficulty place a bound on the extent of creep deformation. The reference stress methods described below can be used to estimate correction factors to account for variations of loadings and temperature with time (Penny and Marriott 1975; Kraus 1977).

\section{REFERENCE STRESS TECHNIQUE}

The reference stress technique advocated by Penny and Marriott (1975) and reviewed by Kraus (1977) has proven to be a useful method to estimate creep deformations that occur during the filling of canisters. This method relates the creep response of a structure to that of a uniaxial creep test. The usefulness of the method has been demonstrated in the literature by a number of experimental correlations.

In its basic form, the concept states that:

$$
\frac{\Delta_{c}}{\Delta_{e}}=\frac{\varepsilon_{c}\left(\sigma_{0}\right)}{\varepsilon_{e}\left(\sigma_{0}\right)}
$$


where

$$
\begin{aligned}
\Delta_{e} & =\text { elastic deflection of structure } \\
\Delta_{c} & =\text { creep deflection of structure } \\
\varepsilon_{e}\left(\sigma_{0}\right)= & \text { elastic strain due to stress } \sigma_{0} \\
\varepsilon_{c}\left(\sigma_{0}\right)= & \text { creep strain at time } t \text { due to } \\
& \text { stress } \sigma_{0}
\end{aligned}
$$

A number of methods have been described for determining a suitable value for the reference stress $\sigma_{0}$. For canister analyses, a computer solution often has been available for the creep deformation of the structure. For a given duration of loading, it is first necessary to determine the particular level of stress that will produce the same strain in a tensile creep test specimen as that calculated for the structure. This gives a ratio between the load in the structure and the corresponding stress in the simple creep test. While the method involves a number of assumptions and approximations, it has pro$v i d e d$ an economical means of performing parametric and design studies.

The reference stress technique has been applied to estimate deflections in flatbottomed, top-supported canisters. In the analysis of such a flat-bottom canister, the reference stress $\sigma_{0}$ is first established for a specific combination of glass loading, bottom diameter, and bottom thickness (i.e., $\left.P_{0}, D_{0}, h_{0}\right)$. For other combinations of these parameters, the reference stress is based on relations obtained from platebending theory. These give a reference stress value of:

$$
\sigma=\sigma_{0}\left(P / P_{0}\right)\left(D / D_{0}\right)^{2}\left(h_{0} / h\right)^{2}
$$

If 0 and 0 are the bottom strain and the stress in a particular computer creep solution, and $\varepsilon$ is the bottom strain estimated using the reference stress method, then the corresponding bottom deflection is estimated as:

$$
\delta=\delta_{0}\left(\varepsilon / \varepsilon_{0}\right)\left(D / D_{0}\right)\left(h_{0} / h\right) .
$$

Sidewall stresses are related to the reference solution by:

$$
\sigma=\sigma_{0}\left(P / P_{0}\right)\left(D / D_{0}\right)\left(h_{0} / h\right)
$$

where $h$ here is the wall thickness of the sidewall and $D$ is the inside diameter of the canister.

In an application of the above equations at PNL, a special purpose computer program has been written to calculate diametric and bottom deformations due to creep in canisters for arbitrary temperature and filling histories. In the analysis a time-step procedure is used and strains are accumulated numerically. The equations describing the creep behavior of the material as a function of stress, temperature, and time of loading were programmed for numerical evaluation. An incremental theory of creep with the strain hardening assumption evaluates creep under conditions of variable stress and temperature. The computer program has been used in parametric studies to evaluate the effect of temperature and wall thickness on creep deformation in canisters. Also, the effects on various filling rates and heating sequences have been evaluated. The computer program has also proven useful in estimating relative creep deformations for canisters subjected to the conditions of trial vitrification runs.

\section{LARGE DEFLECTION EFFECTS}

It is the usual practice in stress analyses to neglect the effect of changes in the geometry on mechanical equilibrium of structures. Such linear solutions are usually excellent approximations of the actual behavior of the structure. However, special circumstances exist, particularly for thin she11-type structures such as waste can isters, where linear analyses are inadequate.

Large deflection effects are presented here in the context of top-supported canisters of relatively short length. In the evolution of the ICM process at PNL, such canister designs were of interest at the time the large deflection analyses presented here were performed. Since that time attention has focused on larger canisters, and the bottom-supported concept has been adopted at PNL. The potential for excessive creep deformation, as identified in the calculations described below, was an important factor leading to the use of bottom-supported canisters. 
The subscale canister of Figure A.l was analyzed for operating temperatures of $1100^{\circ} \mathrm{C}\left(2012^{\circ} \mathrm{F}\right)(\mathrm{glass}$ head of $2.4 \mathrm{~m}$ or $8 \mathrm{f}$ ) and $1050^{\circ} \mathrm{C}\left(1922^{\circ} \mathrm{F}\right.$ ) (glass head of $0.91 \mathrm{~m}$ or $3 \mathrm{f}$ ). Creep was taken into account by use of the isochronous stress-strain curves, as shown in Figure A.2. The curves were based on some preliminary data for 300-series stainless steels and the predictions should be viewed as qualitative and illustrative.

The initial application of the finiteelement program AXISOL (Wilson and Jones 1967) to the analysis of canister bottom deflections resulted in the prediction of gross deformations that were well beyond the linear theory of the program. Subsequently, the computer program NONLEP

(Gerdeen, Simonen and Hunter 1971) was applied to the bottom deflection problem. This program treats both material and geometric nonlinearities and can give a more realistic prediction of deflections in flatbottomed canisters.

Initial calculations were for the $1100^{\circ} \mathrm{C}$ $\left(2012^{\circ} \mathrm{F}\right.$ ) conditions that had been addressed in some previous studies. Figure A. 3 gives

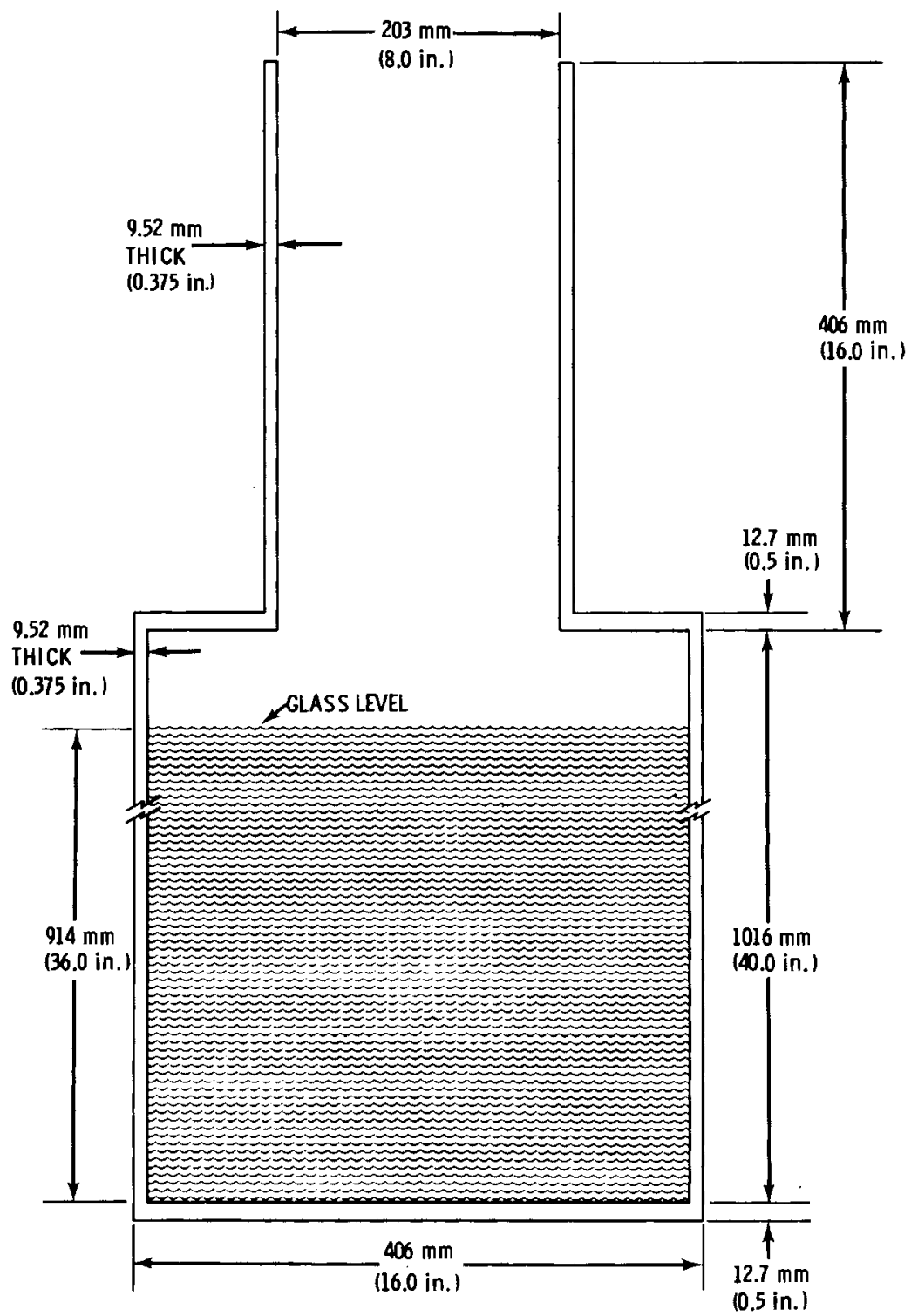

FIGURE A.1. Dimensions of Short Top-Supported Canister 


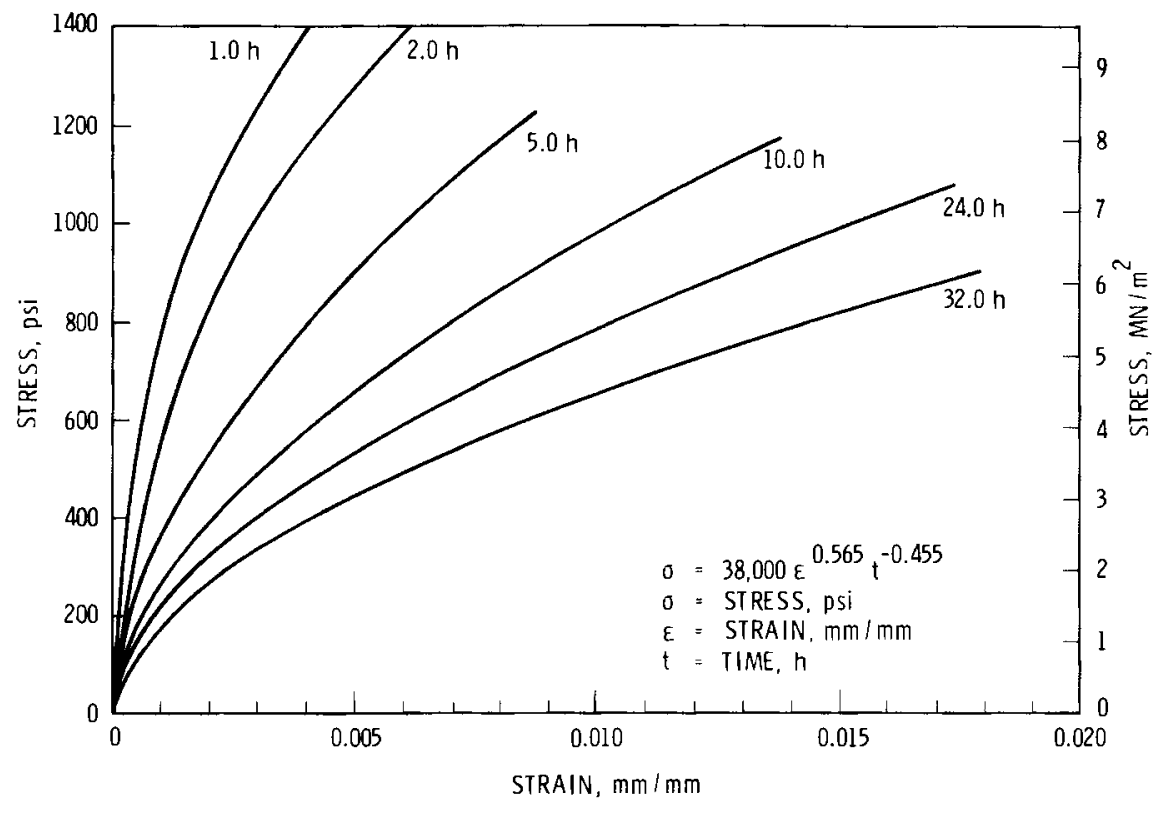

FIGURE A.2. Isochronous Stress-Strain Curves Used in Stress Analyses of Canister at $1050^{\circ} \mathrm{C}\left(1922^{\circ} \mathrm{F}\right)$

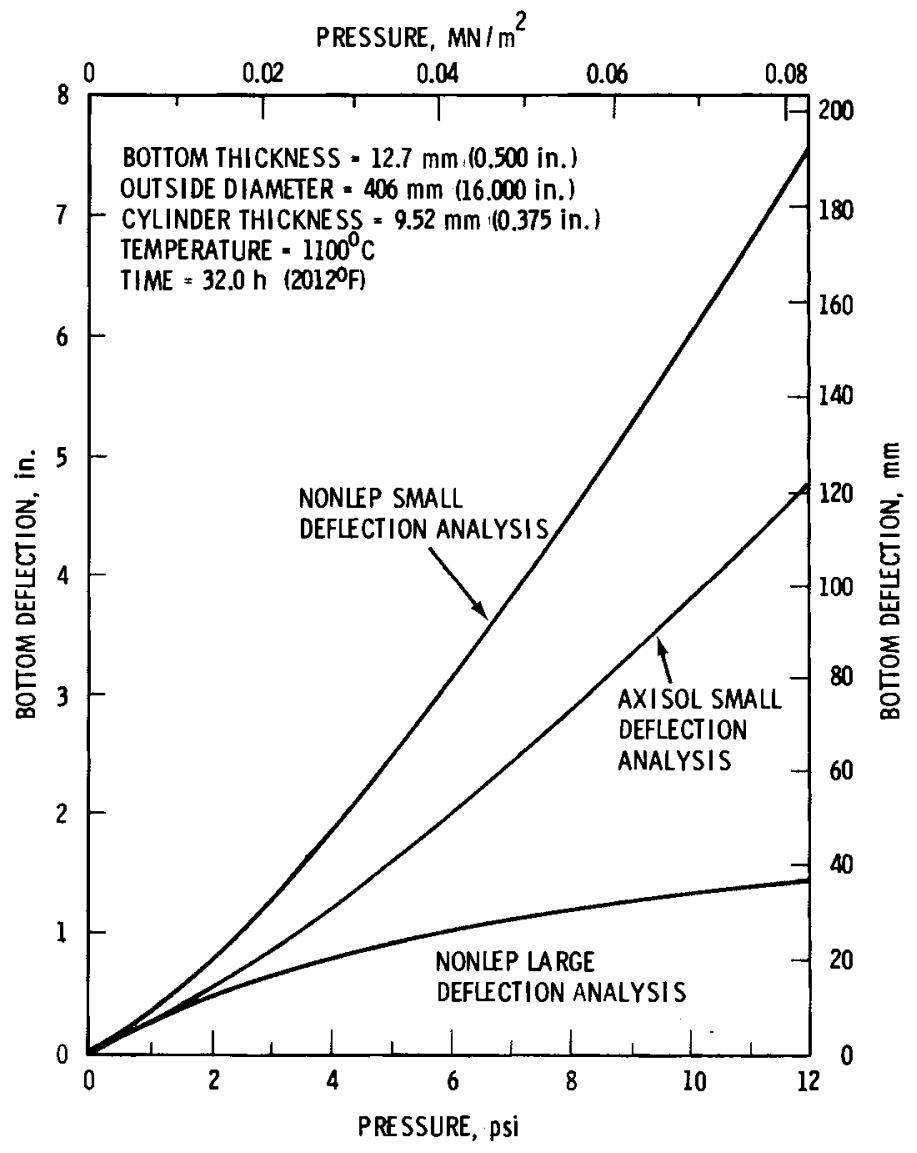

FIGURE A.3. Comparison of Predicted Bottom Deflections from Small and Large Deflection Analyses 
predicted bottom deflections as a function of bottom pressure for three methods of analysis. For each case the pressure was assumed to remain constant for a period of $32 \mathrm{~h}$. It was found that the program NONLEP in the small deflection mode gave deflections that exceeded even those previously predicted by the program AXISOL. In the large deflection analysis, the program NONLEP accounted for the increase in strength of the initially flat-bottom plate as it deformed in a slightly curved shape. This shape can support the bottom pressure loading by both bending and membrane action. For relatively small deflections, all three analyses gave approximately the same results. However, for the full-bottom pressure of $0.83 \mathrm{MN} / \mathrm{m}^{2}(12.0 \mathrm{psi})$, the nonlinear analysis predicts that the deflection will be more nearly $38 \mathrm{~mm}$ (1.5 in.) rather than $203 \mathrm{~mm}$ ( $8 \mathrm{in.}$ ) as predicted by the linear analysis. Figure A.4 shows the predicted deformation patterns for the canister bottom plotted without magnification of the deflection scale.

Figure $A .5$ gives the factor derived from the results of Figure A.3, which can be applied to a linear analysis to correct for large deflection effects. While this factor applies in an exact sense only to the stated conditions, it does provide a guide for estimating the extent of large deflection effects if the results of a linear or small deflection analysis are available.

Figures A.6 and A.7 give results for the $1050^{\circ} \mathrm{C}\left(1922^{\circ} \mathrm{F}\right)$ operating condition. In this case, the predicted bottom-center deflection was $6.1 \mathrm{~mm}(0.24 \mathrm{in.})$. The diametrical expansion was too small to show on the scale of Figure A.6 without magnification. The predicted diametrical expansion of the canister remote from the bottom plate was $0.12 \mathrm{~mm}(0.0046 \mathrm{in.})$ on the $406-\mathrm{mm}-$ (16.00-in.-) dia canister. Predicted strains in both the bottom and side of the canister were less than $1 \%$, which is within reasonable design limits for a 300-series stainless steel. Figure A.7 shows the predicted stress distribution in the canister bottom plate. The large deflection creep
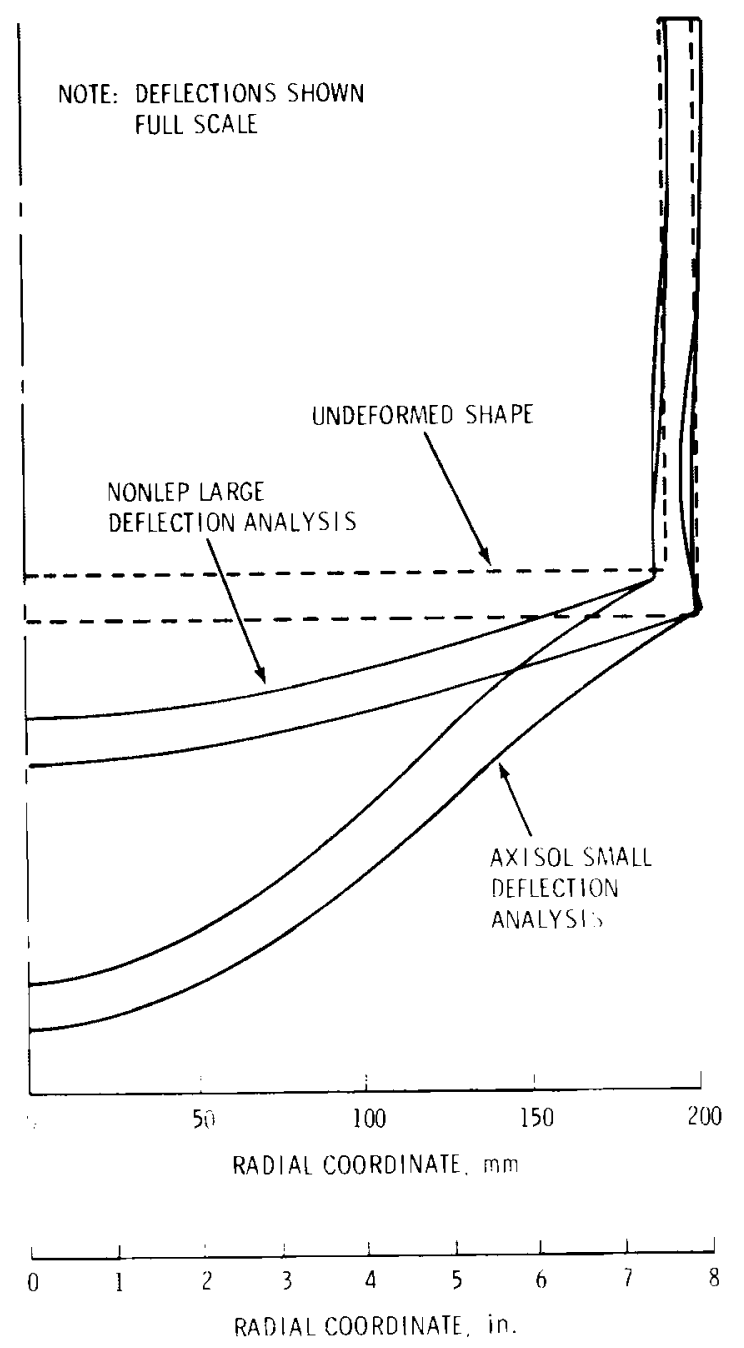

FIGURE A.4. Predicted Bottom Deformation in Canister at $1100^{\circ} \mathrm{C}\left(2012^{\circ} \mathrm{F}\right)$ for $32 \mathrm{~h}$ with 8-f Glass Fill Height

solution shows a reduction in stress over the linear-elastic solution. This reduction occurs as a portion of the pressure load is supported by the bottom in a membrane fashion, as opposed to the bending mode characteristic of a flat plate. 
BOTTOM DEFLECTION FROM GEOMETRIC LINEAR ANALYSIS, mm

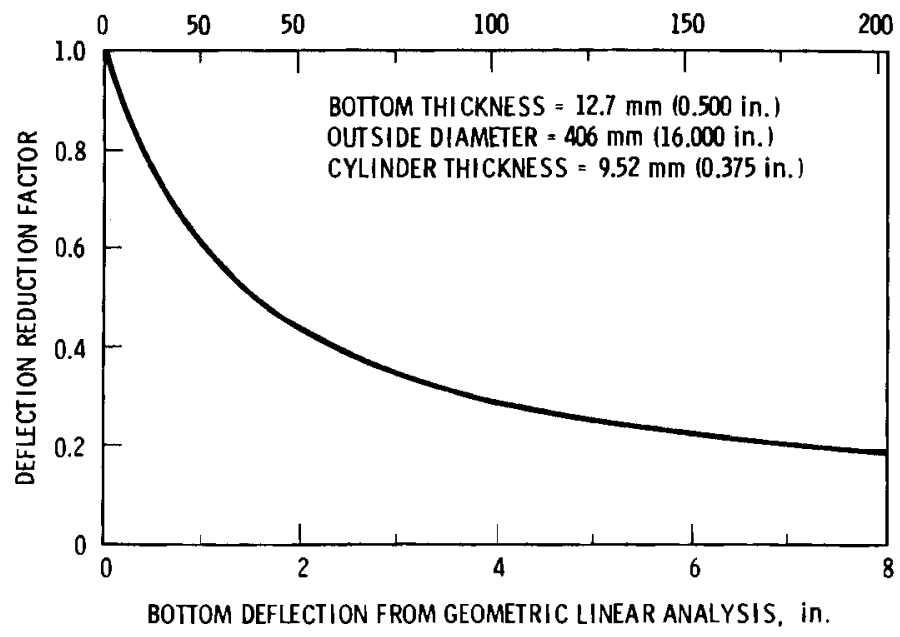

FIGURE A.5. Factor to be Applied to Small Deflection Solution for Bottom of Canister to Correct for Geometric Nonlinear Effect - Based on Isochronous Analyses of Canister at $1100^{\circ} \mathrm{C}\left(2012^{\circ} \mathrm{F}\right)$

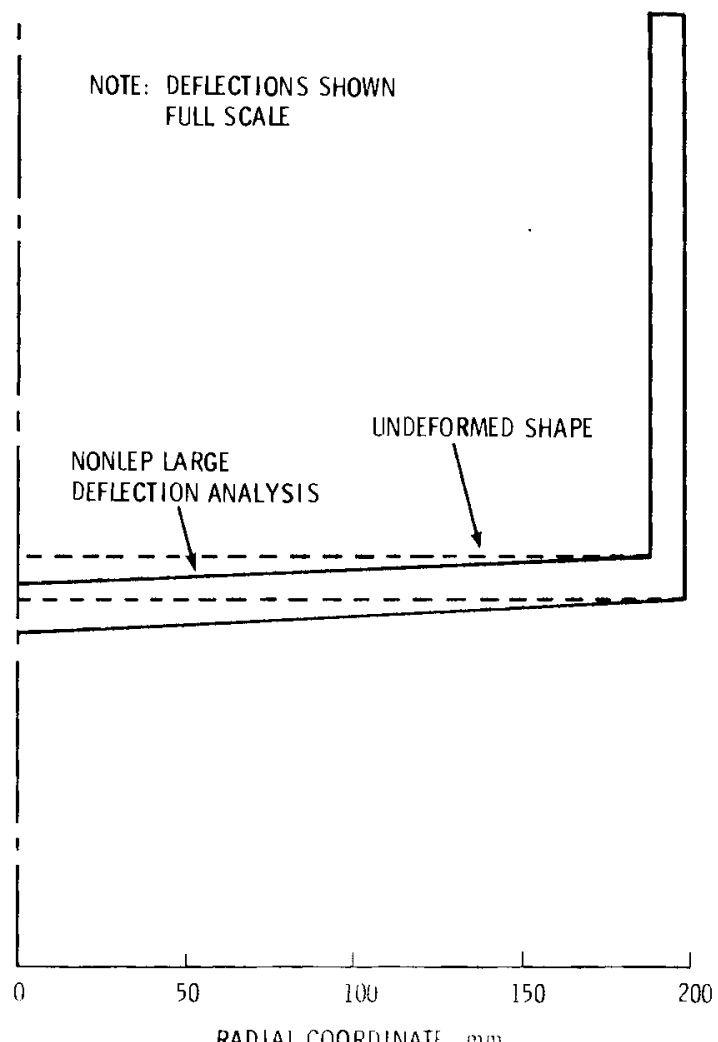

RADIAL COORDINATE, mII

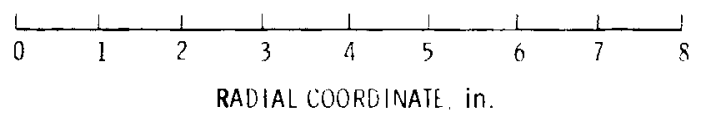

FIGURE A.6. Predicted Bottom Deformation in Canister at $1050^{\circ} \mathrm{C}\left(1922^{\circ} \mathrm{F}\right)$ for $24 \mathrm{~h}$ with 3-f Glass Fill Height 


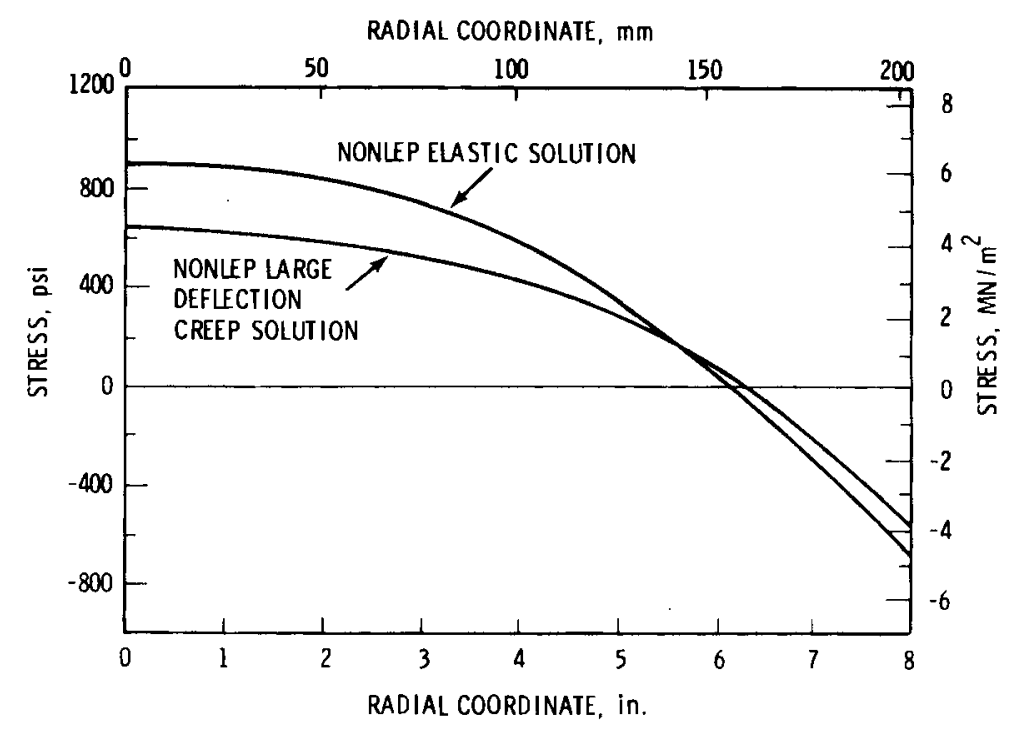

FIGURE A.7. Predicted Bottom Surface Stress in Canister at $1050^{\circ} \mathrm{C}\left(1922^{\circ} \mathrm{F}\right)$ for $24 \mathrm{~h}$ with $3-\mathrm{f}$ Glass $\mathrm{Fill}$ Height

\section{REFERENCES}

DeSalvo, G. J., and J. A. Swanson. 1975. ANSYS Engineering Analys is User's Manual. Swanson Analys is Systems. Elizabeth, Pennsylvania.

Gerdeen, J. C., F. A. Simonen and D. T. Hunter. 1971. "Large Deflection Analysis of Elastic-Plastic Shells Using Numerical Integration." AIAA Journal 9: 1012 .

Greenbaum, G. A., and M. F. Rubens te in. 1968. "Creep Analys is of Axis ymmetric Bodies Using Finite Elements." Nuclear Engineering and Design 7:379-397.

Kraus, H. 1977. Reference Stress Concepts for Creep Analysis. Welding Research Counci1 Bulletin Number 227, New York, New York.

Lestingi, J. F. 1969. Direct Stiffness Analysis of Branch She $17 \mathrm{~s}$ of Revolution Using Numerical Integration Procedures Vol. II. MONSASTIFF User's Mannual. Report Number 70-1, The Institute of Science and Engineering Research, Department of Civil Engineering, The University of Akron, Akron, Ohio.

MARC Analysis Corp. and Control Data Corp. 1974. MARC-CDC Non-L inear Finite Element Analysis Program User Information ManuaT. CYBERNET - Vol. 1, Minneapolis, Minnesota.
Penny, R. K., and D. L. Marriott. 1975. "Creep of Pressure Vessels." Proceedings of the International Conference on Creep and Fatigue in Elevated Temperature App Tications. The Institution of Mechanical Engineers, London, United Kingdom.

Sutherland, W. H. 1969. A Finite-Element Computer Code (AXICRP) for Creep Analys is. BNWL-1142, Pacific Northwest Laboratory, Richland, Washington.

Turner, W. D., and M. Simon-Tov. 1971. HEATING4 - In IBM 360 Heat Conduction Program. ORNL-TM-3208, 0ak Ridge National Laboratory, Oak Ridge, Tennessee.

Wichman, K. R., A. G. Hopper and J. L. Mershon. 1972. Local Stresses in Spherical and Cylindrical Shells Due to External Loads. Welding Research Council BuTletin Number 107, Third Revised Printing, New York, New York.

Wilson, E. L., and R. M. Jones. 1967. Finite Element Stress Analysis of Axisymmetric Solids With Orthotropic, Temperature Dependent Material Properties. Air Force Report No. BSD-TR-67-222, Aerospace Corporation, San Bernardino, California. 
APPENDIX B

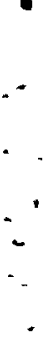


APPENDIX B

\section{APPLICATION OF ASME CODE}

Canisters for vitrified high-level nuclear wastes will be designed and fabricated to high standards and will have strict quality-assurance requirements imposed on their manufacture. However, the canister designer presently lacks an accepted set of rules, such as those presently available for pressure vessels and piping in the ASME Boiler and Pressure Vessel Code. While specific rules for the design and fabrication of waste canisters have not, to date, been proposed or adopted, the question of codes and standards has been the subject of review and study by PNL, as well as by others (Mecham 1976; Kaiser Engineers 1978; and Nuclear Services Corporation 1978). This appendix summarizes the results of these studies.

\section{BACKGROUND AND INTERPRETATION OF CODE}

It is natural to look to the ASME code as a guide to the design and fabrication of waste canisters for the following reasons:

- Materials, design details, and fabrica$t$ ion methods for canisters correspond to those for pressure vessels.

- The ASME code offers a well developed and widely accepted set of rules, which could eliminate the need to develop separate rules for waste canisters.

It is useful here to consider the rules of the code in two broad categories:

1. rules pertaining to materials, fabrication, and quality assurance

2. rules pertaining to design, stress limits, and component usage.

In general, rules in the first category have been found to be useful to waste canister situations. The second category of rules has generally been found to have serious gaps when applied to waste canister technology.

The ASME code has been developed over the years for vessels and piping whose main function is to safely contain high-pressure fluids. It is not surprising that many aspects of canister usage fall outside the scope of the code. The following differences between canister requirements and normal procedures for qualifying pressure vessels have been identified:
- Internal pressures of concern to HLW canisters are relatively low; thus, much of the emphasis of the ASME code relative to design stresses is perhaps inappropriate. Pressure requirements will not dictate canister wall thicknesses, and pressure relief devices will not be required.

- Canister wall temperatures during filling exceed those addressed by the code. Appendix $C$ of this report proposes design rules for high-temperature conditions with low stresses associated with vitrification processes.

- Leakage limitations are probably of more concern to HLW canisters than limitations for pressure vessels and piping. The ASME code focuses on containing high pressures and preventing failure by catastrophic burst.

- Handling and transportation loads are not addressed by the code, since it is specifically stated that the code rules do not apply to movable vessels. Supplementary design rules, such as those given in the cask designer's quide (Shappert 1970) and in Federal regulations (10 CFR 71.64) covering the transport of radioactive materials, help evaluate handling and transportation loads.

- Stress-corrosion cracking has been identified as a major concern for canisters subjected to water-bas in storage. The ASME code does not address stresscorrosion cracking in a direct and systematic manner. The canister designer will need to impose supplementary rules and rely on the results of service-type testing of canisters. 
- Verification testing to validate vessel designs is allowed by the code as an alternative for qualifying vessels that do not otherwise comply, for example, with fatigue stress limits. It is likely that verification testing will play a major role in the licensing of HLW canisters. The code provides little specific guidance in this area.

\section{CONCLUSIONS ON ASME CODE APPLICATIONS}

The provisions of the ASME code have been reviewed for possible application to HLW canisters in studies at PNL and elsewhere. The report by Nuclear Services Corporation to Rockwell Hanford Operations presents a particularly authoritative and comprehensive discussion of the subject. This report also identifies other applicable standards and regulations. The following general conclusions are offered here:

1. Of the various sections of the ASME Boiler and Pressure Vessel Code, Section III, Division I, Class 3 provides the most appropriate set of rules for the fabrication of HLW canisters.

2. Existing provisions of the ASME Code are suitable to ensure canister quality at the time of fabrication, but are inadequate for the evaluation of canister integrity under service loadings and environments.

3. Canister integrity for handling and transportation accidents can be evaluated through application of rules for transport of radioactive materials (Shappert 1970, 10 CFR 71.64).

4. Additional research is needed for evaluating canister materials performance under service environments and for design verification by testing canisters under simulated service conditions.

5. The data developed in special research studies could form the basis of a new code subsection in subsection $\mathrm{NH}$ to Section III --Nuclear Power Plant Components (Nuclear Services Corporation 1978).

6. Code Case 1592-11 (Class 1 - Components in Elevated Temperature Service) provides a useful framework for evaluating canister integrity during filling at elevated temperatures. Estimated inelastic strain levels are within limits imposed by this code case. Additional materials data is required, however, to qualify materials for temperatures reached during canister processing.

\section{REFERENCES}

Code of Federal Regulations, Title 10 , part 71, section 64, Appendix B.

Kaiser Engineers. 1978. Classification of Fuel Element Canisters with Respect to ASME Boiler and Pressure Vessel Code for Use in Spent Fuel Handling Studies. Report for Rockwell Hanford Operations by Kaiser Engineers, Oakland, California.

Mecham, W. J., W. B. Seefeldt and M. J. Ste indler. 1976. An Analys is of Factors Influencing the Reliability of Retrievable Storage Canisters for Containment of Solid High-Level Radioactive Waste. ANL-76-82, Argonne National Laboratory, Argonne, Illinois.
Nuclear Services Corporation. 1978. Recommendations for Codes and Standards to be Used for Design and Fabrication of High Level Waste Canister. NSC-1-78-004, by Nuclear Services Corporation for Rockwell Hanford Operations. (Rockwell Report RHO-C-13), Campbel1, California.

Shappert, L. B. 1970. A Guide for the Design, Fabrication and Operation of Shipping Casks for Nuclear Application. ORNL-NSIC-68, Oak Ridge National Laboratory, Oak Ridge, Tennessee. 
APPENDIX C 
APPENDIX C

\section{FILLING STRESSES}

During filling, waste canisters must serve as a mold until the glass solidifies. In this step of the processing cycle, canister wall temperatures can approach the melting points of the potential canister materials. With the loss of material strength at these temperatures, the potential for excessive creep deformation in the canister has been the focus of considerable attention at PNL. The design of canisters for the filling cycle has been particularly difficult because of the lack of design procedures and engineering data for operating regimes of interest. This appendix describes some of the design procedures developed at PNL and presents the results of some typical design calculations.

Due to more severe operating temperatures, the emphasis in this appendix is on conditions for the ICM process, although canister design for the CM process is also addressed. For each of the processes, the factors that govern the selection of suitable canister wall thicknesses are identified. Design strengths of canister materials are given for each process. A creeptesting program to obtain design strength-data for the ICM process is described in Appendix $D$. For the ICM process, a step-by-step procedure for establishing wall thickness is recommended and safety factors are estimated. The validity of the stress analysis procedure is then checked; deformation data is compared from canisters taken from ICM process trials and those subjected to controlled canister creep tests. The appendix concludes with estimates of filling rate effects and an analysis of local stresses at geometric and temperature discontinuities.

\section{WALL THICKNESS - GENERAL CONSIDERATIONS}

There are numerous factors that can be identified as affecting the required wall thickness of canisters for high-level nuclear wastes. The focus of work at PNL has been on the conditions during filling and the potential creep deformation that can occur at the extreme temperatures of filling. Nevertheless, there are other perhaps more conventional considerations that also govern the selection of a canister wall thickness. The discussion below will briefly describe some of these considerations.

An allowance must be made for corrosion that may occur at both the inner and outer surfaces of the canister during filling. For the CM process, canister temperatures are sufficiently low so that corrosion observed in process trials at PNL has been negligible. No corrosion allowance need be made. For the ICM process, both internal corrosive attack of the canister by the glass and external oxidation by the furnace environment have been observed. Slate and
Maness (1978) have reported corrosion rates. Experience with $304 \mathrm{~L}$ stainless steel at ICM temperatures in an air environment suggests that an allowance for a $0.25 \mathrm{~mm}$ (0.010 in.) loss of oxide scale should be adequate. Corrosive attack at the canister inside surface is dependent on the composition of the waste glass. However, an allowance of $0.25 \mathrm{~mm}$ (0.010 in.) should provide a suitable allowance for such attack. It is recommended, however, that specific corrosion tests be performed for new combinations of glass composition and canister materials.

In addition to the conditions of the filling cycle, canisters must be sufficiently rugged to sustain both normal lifting loads and possible abuse from a lowprobability impact load. Lifting loads are addressed in Appendix $E$ of this report, which covers the subject of closure design. Impact performance is discussed in Appendix $H$. Thickness requirements for impact performance are largely subject to engineering judgment. Results of impact tests suggest that wall thickness per se may not be as important as material ductility, joint 
design, and good welding practice. In general, PNL has specified wall thicknesses greater than those needed merely to meet creep and corrosive conditions imposed on the canister during filling. This has led to typical values of specified wall thicknesses in the range of 6.3 to $12.7 \mathrm{~mm}$ $(0.25$ to $0.50 \mathrm{in.})$, depending on the canister diameter. The greater wall thickness would correspond to canister dia in the $600 \mathrm{~mm}$ (24 in.) range.

\section{WALL THICKNESS FOR ICM}

Procedures are detailed below for establishing minimum wall thickness for the ICM process based on consideration of material creep strength. The canister materials considered are $304 \mathrm{~L}$ stainless steel and Inconel Alloy 601. These alloys tend to bound the types of alloys of interest to the ICM process in terms of strength.

\section{Material Strength}

Figures $C .1$ and $C .2$ give design strengths for $304 \mathrm{~L}$ stainless steel and Inconel alloy 601. These design curves were developed on the basis of creep tests described in Appendix $D$ of this report. The curves give allowable stress as a function of temperature for a criteria of $1 \%$ total creep strain. To allow for unaccounted scatter, the raw strength-data of the creep tests were reduced by a factor of two before the design strength curves of Figures C.1 and C.2 were plotted.
It should be noted that the curves for $304 \mathrm{~L}$ stainless steel indicate that the strength decreases rapidly for temperatures above $1050^{\circ} \mathrm{C}\left(1922^{\circ} \mathrm{F}\right)$. Above $1100^{\circ} \mathrm{C}$ $\left(2012^{\circ} \mathrm{F}\right)$, the indicated strengths become negligible. This decrease in strength is a reflection of accelerated oxidation of the test specimens. The loss of cross sections of the specimens (0.25 in. in dia) gave rise to an apparent loss of strength. With the larger stressed cross sectional area relative to exposed surface area for a canister, a loss of surface material by oxidation will not have so profound an effect on strength. Nevertheless, $1050^{\circ} \mathrm{C}\left(1922^{\circ} \mathrm{F}\right)$ is probably a practical temperature limit for $304 \mathrm{~L}$ stainless steel. The accumulation of spalled oxide scale is likely to interfere with furnace operation.

\section{Design Procedure}

A design procedure has been developed to establish wall thicknesses for the ICM process to ensure that excessive creep deformation (i.e., diameteric expansion) does not occur. The loading to the canister is due to the pressure head of the molten glass in the canister.

The procedure is intended for bottomsupported canisters. For top-supported canisters, bottom stresses and local stresses at top-support points should also be considered. As indicated by results presented in Appendix A, these stresses for a topsupported canister can be substantial and can far exceed side-wall hoop stresses

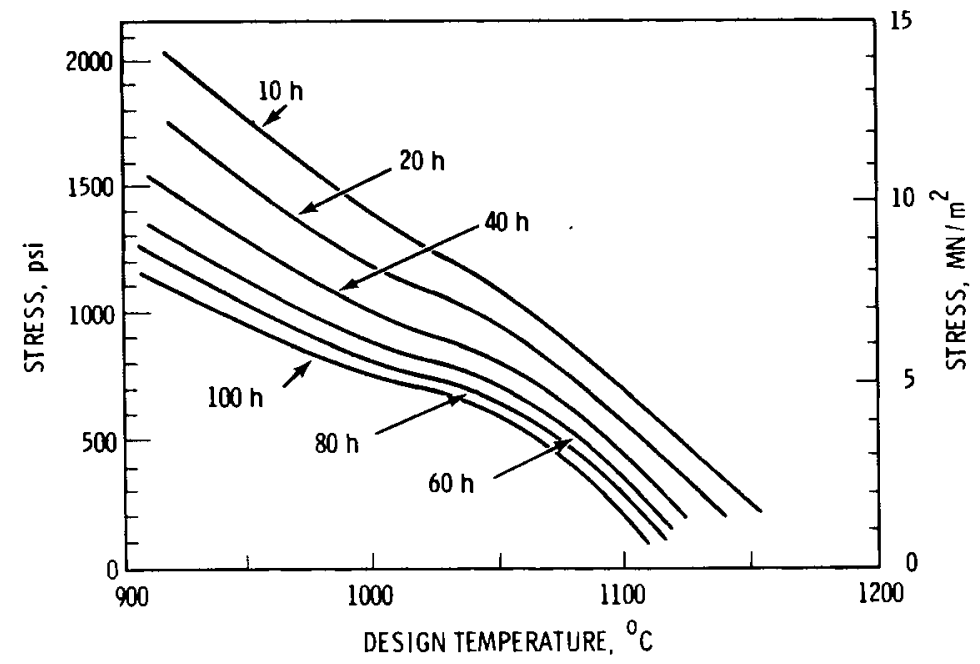

FIGURE C.1. Design Strength of 304L Stainless Steel Based on Stress to Produce $1 \%$ Strain in a Specified Time Period 


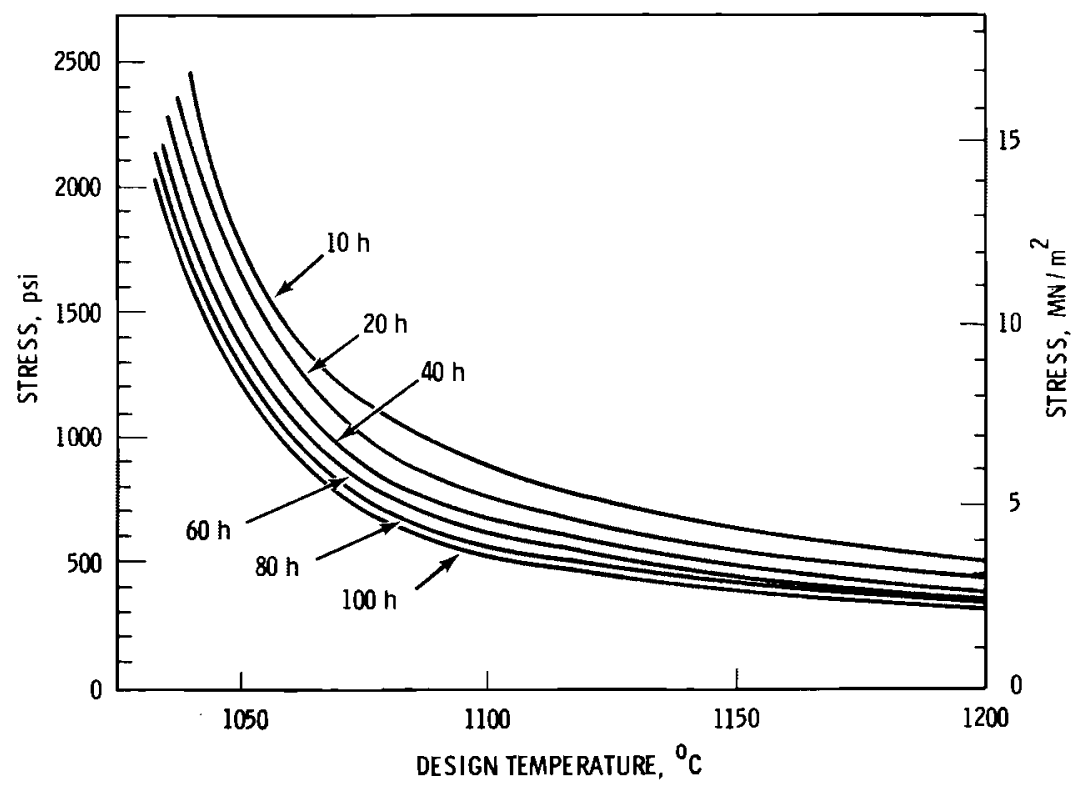

FIGURE C.2. Design Strength of Inconel Alloy 601 Based on Stress to Produce $1 \%$ Strain in a Specified Time Period.

considered in the design procedure presented here.

The recommended procedure for establishing canister wall thicknesses for the ICM process is given in the following step-bystep format:

1. The relevant design conditions must be established in terms of the canister ID, fill height, total process time based on fill rate and hold time after filling, and maximum can ister wall temperature during filling.

2. A $50^{\circ} \mathrm{C}$ ( $\left.90^{\circ} \mathrm{F}\right)$ margin should be allowed for overheating, and an allowable stress level should be established for the canister material. In the example calculations that follow, this stress results in $1 \%$ total creep strain over the time span of the process cycle at a temperature equal to the process temperature, plus the $50^{\circ} \mathrm{C}\left(90^{\circ} \mathrm{F}\right)$ overheat allowance. The curves in Figures $C .1$ and $C .2$ are utilized.

3. The wall thickness should be calculated from the equations listed below:

$$
\begin{aligned}
& t=\frac{p D_{i}}{2 \sigma} \\
& p=\rho h
\end{aligned}
$$

where: $\quad p$ - static pressure,

$\rho$ - glass density,

h - fill height,

$D_{j}$ - inside diameter of canister,

$\sigma$ - design stress.

4. The thickness of step 3 should prevent excessive expansion of the canister from high-temperature creep. To this thickness, a corrosion allowance must be added to account for oxidation at the canister outer surface and for glass attack at the inside surface.

5. The thickness of step 4 should be com pared with minimum thickness requirements from impact and handling considerations. If necessary, the thickness of step 4 should be increased to meet minimum thickness requirements as discussed above.

\section{Wall Thicknesses for Typical Designs}

Wall thickness requirements for bottomsupported canisters were estimated for specific filling conditions and canister sizes. The conditions were for ICM with the following design parameters: 
Glass density $=3.2 \mathrm{gm} / \mathrm{cc}$

Melting rate $=50 \mathrm{~kg} / \mathrm{h}$

Fill height $=1.98 \mathrm{~m}(6.5 \mathrm{f})$

Hold time $=10 \mathrm{~h}$

Canister size $=12,16,20$ and 24 in.

Based on the creep data of Appendix $D$, wall thicknesses were calculated for canisters of 304L stainless steel and Inconel 601 . The design curves in Figures $C .1$ and $C .2$ give the design stress as a function of temperature for a criteria of $1 \%$ total creep strain within a specified period of time. (It should be recalled that to allow for unaccounted scatter, the raw strength-data of Appendix $D$ were reduced by a factor of two before the design strength curves were plotted.)

Tables C.1 and C.2 give the required wall thickness for a range of canister wall temperatures during filling. The actual design temperatures were $50^{\circ} \mathrm{C}\left(90^{\circ} \mathrm{F}\right)$ above the stated fill temperatures. The given wall thicknesses are minimum values based only on high-temperature creep considerations. These thicknesses do not include any allowance for corrosion, nor do they consider handling loads or the need for impact resistance.

Table C.1 gives wall thicknesses for $304 \mathrm{~L}$ for temperatures from $900^{\circ}$ to $1050^{\circ} \mathrm{C}\left(1652^{\circ}\right.$ to $1922^{\circ} \mathrm{F}$ ). For Inconel 601 (Table C.2), the temperature range is $1000^{\circ}$ to $1150^{\circ} \mathrm{C}\left(1832^{\circ}\right.$ to $\left.2102^{\circ} \mathrm{F}\right)$. Above $1050^{\circ} \mathrm{C}\left(1922^{\circ} \mathrm{F}\right)$, the strength of $304 \mathrm{~L}$ decreases rapidly, and it was not feasible to design a $304 \mathrm{~L}$ canister for temperatures above this level. Within the temperature range of $1000^{\circ}$ to $10500^{\circ} \mathrm{C}$ (18320 to $\left.1922^{\circ} \mathrm{F}\right)$, the required wall thicknesses for the Inconel 601 canisters are $53 \%$ to $75 \%$ of those for $304 \mathrm{~L}$ canisters.

It $c$ an be seen in Tables $C .1$ and $C .2$ that in several cases wall thicknesses of $2.5 \mathrm{~mm}$ ( 0.10 in.) or less are sufficient to prevent excessive creep deformation. In practice, these wall thicknesses should be increased to allow for corrosion, as well as for hạndling and impact loads. A typical corrosion a llowance of 0.25 to $0.50 \mathrm{~mm}(0.010$ to

TABLE C.1. Minimum Wall Thickness - 304L Stainless Steel - To Avoid Excessive Creep Deformation During Filling by ICM

\begin{tabular}{|c|c|c|c|c|c|}
\hline $\begin{array}{c}\text { Canister } \\
\text { Size } \\
\text { ID, in. }\end{array}$ & $\begin{array}{c}\text { Fi11 } \\
\text { Time, } \\
\mathrm{h} \\
\end{array}$ & $\begin{array}{l}900^{\circ} \mathrm{C} F \mathrm{FTT} \\
\text { Temper ature }\end{array}$ & $\begin{array}{l}\text { Wall Thickn } \\
-950^{\circ} \mathrm{C} \text { Fill } \\
\text { Temperature }\end{array}$ & $\begin{array}{l}5, \mathrm{~mm} \text { (in.) } \\
\text { 10000C Fi } \\
\text { Temperature }\end{array}$ & $\begin{array}{l}1050^{\circ} \mathrm{C} \text { Fil } \\
\text { Temperature }\end{array}$ \\
\hline $\begin{array}{l}12 \\
16 \\
20 \\
24\end{array}$ & $\begin{array}{l}20 \\
27 \\
36 \\
47\end{array}$ & $\begin{array}{l}1.8(0.070) \\
2.5(0.100) \\
3.5(0.136) \\
4.5(0.178)\end{array}$ & $\begin{array}{l}2.3(0.090) \\
3.2(0.128) \\
4.4(0.174) \\
5.7(0.224)\end{array}$ & $\begin{array}{l}2.8(0.112) \\
4.0(0.158) \\
5.4(0.212) \\
7.1(0.278)\end{array}$ & $\begin{array}{r}4.8(0.188) \\
7.0(0.276) \\
9.9(0.390) \\
13.7(0.540)\end{array}$ \\
\hline
\end{tabular}

TABLE C.2. Minimum Wall Thickness - Inconel 601 - To Avoid Excessive Creep Deformation During Filling by ICM

\begin{tabular}{|c|c|c|c|c|c|}
\hline \multirow{3}{*}{$\begin{array}{c}\text { Canister } \\
\text { Size } \\
\text { iD in. }\end{array}$} & \multirow{3}{*}{$\begin{array}{l}\text { Fill } \\
\text { Time, } \\
\mathrm{h}\end{array}$} & \multicolumn{4}{|c|}{ Wall Thickness, mm (in.) } \\
\hline & & $1000^{\circ} \mathrm{C} F \mathrm{~F} 11$ & $1050^{\circ} \mathrm{C} F \mathrm{FiT1}$ & $1100^{\circ} \mathrm{C} F \mathrm{Fil}$ & $1150^{\circ} \mathrm{C} \mathrm{Fil1T}$ \\
\hline & & Temperature & Temperature & Temperature & Temperature \\
\hline 12 & 20 & $1.6 \quad 0.06$ & $3.6(0.1$ & 4.9 & 6.3 \\
\hline 16 & 27 & $2.3(0.090)$ & $5.0(0.198)$ & 61 & $352)$ \\
\hline 20 & 36 & $3.0(0.118)$ & $6.6(0.260)$ & $9.2(0.364)$ & $12.0(0.474)$ \\
\hline 24 & 47 & $3.8(0.148)$ & $8.4(0.330)$ & $11.7(0.460)$ & $15.2(0.600)$ \\
\hline
\end{tabular}


0.02 in.) has normally been accommodated by rounding up to the next standard pipe or plate thickness. To allow for handling and impact loads, PNL has avoided wall thicknesses of less than about $6 \mathrm{~mm}(0.25 \mathrm{in.})$ for small-diameter canisters (e.g., 12 in.). For larger canisters the practice has been to increase the minumum wall thickness to about $13 \mathrm{~mm}(0.50 \mathrm{in}$.$) for canisters in the$ 24-in. size range.

\section{Estimated Safety Factors}

The above design procedure includes a number of conservative assumptions, and safety factors associated with these assumptions have been estimated. The assumptions are listed below:

- overheat allowance of $50^{\circ} \mathrm{C}$ (900 F)

- $1 \%$ strain limit rather than creep rupture criterion

- derating of nominal strength properties by a factor of two to account for unknown variables in material strength

- canister is filled instantaneously

- bottom zones of furnace are not cooled as glass level rises in canister.

Numerical values of the safety factors arising from each source are estimated in Table C.3. The factors are given both in terms of stress (equivalent to wall thickness) and time. The overheat allowance and assumptions on filling rate have a

TABLE C.3. Est imate of Safety Factors in Design of Canisters for ICM

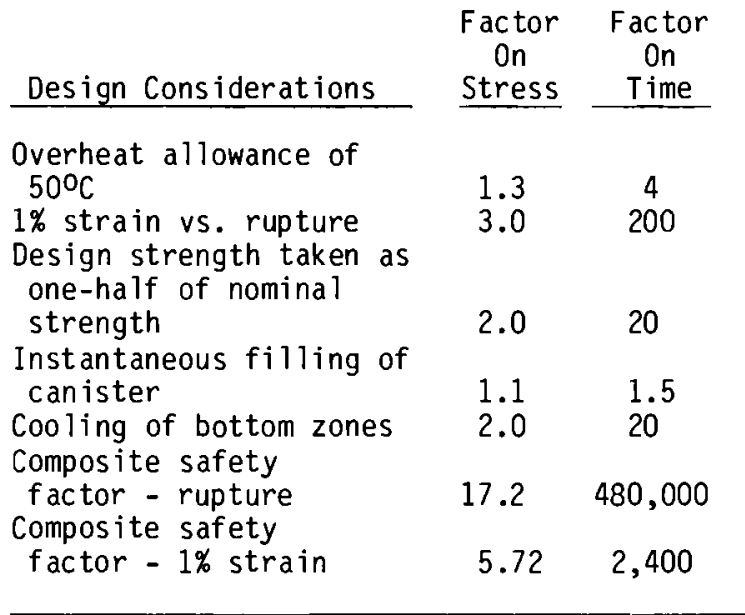

relatively small impact on the design. All other factors have the effect of increasing the wall thickness by a factor of two or more.

The composite safety factor on creep rupture or catastrophic failure of a canister is estimated to be 17.2 on stress, or 480,000 on a time basis. This means that the wall thickness could be reduced by a factor of about 17 before rupture of the canister wall would be considered probable.

Relative to the $1 \%$ strain limitation, the safety factor is 5.72 on stress and 2400 on the basis of time. The factor on time can be interpreted to mean that the actual creep strain will be less than $1.0 \%$ by a factor of 2400 . For a 16-in.-dia canister, this would amount to an actual increase in diameter of $0.0017 \mathrm{~mm}$ $(0.000066$ in.).

It is concluded that the recommended design procedure provides substantial margins of safety against excess creep deformation during filling of canisters by ICM. Furthermore, unless a combination of upset events occurs simultaneously, the actual amount of creep deformation that will occur in practice will be difficult to detect through diametrical measurements.

\section{WALL THICKNESS FOR CM}

Canister temperatures during filling from the $C M$ are modest in comparison to those encountered in the ICM process. Consequently, wall thicknesses to sustain filling stresses can be relatively thin. Also, materials such as low-carbon and low-alloy steels have sufficient strength and corrosion resistance to perform at the filling temperatures of interest.

Although molten glass enters the canisters from the melter at temperatures of $1000^{\circ} \mathrm{C}\left(1832^{\circ} \mathrm{F}\right)$ or higher, the actual canister wall temperatures are considerably lower. Canister wall temperatures will be dependent on such factors as the rate of pour, insulation on the outside of the canister, the procedures used to cool the outside of the canister, and the rate of internal heat generation within the vitrified waste. Data from canister wall-mounted thermocouples have indicated peak temperatures of less than $600^{\circ} \mathrm{C}\left(1112^{\circ} \mathrm{F}\right)$ in process development trials at PNL. For canister design purposes, it will be necessary to establish this peak temperature for the particular process and facility of interest. For the purposes of this report, a 
representative metal temperature of $700^{\circ} \mathrm{C}$ (12920 F) was assumed. With a $50^{\circ} \mathrm{C}\left(90^{\circ} \mathrm{F}\right)$ overheat allowance, the design wall temperature was then $750^{\circ} \mathrm{C}\left(1382^{\circ} \mathrm{F}\right)$.

Comparative strength data for various alloys are presented below for temperatures of canisters filled from a CM. Minimum wall thicknesses to sustain filling stresses are then estimated for a typical set of filling conditions.

\section{Material Strength}

For the design of canisters for use with the $C M$, material strength data in the temperature range of $500^{\circ}$ to $800^{\circ} \mathrm{C}\left(932^{\circ} \mathrm{F}\right.$ to $\left.1472^{\circ} \mathrm{F}\right)$ are required. Such data are readily available for heat- and corrosion-resistant alloys such as 304L stainless steel. For low-carbon and low-alloy steels, such temperatures exceed the temperatures of normal engineering application, and strength data are relatively sparse. However, sufficient data is available to permit structural integrity evaluations to be performed.

Figure C.3 shows the strength of $304 \mathrm{~L}$ stainless steel for the temperature range of interest. In this temperature range, creep rates for austenitic stainless steel can be relatively modest for the time needed to fill canisters. Short-time yield strength may be more relevant to design calculations. Shown in Figure C.3 are design stresses for various allowable creep rates, along with a design stress based on a safety factor of 3.0 on short-time yield strength. An allowable minimum creep rate of $0.001 \% / \mathrm{h}$ represents a reasonable limit since it would result in a diametrical expansion of $1 \%$ or less over the time period of canister filling. Figure C. 3 indicates that short-time yield strength is more restrictive than creep strength. For example, the yield strength limit gives a design stress at $750^{\circ} \mathrm{C}\left(1382^{\circ} \mathrm{F}\right)$ of $25.5 \mathrm{MN} / \mathrm{m}^{2}$ (3700 psi) for $304 \mathrm{~L}$ stainless steel. At this stress, little or no creep should occur during canister filling.

Figure C.4 shows strength data given in the Metals Handbook (American Society for Metals 1971) and by Randall (1960) for lowcarbon and various low-alloy steels. Compared with $304 \mathrm{~L}$ stainless steel, all of these alloys are relatively weak. At $650^{\circ} \mathrm{C}$ (12020 F), the low-alloy steels (e.g., $2-1 / 4 \% \mathrm{Cr}$ - 1\% Mo) are definitely stronger than low-carbon steel. However, the strengths of the low-alloy steels drop rapidly as the temperature is increased to $750^{\circ} \mathrm{C}\left(1382^{\circ} \mathrm{F}\right)$, and at $750^{\circ} \mathrm{C}\left(1382^{\circ} \mathrm{F}\right)$ these steels offer little strength advantage over low-carbon

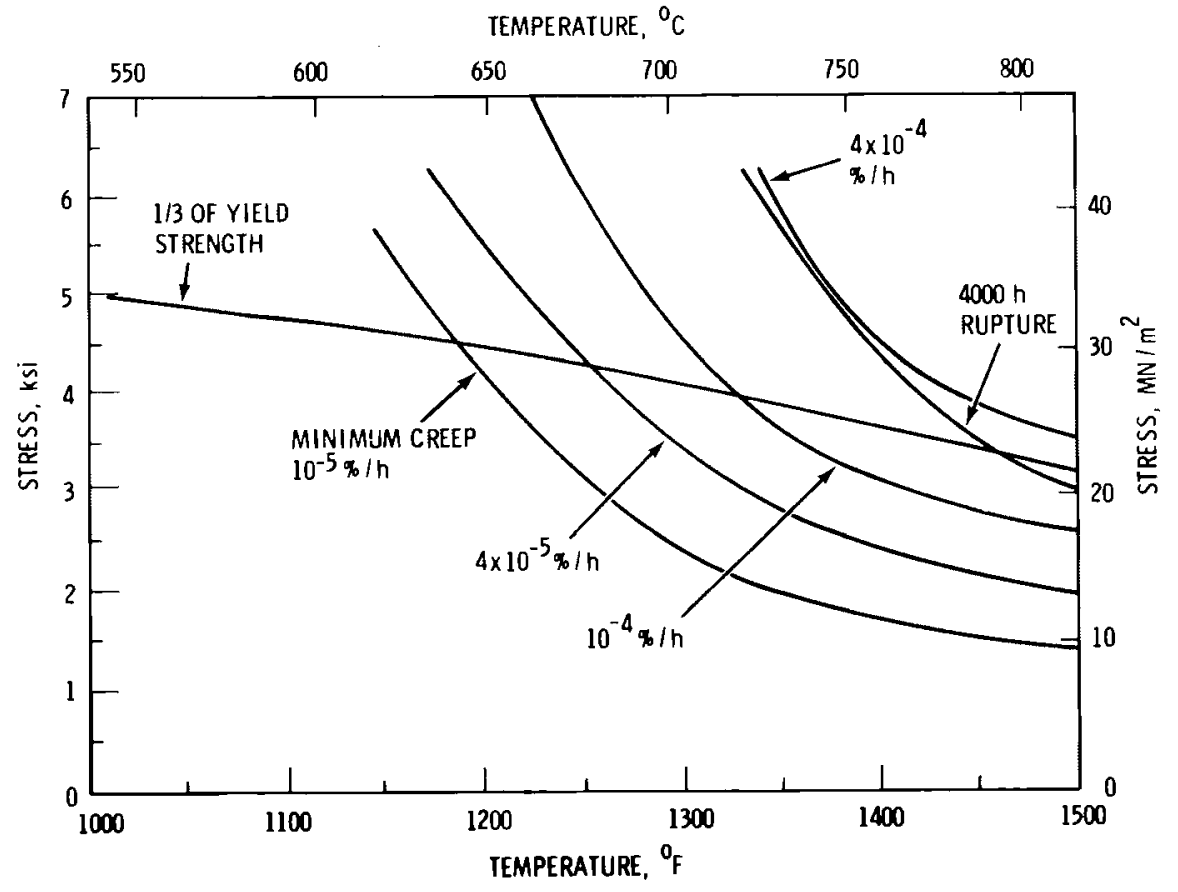

FIGURE C.3. Strength of 304L Stainless Steel vs Temperature 


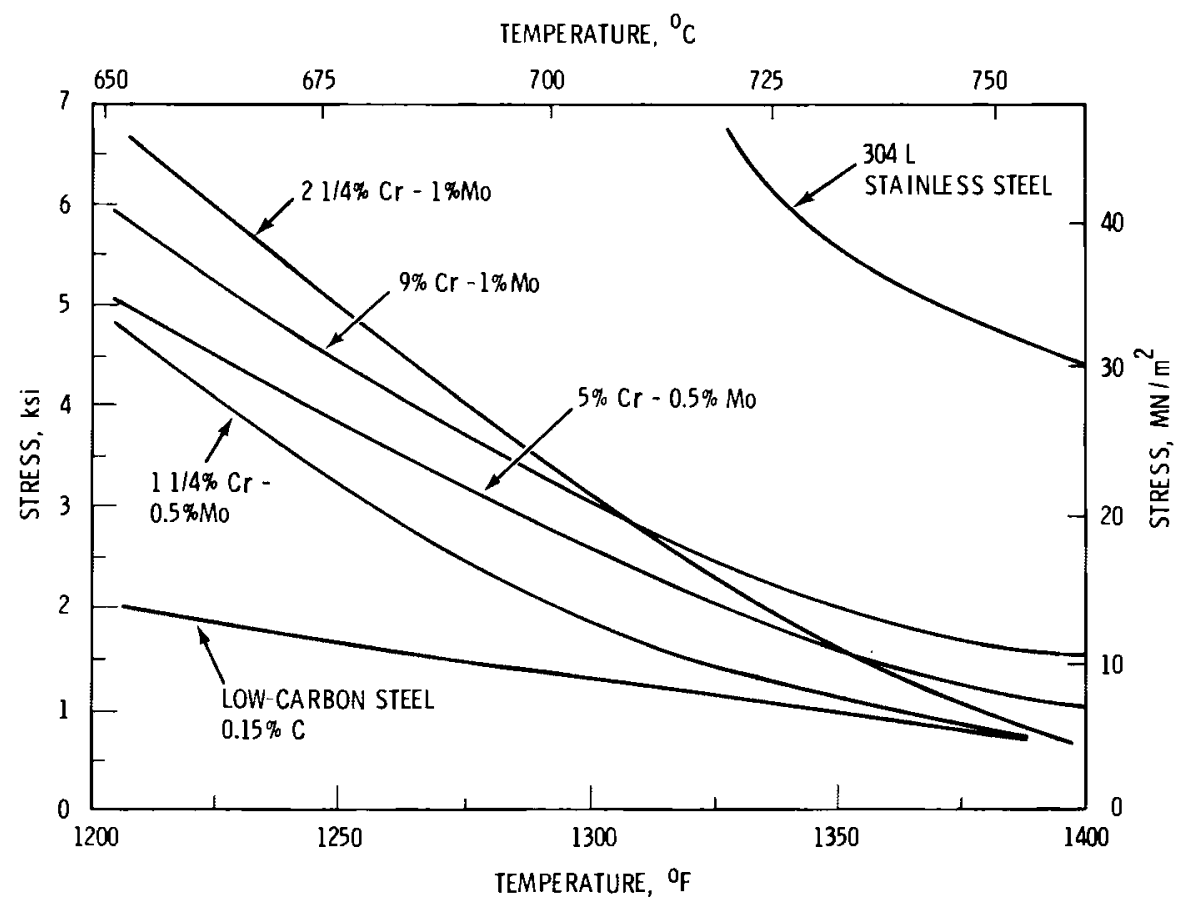

FIGURE C.4. Comparison of 4000-h Rupture Strength of Various Alloys

steel. However, the low-alloy steels should be used to advantage if a $650^{\circ} \mathrm{C}$ ( $1202^{\circ} \mathrm{F}$ ) design temperature is appropriate for canisters with the CM. As shown in Figure C.3, at $750^{\circ} \mathrm{C}$ (13820F) low-carbon and low-alloy steels have strengths of about $6.9 \mathrm{MN} / \mathrm{m}^{2}$ (1000 psi), which is adequate to sustain the molten glass during filling of canisters.

\section{Wall Thicknesses for Typical Designs}

Wall thicknesses for bottom-supported canisters were estimated for canisters for use with the CM. The canister sizes and filling conditions were as follows:

glass density $=3.2 \mathrm{gm} / \mathrm{cc}$

fill height $=2.44 \mathrm{~m}(8 \mathrm{f})$

canister size $=12,16,18,20,24$, and 36 in.

The peak wall temperature was taken to be $700^{\circ} \mathrm{C}\left(1292^{\circ} \mathrm{F}\right)$. An allowance of $50^{\circ} \mathrm{C}\left(90^{\circ} \mathrm{F}\right)$ for heating was made, so that the design temperature was $750^{\circ} \mathrm{C}\left(1382^{\circ} \mathrm{F}\right)$. Since it was assumed that the canisters were of a bottom-supported design, bottom deformation was not of concern.
In establishing canister thicknesses, it was assumed that canister diametrical expansions on the order of $1 \%$ would be unacceptable. For 24-in.-dia canisters, this would amount to an expansion of about $6.35 \mathrm{~mm}$ $(0.25$ in.). While such an expansion would be noticeable, it would not approach the strain required to rupture the canister wall. If $1 \%$ strain is considered unacceptable, a small increase in wall thickness would significantly reduce the level of strain. The trends of the available creep data indicate that increasing the wall thickness by a factor of two would result in about a 10 -fold reduction in strain.

Thicknesses were established for two materials, low-carbon steel and 304L; these values are listed in Tables C.4 and C.5. These thicknesses are based only on criteria to prevent canister deformation during filling at elevated temperatures. Experience with the CM at PNL suggests that these dimensions need not be increased to allow for material loss due to corrosive attack during filling. Very little corrosion is expected.

Thicknesses for low-carbon steel canisters are listed in Table C.4. Design stresses were based on data on creep-rupture strength at the design temperature of $750^{\circ} \mathrm{C}$. The safety factors of 3.0 on rupture stress 
TABLE C.4. Minimum Thickness of Low-Carbon Steel Canister Wall To Sustain Stresses During Filling with the CM

\begin{tabular}{|c|c|c|c|c|c|}
\hline \multirow{2}{*}{$\begin{array}{c}\text { Canister } \\
\text { Size, } \\
\text { in. } \\
\end{array}$} & \multirow{2}{*}{$\begin{array}{c}\text { Fill } \\
\text { Time, } \\
\mathrm{h} \\
\end{array}$} & \multicolumn{2}{|c|}{$\begin{array}{l}\text { Safety Factor of } 3.0 \\
\text { on Rupture Stress }\end{array}$} & \multicolumn{2}{|c|}{$\begin{array}{l}\text { Safety Factor of } 20 \\
\text { on Time to Rupture }\end{array}$} \\
\hline & & $\begin{array}{l}\text { Design Stress, } \\
\mathrm{MN} / \mathrm{m}^{2} \text { (psi) } \\
\end{array}$ & $\begin{array}{l}\text { Wa11 Thickness } \\
\text { mm (in.) } \\
\end{array}$ & $\begin{array}{l}\text { Design Stress, } \\
\mathrm{MN} / \mathrm{m}^{2}(\mathrm{psi}) \\
\end{array}$ & $\begin{array}{l}\text { Wall Thickness } \\
\text { mm (in.) }\end{array}$ \\
\hline $\begin{array}{l}12 \\
16 \\
18 \\
20 \\
24 \\
36\end{array}$ & $\begin{array}{r}11 \\
20 \\
26 \\
32 \\
46 \\
102\end{array}$ & $\begin{array}{l}8.7(1270) \\
7.5(1080) \\
6.9(1000) \\
6.5(940) \\
5.8(840) \\
4.7(680)\end{array}$ & $\begin{array}{l}1.32(0.052) \\
2.08(0.082) \\
2.54(0.100) \\
3.00(0.118) \\
4.04(0.159) \\
7.44(0.293)\end{array}$ & $\begin{array}{r}11.4(1660) \\
9.5(1380) \\
8.9(1290) \\
8.3(1200) \\
7.5(1090) \\
6.1 \quad(890)\end{array}$ & $\begin{array}{ll}1.02 & (0.040) \\
1.63 & (0.064) \\
1.96 & (0.077) \\
2.33 & (0.092) \\
3.07 & (0.121) \\
6.10 & (0.240)\end{array}$ \\
\hline
\end{tabular}

and 20 on time to rupture were selected to roughly correspond to a strain limit of $1 \%$. Minimum wall thicknesses for low-carbon steel are significantly greater than those for 304L stainless steel (discussed below). However, even for low-carbon steel, the minimum thicknesses of Table C.4 should be increased to provide sufficient ruggedness to the canister for handling loads and impact accidents.

For 304L stainless steel, the thickness evaluations of Table C.5 were based on a safety factor of 3.0 on short-time yield strength at the design temperature of $750^{\circ} \mathrm{C}$ $\left(1382^{\circ} \mathrm{F}\right)$. This gave a design stress of $25.5 \mathrm{mN} / \mathrm{m}^{2}$ (3700 psi). Some of the wall thicknesses are as thin as $0.46 \mathrm{~mm}$ $(0.018 \mathrm{in.})$. Although of sufficient thickness to sustain pressures from molten glass during filling, such thin-walled canisters would be prone to damage from loadings during normal handling. As for ICM canisters, increases in wall thickness to a range of 6 to $13 \mathrm{~mm}(0.425$ to $0.50 \mathrm{in}$.) are recommended.

TABLE C.5. Minimum Thickness of 304L Stainless Steel Canister Wall to Sustain Stresses During Filling with the CM-Design Stress of $25.5 \mathrm{MN} / \mathrm{m}^{2}(3700 \mathrm{psi})$

\begin{tabular}{|c|c|c|}
\hline $\begin{array}{l}\text { Canister } \\
\text { Size, in. }\end{array}$ & $\begin{array}{c}\text { Fill Time, } \\
\mathrm{h}\end{array}$ & $\begin{array}{c}\text { Wall Thickness, } \\
\text { mm (in.) }\end{array}$ \\
\hline $\begin{array}{l}12 \\
16 \\
18 \\
20 \\
24 \\
36\end{array}$ & $\begin{array}{r}11 \\
20 \\
26 \\
32 \\
46 \\
102\end{array}$ & $\begin{array}{ll}0.46 & (0.018) \\
0.61 & (0.024) \\
0.68 & (0.027) \\
0.76 & (0.030) \\
0.91 & (0.036) \\
1.37 & (0.054)\end{array}$ \\
\hline
\end{tabular}

Experience at PNL has shown that the thin-walled canisters can be filled from the CM with minimal canister deformation. Such is the case, in particular, if the pouring rate is relatively slow and glass in the lower portions of the canister solidifies as pouring proceeds. Under such conditions the canister never experiences the full pressure from the head of molten glass, which formed the basis of the above design calculations.

\section{CANISTER CREEP TEST}

It is always desirable to validate predictive methods by comparing them with service experience and experimental results. To measure creep at elevated temperatures under well controlled conditions, a canister was tested at PNL under an internal pressure of $0.103 \mathrm{MN} / \mathrm{m}^{2}$ (15 psi) of argon. The test configuration is shown in Figure C.5.

In the test the canister was heated to $1050^{\circ} \mathrm{C}\left(1922^{\circ} \mathrm{F}\right)$, and the pressure was maintained for $24 \mathrm{~h}$. The 00 of the $304 \mathrm{~L}$ stainless steel canister was $324 \mathrm{~mm}$ (12.75 in.), and the wall thickness was $9.5 \mathrm{~mm}$ $(0.375 \mathrm{in.})$. The bottom was made of $a$ 12.7-mm- (0.50-in.-) thick flat plate.

The measured and predicted bottom deformations were compared using the computer program NONLEP (Gerdeen, Simonen, and Hunter 1971). In the calculations the isochronous stress-strain curves of Figure $C .6$ were used. Figures $C .7$ and $C .8$ indicate the correlation of predicted and measured bottom deformations, which attained a value of about $7.1 \mathrm{~mm}(0.28 \mathrm{in}$.) at the center of the canister bottom. Thermocouples on the canister wall registered temperatures in the $1050^{\circ} \mathrm{C}\left(1922^{\circ} \mathrm{F}\right)$ to $1060^{\circ} \mathrm{C}$ 


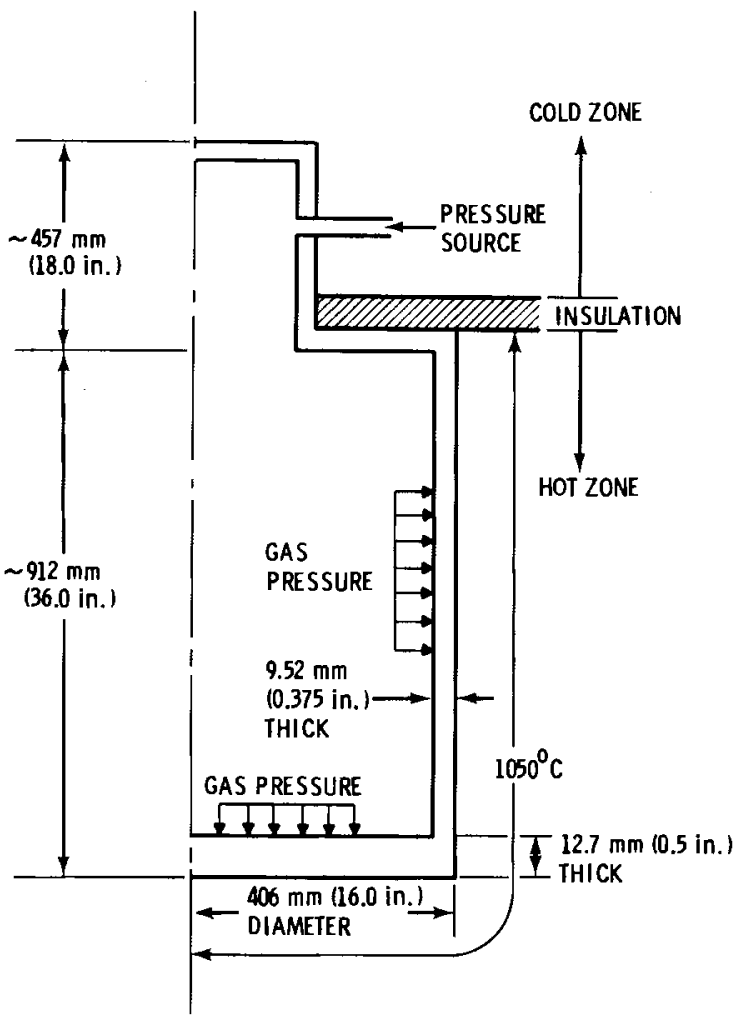

FIGURE C.5. Canister Creep Test Configuration 304L Stainless Steel $\left(1940^{\circ} \mathrm{F}\right)$ range. There were no thermocouples on the canister bottom. Since there is some uncertainty as to actual bottom temperatures, analyses were performed for both $1050^{\circ} \mathrm{C}\left(1922^{\circ} \mathrm{F}\right)$ and $1060^{\circ} \mathrm{C}\left(1940^{\circ} \mathrm{F}\right)$. The shape of the deformed bottom profile was measured relative to a clamped straight-rule using a vernier depth gage. As can be seen in Figures $C .7$ and $C .8$, the deformation pattern was nonsymmetrical along the selected diameter of the measurements. This is probably due to anisotropy of the bottom plate material associated with the rolling and transverse directions of the plate material. The correlation between the predicted and measured deformations is considered excellent and is much better than is often observed in such creep experiments. Results of this study support the methods being used to design canisters for the loads and environment of the ICM process.

Post-test diameter and length measurements were made using a micrometer and vernier caliper. The measurements indicated a reduction in length between $0.25 \mathrm{~mm}$ and $0.76 \mathrm{~mm}(0.010 \mathrm{in}$. to $0.030 \mathrm{in.})$, whereas the analysis predicted essentially no change in length. The measured reduction in length is attributed to the formation and the subsequent removal by sandblasting of an oxide scale on the outer surface of the canister. The measured diameter changes ranged from

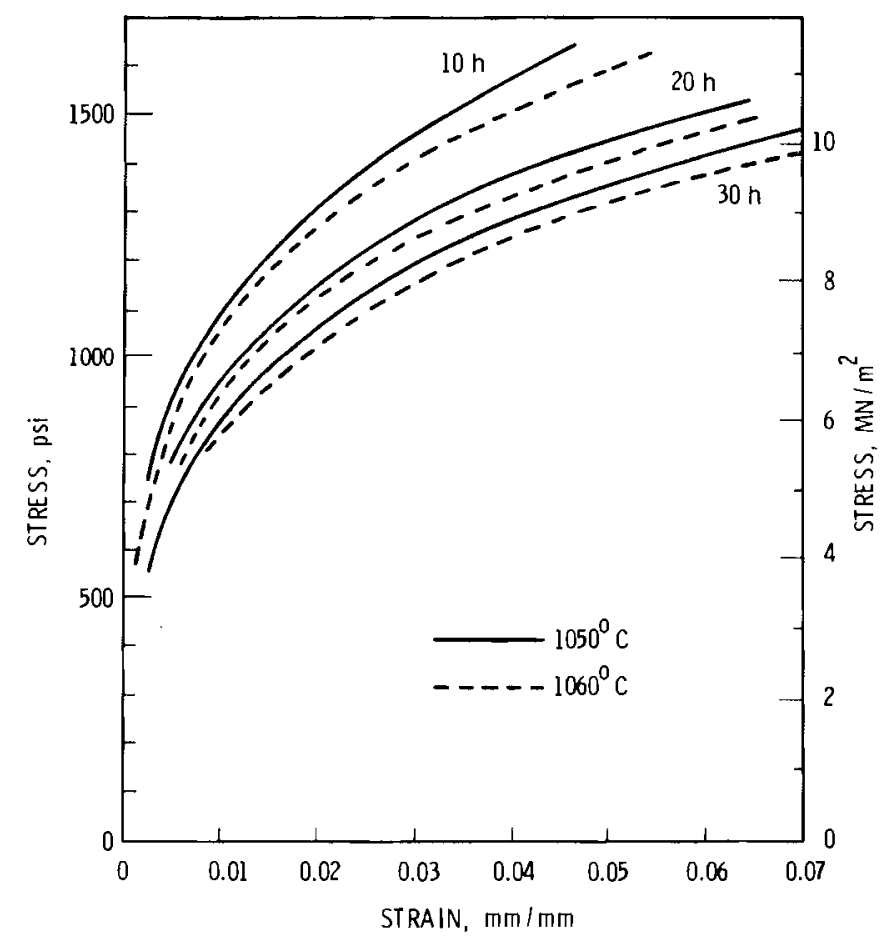

FIGURE C.6. Isochronous Stress-Strain Curves Used in Calculation of Canister Creep Deformation 


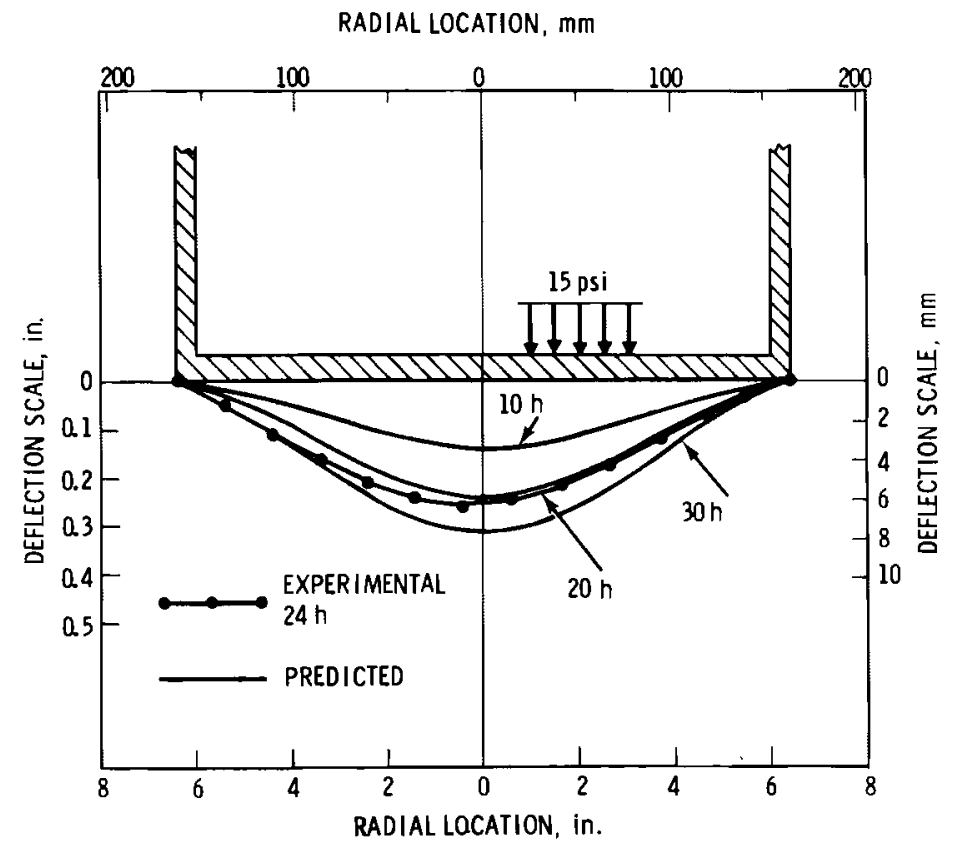

FIGURE C.7. Comparison of Predicted and Measured Canister Bottom Deformation for Assumed Bottom Temperature of $1050^{\circ} \mathrm{C}\left(1922^{\circ} \mathrm{F}\right)$

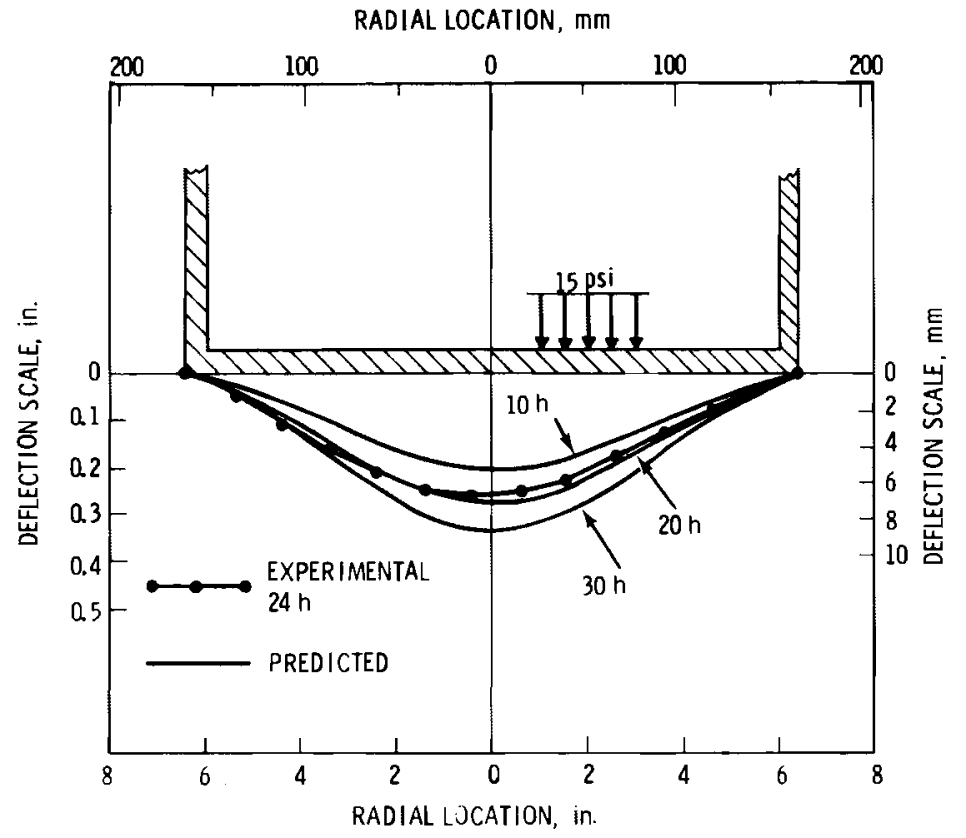

FIGURE C.8. Comparison of Predicted and Measured Canister Bottom Deformation for Assumed Bottom Temperature of $1060^{\circ} \mathrm{C}\left(1940^{\circ} \mathrm{F}\right)$ 
$-0.46 \mathrm{~mm}$ to $+0.20 \mathrm{~mm}(-0.018 \mathrm{in}$. to $+0.008 \mathrm{in.}$, , whereas the predicted diameter change was $+0.20 \mathrm{~mm}(+0.008 \mathrm{in}$.$) . Again,$ the difference is attributed to the loss of an oxide scale.

\section{EVALUATION OF ICM TRIALS}

In the course of process development ef forts at PNL, numerous $304 \mathrm{~L}$ stainless steel canisters have been filled by the ICM furnace. Canister diameters are routinely measured before and after filling. This data base was thus available to validate analytical predictions of canister creep deformations.

A survey of processing data was made to establish time, temperature, and fill rate histories of each of 13 early canisters. Table C.6 gives geometric and loading cycle parameters for these particular canisters. All the canisters had been filled in a topsupported condition so that bulging of the unsupported bottoms could occur if a sufficient static head of molten glass was present during filling. For certain canisters the bottom thicknesses were unknown except that the bottom plates were either 9.525or 12.7-mm- (3/8- or 1/2-in.) thick. For those canisters where bottom thickness data were lacking, $12.7 \mathrm{~mm}$ (0.500 in.) was assumed.

For creep analyses, only the hightemperature portion of the total canister thermal history was of interest. Heat-up and quenching operations were not of interest. For the purpose of analyses, the loading cycles were simplified. The first phase consisted of a filling at a uniform rate with the canister wall at uniform and constant temperature. The second phase consisted of a hold at constant temperature after filling. In each case the analyses were for the maximum temperature in the canister wall at the critical bottom location.

Deformations were measured on a number of canisters after fill. Due to the rugged design and limited fill height, the amount of creep for all the canisters was relatively small. In addition to creep deformation, the measured diametrical expansions include effects of both: 1) the loss of oxidized surface material by spalling, and 2) an increase in canister diameter due to differen$t i a l$ thermal contraction of the glass and metal during cooling and solidification of the glass.
The calculated diameter changes were adjusted downward by $0.254 \mathrm{~mm}(0.010 \mathrm{in}$.) to account for surface spalling. An additional correction for differential thermal expansion effects between the glass and canister was made as follows. The expansion coefficients of the steel and glass were taken to be $14.4 \times 10^{-6} \mathrm{~mm} / \mathrm{mm} /{ }^{\circ} \mathrm{C}$ and $9.0 \times 10^{-6} \mathrm{~mm} /$ $\mathrm{mm} /{ }^{\circ} \mathrm{C}$, respectively. At $550^{\circ} \mathrm{C}\left(1022^{\circ} \mathrm{F}\right)$, the glass can be considered cool enough to behave essentially as a solid. In cooling to room temperature $\left(21^{\circ} \mathrm{C}\right.$ or $\left.70^{\circ} \mathrm{F}\right)$ the glass will contract by an amount of:

$$
\begin{aligned}
\alpha \Delta T & =\left(9 \times 10^{-6}\right)(550-21) \\
& =4.8 \times 10^{-3} \mathrm{~mm} / \mathrm{mm},
\end{aligned}
$$

while the steel will attempt to contract by an amount of:

$$
\begin{aligned}
\alpha \Delta T & =\left(14.4 \times 10^{-6}\right)(550-21) \\
& =7.6 \times 10^{-3} \mathrm{~mm} / \mathrm{mm} .
\end{aligned}
$$

The difference in contraction of the glass and steel results in a mechanical strain in the steel of:

$$
\begin{aligned}
\varepsilon & =(7.6-4.8) \times 10^{-3} \\
& =2.8 \times 10^{-3} \mathrm{~mm} / \mathrm{mm}
\end{aligned}
$$

and a tensile stress for an elastic modulus of $E=0.193 \mathrm{MN} / \mathrm{m}^{2}\left(28 \times 10^{6} \mathrm{psi}\right)$ of

$$
\begin{aligned}
\sigma & =E \varepsilon \\
& =\left(0.193 \times 10^{+6}\right)\left(2.8 \times 10^{-3}\right) \\
& =540 \mathrm{MN} / \mathrm{m}^{2}(78,400 \mathrm{psi}) .
\end{aligned}
$$

The predicted diameter changes for the two canister sizes of interest are then:

$$
\begin{aligned}
\text { 8-in. Canister - D } & =\left(8.625 \times 2.8 \times 10^{-3}\right) \\
& =0.61 \mathrm{~mm}(0.024 \mathrm{in.}) \\
12 \text {-in. Canister - D } & =\left(12.75 \times 2.8 \times 10^{-3}\right) \\
& =0.91 \mathrm{~mm}(0.036 \mathrm{in.})
\end{aligned}
$$

Table C.7 gives predicted and measured diametrical expansions. The canisters are listed in order of decreasing diameter change as measured on the experimental 
TABLE C.6. Canister Parameters and Loading Cycle Definition

\begin{tabular}{|c|c|c|c|c|c|}
\hline $\begin{array}{l}\text { Canister } \\
\text { Number }\end{array}$ & $\begin{array}{l}\text { Outside } \\
\text { Thickness } \\
\text { mm (in.) } \\
\end{array}$ & $\begin{array}{c}\text { Wall } \\
\text { Thickness, } \\
\text { mm (in.) }\end{array}$ & $\begin{array}{c}\text { Bot tom } \\
\text { Thickness, } \\
\text { mm (in.) }\end{array}$ & $\begin{array}{r}\text { Fill } \\
\text { Height, } \\
m(f)\end{array}$ & Loading Cycle \\
\hline ICM-3 & $219(8.625)$ & $8.18(0.322)$ & $9.52(0.375)$ & $0.61(2.0)$ & $\begin{array}{l}3-\mathrm{h} \text { fill at } 1075^{\circ} \mathrm{C} \\
3-\mathrm{h} \text { hold at } 1075^{\circ} \mathrm{C}\end{array}$ \\
\hline ICM-4 & $324(12.75)$ & $9.52(0.375)$ & $12.70(0.500)$ & $1.00(3.3)$ & $\begin{array}{l}12-\mathrm{h} \text { fill at } 1050^{\circ} \mathrm{C} \\
13-\mathrm{h} \text { hold at } 1050^{\circ} \mathrm{C}\end{array}$ \\
\hline ICM-5 & $219(8.625)$ & $8.18(0.322)$ & -- & $0.61(2.0)$ & $\begin{array}{l}4-\mathrm{h} \text { fill at } 1050^{\circ} \mathrm{C} \\
6-\mathrm{h} \text { hold at } 1050^{\circ} \mathrm{C}\end{array}$ \\
\hline ICM-6 & $219(8.625)$ & $8.18(0.322)$ & -- & $0.85(2.8)$ & $\begin{array}{l}10-\mathrm{h} \text { fill at } 1060^{\circ} \mathrm{C} \\
11-\mathrm{h} \text { hold at } 1060^{\circ} \mathrm{C}\end{array}$ \\
\hline ICM-7 & $219(8.625)$ & $8.18(0.322)$ & -- & $0.46(1.5)$ & $\begin{array}{l}\text { 4-h fill at } 1075^{\circ} \mathrm{C} \\
6-\mathrm{h} \text { hold at } 1075^{\circ} \mathrm{C}\end{array}$ \\
\hline ICM-8 & $219(8.625)$ & $8.18(0.322)$ & -- & $0.55(1.8)$ & $\begin{array}{r}5-h \text { fill at } 1075^{\circ} \mathrm{C} \\
15-\mathrm{h} \text { hold at } 1075^{\circ} \mathrm{C}\end{array}$ \\
\hline ICM-11 & $324(12.75)$ & $9.52(0.375)$ & $12.70(0.500)$ & $0.67 \quad(2.2)$ & $\begin{array}{l}13-h \text { fill at } 1095^{\circ} \mathrm{C} \\
14-\mathrm{h} \text { hold at } 1095^{\circ} \mathrm{C}\end{array}$ \\
\hline ICM-13 & $324(12.75)$ & $9.52(0.375)$ & $12.70(0.500)$ & $0.52(1.7)$ & $\begin{array}{l}5-\mathrm{h} \text { fill at } 1085^{\circ} \mathrm{C} \\
3-\mathrm{h} \text { hold at } 1085^{\circ} \mathrm{C}\end{array}$ \\
\hline ICM-16 & $324(12.75)$ & $9.52(0.375)$ & $12.70(0.500)$ & $0.79(2.6)$ & $\begin{array}{l}3-\mathrm{h} \text { fill at } 1135^{\circ} \mathrm{C} \\
5-\mathrm{h} \text { hold at } 1130^{\circ} \mathrm{C} \\
5-\mathrm{h} \text { hold at } 1090^{\circ} \mathrm{C}\end{array}$ \\
\hline ICM-17 & $324(12.75)$ & $9.52(0.375)$ & $12.70(0.500)$ & $0.82(2.7)$ & $\begin{array}{r}10-h \text { fill at } 1115^{\circ} \mathrm{C} \\
5-h \text { hold at } 1115^{\circ} \mathrm{C}\end{array}$ \\
\hline ICM-18 & $219(8.625)$ & $8.18(0.322)$ & -- & $0.70(2.3)$ & $\begin{array}{l}5-\mathrm{h} \mathrm{fill} \text { at } 1095^{\circ} \mathrm{C} \\
4-\mathrm{h} \text { hold at } 1095^{\circ} \mathrm{C}\end{array}$ \\
\hline ICM-19 & $219(8.625)$ & $8.18(0.322)$ & - & $0.55(1.8)$ & $\begin{array}{l}8.5-h \text { fi } i 11 \text { at } 1075^{\circ} \mathrm{C} \\
5-\mathrm{h} \mathrm{fil1} \mathrm{at} 1085^{\circ} \mathrm{C} \\
7-\mathrm{h} \text { hold at } 1085^{\circ} \mathrm{C}\end{array}$ \\
\hline ICM-20 & $219(8.625)$ & $8.18(0.322)$ & - & $0.76(2.5)$ & $\begin{array}{r}3-\mathrm{h} \text { fill at } 1075^{\circ} \mathrm{C} \\
4-\mathrm{h} \text { hold at } 1075^{\circ} \mathrm{C} \\
40-\mathrm{h} \text { hold at } 1025^{\circ} \mathrm{C}\end{array}$ \\
\hline
\end{tabular}

canisters. The value listed is the maximum local expansion of the canister, which in each case was at a location near to, but slightly above the very bottom of the canister. It is apparent that none of the canisters were severely challenged structura 1ly. Except for the few canisters listed at the top of the table, the entire measured expansion can be accounted for in terms of the differential thermal expansion effect between the glass and canister. It is apparent that the severity of the loading cycles was relatively modest compared to the canister strengths. This limits the usefulness of the measured diameter changes as a means of validating the predictive methods. It may be stated, however, that the analyses are in agreement with the test data in predicting little creep deformation and relatively small diameter changes. With one or two exceptions, the analyses correctly identified those canisters that experienced the greatest diameter changes. 
TABLE C.7. Calculated and Measured Diametrical Expansions of Canisters

\begin{tabular}{|c|c|c|}
\hline $\begin{array}{c}\text { Canister } \\
\text { Number }\end{array}$ & $\begin{array}{l}\text { Mea sured } \\
\text { Diameter } \\
\text { Change, } \\
\text { mm (in.) }\end{array}$ & $\begin{array}{l}\text { Calculated } \\
\text { Diameter } \\
\text { Change, } \\
\text { mm (in.) }\end{array}$ \\
\hline ICM-16 & $1.27(0.050)$ & $0.89(0.035)$ \\
\hline ICM-13 & $1.27(0.050)$ & $0.66(0.026)$ \\
\hline ICM-19 & $0.99(0.039)$ & $0.36(0.014)$ \\
\hline ICM-17 & $0.76(0.030)$ & $0.81(0.032)$ \\
\hline ICM-11 & $0.76(0.030)$ & $1.17(0.046)$ \\
\hline ICM-20 & $0.76(0.030)$ & $0.36(0.014)$ \\
\hline I CM- 6 & $0.76(0.030)$ & $0.36(0.014)$ \\
\hline ICM-5 & $0.63(0.025)$ & $0.36(0.014)$ \\
\hline ICM-8 & $0.51(0.020)$ & $0.36(0.014)$ \\
\hline ICM- 4 & $0.51(0.020)$ & $0.66(0.026)$ \\
\hline ICM-3 & $0.51(0.020)$ & $0.36(0.014)$ \\
\hline ICM-18 & $0.41(0.016)$ & $0.36(0.014)$ \\
\hline ICM-7 & $0.38(0.015)$ & $0.36(0.014)$ \\
\hline
\end{tabular}

Table C. 8 lists the experimental canisters in order of decreasing bottom deflection as predicted by the calculations. Bottom deflections were not measured on the experimental canisters. However, canister ICM-16 was identified as clearly having the greatest extent of deformation, which was reported to be roughly $8 \mathrm{~mm}(0.3 \mathrm{in}$.$) . The$ stress analyses correctly identified ICM-16 as having the greatest potential for bottom deformation. Also, insignificant bottom deformation was predicted for most of the

TABLE C.8. Calculated and Measured Bottom Deflection of Can isters

\begin{tabular}{|c|c|c|}
\hline $\begin{array}{c}\text { Canister } \\
\text { Number } \\
\end{array}$ & $\begin{array}{c}\text { Calculated } \\
\text { Bottom } \\
\text { Deflection } \\
\text { (Relative Values) } \\
\end{array}$ & $\begin{array}{c}\text { Measured } \\
\text { Bottom } \\
\text { Defleçtion } \\
10^{-3} \text { in. } \\
\end{array}$ \\
\hline ICM-16 & 100 & 300 \\
\hline ICM- 17 & 71 & -- \\
\hline ICM-11 & 49 & -- \\
\hline ICM- 4 & 16 & -- \\
\hline ICM-13 & 8 & -- \\
\hline ICM-18 & 5 & -- \\
\hline ICM-19 & 4 & -- \\
\hline ICM-8 & 3 & -- \\
\hline ICM-20 & 3 & -- \\
\hline ICM-6 & 3 & -- \\
\hline ICM-7 & 1 & -- \\
\hline ICM-5 & 1 & -- \\
\hline ICM-3 & 1 & -- \\
\hline
\end{tabular}

canisters, which is in agreement with observations.

\section{EFFECT OF FILLING RATE}

In the analyses of canister deformations, it is convenient to assume that the canister is instantaneously filled and that the load does not vary while the canister is at operating temperature. This assumption greatly simplifies and reduces the cost of the computer stress analysis. Also, the predicted results should be conservative for design purposes since the magnitude and duration of loading is overestimated.

The effect of a uniform fill rate followed by a hold period at operating temperature was evaluated on the basis of the creep equation,

$$
\text { where: } \begin{aligned}
\sigma & =49,500 \mathrm{e}^{0.765 \mathrm{t}-0.585,} \\
\mathrm{e} & =\text { stress, psi } \\
t & =\text { strain, } \mathrm{mm} / \mathrm{mm} \\
\mathrm{t} & =\mathrm{h}, \mathrm{h} .
\end{aligned}
$$

This equation was adopted to represent the behavior of a 300-series stainless steel at $1100^{\circ} \mathrm{C}\left(2012^{\circ} \mathrm{F}\right)$. Figure C.9a defines

the pressure time history and Figure C.9b shows the estimated reduction in deflection that results from a gradual pressure app $1 i-$ cation instead of an instantaneous application. For example, a typical canister is being filled during about half of its total hold time at maximum temperature. For this case, a computer solution that assumes that the canister is filled at the start will overestimate deflections by a factor of about $30 \%$.

For Figure $\mathrm{C.9b}$, the isochronous stressstrain equations were recast in the form of an incremental creep law. The creep response of an uniaxial specimen to the load time history of Figure C.9a was calculated numerically for a range of maximum stress levels using a strain-hardening theory of creep. For the particular equations developed for the 300-series stainless steel at $1100^{\circ} \mathrm{C}\left(2012^{\circ} \mathrm{F}\right)$, the normalized response given in Figure $\mathrm{C} .9 \mathrm{~b}$ was found to be insensitive to stress level.

It was concluded that an assumption of instantaneous filling is reasonable, and will lead to conservative wall thicknesses. This, however, assumes that the entire 


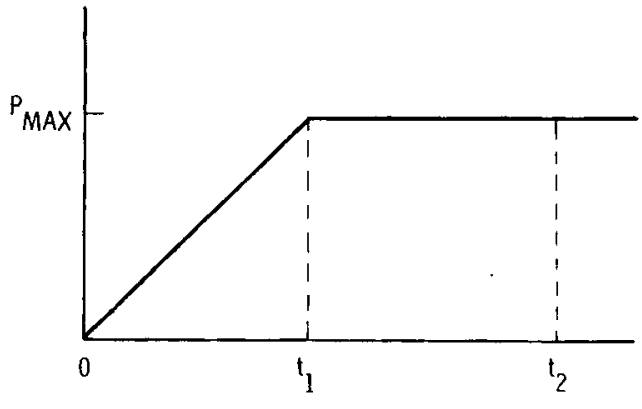

(a) PRESSURE TIME HISTORY

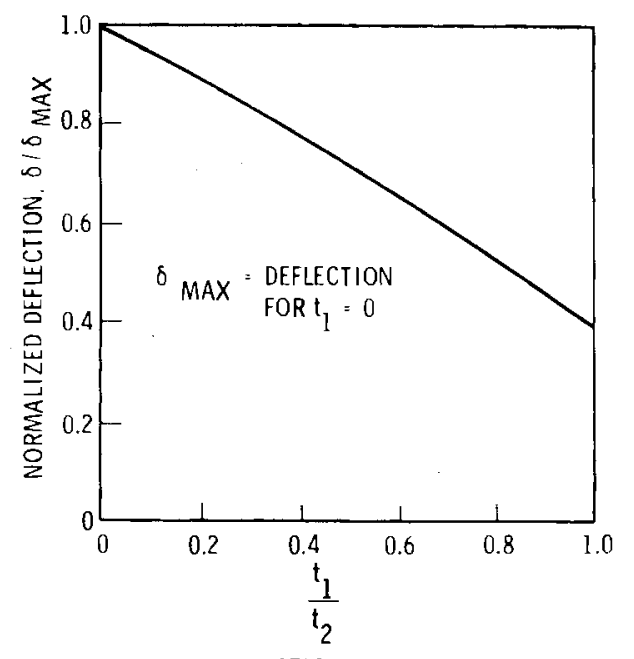

(b) FINAL DEFLECIION

FIGURE C.9. Effect of Pressure History and FiTाRate on Bottom Def lection of a Canister

canister is held at peak temperature throughout the actual period of filling and during subsequent hold periods at the operating temperature. It should be noted that current ICM furnaces are zone furnaces, which can allow lower portions of the canister to cool as the glass level rises. For such a mode of operation, instantaneous filling could lead to additional conservatism in creep-deformation predictions.

\section{LOCAL STRESSES DURING FILLING}

When canisters are filled with vitrified waste, they are exposed to very high temperatures, which for ICM are in the range of $1050^{\circ} \mathrm{C}\left(1922^{\circ} \mathrm{F}\right)$. Material strengths at these temperatures are very low, and thus great care must be exercised in the design of canisters to minimize stress levels. For example, the desire to reduce stress levels has been a major reason for the use of the bottom-supported canister concept at PNL.
In this section some specific case studies of local stress effects are described as a means of providing insight into good canister design practice. In one of these studies alternative bottom designs for a bottom-supported canister are evaluated. The other studies evaluate stresses and deformations due to thermal gradients in walls of canisters.

\section{Bottom Joint Design}

Figures C.10 and C.11 show two alternative joint designs for attachment of a flat bottom to the cylindrical body of a canister. The corner weld shown in Figure C.10 is simple to fabricate, but was believed to be a less desirable design than the configuration shown in Figure C.11. Analyses of both designs were performed to determine comparative stress states, using the shell of revolution computer program MONSASTIFF (Lestingi 1970). For both designs, the bottom was assumed to be supported by a flat, rigid base. Rotation action due to bending effects at the corners was simulated. This resulted in a local loss of contact between the bottom plate and the supporting base. The loading to the canister had a pressure of $0.079 \mathrm{MN} / \mathrm{m}^{2}$ (11.46 psi), simulating a hydrostatic head of molten glass. The canister wall was a 16-in.-dia, schedule-40 pipe (0.5-in.thick), and the bottom was of $12.7-\mathrm{mm}$ $(0.5$-in.) plate.

Figures $C .10$ and $C .11$ show calculated stress levels at the critical location, which is the root of the weld at the inside surface of the canister. For the simple flat bottom, the stress is $1.61 \mathrm{MN} / \mathrm{m}^{2}$ (233 psi) in tension, as opposed to $0.12 \mathrm{MN} / \mathrm{m}^{2}$ (17 psi) in compression for the bottom with a turned corner. The design of Figure C.11 is clearly preferable since peak stresses do not occur at the weld.

A review of closure designs in the ASME pressure vessel code indicates that the turned corner configuration of Figure C.11 is recommended over the design of Figure C.10. The flat plate design would be acceptable to the ASME code only with a modified weld joint, which incorporates the addition of a fillet weld at the inside location of the joint. Such a weld would be difficult to perform for canisters of any reasonable length, since access would be difficult to the inside location of the joint for welding.

The cask designer's guide (Shappert 1970) discusses the design of impact- 


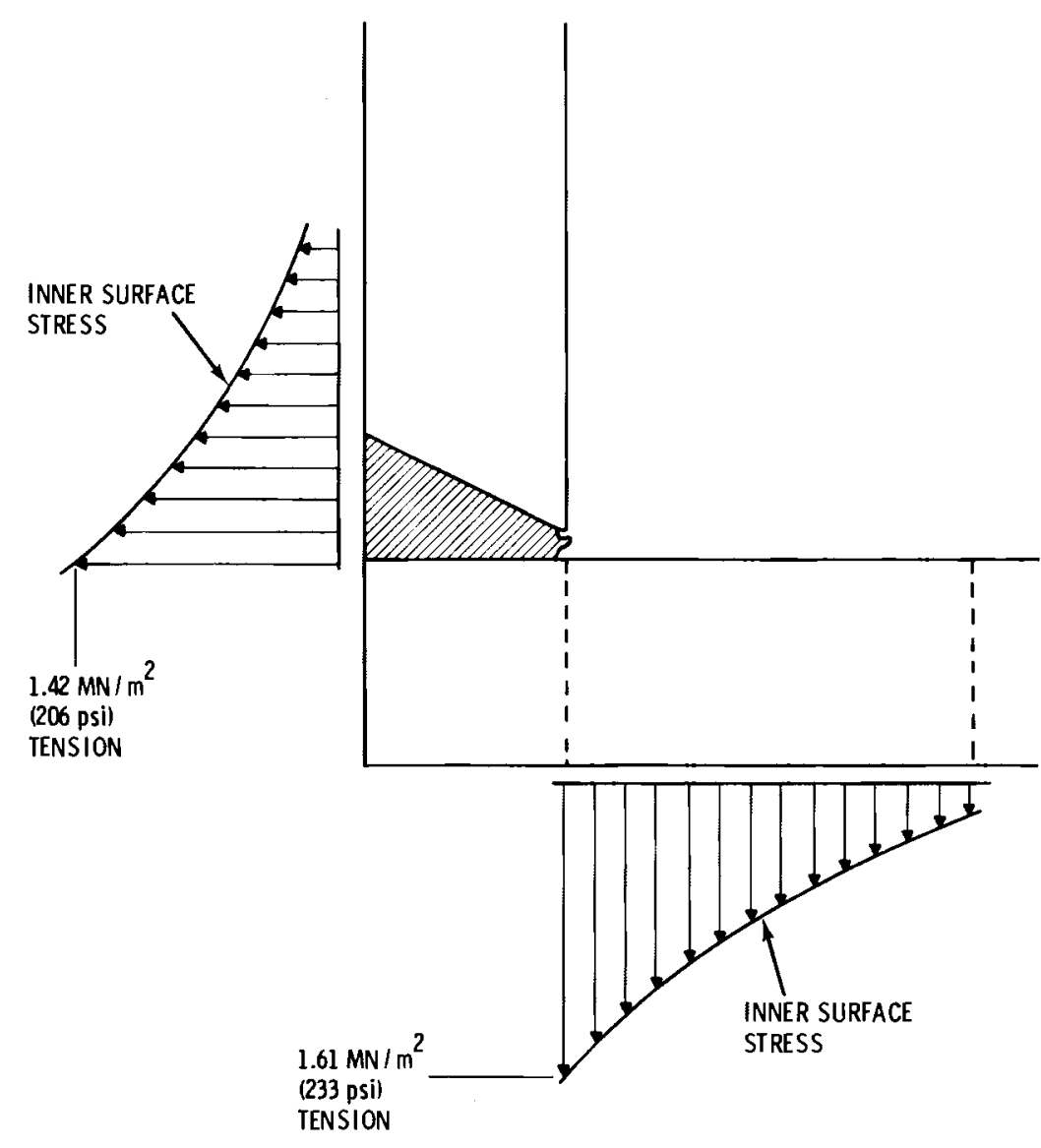

FIGURE C.10. Joint Stresses for Bottom-Supported Canister with Flat Bottom and Turned Corner

resistant corners for nuclear shipping containers. Data show that the joint of Figure C.10 is prone to cracking in corner impacts, and the joint of Figure C.11, which removes the weld from the location of severe bending, corresponds to a recommended design in the Cask Designer's Guide.

Inspection and fabrication costs are also considerations in joint design. The simple weld joint of Figure $C .10$ will be less expensive to fabricate, but would be more difficult to inspect. It is likely that savings in fabrication costs would be consumed in higher inspection costs.

\section{Canister Stresses at Zone Transitions}

In the zone furnace for ICM, adjacent zones will maintain the canister wall at different temperature levels. At the transition between zones, longitudinal temperature gradients will be present. These gradients are a potential source of thermal stress and permanent distortion of the canister wall. To determine the severity of these stresses, the computer program MONSASTIFF (Lestingi 1970) was applied to a postulated thermal gradient condition.

Radial or through-the-wall temperature gradients were neglected, and a longitudinal gradient of $150^{\circ} \mathrm{C}\left(270^{\circ} \mathrm{F}\right)$ over $25.4 \mathrm{~mm}$ (1.0 in.) was assumed. This gradient was intended to bound the gradient anticipated during filling. For this analysis, elastic behavior was assumed. However, the effect of increasing temperature on material strength and resulting inelastic strain was simulated as a temperature-dependent elastic modulus. A review of estimated strengths for 304L stainless steel suggested a 4-to-1 ratio of moduli between the cold and hot zones of the canister.

Figure C.12 shows predicted stress distributions in the region of the temperature gradient. Stresses have been normalized 


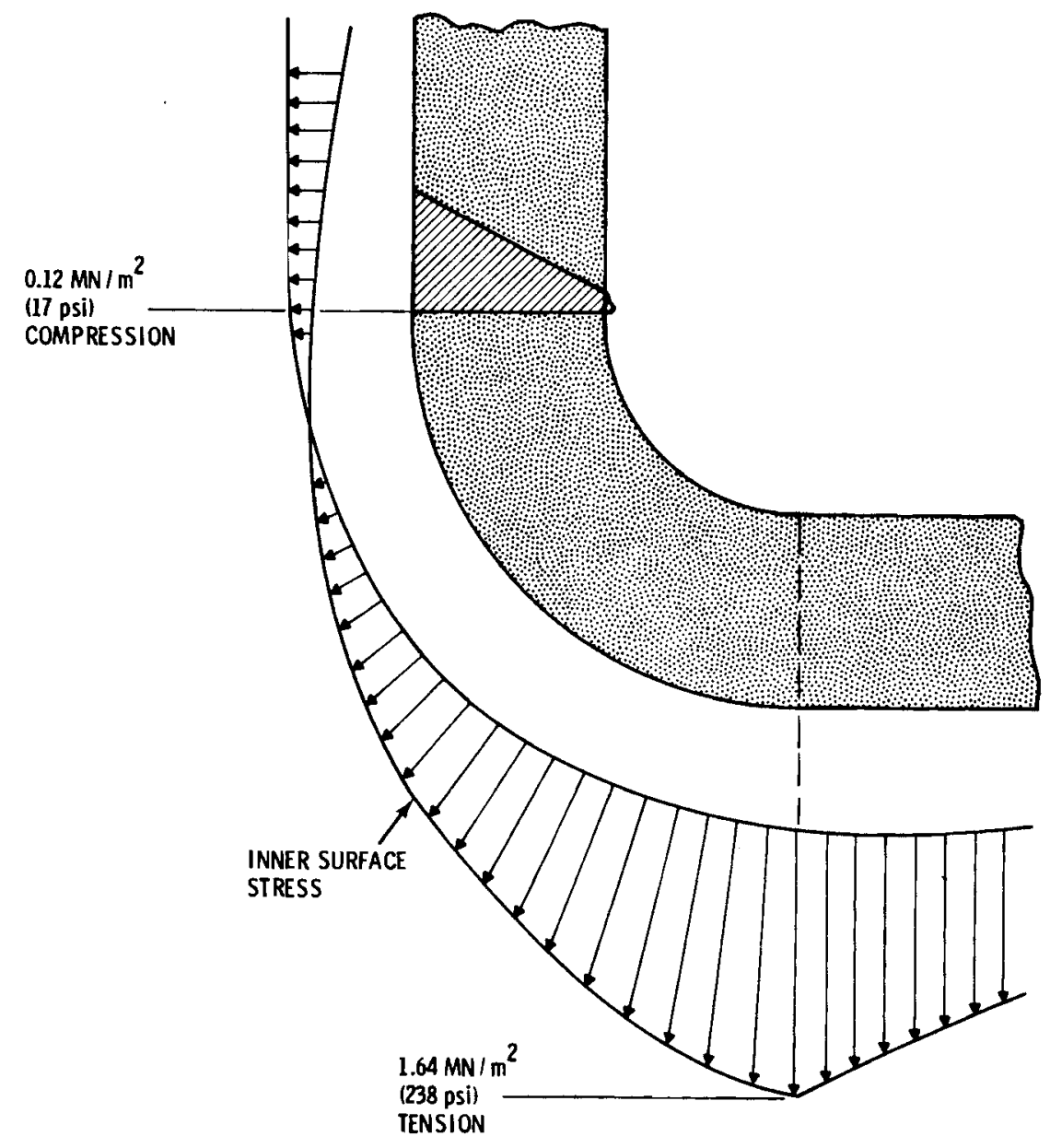

FIGURE C.11. Joint Stresses for Bottom-Supported Canister with Flat Bottom and Turned Corner

with respect to the temperature dependent elast ic modulus. The curves shown in Figure C.12 can be interpreted as an estimate of the strains induced in the canister wall by the longitudinal temperature gradient. These estimated strains are on the order of $0.1 \%$. Strains of this magnitude should not affect the structural integrity of the canister.

Figure $C .13$ shows the estimated permanent deformation of the canister wall resulting from exposure of the narrow zone transition region to the longitudinal temperature gradient. It was assumed that local changes in canister diameter will occur as a result of differences in material strength in the thermally affected region, with the cold length of canister restraining the thermal expansion of the hot length of canister wall. The hot length is plastically deformed in compression, and this compressive strain results in a local decrease in diameter of the canister after cooling to room temperature. The computer program MONSASTIFF was used to calculate the deformation profile shown in Figure C.13. This profile represents the difference between solutions with a uniform elastic modulus, and a solution with a degraded modulus, as described above. As seen in Figure C.13, the predicted canister deformation is a $0.058 \mathrm{~mm}(0.0023 \mathrm{in.})$ permanent change in the $203 \mathrm{~mm}$ ( $8.0 \mathrm{in.}$ ) nominal radius. This predicted diameter change is not considered significant and, in practice, would be overshadowed by the so-called "ratchet" strain associated with the differential thermal contractions of the glass and metal canister. 

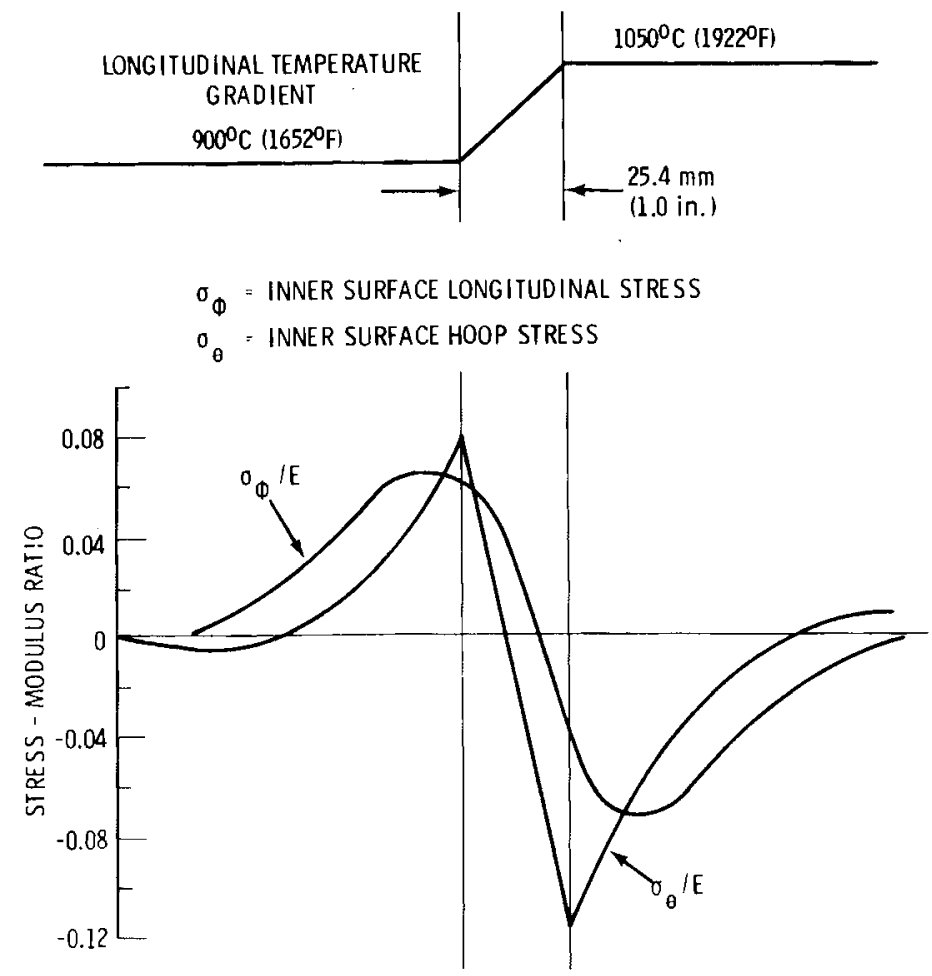

FIGURE C.12. Canister Thermal Stresses in Region of Zone Separation in Zone Melting Furnace, 16-in.-Dia Canister with $6.35-\mathrm{mm}-$ (0.25-in.-) Thick Wail

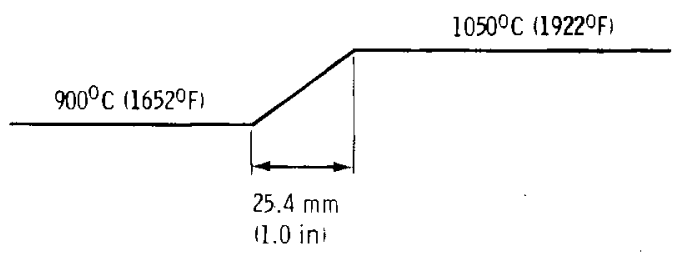

(a) LONGITUDINAL TEMPERATURE GRADIENT

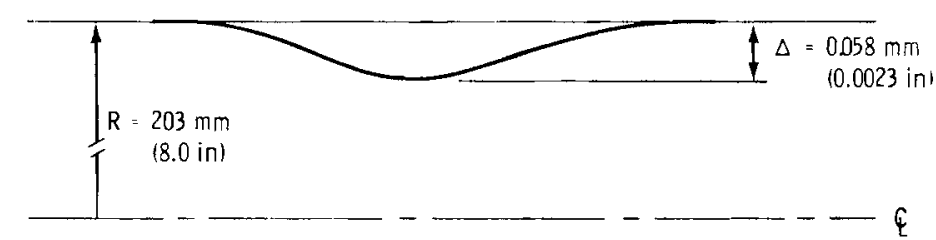

(b) PERMANENT DEFORMATION OF CANISTER WALL

FIGURE C.13. Estimated Permanent Deformation of Canister Wall at Zone Separation Points of Zone Melting Furnace, 16-in.-Dia Canister with 6.35-mm- (0.025-in.-) Thick Wall 
Thermal Deformation in a "Banana Mode"

Under the conditions of the ICM process, canisters experience unusually high temperatures and at these temperatures severe degradation of mechanical strength occurs. Such conditions would appear conducive to distortion of canisters. In this discussion, a bottom-supported canister is considered and distortion due to differential heating of the canister wall is evaluated.

Figure $C .14$ shows the configuration of interest. A cooled strip down the length of the canister is assumed. This cooled strip could approximate a circumferential temperature variation due, for example, to some unspec ified furnace irregularity. A circumferential variation in temperature is of particular interest, since it can result in a bowing of the canister. This can be described visually as a "banana mode" of deformation. The analysis below relates the extent of deformation to the temperature differential $\Delta T$ of the cooled strip and the subtended angle $\theta$ of the strip. The results of the analysis serve to indicate the sensitivity of this deformation to small varia tions in temperature and to estimate allowances for thermally induced movement that must be made in the design of canisterconnecting equipment.
If the thermal expansion due to the circumferential temperature variation is to be fully constrained, a bending moment must be applied as follows:

$$
M=2 \int_{0}^{\theta / 2} \text { (stress) (Z) (dA), }
$$

where:

$$
\begin{aligned}
\text { Stress } & =E \alpha \Delta T \\
Z & =R \cos \phi \\
d A & =R t d \phi \\
t & =\text { wall thickness } \\
E & =\text { elastic modulus } \\
\alpha & =\text { thermal expansion coefficient. }
\end{aligned}
$$

Evaluation of the integral gives

$$
M=2 E \alpha \Delta T t^{2} \sin (\theta / 2) .
$$

The radius of curvature $\rho$ of the canister in the absence of such a restraining moment

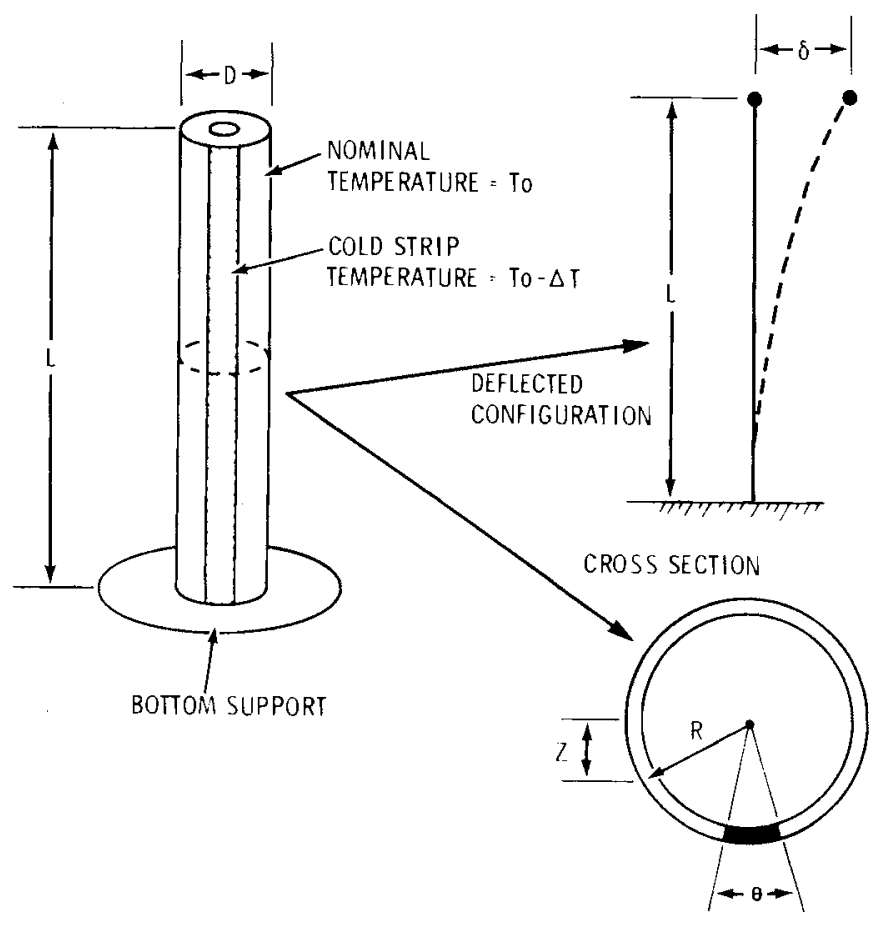

FIGURE C.14. Model for Analysis of Banana Mode of Canister Thermal Distortion 
can be estimated from the equation for beam bending as follows:

$$
1 / p=M / E I,
$$

where:

$$
I=\pi R^{3} t \text {. }
$$

The corresponding lateral deflection at the top of the canister can be calculated from simple geometric considerations to give

$$
\sigma=L^{2} / 2 \rho
$$

Substituting for the radius of curvature $\rho$ results in

$$
\sigma=(\alpha \Delta T \sin \theta / 2)\left(L^{2} / \pi R\right) .
$$

Figure $C .15$ shows the estimated lateral motion for the following specific parameters

$$
\begin{aligned}
& L=3.05 \mathrm{~m}(10 \mathrm{f}) \\
& D=406 \mathrm{~mm}(16 \mathrm{in.}) \\
& \alpha=5.0 \times 10^{-6} \mathrm{~mm} / \mathrm{mm} /{ }^{\circ} \mathrm{C}
\end{aligned}
$$

$$
\begin{aligned}
\Delta T & =20^{\circ}, 40^{\circ}, 60^{\circ}, 80^{\circ}, 100^{\circ} \mathrm{C} \\
\theta & =0 \text { to } 360 \text { degrees. }
\end{aligned}
$$

The curves show a lateral deflection approaching $25 \mathrm{~mm}$ ( $1.0 \mathrm{in.}$ ) for the $3.05-\mathrm{m}$ $(10-f)$ canister for the worst combination of temperature differential $\left(\Delta T=100^{\circ} \mathrm{C}\right.$ ) and circumferential distribution $(\theta=180$ degrees). This estimate probably greatly exceeds any deflection that could occur in practice, since it is based on an improbable set of temperature conditions.

The normal lengthwise thermal expansion of the $3.05-\mathrm{m}(10-f)$ canister when heated to an ICM temperature of $1050^{\circ} \mathrm{C}\left(1922^{\circ} \mathrm{F}\right)$ is also of interest. This change in length is about $50 \mathrm{~mm}$ (2 in.), which is about twice the upper bound estimate for lateral deflection.

It should be emphasized that the banana mode of deformation considered here is largely hypothetical. Canister distortion of this type has never been experienced in the numerous process trials performed at PNL. Canister dimensional changes from the filling process have been minor. Typically, a small increase in canister diameter and length can be detected by careful measurement. Representative diameter changes are given in Table C.6 for this Appendix. These dimensional changes are not considered to be of any consequence to the use of canisters.

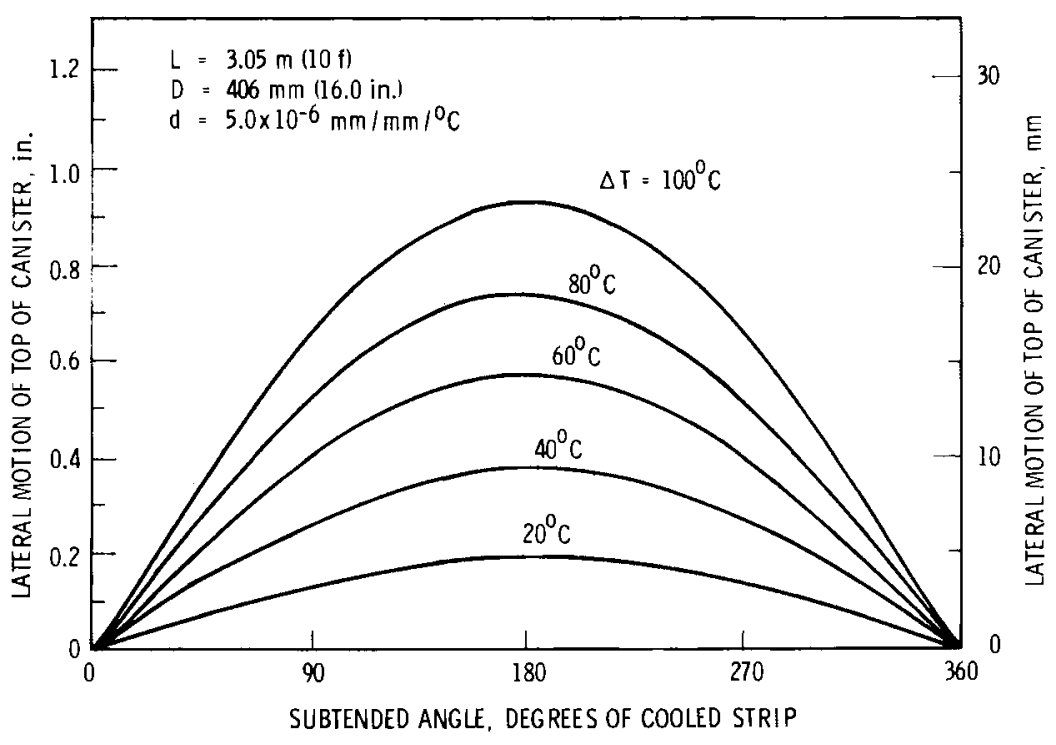

FIGURE C.15. Predicted Thermal Distortion of Canister for Banana Mode 


\section{REFERENCES}

Gerdeen, J. C., F. A. Simonen, and D. T. Hunter. 1971. "Large Deflection Analysis of Elastic-Plastic Shells Using Numerical Integration." AIAA J. 9: 1012 .

Lestingi, J. R. 1970. Direct Stiffness Analys is of Branch Shells of Revolution Using Numerical Integration Procedures Vol. II MONSASTIFF User's Manual. Report Number 70-1, The Institute of Science and Engineering Research, Department of Civil Engineering, The University of Akron, Akron, Ohio.

American Society for Metals. 1971. Metals Handbook, Vol. 1, Properties and Selection of Metals. 8th Edition, Metals Park, Novelty, Ohio.
Randa11, P. N. 1960. "Creep-Rupture Properties of a Carbon Stee 1 and a LOW-Alloy Steel at $1200^{\circ}$ to $1800^{\circ} \mathrm{F} . "$ In ASTM Proceedings 60:885-892.

Shappert, L. B. 1970. A Guide for the Design, Fabrication and Operation of Shipping Casks for Nuclear Application. ORNL-NSIC-68, Oak Ridge National Laboratory, Oak Ridge, Tennessee.

Slate, S. C., and R. F. Maness. 1978. "Corrosion Experience in Nuclear Waste Processing at Battelle-Northwest." Materials Performance 17(6):13-21. 
APPENDIX D 
APPENDIX D

\section{CREEP STRENGTH OF CANISTER MATERIALS}

This appendix describes an investigation of the high-temperature creep properties of $304 \mathrm{~L}$ stainless steel and Inconel alloy $601 \mathrm{plate}$ over the temperature range of $950^{\circ} \mathrm{C}$ to $1150^{\circ} \mathrm{C}$ $\left(1742^{\circ} \mathrm{F}\right.$ to $\left.2102^{\circ} \mathrm{F}\right)$. In a series of tests performed by Battelle Columbus Laboratories for PNL, short-time tensile creep data were obtained for application to the design of canisters for the ICM process.

\section{MATERIALS SELECTION CONSIDERATIONS}

The selection of canister materials is based on such factors as elevated temperature strength, oxidation resistance, corrosion resistance to glass compounds at glass melting temperatures, resistance to stresscorrosion cracking during water-basin storage, and ductility at low temperatures to sustain accidental impact. The combination of these requirements has focused the selection process on wrought, austenitic stainless steels and nickel chromium alloys. The alloys 304L stainless steel and Inconel 601 were selected for study since they were prime candidates for the canister application and are representative of the two ends of the spectrum of alloy content for the class of materials of interest. They were also expected to exhibit significant differences in creep strength.

The AISI-type $304 \mathrm{~L}$ stainless steel $(18 \% \mathrm{Cr}-8 \% \mathrm{Ni})$ is the low-carbon $(0.03$ maximum) form of the standard 304 steel. The low carbon increases corrosion resistance by reducing carbide precipitation at the grain boundaries. It can be safely welded with a minimum danger of intergranular attack. In general, its strength properties are among the lowest for the 300 series of stainless steels, comparable to types 302 and 304 , with normal (0.08) carbon levels (Simmons and Cross 1952).

While there is a lack of specific hightemperature strength data for the $304 \mathrm{~L}$ steel, in the very high temperature range of $950^{\circ} \mathrm{C}$ to $1100^{\circ} \mathrm{C}\left(1742^{\circ} \mathrm{F}\right.$ to $\left.2102^{\circ} \mathrm{F}\right)$, the strengths of all the 300 -series steels are very nearly the same (Simmons and Cross 1952). Thus, for relating rupture strengths, a comparison with types 302 (Brickner, Ratz, and Dornagala 1965) or 310 (VanEcho, Roach, and Hall 1977) is adequate. A major drawback is a lack of oxidation resistance at very high temperatures (Allegheny Ludium Steel Corporation 1956) since even short time periods at $1100^{\circ} \mathrm{C}$ $\left(2012^{\circ} \mathrm{F}\right)$ produce significant scaling.

On the other hand, Inconel $601(60 \% \mathrm{Ni}$, $23 \%(\mathrm{Cr})$ is an excellent oxidation-resistant alloy. It displays very little weight loss when exposed for up to $500 \mathrm{~h}$ at $1100^{\circ} \mathrm{C}$ $\left(2012^{\circ} \mathrm{F}\right)$ and $1150^{\circ} \mathrm{C}\left(2102^{\circ} \mathrm{F}\right)$ (International Nickel Co., Inc. 1973). It can be welded and has good high-temperature strength properties (International Nickel Co., Inc. 1973; Simmons 1968). The alloy is also resistant to carbonization, sulfidation and stresscorrosion cracking (International Nickel Co., Inc. 1973).

The specific purpose of this study was to establish the engineering creep and rupture properties of $304 \mathrm{~L}$ stainless steel and Incone 1601 at temperatures in the range of $950^{\circ} \mathrm{C}$ to $1150^{\circ} \mathrm{C}\left(1742^{\circ} \mathrm{F}\right.$ to $\left.2102^{\circ} \mathrm{F}\right)$. This temperature range covered the anticipated melting conditions and also allowed evaluation of canister performance under overheating conditions. Since service exposure times will be relatively short, it was necessary to establish creep performance to only about $100 \mathrm{~h}$. One of the major uses of the data was to permit prediction of canister deformation under normal service conditions. Thus, many of the tests were at relatively low stress levels in order to be representative of design stress levels. These low stress tests were discontinued after the trend of the creep curve was established, since rupture was not expected within the time frame of interest. For $304 \mathrm{~L}$ stainless steel, a few tests were performed in a vacuum to determine the effect of the air environment on creep performance. This factor is related to ICM, since an inert gas environment is a possible means of limiting the extent of external oxidation and scaling of canisters during processing. 


\section{MATERIALS TESTED}

The materials tested were obtained from commercial heats of $304 \mathrm{~L}$ stainless steel and Inconel 601 . Three lots of materials were tested. These were taken from a $6.35-\mathrm{mm}-$ (0.250-in.-) thick Inconel 601 plate, a 1/2-in.-thick 304L plate, and a 1/4-in. $304 \mathrm{~L}$ plate. The chemical compositions of the three materials, as compared with specification ranges, are given in Table 0.1 .

Type 304L is an entirely austenitic alloy, as seen in Figure D.1. Coring is present in both thicknesses, shown by the faint lines in the figure. There is a slight amount of carbide precipitation at the grain boundaries (sensitization). The 1/2-in. plate contains ferrite stringers, which is the major difference between the two thicknesses of material. However, the stringers are not believed to produce a difference in strength.

Inconel 601 is a solid-solution, face centered cubic alloy with good stability. Figure D.1 shows an austenitic matrix with carbide precipitation in the grain boundaries. The large blotchy particles are titanium nitride, and the smaller particles are chromium nitrides. This alloy generally does not show any embrittling intermetallic phases. It has good oxidation resistance, shown by the lack of scaling of the creep specimens at any of the test temperatures. It was concluded that all materials were typical of commercial heats.

\section{TEST PROCEDURES}

Two specimen configurations were tested. The 12.7-mm- (0.50-in.-) thick stainlesssteel plate was machined into a 76.2-mm(3-in.-) long round specimen with a $6.35 \mathrm{~mm}$ $(0.25$ in.) dia. in the gage length. Flat specimens were made from the $6.35-\mathrm{mm}-10.25-$ in.-) thick 304L and Inconel 601 materials. The overall length was $254 \mathrm{~mm}$ (10 in.) with 6.35-mm. (0.25-in.-) square by 57.2-mm(2.250-in.-) long reduced sections. The 245-mm (10-in.) length permitted loading by pins in a relatively cold portion of the furnace. All specimens were machined to allow stressing in a direction transverse to the rolling direction of the plate materials. Figure 0.2 shows typical specimens after testing. The effect of exposure to air and vacuum environments is evident from the appearance of the specimens.

The creep tests were made in standard $B C L$-type creep-testing frames. Specimens were dead-weight loaded with a 9-to-1 ratio lever arm. The exact ratio was determined by calibration and considered well within the 1\% specified in ASTM Standard E139-70. The axiality of the creep frames had also been checked and adjusted so that it did not exceed the $10 \%$ elastic-strain difference prescribed by ASTM.

Several types of furnaces were used in this program. For the very high temperatures, $1100^{\circ} \mathrm{C}$ and $1150^{\circ} \mathrm{C}\left(2012^{\circ} \mathrm{F}\right.$ and $\left.2102^{\circ} \mathrm{F}\right)$, air tests, platinum wire-wound resistance furnaces were used. The vacuum tests were made

TABLE D.1. Chemical Composition of Materials Tested (wt\%)

\begin{tabular}{|c|c|c|c|}
\hline \multirow{2}{*}{$\begin{array}{l}\text { Chemical } \\
\text { Element }\end{array}$} & \multicolumn{2}{|c|}{ Type 304L Stainless Steel } & \multirow[b]{2}{*}{ Inconel 601} \\
\hline & 1/2-in. plate & 1/4-in. plate & \\
\hline c & $0.03(0.03 \mathrm{M})$ & $0.03(0.03 \mathrm{M})$ & $0.06(0.10 \mathrm{M})$ \\
\hline Si & $0.53(1.0 \mathrm{MT}$ & $0.56(1.0 \mathrm{MT}$ & $0.16(0.50 \bar{M})$ \\
\hline Mn & $1.74(2.0 \bar{M})$ & $1.33(2.0 \bar{M})$ & $0.31(1.0 \mathrm{M})^{\prime}$ \\
\hline $\mathrm{p}$ & $0.032(0.0 \overline{4} 5 \mathrm{M})$ & $0.018(0.0 \overline{4} 5 \mathrm{M})$ & $0.038(0.015 \mathrm{M})$ \\
\hline $\mathrm{s}$ & $0.009(0.030 \bar{M})$ & $0.016(0.030 \bar{M})$ & $0.002(0.015 \bar{M})$ \\
\hline $\mathrm{Ni}$ & $8.44(8 / 10)$ & $8.58(8 / 10)$ & Balance \\
\hline $\mathrm{Cr}$ & $18.80(17 / 19)$ & $18.10(17 / 19)$ & $22.69(21 / 25)$ \\
\hline Mo & 0.55 & 0.27 & -- \\
\hline $\mathrm{Cu}$ & 0.19 & 0.22 & 0.33 \\
\hline Al & -- & -- & $1.11(1.0 / 1.7)$ \\
\hline $\mathrm{Fe}$ & Balance & Balance & 17.50 \\
\hline
\end{tabular}

Note: Values in parentheses are the specified ranges for each alloy. 
MICROSTRUCTURES BEFORE TESTING (100X)

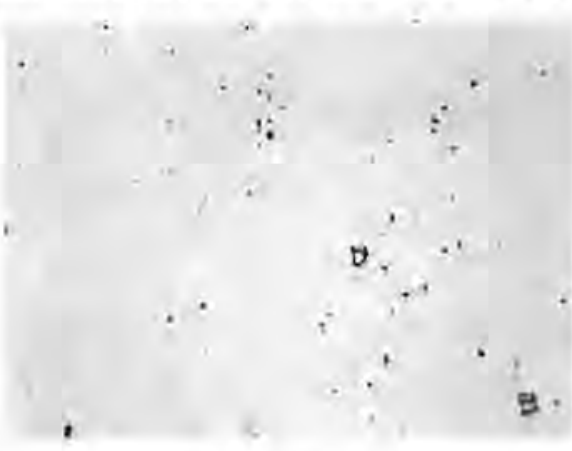

(a) INCONEL 601

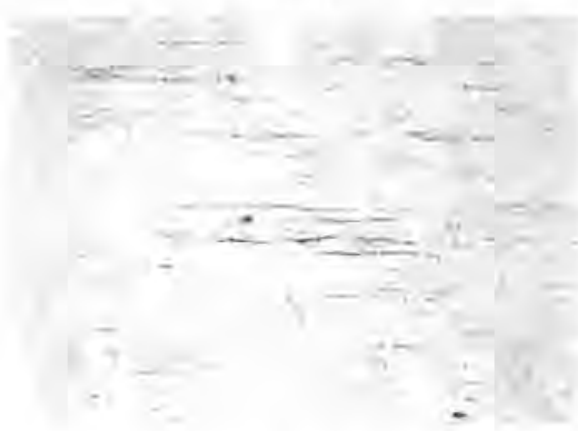

(b) 304L 1/2-in. PLATE

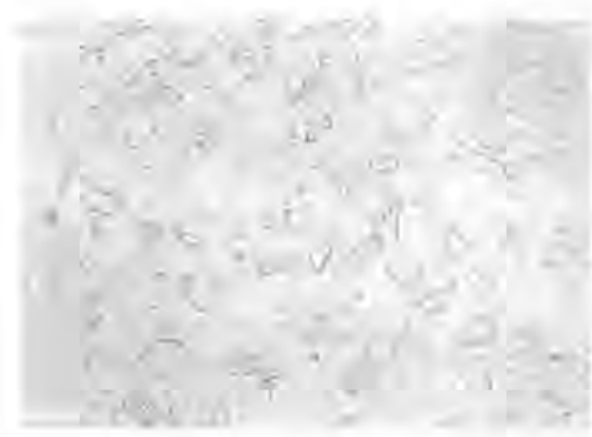

(c) 304L 1/4-in. PLATE

FIGURE D.1. Microstructures of Materials Before Testing Glyceregia Etch, Magnified $100 \mathrm{X}$

in a molybdenum-heater vacuum furnace. The vacuum pressure attained was of the order of $5 \times 10^{-6}$ torr.

Foxboro temperature controllers, operating on a high-low power input, controlled the test temperature to within about $+3^{\circ} \mathrm{C}$ of the intended temperature. The temperatures were checked and, if necessary, adjusted daily to maintain this tolerance. Several auxiliary factors were helpful in maintaining accurate temperature control.
These factors include using anticipators in the temperature-control circuits, regulating the input voltage to the furnaces, and maintaining a uniform laboratory temperature with air conditioning.

Three thermocouples were attached to the gaged section of each specimen. In all tests Pt-Pt10Rh (18-gage) thermocouples were used. A11 thermocouples were individually calibrated before they were used. The thermocouple at the center of the gaged section was used to control the temperature and one, or both, of the other thermocouple outputs were recorded on a L\&N 12-point recorder.

Deformation in the test specimen was measured optically by platinum strip extensometers attached either directly to the gaged section or to shoulders of the specimen. The extensometer consists of two platinum strips of metal, one of which slides within the folded edges of the other. The surfaces of the strips are polished so that they have a good reflecting surface, and a series of very fine marks is scribed on them. Two cross marks, one on each strip, serve as reference marks and the distance between them is measured periodically with a filar microscope. The change in the distance between these two reference marks is a measure of the change in length, or creep of the specimen.

Strain measurements were made with a microscope fitted with a filar eyepiece and mounted on a graduated screw. The smallest division on the filar eyepiece is $0.00005 \mathrm{in.}$, which on a 1-in. gage length would be equal to $0.0050 \%$. The zero reading was taken with the specimen at the test temperature and no stress applied. The initial deformation was obtained by applying the entire stress as rapidly as possible. Succeeding readings were taken regulariy to produce a smooth creep curve.

\section{TEST RESULTS}

\section{Test Parameters}

The $304 \mathrm{~L}$ material was tested at temperatures of $950^{\circ}, 1000^{\circ}, 1050^{\circ}$ and $1100^{\circ} \mathrm{C}$ $\left(1742^{\circ}, 1832^{\circ}, 1922^{\circ}\right.$ and $\left.2012^{\circ} \mathrm{F}\right)$ for the stress Tevels indicated in Table D.2. The Inconel 601 material was tested at somewhat higher temperatures of $1050^{\circ}, 1100^{\circ}$ and $1150^{\circ} \mathrm{C}\left(1922^{\circ}, 2012^{\circ}\right.$ and $\left.2102^{\circ} \mathrm{F}\right)$ for the stress levels given in Table D.3. Two tests were conducted on the $6.35-\mathrm{mm}(0.250-\mathrm{in}$.) $304 \mathrm{~L}$ plate to compare its creep and creep- 

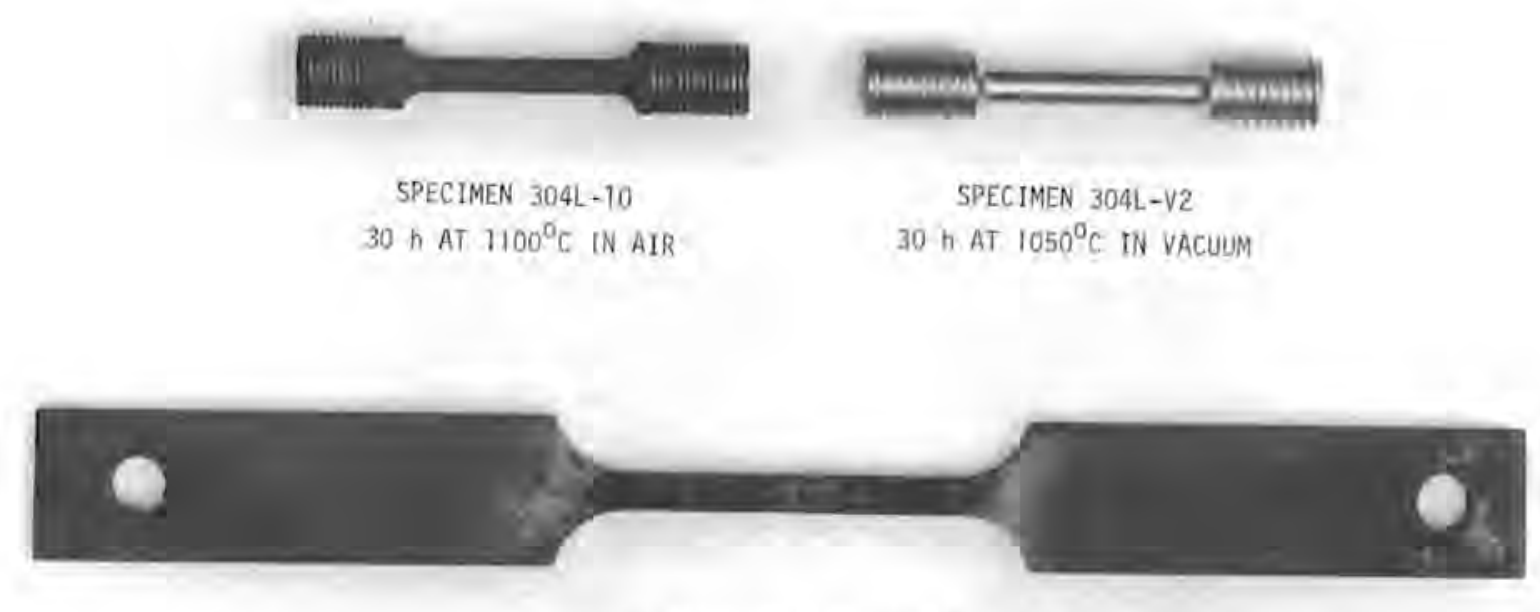

SPECIMEN $601-830 \mathrm{~h}$ AT $1100^{\circ} \mathrm{C}$ IN AIR

FIGURE D.2. Test Specimens After Exposure

rupture strength with the plate. In addition, four tests were conducted on the $12.7-\mathrm{mm}(0.50-\mathrm{in}$.$) plate in vacuum to obtain$ an indication of environmental effects. The data from all tests are summarized in Tables D.2 and D.3.

For most tests, the duration was $30 \mathrm{~h}$. The tests at higher stress levels were, however, continued until rupture occurred to obtain an indication of creep rupture strengths. For waste canister applications, the 30-h tests were sufficient to establish creep curves for stress levels indicative of service conditions. Detailed creep data were of major interest as input parameters for analytical prediction of canister deformations during service. Continuation of most of the lower stress tests to rupture would have involved very long tests. A few of the tests were continued beyond $30 \mathrm{~h}$ to obtain at least a $0.2 \%$ creep strain.

\section{Creep Curves}

Creep curves for all tests are given in Figures 0.3 to 0.18 . Results of tests in air of the 1/2-in. 304L plate are shown in Figures $D .3$ to $D .7$, and Figures D.8 and D.9 indicate the relative difference in creep strength between the $1 / 2-i n$. and $1 / 4-i n$. $304 \mathrm{~L}$ plate materials. Figures D.10 to $\mathbf{D . 1 2}$ compare the creep of the 1/2-in. 304L plate in air with results from the vacuum tests. Final1y, creep curves from the tests on the 1/4-in. Incone1 601 plate material are shown in Figures 0.13 to 0.18 .
For the tests continued up to rupture Tevels, significant rupture ductility was exhibited. For example, specimen 601-12 at $1150^{\circ} \mathrm{C}$ gave an elongation of $84.6 \%$ within the $50.8-m(2-i n$.$) gage length. The min-$ imum elongation recorded was $21.0 \%$ for specimen $304 \mathrm{~L}-12$, but this was associated with a reduction in area of $62.6 \%$.

The data clearly indicate that the Inconel 601 material is significantly stronger than the $304 \mathrm{~L}$ stainless steel. A review of the overall data trends indicated that the strength of 304L stainless steel was roughly $60 \%$ the strength of Inconel 601 up to a temperature of about $1050^{\circ} \mathrm{C}$ (19220 F). Above $1050^{\circ} \mathrm{C}$, the apparent strength of $304 \mathrm{~L}$ in air is degraded by oxidation and subsequent loss of specimen cross-section from scaling.

\section{Rupture Strengths}

Although a direct comparison is difficult because of the lack of data, the current results on $304 \mathrm{~L}(1 / 2-\mathrm{in}$. plate) are comparable to values found by Simmons and Cross (1952). For example, they give the 100-h rupture strength at $1800^{\circ} \mathrm{F}$ as $15.2 \mathrm{MN} / \mathrm{m}^{2}$ (2200 psi). Based on the current tests, the $100-\mathrm{h}$ rupture strength of $304 \mathrm{~L}$ at $1000^{\circ} \mathrm{C}\left(1832^{\circ} \mathrm{F}\right)$ is approximately $14.5 \mathrm{MN} / \mathrm{m}^{2}$ (2100 psi). The lower strength is offset by the slightiy higher temperature. By extrapolating values of Simmons and cross (1952), similar relationships can be found at the other temperatures. 
TABLE D.2. Sumary of Data on Creep and Rupture Properties for 304L Stainless Steel Plate

\begin{tabular}{|c|c|c|c|c|c|c|c|c|c|c|c|c|c|}
\hline \multirow[t]{2}{*}{$\begin{array}{l}\text { Specimen } \\
\text { Number } \\
\end{array}$} & \multicolumn{2}{|c|}{$\begin{array}{c}\text { Stress } \\
\mathrm{MN} / \mathrm{m}^{2}(k s i) \\
\end{array}$} & \multirow[t]{2}{*}{$\begin{array}{c}\text { Temperature, } \\
\end{array}$} & $\frac{\text { Hours to }}{0.2}$ & $\begin{array}{c}\text { Indicate } \\
0.5\end{array}$ & \multicolumn{3}{|c|}{$\begin{array}{l}\text { d Creep Deformation, } * \\
1.0 \quad 2.0 \quad 10\end{array}$} & \multirow[t]{2}{*}{$\begin{array}{l}\text { Initial } \\
\text { Strain, } \\
\quad x \\
\end{array}$} & \multirow[t]{2}{*}{$\begin{array}{l}\text { Rupture } \\
\text { Tjme, } \\
\text { h(a) } \\
\end{array}$} & \multirow[t]{2}{*}{$\begin{array}{l}\text { Elonga- } \\
\text { tion in } \\
2 \text { in., } x \\
\end{array}$} & \multirow[t]{2}{*}{$\begin{array}{l}\text { Reduc- } \\
\text { tion of } \\
\text { Area, } \% \\
\end{array}$} & \multirow[t]{2}{*}{$\begin{array}{l}\text { Minimum } \\
\text { Creep } \\
\text { Rate, } \% \mathrm{~h} \\
\end{array}$} \\
\hline & \multicolumn{7}{|c|}{$\underline{1 / 2 \text {-in. Plate-Air }}$} & & & & & & \\
\hline $\begin{array}{l}304 L-1 \\
304 L-4 \\
304 L-6\end{array}$ & $\begin{array}{c}13.8 \\
6.9 \\
3.45\end{array}$ & $\begin{array}{l}(2.0) \\
(1.0) \\
(0.5)\end{array}$ & $\begin{array}{l}950 \\
950 \\
950\end{array}$ & $\begin{array}{l}0.6 \\
6.9 \\
--\end{array}$ & ${ }_{40}^{3}(b)$ & $\begin{array}{l}7.2 \\
-- \\
--\end{array}$ & $\begin{array}{l}16 \\
-- \\
--\end{array}$ & $\begin{array}{r}105 \\
-- \\
--\end{array}$ & $\begin{array}{l}0.101 \\
0.045 \\
0\end{array}$ & $\begin{array}{r}495.8 \\
50.0 \\
30.0\end{array}$ & $\begin{array}{l}47.4 \\
0.443 \\
0.067\end{array}$ & $\begin{array}{l}31.6 \\
-- \\
--\end{array}$ & $\begin{array}{c}0.087 \\
-- \\
--\end{array}$ \\
\hline $\begin{array}{l}304 \mathrm{~L}-14 \\
304 \mathrm{~L}-2 \\
304 \mathrm{~L}-5 \\
304 \mathrm{~L}-7\end{array}$ & $\begin{array}{c}20.7 \\
13.8 \\
6.9 \\
3.45\end{array}$ & $\begin{array}{l}(3.0) \\
(2.0) \\
(1.0) \\
(0.5)\end{array}$ & $\begin{array}{l}1000 \\
1000 \\
1000 \\
1000\end{array}$ & $\begin{array}{l}0.1 \\
0.2 \\
3.2 \\
--\end{array}$ & $\begin{array}{c}0.25 \\
0.7 \\
14.0 \\
--\end{array}$ & $\begin{array}{c}0.5 \\
1,6 \\
38(b) \\
--\end{array}$ & $\begin{array}{l}1.1 \\
3.6 \\
-- \\
--\end{array}$ & $\begin{array}{l}5.6 \\
26 \\
-- \\
--\end{array}$ & $\begin{array}{l}0.147 \\
0.113 \\
0.038 \\
0\end{array}$ & $\begin{array}{r}19.2 \\
120.7 \\
30.0 \\
30.0\end{array}$ & $\begin{array}{l}57.9 \\
48.2 \\
0.864 \\
0.106\end{array}$ & $\begin{array}{c}39.3 \\
37.7 \\
-- \\
--\end{array}$ & $\begin{array}{l}1.5 \\
0.32 \\
-- \\
--\end{array}$ \\
\hline $\begin{array}{l}304 L-9 \\
304 L-11 \\
304 L-3 \\
304 L-8\end{array}$ & $\begin{array}{c}13.8 \\
10.3 \\
6.9 \\
3.45\end{array}$ & $\begin{array}{l}(2.0) \\
(1.5) \\
(1.0) \\
(0.5)\end{array}$ & $\begin{array}{l}1050 \\
1050 \\
1050 \\
1050\end{array}$ & $\begin{array}{l}0.1 \\
0.3 \\
1.2 \\
33.5(b)\end{array}$ & $\begin{array}{l}0.25 \\
1.0 \\
5.8 \\
--\end{array}$ & $\begin{array}{r}0.6 \\
2.2 \\
15.8 \\
--\end{array}$ & $\begin{array}{c}1.3 \\
5,0 \\
39(\mathrm{~b}) \\
--\end{array}$ & $\begin{array}{l}10 \\
38 \\
-- \\
--\end{array}$ & $\begin{array}{l}0.071 \\
0.041 \\
0.038 \\
0\end{array}$ & $\begin{array}{r}33.6 \\
130.4 \\
30.0 \\
30.0\end{array}$ & $\begin{array}{l}45.1 \\
35.3 \\
1.627 \\
0.184\end{array}$ & $\begin{array}{c}38.2 \\
40.0 \\
-- \\
--\end{array}$ & $\begin{array}{c}0.75 \\
0.23 \\
-- \\
--\end{array}$ \\
\hline $\begin{array}{l}304 L-15 \\
304 L-12 \\
304 L-10 \\
394 L-13\end{array}$ & $\begin{array}{l}10.3 \\
6.9 \\
3.45 \\
1.38\end{array}$ & $\begin{array}{l}(1.5) \\
(1.0) \\
0.5) \\
(0.2)\end{array}$ & $\begin{array}{l}1100 \\
1100 \\
1100 \\
1100\end{array}$ & $\begin{array}{r}0.1 \\
0.4 \\
5.6 \\
14.0\end{array}$ & $\begin{array}{l}0.25 \\
1.2 \\
15,3 \\
39(b)\end{array}$ & $\begin{array}{c}0.5 \\
3,0 \\
35(b) \\
--\end{array}$ & $\begin{array}{l}1.2 \\
6.5 \\
-- \\
--\end{array}$ & $\begin{array}{l}8.6 \\
43 \\
---\end{array}$ & $\begin{array}{l}0.054 \\
0.064 \\
0 \\
0.007\end{array}$ & $\begin{array}{l}33.1 \\
82.9 \\
30.0 \\
30.0\end{array}$ & $\begin{array}{l}42.3 \\
21.0 \\
0.884 \\
0.395\end{array}$ & $\begin{array}{c}48.7 \\
62.6 \\
-- \\
--\end{array}$ & $\begin{array}{c}0.83 \\
0.20 \\
-- \\
--\end{array}$ \\
\hline \multicolumn{14}{|c|}{ 1/2-in. Plate-Vacuum } \\
\hline $\begin{array}{l}304 \mathrm{~L}-V_{3} \\
304 \mathrm{~L}-V_{2}\end{array}$ & $\begin{array}{r}10.3 \\
6.9\end{array}$ & $(1.5)$ & $\begin{array}{l}1050 \\
1050\end{array}$ & $\begin{array}{l}0.25 \\
0.7\end{array}$ & $\begin{array}{l}0.9 \\
2.3\end{array}$ & $\begin{array}{l}1.9 \\
5.5\end{array}$ & $\begin{array}{r}4.0 \\
11.8\end{array}$ & $\begin{array}{l}25.2 \\
--\end{array}$ & $\begin{array}{l}0.012 \\
0.008\end{array}$ & $\begin{array}{l}82.9 \\
30.0\end{array}$ & $\begin{array}{l}36.0 \\
4.545\end{array}$ & $\begin{array}{c}41.7 \\
--\end{array}$ & $\begin{array}{c}0.32 \\
--\end{array}$ \\
\hline $\begin{array}{l}304 L-V 5 \\
304 L-V 4\end{array}$ & $\begin{array}{r}10.3 \\
6.9\end{array}$ & $\begin{array}{l}(1.5) \\
(1.0)\end{array}$ & $\begin{array}{l}1100 \\
1100\end{array}$ & $\begin{array}{l}0.1 \\
0.4\end{array}$ & $\begin{array}{l}0.25 \\
1.0\end{array}$ & $\begin{array}{l}0.55 \\
2.3\end{array}$ & $\begin{array}{l}1.1 \\
6.0\end{array}$ & $\begin{array}{r}6 \\
48\end{array}$ & $\begin{array}{l}0.196 \\
0.148\end{array}$ & $\begin{array}{r}19.7 \\
111.2\end{array}$ & $\begin{array}{l}59.2 \\
44.8\end{array}$ & $\begin{array}{l}54.8 \\
53.9\end{array}$ & $\begin{array}{l}1.5 \\
0.15\end{array}$ \\
\hline \multicolumn{14}{|c|}{ 1/4-in. Plate-Air } \\
\hline $\begin{array}{l}304 L-2 A \\
304 L-1 A\end{array}$ & $\begin{array}{r}10.3 \\
6.9\end{array}$ & $\begin{array}{l}(1.5) \\
(1.0)\end{array}$ & $\begin{array}{l}1050 \\
1050\end{array}$ & $\begin{array}{c}0.25 \\
0.7\end{array}$ & $\begin{array}{l}0.75 \\
3.0\end{array}$ & $\begin{array}{l}1.8 \\
8.4\end{array}$ & $\begin{array}{l}3.6 \\
20.9\end{array}$ & $\begin{array}{l}27.6 \\
--\end{array}$ & $\begin{array}{l}0.048 \\
0.040\end{array}$ & $\begin{array}{l}66.0 \\
30.0\end{array}$ & $\begin{array}{l}26.3 \\
2.688\end{array}$ & $\begin{array}{c}53.6 \\
--\end{array}$ & $\begin{array}{c}0.32 \\
--\end{array}$ \\
\hline
\end{tabular}

(a) All 30-h tests were discontinued at this time.

(b) Estimate

TABLE D.3. Summary of Data on Creep and Rupture Properties of Inconel 601 Plate (1/4 in.)

\begin{tabular}{|c|c|c|c|c|c|c|c|c|c|c|c|c|c|}
\hline $\begin{array}{l}\text { Specimen } \\
\text { Number }\end{array}$ & $\begin{array}{r}\text { Stre } \\
M N / m^{2}\end{array}$ & iksi) & $\begin{array}{l}\text { Temperature, } \\
{ }^{\circ} \mathrm{C}\end{array}$ & $\frac{\text { Hours }}{0.2}$ & $\frac{\text { to Indicated }}{0.5}$ & $\begin{array}{l}\text { Creep } \\
1.0 \\
\end{array}$ & $\begin{array}{c}\frac{\text { Def ormat }}{2.0} \\
\end{array}$ & $\frac{\text { on, } x}{10}$ & $\begin{array}{l}\text { Initial } \\
\text { Strain, } \\
\underset{x}{ } \\
\end{array}$ & $\begin{array}{c}\text { Rupture } \\
\text { Time, } \\
\text { H }\end{array}$ & $\begin{array}{l}\text { Elonga- } \\
\text { tion in } \\
2 \text { in., } \% \\
\end{array}$ & $\begin{array}{l}\text { Reduc- } \\
\text { tion of } \\
\text { Area, } 8 \\
\end{array}$ & $\begin{array}{c}\text { Minimum } \\
\text { Creep } \\
\text { Rate, xh }\end{array}$ \\
\hline $\begin{array}{l}601-5 \\
601-2 \\
601-10 \\
601-1 \\
601-13 A \\
601-13\end{array}$ & $\begin{array}{c}20.7 \\
13.8 \\
13.8 \\
6.9 \\
5.17 \\
3.45\end{array}$ & 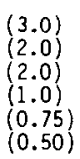 & $\begin{array}{l}1050 \\
1050 \\
1050 \\
1050 \\
1050 \\
1050\end{array}$ & $\begin{array}{c}0.05 \\
1.7 \\
1.0 \\
15.4 \\
64.0 \\
-. .\end{array}$ & $\begin{array}{l}0.15 \\
5.7 \\
3.0 \\
31.2(b) \\
-. \\
-.\end{array}$ & $\begin{array}{c}0.35 \\
10.4 \\
7.0 \\
-- \\
--\end{array}$ & $\begin{array}{c}0.85 \\
17.6 \\
15.0 \\
-- \\
-- \\
--\end{array}$ & $\begin{array}{c}4.8 \\
-- \\
48.0 \\
-- \\
-- \\
--\end{array}$ & $\begin{array}{l}0.113 \\
0.044 \\
0.028 \\
0.020 \\
0 \\
0\end{array}$ & $\begin{array}{c}9.2 \\
30.0(a) \\
126.0 \\
30.0(a) \\
64.5 \\
30.0(a)\end{array}$ & $\begin{array}{c}37.1 \\
4.37 \\
45.7 \\
0.476 \\
0.202 \\
0.016\end{array}$ & $\begin{array}{c}61.8 \\
42.0 \\
-- \\
--\end{array}$ & $\begin{array}{l}1.8 \\
-- \\
0.095 \\
-- \\
-- \\
--\end{array}$ \\
\hline $\begin{array}{l}601-4 \\
601-3 \\
601-14 \\
601-6 \\
601-16 \\
601-8 \\
601-19 \\
601-15\end{array}$ & $\begin{array}{c}20.7 \\
13.8 \\
10.3 \\
6.9 \\
5.17 \\
3.45 \\
2.76 \\
1.38\end{array}$ & $\begin{array}{l}(3.0) \\
(2.0) \\
(1.5) \\
(2.0) \\
(0.75) \\
(0.5) \\
(0.4) \\
(0.2)\end{array}$ & $\begin{array}{l}1100 \\
1100 \\
1100 \\
1100 \\
1100 \\
1100 \\
1100 \\
1100\end{array}$ & $\begin{array}{l}0 . \\
0.05 \\
0.2 \\
0.8 \\
2(2 \\
55(b) \\
57 \\
--\end{array}$ & $\begin{array}{l}-- \\
0.15 \\
0.5 \\
2.4 \\
6.5 \\
--- \\
--\end{array}$ & $\begin{array}{c}0.01 \\
0.4 \\
1.0 \\
5.6 \\
16.3 \\
-- \\
-- \\
--\end{array}$ & $\begin{array}{c}0.03 \\
0.95 \\
2.5 \\
17 \\
60(\mathrm{~b}) \\
-- \\
-- \\
--\end{array}$ & $\begin{array}{c}0.5 \\
6.3 \\
22.5 \\
-- \\
-- \\
-- \\
--\end{array}$ & $\begin{array}{l}0.775 \\
0.107 \\
0.042 \\
0.004 \\
0.012 \\
0 \\
0 \\
0\end{array}$ & $\begin{array}{l}1.5 \\
14.5 \\
30.0(\mathrm{a}) \\
30.0(\mathrm{~d}) \\
30.0(\mathrm{~d}) \\
30.0 \text { (a) } \\
94.0 \text { (a) } \\
30.0(\mathrm{~d})\end{array}$ & $\begin{array}{l}75.8 \\
51.4 \\
13.570 \\
2.692 \\
1.427 \\
0.129 \\
0.287 \\
0.008\end{array}$ & $\begin{array}{l}95 \\
46.1 \\
-- \\
-- \\
-- \\
-- \\
-- \\
--\end{array}$ & $\begin{array}{l}7.2 \\
1.4 \\
-- \\
-- \\
-- \\
-- \\
--\end{array}$ \\
\hline $\begin{array}{l}601-12 \\
601-7 \\
601-11 \\
601-17 \\
601-9 \\
601-18\end{array}$ & $\begin{array}{l}10.3 \\
6.9 \\
6.9 \\
5.17 \\
3.45 \\
2.07\end{array}$ & $\begin{array}{l}(1.5) \\
(1.0 \\
(1.0) \\
(0.75) \\
(0.5) \\
(0.3)\end{array}$ & $\begin{array}{l}1150 \\
1150 \\
1150 \\
1150 \\
1150 \\
1150\end{array}$ & $\begin{array}{l}0.08 \\
0.21 \\
-- \\
1.1 \\
10 \\
33.5\end{array}$ & $\begin{array}{c}0.15 \\
0.6 \\
0.4 \\
4,1 \\
75(\mathrm{~b}) \\
150(\mathrm{~b})\end{array}$ & $\begin{array}{r}0.3 \\
1.5 \\
1.4 \\
12.0 \\
-.-\end{array}$ & $\begin{array}{c}0.9 \\
4.4 \\
4.7 \\
34 \\
--.\end{array}$ & $\begin{array}{c}6.0 \\
-- \\
85 \\
-- \\
--\end{array}$ & $\begin{array}{l}0.241 \\
0.020 \\
0.125 \\
0.028 \\
0.004 \\
0.010\end{array}$ & $\begin{array}{c}30.0 \\
30.0(a) \\
434.2 \\
30.0(a) \\
30.0(a) \\
75.1(a)\end{array}$ & $\begin{array}{c}84.6 \\
5.749 \\
52.6 \\
1.805 \\
0.320 \\
0.320\end{array}$ & $\begin{array}{c}73.5 \\
34.4 \\
-- \\
-- \\
--\end{array}$ & $\begin{array}{l}1.6 \\
-- \\
0.097 \\
-- \\
-- \\
--\end{array}$ \\
\hline
\end{tabular}

(a) Test discont inued.

(b) Est imate 


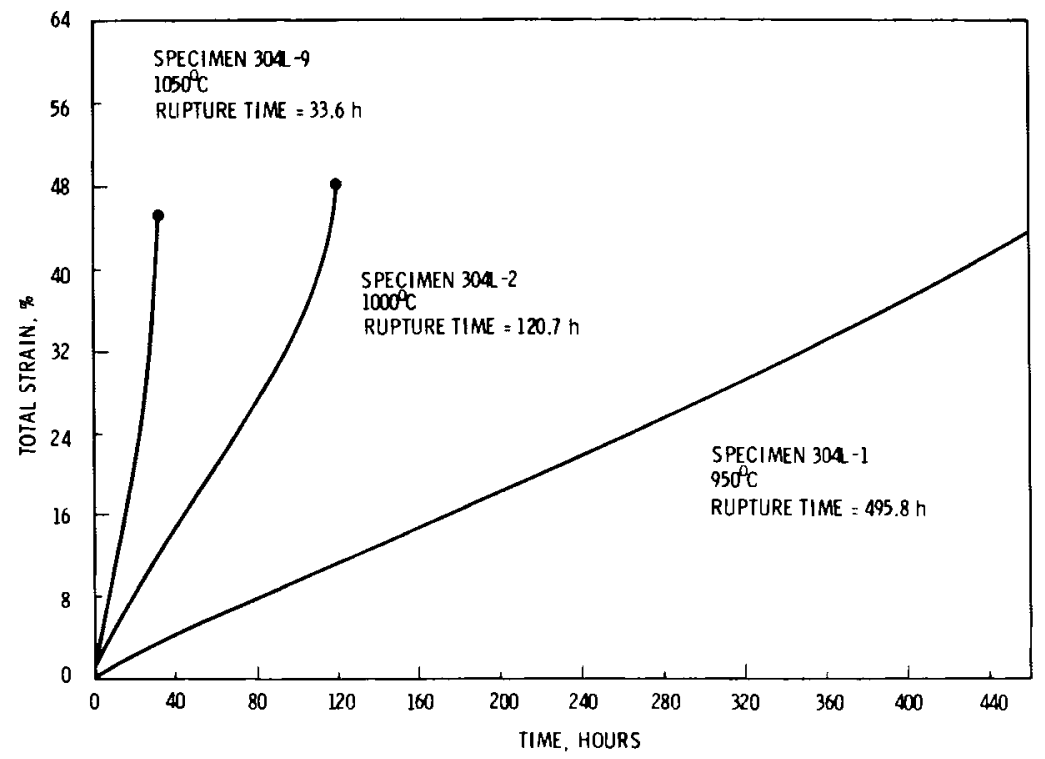

FIGURE D.3. Creep Curves for 304L Stainless Steel Plate (1/2 in.) Tested at $950^{\circ}$, $1000^{\circ}$ and $1050^{\circ} \mathrm{C}$ and $13.8 \mathrm{MN} / \mathrm{m}^{2}(20 \mathrm{ksi})$ in Air

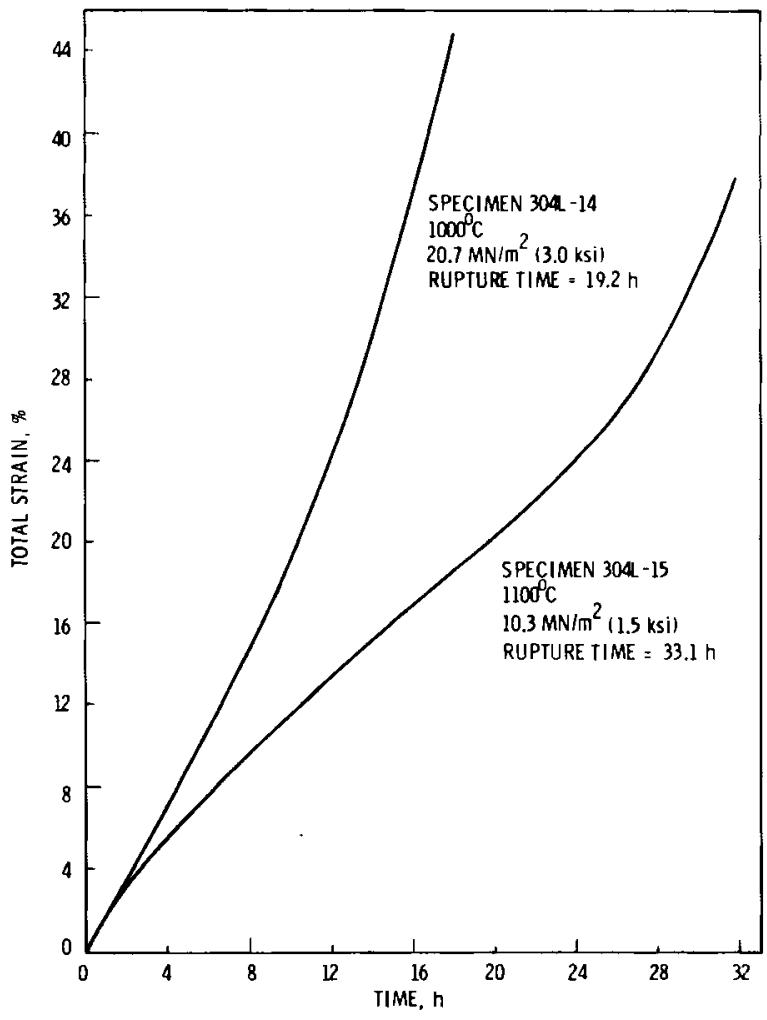

FIGURE D.4. Creep Curves for 304L Stainless Steel Plate (1/2 in.) Tested in Air at $1000^{\circ} \mathrm{C}-20.7 \mathrm{MN} / \mathrm{m}^{2}(3.0 \mathrm{ksi})$ and $1100^{\circ} \mathrm{C}-10.3 \mathrm{MN} / \mathrm{m}^{2}(1.5 \mathrm{ksi})$

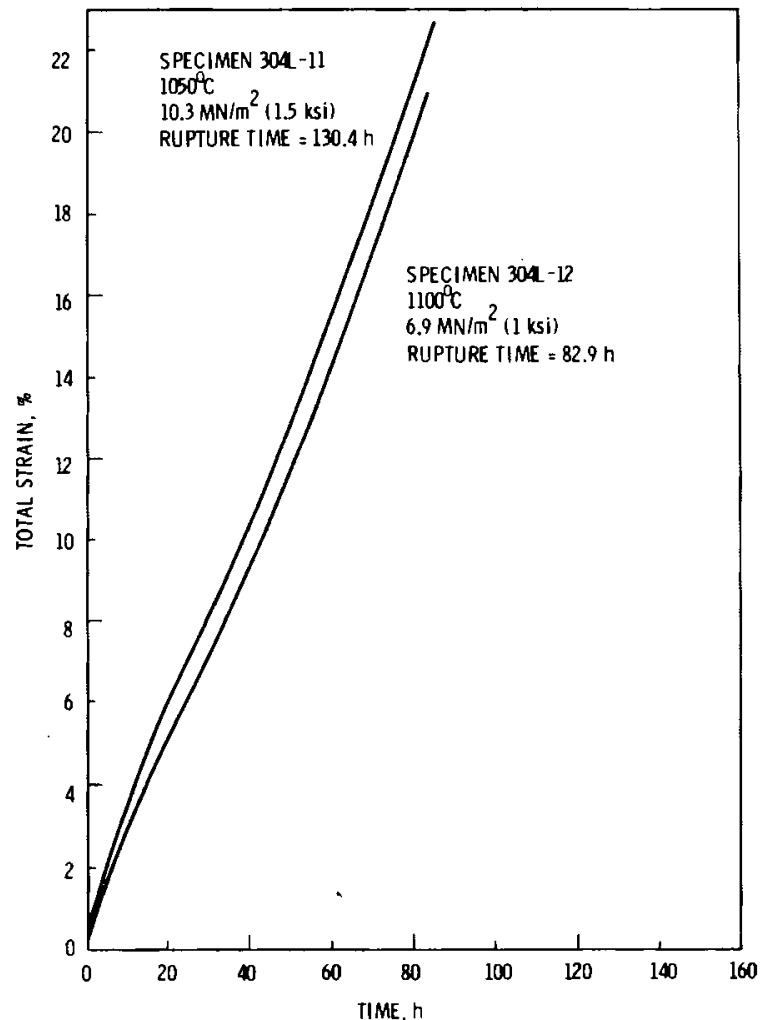

FIGURE D.5. Creep Curves for 304L Stainless Steel Plate (1/2 in.) Tested in Air at $1050^{\circ}$ and $1100^{\circ} \mathrm{C}$ 


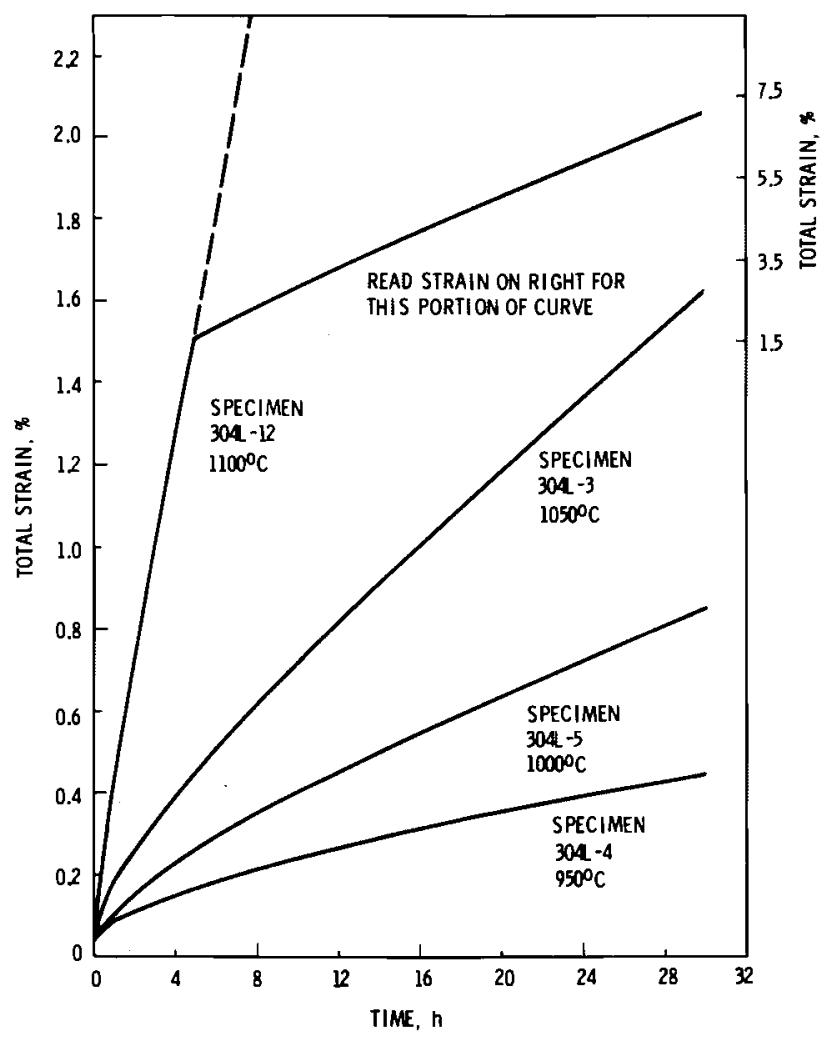

FIGURE D.6. Creep Curves for 304L Stainless steel Plate ( $1 / 2$ in.) Tested in Air at $950^{\circ}, 1000^{\circ}$, $1050^{\circ}$ and $1100^{\circ} \mathrm{C}$ and $6.9 \mathrm{MN} / \mathrm{m}^{2}$ (1.0 ksi)

FIGURE D.7. Creep Curves for 304L Stainless Steel Plate (1/2 in.) Tested in Air at $950^{\circ}, 1000^{\circ}$, $1050^{\circ}$ and $1100^{\circ} \mathrm{C}$ and $1.38 \mathrm{MN} / \mathrm{m}^{2}$ $(0.2 \mathrm{ksi})$ and $3.45 \mathrm{MN} / \mathrm{m}^{2}(0.5 \mathrm{ksi})$

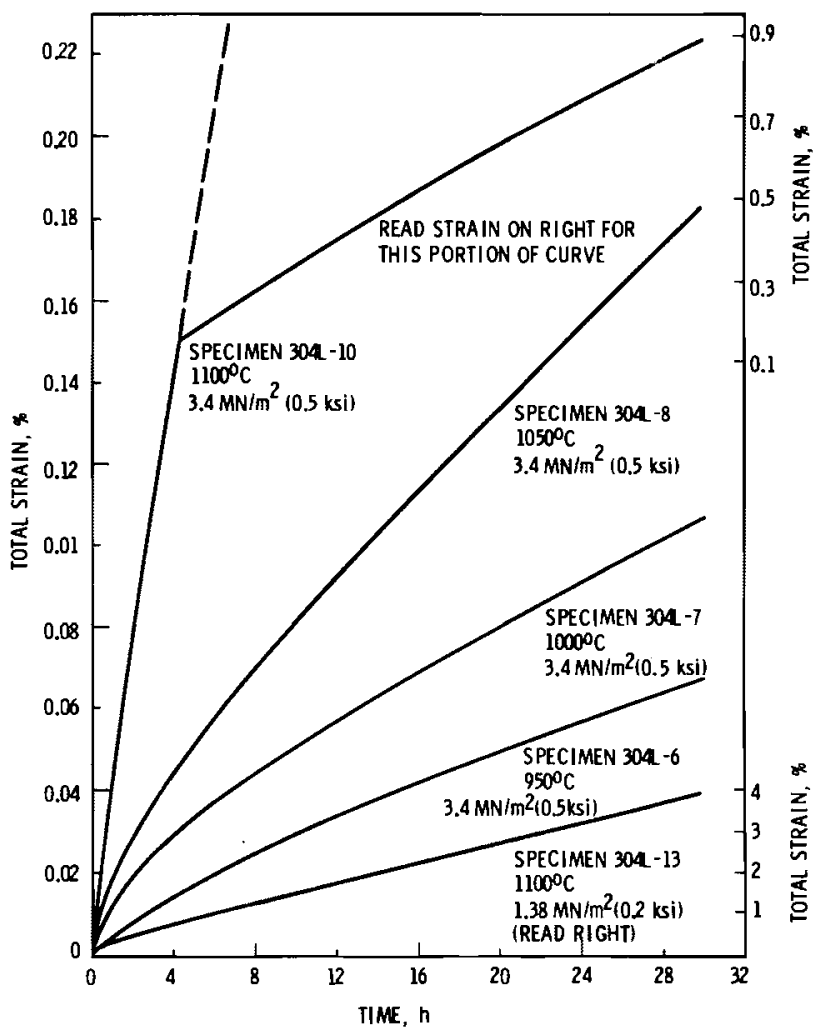




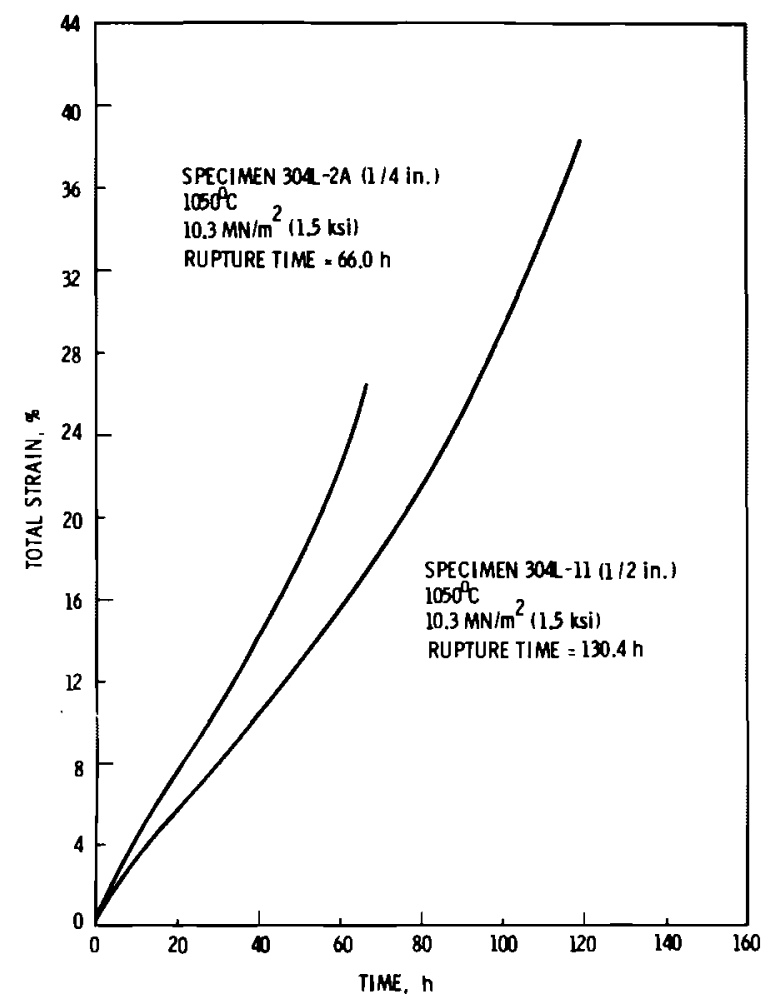

FIGURE D.8. Relative Creep Strengths of 1/4-in. and 1/2-in. 304L Stainless Stee 1 Plate Tested in Air at $1050^{\circ} \mathrm{C}$ and $10.3 \mathrm{MN} / \mathrm{m}^{2}(1.5 \mathrm{ksi})$

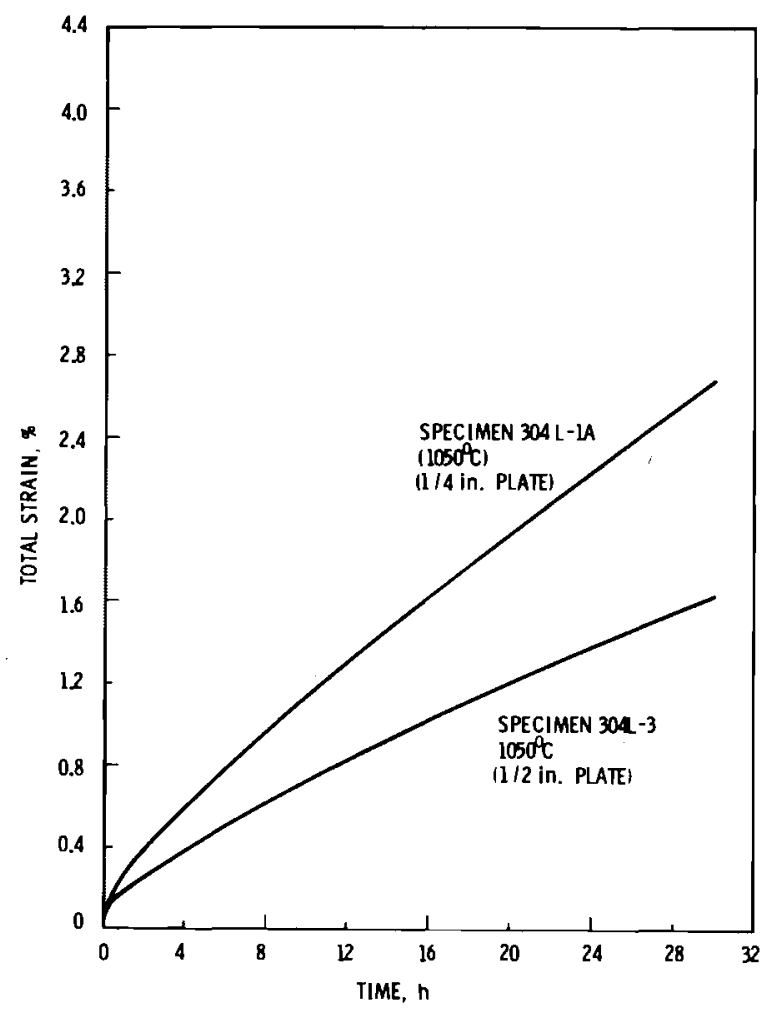

FIGURE D.9. Effect of Plate Thickness (1/4 vs. $1 / 2$ in.) On the Creep Strength of $304 \mathrm{~L}$ Stainless Steel at $1050^{\circ} \mathrm{C}$ and $6.9 \mathrm{MN} / \mathrm{m}^{2}(1.0 \mathrm{ksi})$

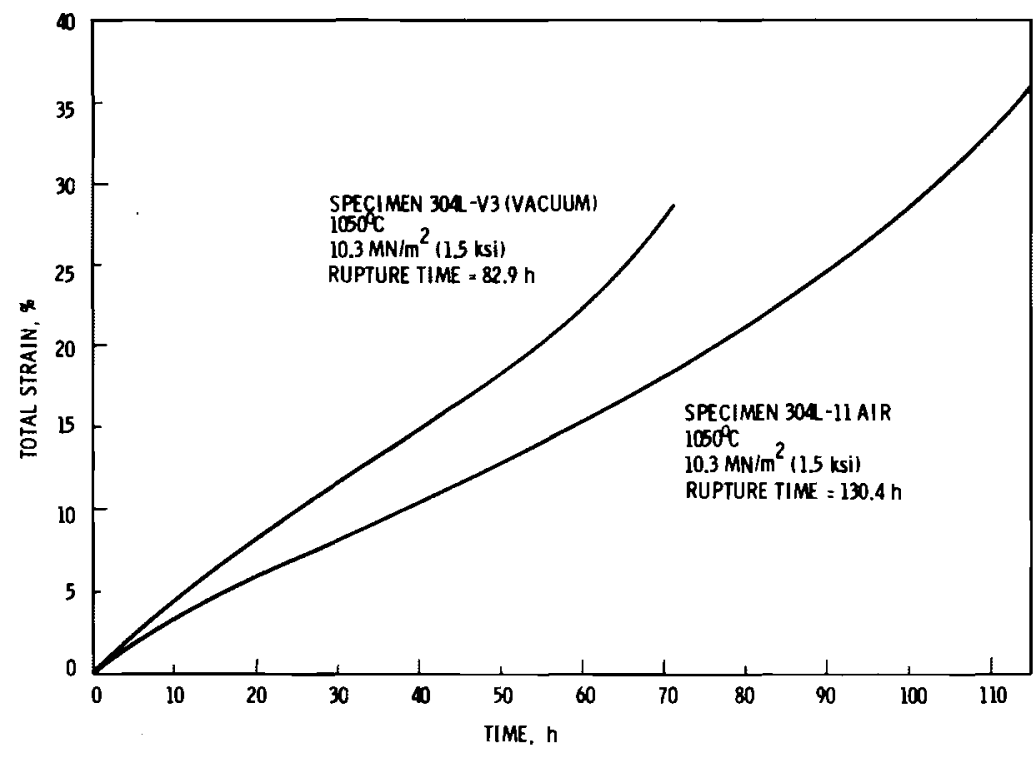

FIGURE D.10. Effect of Vacuum Versus Air Environment on the Creep Strength of $304 \mathrm{~L}$ Stainless Steel Plate $(1 / 2 \mathrm{in.})$ at $1050^{\circ} \mathrm{C}$ and $10.3 \mathrm{MN} / \mathrm{m}^{2}(1.5 \mathrm{ksi})$ 


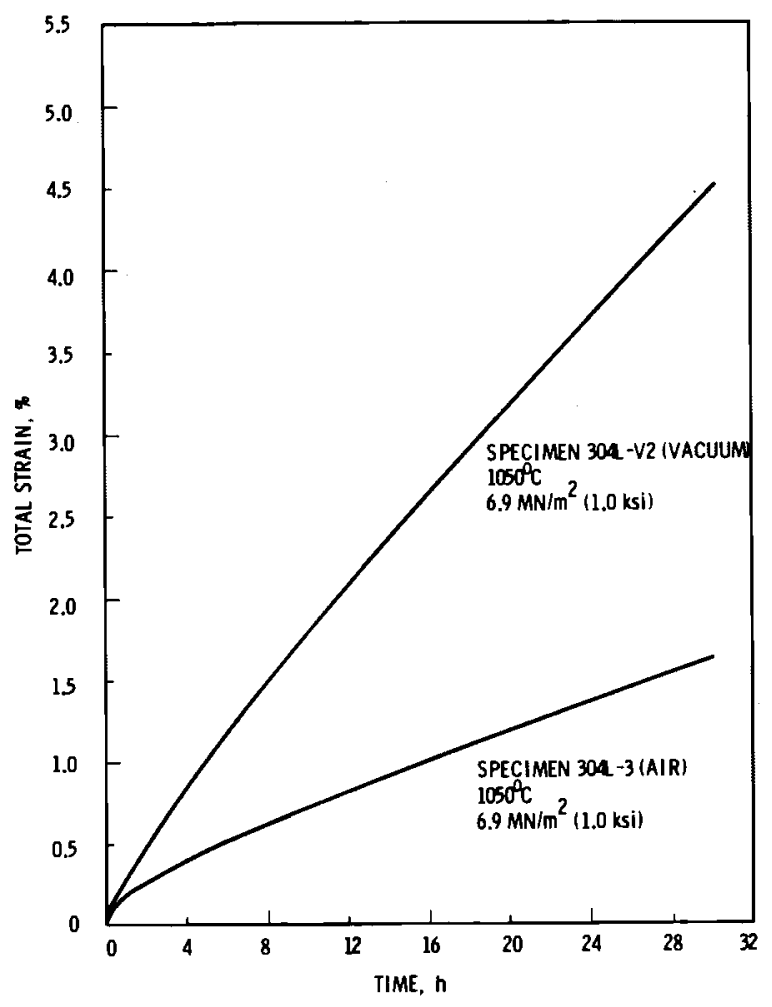

FIGURE D.11. Effect of Vacuum Versus Air Environment on the Creep Strength of $304 \mathrm{~L}$ Stainless Steel Plate $\left(1 / 2\right.$ in.) at $1050^{\circ} \mathrm{C}$ and $6.9 \mathrm{MN} / \mathrm{m}^{2}(1.0 \mathrm{ksi})$

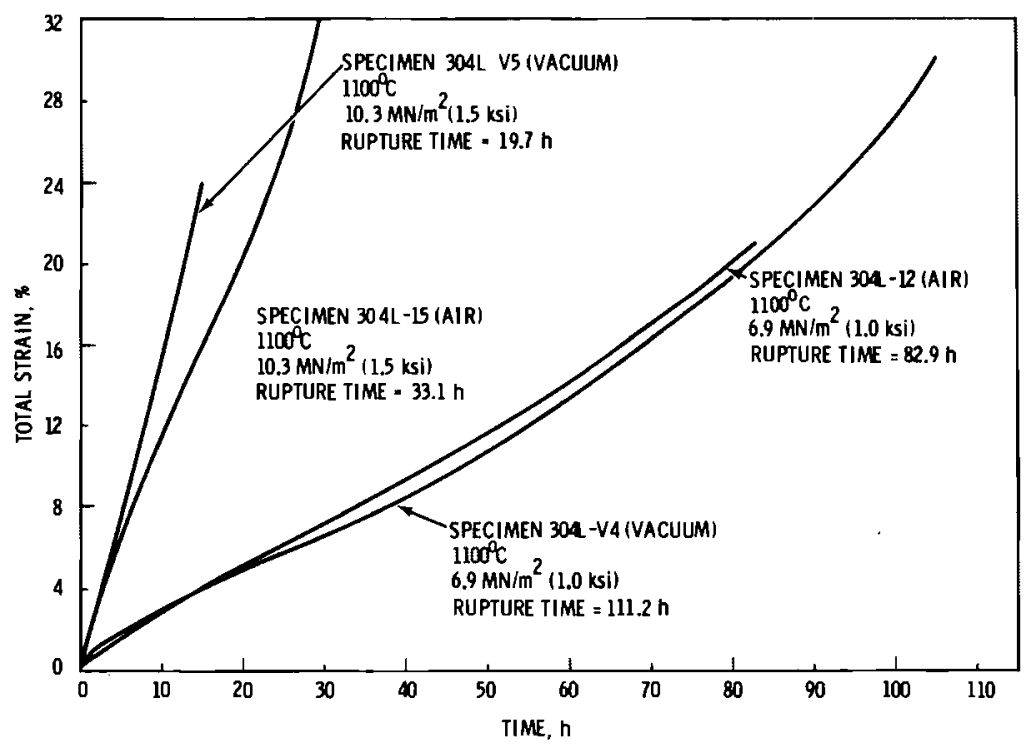

FIGURE D.12. Effect of Vacuum Versus Air Environment On the Creep Strength of 304L Stainless Steel Plate (1/2 in.) at $1100^{\circ} \mathrm{C}$ 


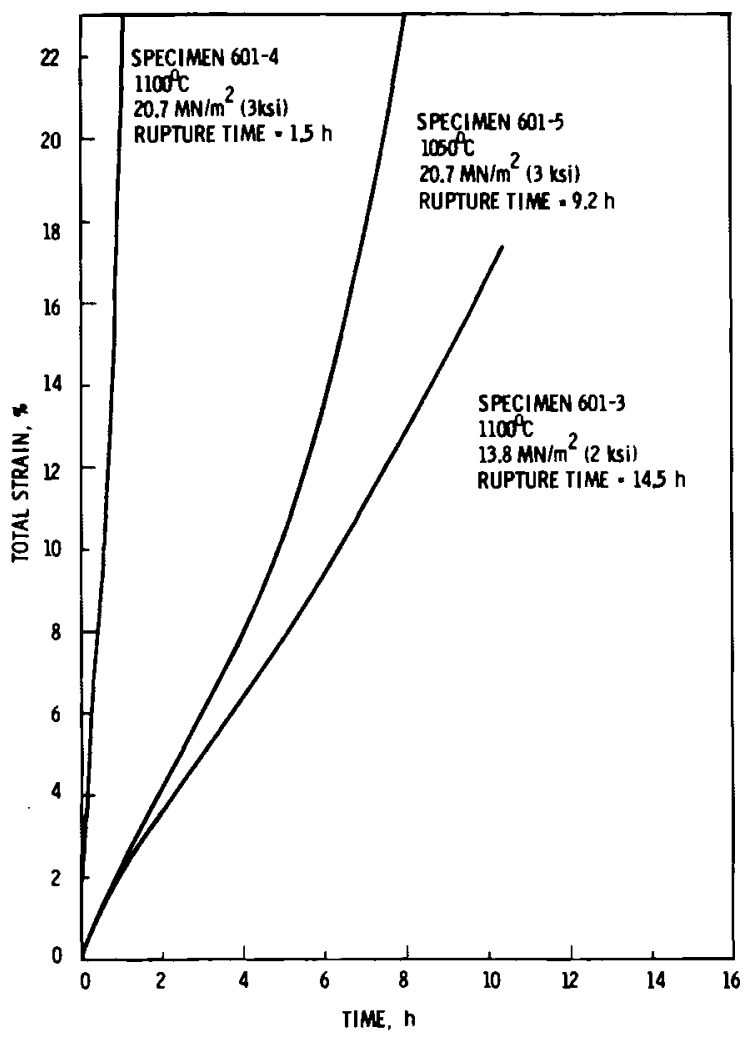

FIGURE D.13. Creep Curves for Inconel 601 Plate (1/4 in.) Tested in Air at $1050^{\circ}$ and $1100^{\circ} \mathrm{C}$

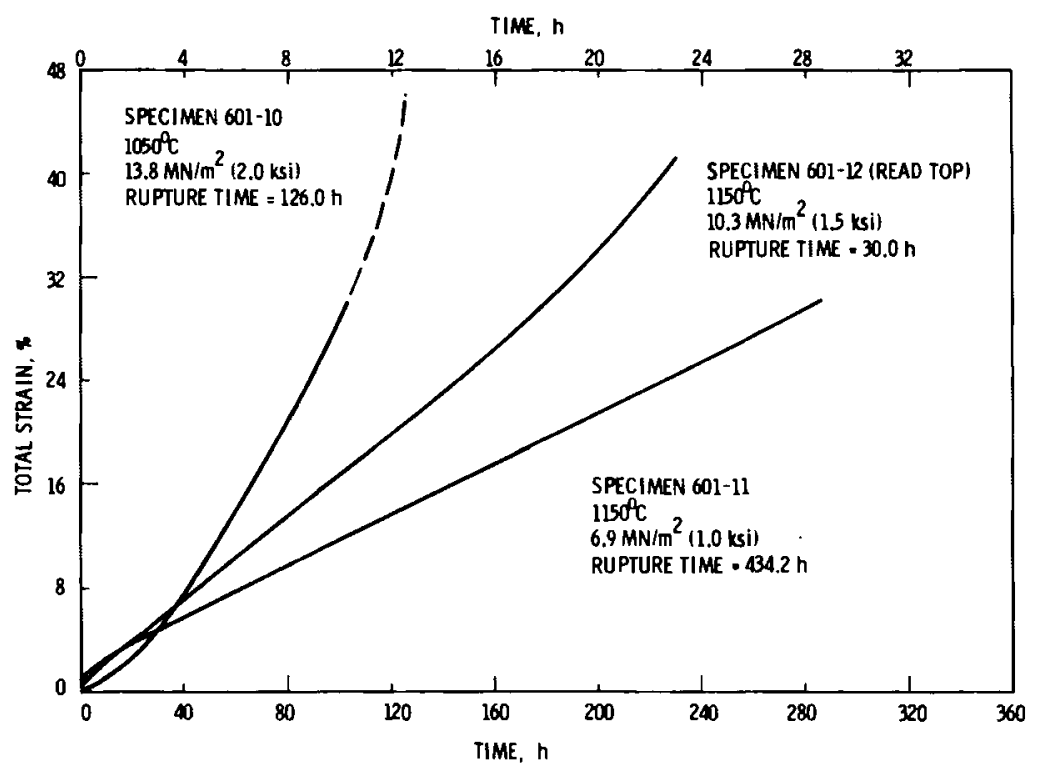

FIGURE 0.14. Creep Curves for Inconel 601 Plate (1/4 in.) Tested at $1050^{\circ}$ and $1150^{\circ} \mathrm{C}$ in Air 


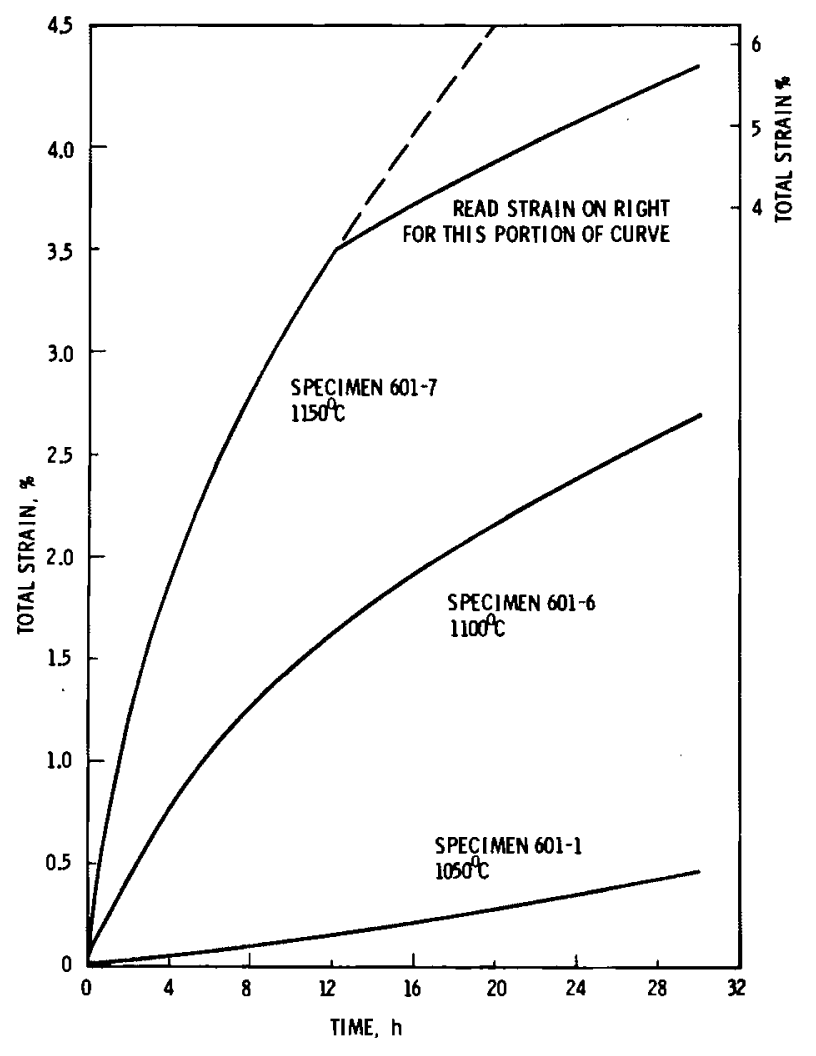

FIGURE D.15. Creep Curves for Incone 601 Plate (1/4 in.)

Tested in Air at $1050^{\circ}, 1100^{\circ}$ and $1150^{\circ} \mathrm{C}$ and $6.9 \mathrm{MN} / \mathrm{m}^{2}$ $(1.0 \mathrm{ksi})$

FIGURE D.16. Creep Curves for Inconel 601 Plate $(1 / 4$ in.) Tested in Air at $1050^{\circ}, 1100^{\circ}$ and $1150^{\circ} \mathrm{C}$.

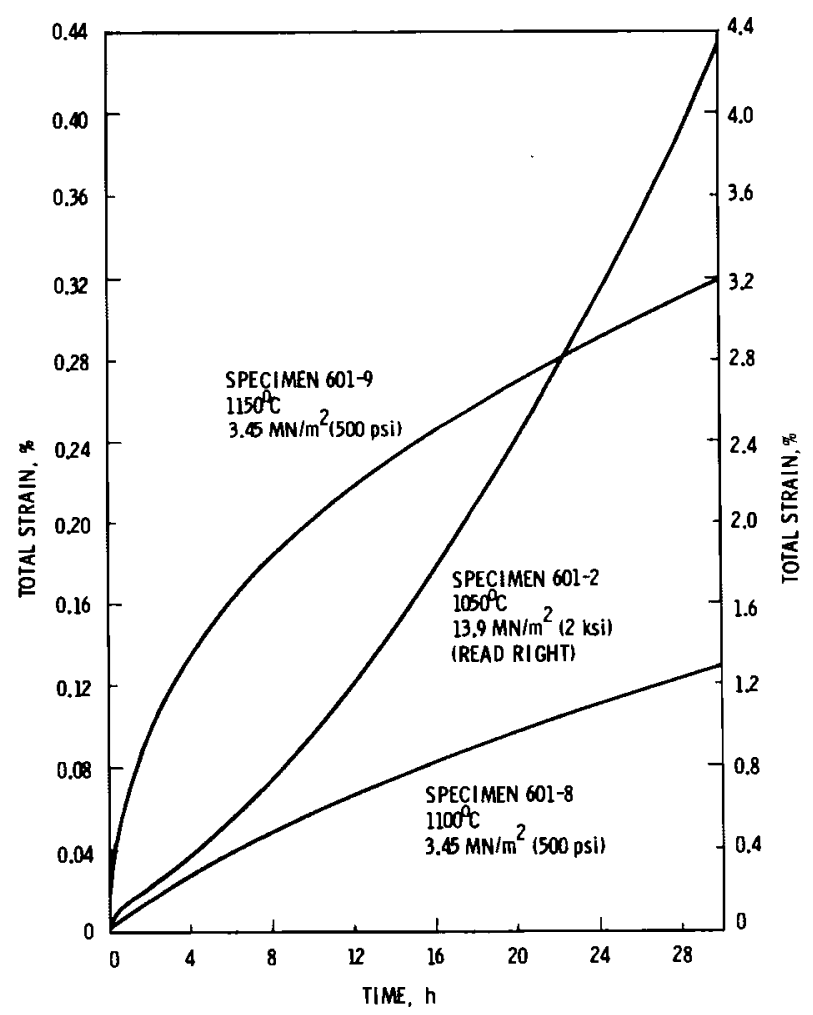




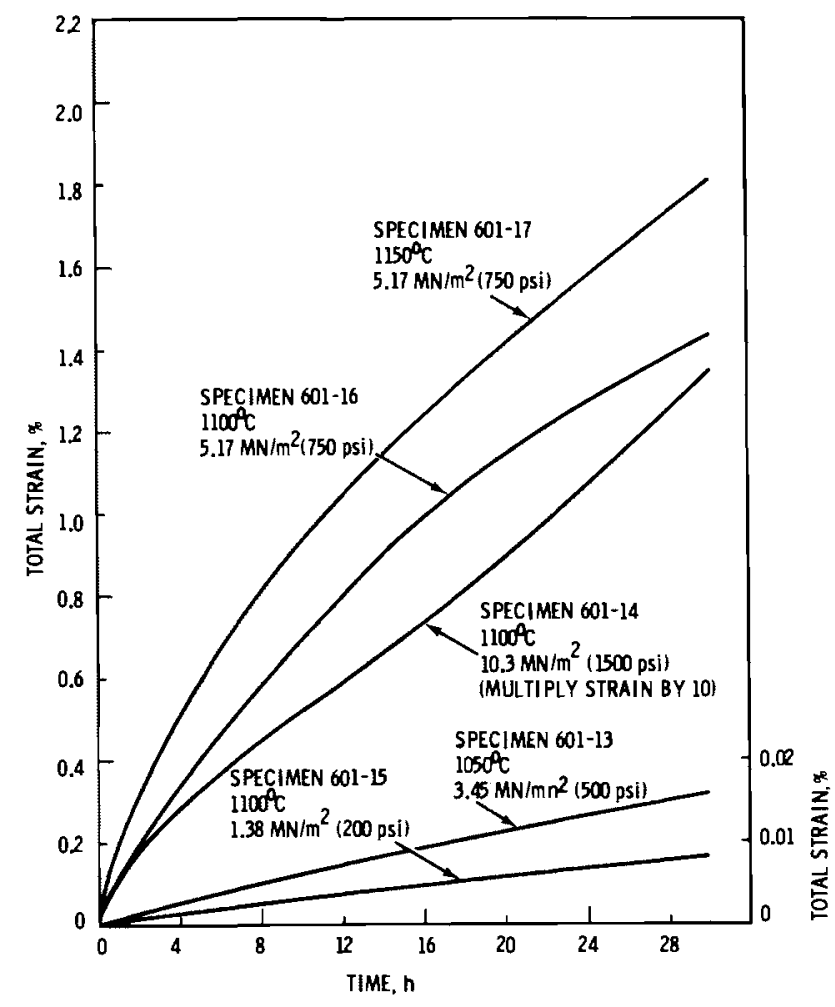

FIGURE D.17. Creep Curves for Incone 1601 Plate (1/4 in.) Tested in Air at $1100^{\circ}$ and $1150^{\circ} \mathrm{C}$

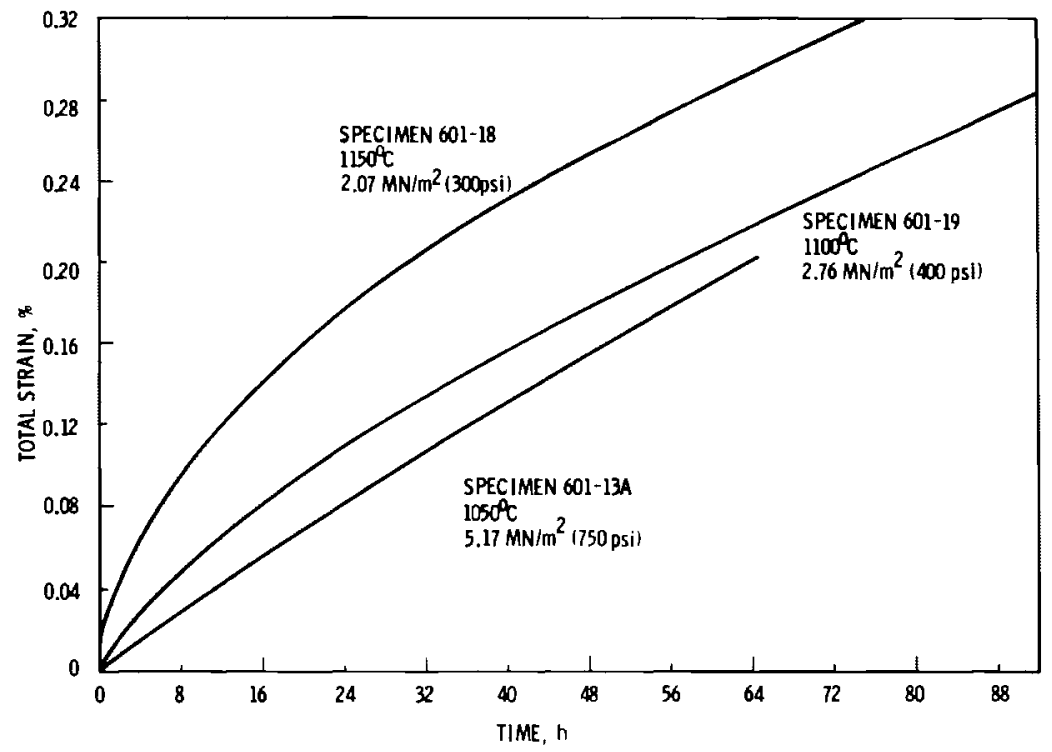

FIGURE D.18. Creep Curves for Incone 1601 Plate ( $1 / 4$ in.) Tested in Air at $1050^{\circ}, 1100^{\circ}$ and $1150^{\circ} \mathrm{C}$ 
High-temperature (to $1150^{\circ} \mathrm{C}$ or $2100^{\circ} \mathrm{F}$ ) creep-rupture values for Inconel 601 are reported in the Huntington Alloys Bullet in (International Nickel Co., Inc. 1973). Rupture times are limited to a minimum of about $50 \mathrm{~h}$ and the longest rupture time recorded in the current study is $434 \mathrm{~h}$. Based on limited data, our values show the test material to have a slightly lower rupture strength than that reported in the bulletin.

The creep-rupture strengths of these two alloys obtained in our investigation are compared with data found in the literature in the Larson-Miller Parameter Plot shown in Figure D.19. Based on this comparison, the two materials appear to be within an expected scatter band, typical of commercial heats. Slight differences in strength can be attributed to compositional and processing variations, size and stock used, specimen size and, perhaps, to other factors.

\section{Thickness Effect}

Two tests were conducted on the $1 / 4-i n$. $304 \mathrm{~L}$ plate to determine the effect of thickness on creep-rupture strength. Specimen $304 \mathrm{~L}-2 \mathrm{~A}$ was tested at $1050^{\circ} \mathrm{C}\left(1922^{\circ} \mathrm{F}\right)$ and $10.3 \mathrm{MN} / \mathrm{m}^{2}$ (1500 psi) for comparison with test $304 \mathrm{~L}-11$ under the same conditions. The results are summarized in Table D.1. (The creep curves for both tests are given in Figure D.8.) The 1/4-in. plate has a higher creep rate $(0.32 \%$ vs. $0.23 \% / h)$, and about one-half the rupture time ( 66.0 vs. $130.4 \mathrm{~h}$ ) of the 1/2-in. plate under the conditions specified. The second test (304L-1A) was carried out at a lower stress $\left(6.89 \mathrm{MN} / \mathrm{m}^{2}\right.$ or $1000 \mathrm{psi}$ ) but also at $1050^{\circ} \mathrm{C}$; the results are shown in Figure D.9. Comparison with test $304 \mathrm{~L}-3$ made under the same conditions again shows the 1/4-in. plate to have the lower strength. After $30 \mathrm{~h}$, the $1 / 4-$ in. plate crept $2.658 \%$, compared with $1.627 \%$ for the thicker $1 / 2-i n$. plate. This is probably not truly a size effect, since the two plates were from different heats of material. Chemical analyses indicate that the two plates are from different heats. The most significant difference in composition is in the molybdenum content; the $1 / 2-i n$. plate contains $0.55 \%$, compared with $0.27 \%$ for the $1 / 4-i n$. plate. The $1 / 2-i n$. plate also has more manganese (1.74\% vs. $1.33 \%)$ and more chromium (18.80\% vs. $18.10 \%)$. These compositional differences could very well be the cause of the different strengths.

\section{Vacuum Tests}

The two vacuum tests at $1050^{\circ} \mathrm{C}$ $\left(1922^{\circ} \mathrm{F}\right)$ indicate that the $304 \mathrm{~L}$ material

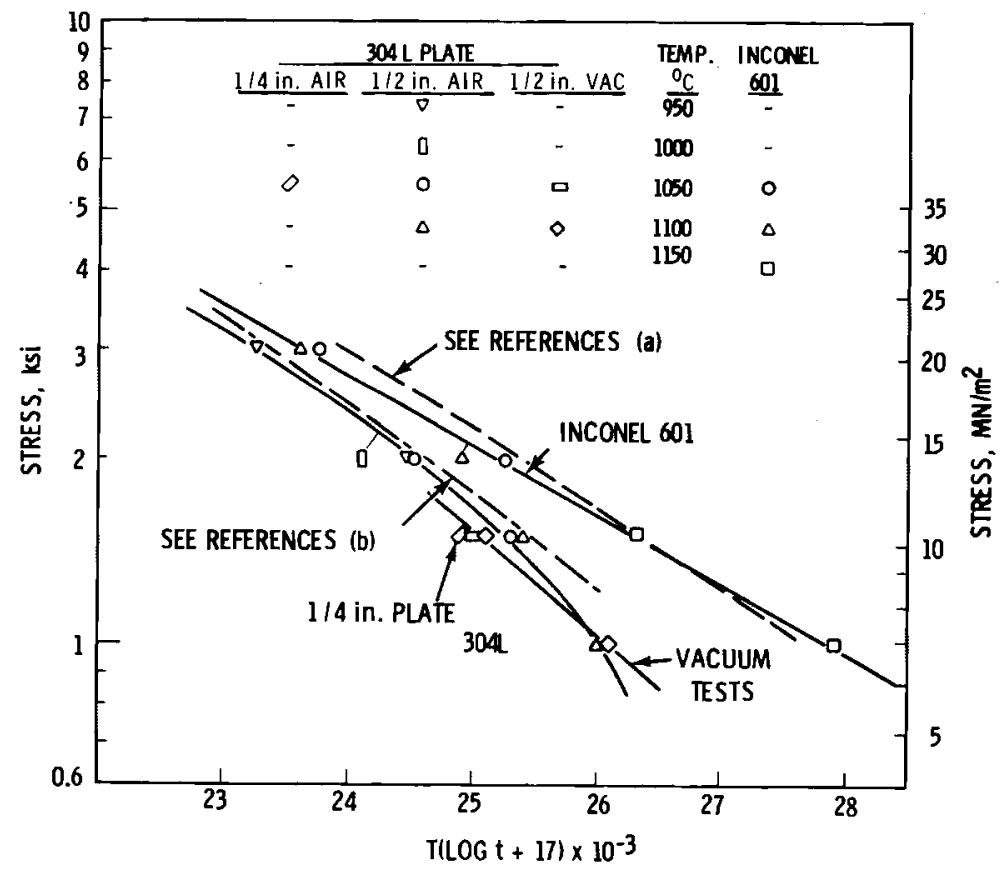

FIGURE D.19. Larson-Miller Plot of Rupture Strengths for Type 304L Stainless Steel and Inconel 601 
is moderately stronger in air than in vacuum. A short-time test at $1100^{\circ} \mathrm{C}\left(2012^{\circ} \mathrm{F}\right)$ shows a similar relationship. This type of behavior is expected, based on previous experience. Heat-resistant alloys are often strengthened from a nitrogen pick-up (VanEcho, Roach and Hall 1977). A longer exposure at $1100^{\circ} \mathrm{C}\left(2012^{\circ} \mathrm{F}\right)$ did not show the $304 \mathrm{~L}$ material as being stronger in air (Figure D.12), which may appear to be an inconsistency. Visual examination of specimen 304L-12 tested in air indicated that the material scaled heavily at $1100^{\circ} \mathrm{C}\left(2012^{\circ} \mathrm{F}\right)$. This resulted in a reduction in crosssection, which produced a gradual increase in the stress level. As Figure D.12 shows, the specimen tested in air was stronger during the early stages when the crosssection was essentially unchanged.

The tested specimens were examined visually for surface condition. Most of the $304 \mathrm{~L}$ specimens tested at $950^{\circ}, 1000^{\circ}$ and $1050^{\circ} \mathrm{C}\left(1742^{\circ}, 1832^{\circ}\right.$ and $\left.1922^{\circ} \mathrm{F}\right)$ appeared in good condition, with only a slight oxide coating on the surface. Specimen $304 \mathrm{~L}-11$, which was tested at $1050^{\circ} \mathrm{C}\left(1922^{\circ} \mathrm{F}\right)$ for $130.4 \mathrm{~h}$, and all specimens tested at $1100^{\circ} \mathrm{C}$ $\left(2012^{\circ} \mathrm{F}\right)$ were moderately scaled and pitted and nearly all of the exposed threads had deteriorated away. Specimen 304L-12, which had been exposed to $1100^{\circ} \mathrm{C}$ (2012 ${ }^{\circ} \mathrm{F}$ ) for $82.9 \mathrm{~h}$, was badly scaled, with numerous deep pits. It is very likely that the creeprupture results were affected by the reduced cross-section in this specimen. All of the Inconel 601 specimens, including those tested at $1150^{\circ} \mathrm{C}\left(2102^{\circ} \mathrm{F}\right)$, had a good surface appearance, with only a light oxide coating on the surface. However, all the ruptured specimens had numerous cracks throughout the entire gage length.

\section{Design Curves}

Design curves were prepared for both $304 \mathrm{~L}$ and Incone 1601 , shown in Figures D.20, D.21 and 0.22 . These curves allow a designer to select a stress which will produce a limiting amount of creep strain at a particular temperature. Creep strains of $0.2 \%, 0.5 \%$, $1.0 \%, 2 \%$, and $10 \%$ were chosen from the creep curves. 0ther creep strains can be chosen from the creep curves and similar design curves constructed. The effect of air exposure at $1100^{\circ} \mathrm{C}\left(2012^{\circ} \mathrm{F}\right)$ on the $304 \mathrm{~L}$ material is evident in the $1100^{\circ} \mathrm{C}$ design curves (Figure D.21). The slopes of the curves increase from a linear relationship at long times, represented by the dotted lines. The stress on the specimen, initially stressed at $1.38 \mathrm{MN} / \mathrm{m}^{2}$ (200 psi) was gradually increasing as scaling progressed and creep occurred more rapidly.

\section{Isochronous Stress-Strain Curves}

For structural analys is purposes, representation of creep data using isochronous stress-strain curves is often useful. Such curves are a result of plotting the value of total strain (elastic-plus-plastic-pluscreep) as a function of stress at a given constant end-of-test time. A more complete description of the generation of isochronous stress-strain curves can be found in

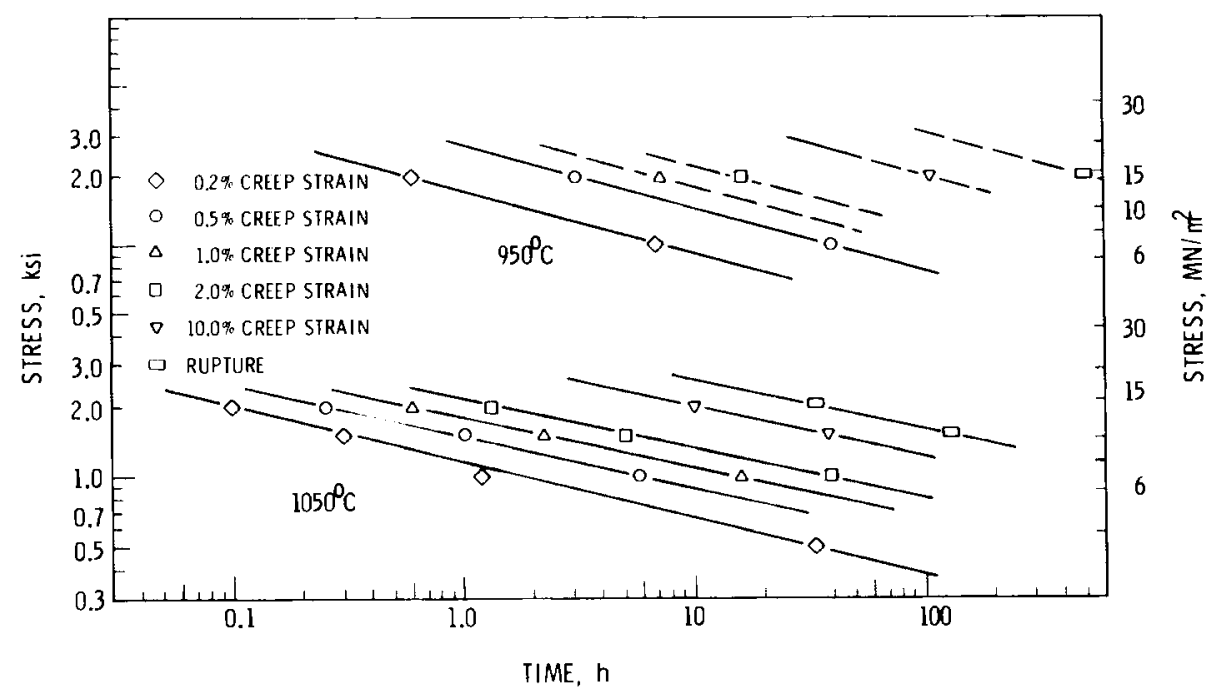

FIGURE D.20. Design Curves for 304L Stainless Steel Plate (1/2 in.) in Air 


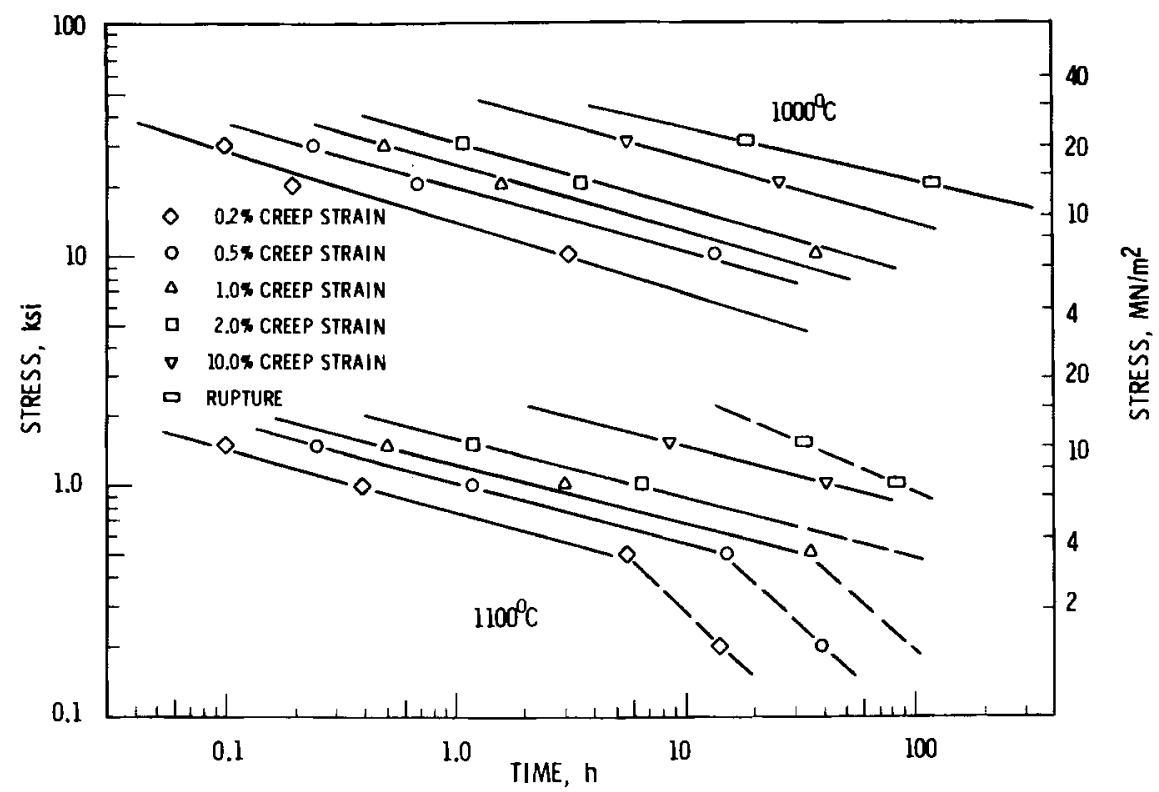

FIGURE D.21. Design Curves for 304L Stainless Steel Plate (1/2 in.) in Air

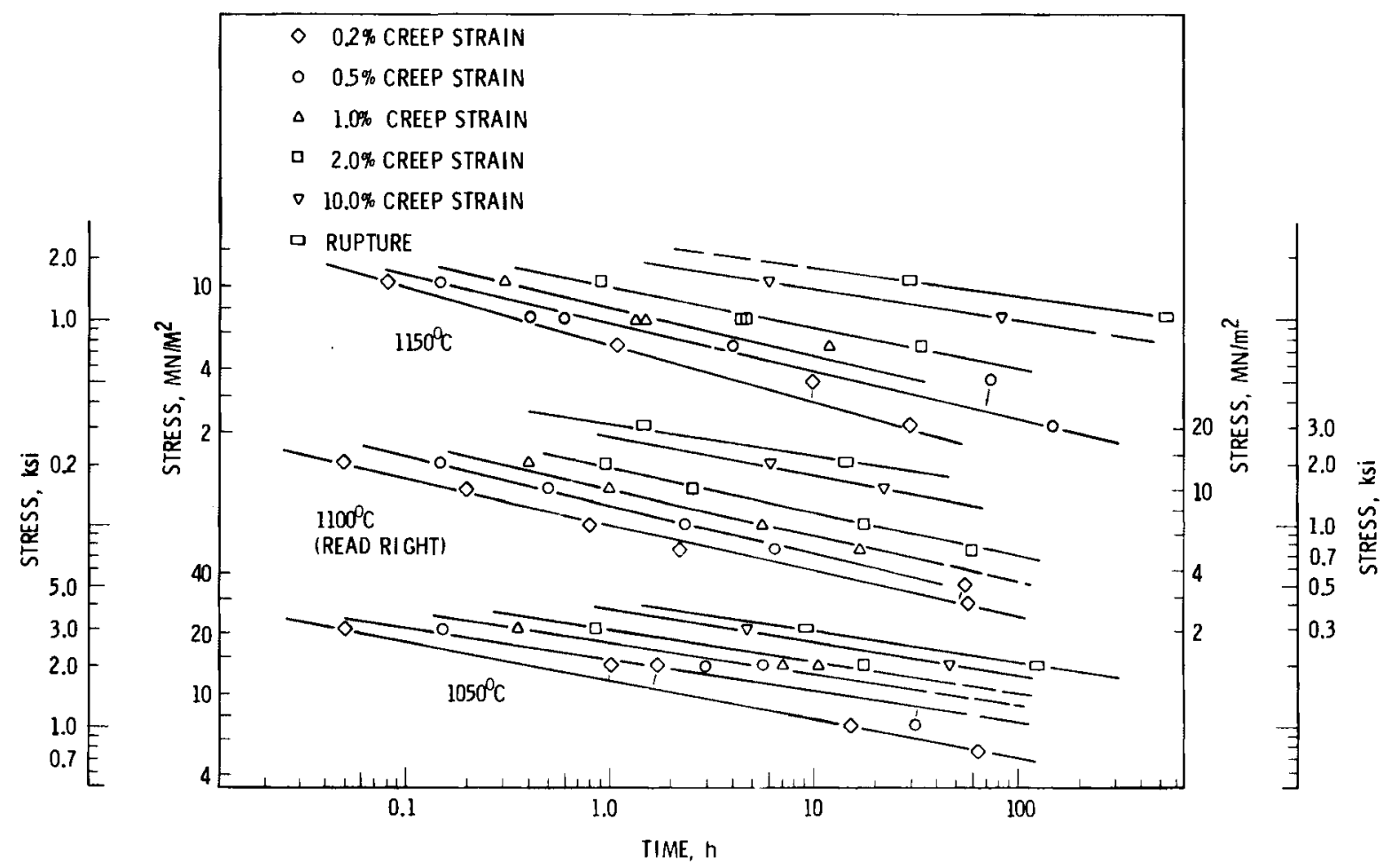

FIGURE D.22. Design Curves for Inconel $601 \mathrm{Plate}\left(1 / 4\right.$ in.) at $1050^{\circ}, 1100^{\circ}$ and $1150^{\circ} \mathrm{C}$ 
The Generation of Isochronous Stress-Strain Curves (ASME 1972).

Isochronous stress-strain curves for 304L stainless steel and Inconel alloy 601 are given in Figures D.23 to D.29. The curves cover the temperature range of $950^{\circ}$ to $1150^{\circ} \mathrm{C}\left(1742^{\circ}\right.$ to $\left.2102^{\circ} \mathrm{F}\right)$ and the time domain of $1 \mathrm{~h}$ to $100 \mathrm{~h}$. This range of time and temperature cover the conditions of interest to the filling phase of the ICM process.

\section{SUMMARY OF CREEP BEHAVIOR}

Short-time creep and creep-rupture data were obtained for two austenitic alloys. The difference in strength of the alloys was significant, with the $304 \mathrm{~L}$ stainless stee 1 being about $60 \%$ as strong as Inconel 601 . The effect of environment on the strength of 304L appears to be temperature dependent. Below $1050^{\circ} \mathrm{C}\left(1922^{\circ} \mathrm{F}\right)$ the presence of air had a strengthening effect, which is attributed to nitrogen pickup. Above $1050^{\circ} \mathrm{C}$, the loss of specimen cross-section from oxidation was significant at test times as low as $100 \mathrm{~h}$, and a noticeable reduction in life was observed.

As mentioned previously, the test program was intended specifically to provide design data for canisters used for vitrification of radioactive waste materials by the ICM process. Creep curves at design stress levels were a key output of the test program. These creep curves formed the basis for the construction of isochronous stress-strain curves. Stress-strain curves of this type have been used as input to computerized stress calculations with the objective to predict canister deformations during processing. Simonen and Slate (1977) reported the results of such calculations; excellent agreement with experimental results has been achieved.

The data base established thus far is limited in extent; however, these data have been adequate for preliminary design and for identification of process and material limitations. No single material has yet been identified for waste canister applications; thus, an in-depth material test program has not been undertaken. Once a spec if ic material or materials have been selected, a more comprehensive test program than reported here will be appropriate. It is envisioned that factors such as heat-to-heat strength variations will be investigated. Other factors of potential importance are material anisotropy, weld strength and defect sensitivity.

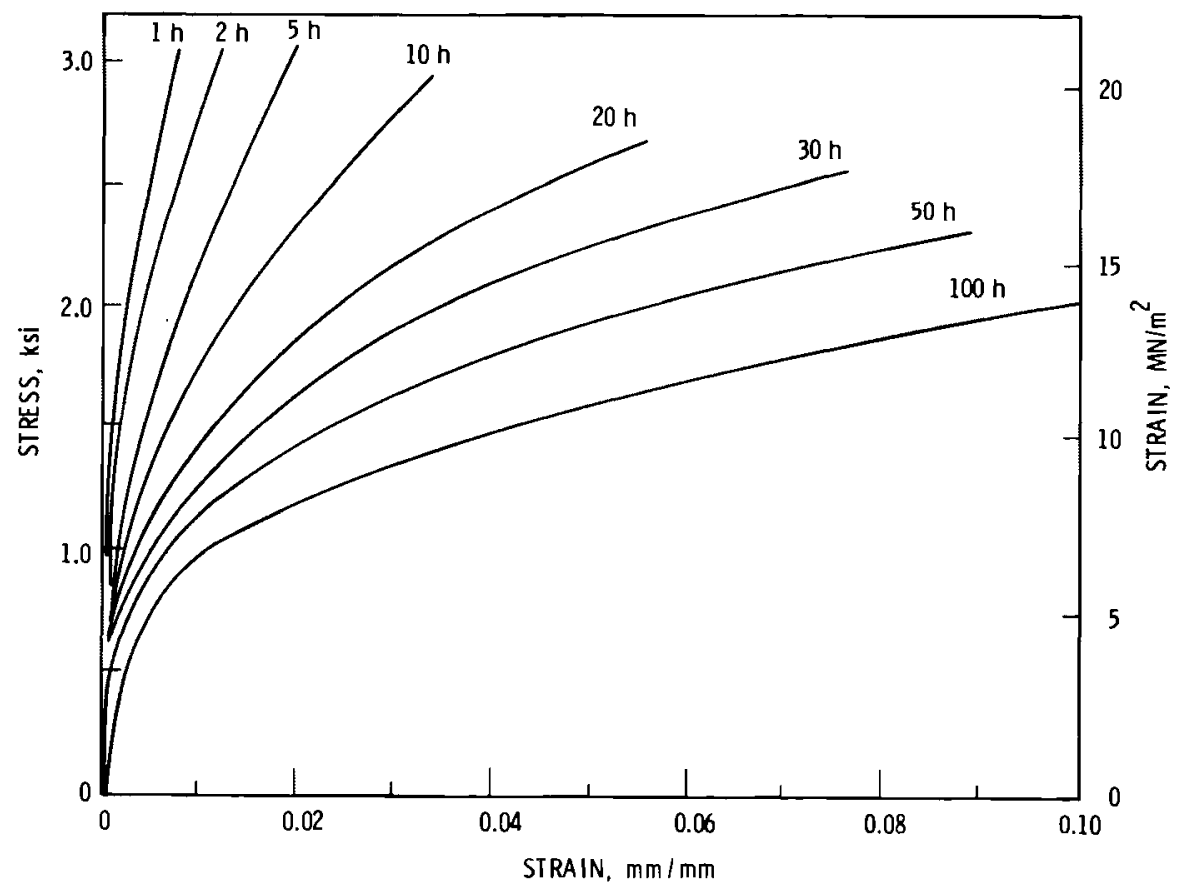

FIGURE D.23. Isochronous Stress-Strain Curves for 304L Stainless Stee 1 at $950^{\circ} \mathrm{C}$ 


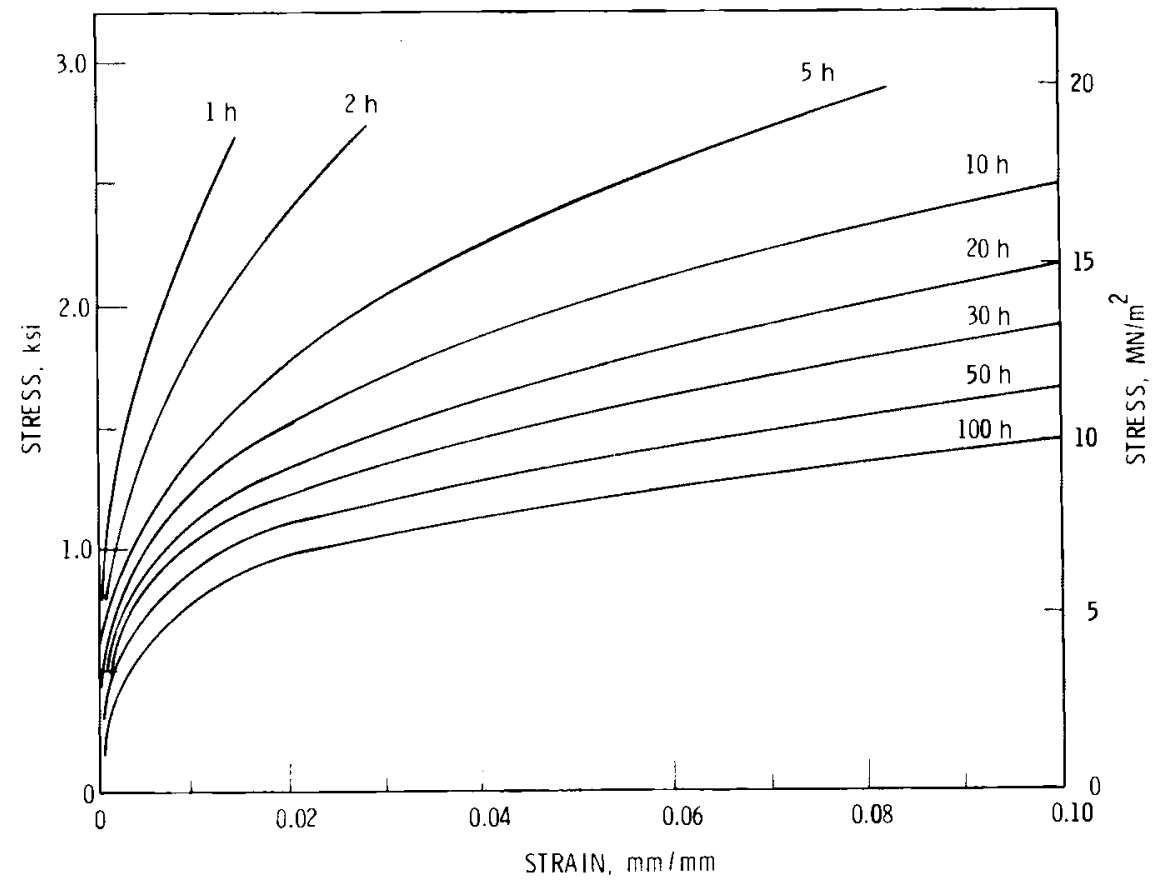

FIGURE D.24. Isochronous Stress-Strain Curves for 304L Stainless Stee 1 at $1000^{\circ} \mathrm{C}$

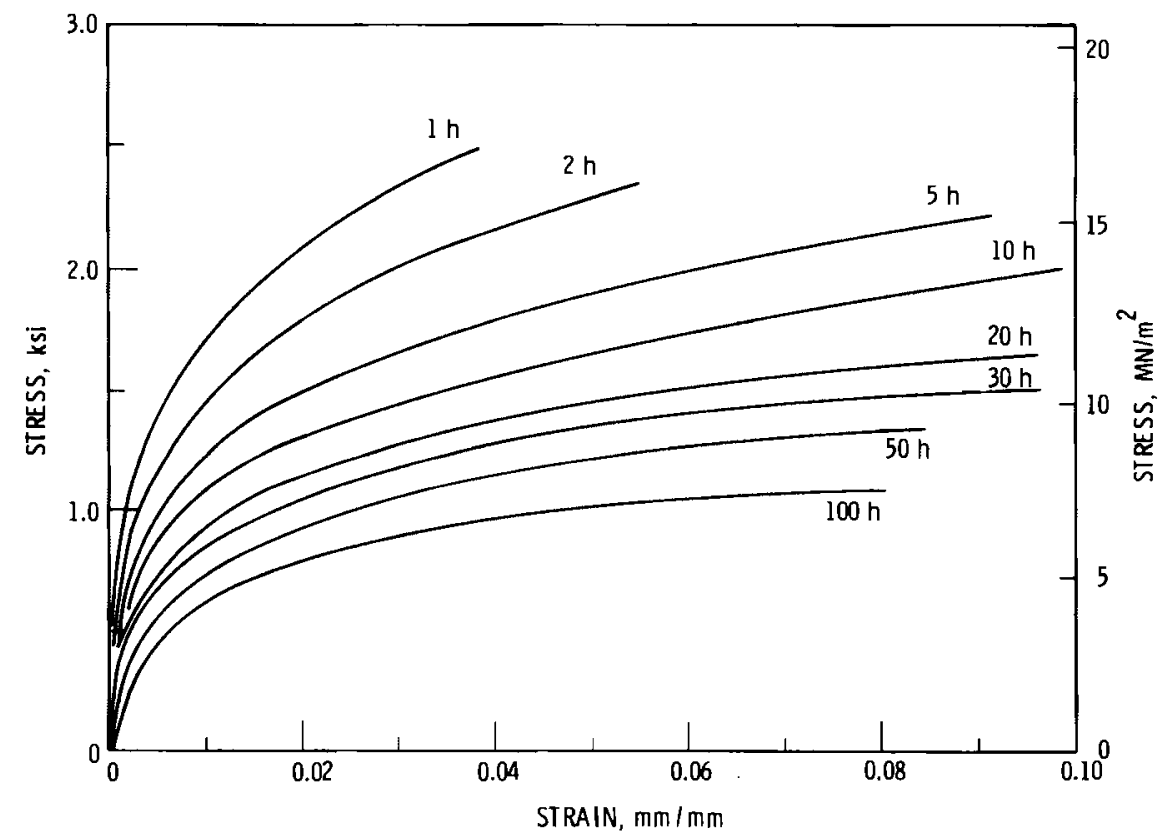

FIGURE D.25. Isochronous Stress-Strain Curves for 304L Stainless Steel at $1050^{\circ} \mathrm{C}$ 


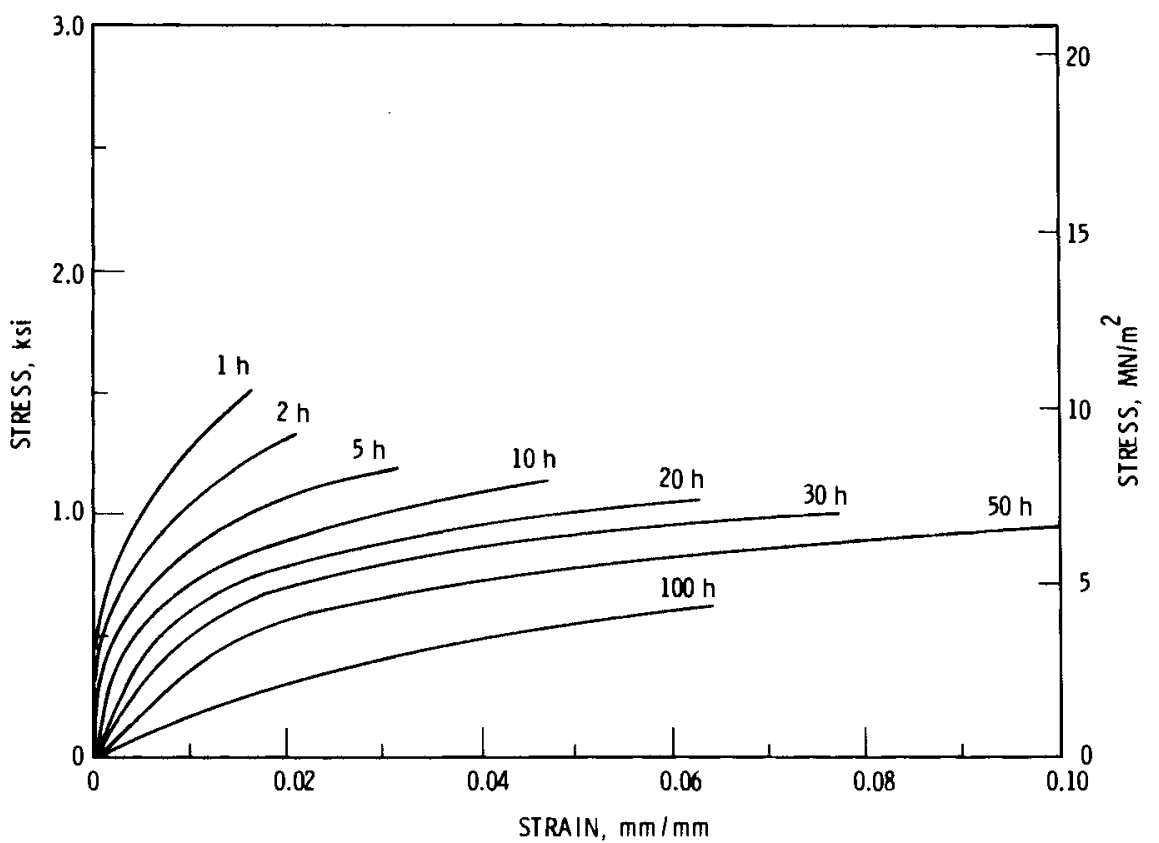

FIGURE D.26. Isochronous Stress-Strain Curves for 304L Stainless Steel at $1100^{\circ} \mathrm{C}$

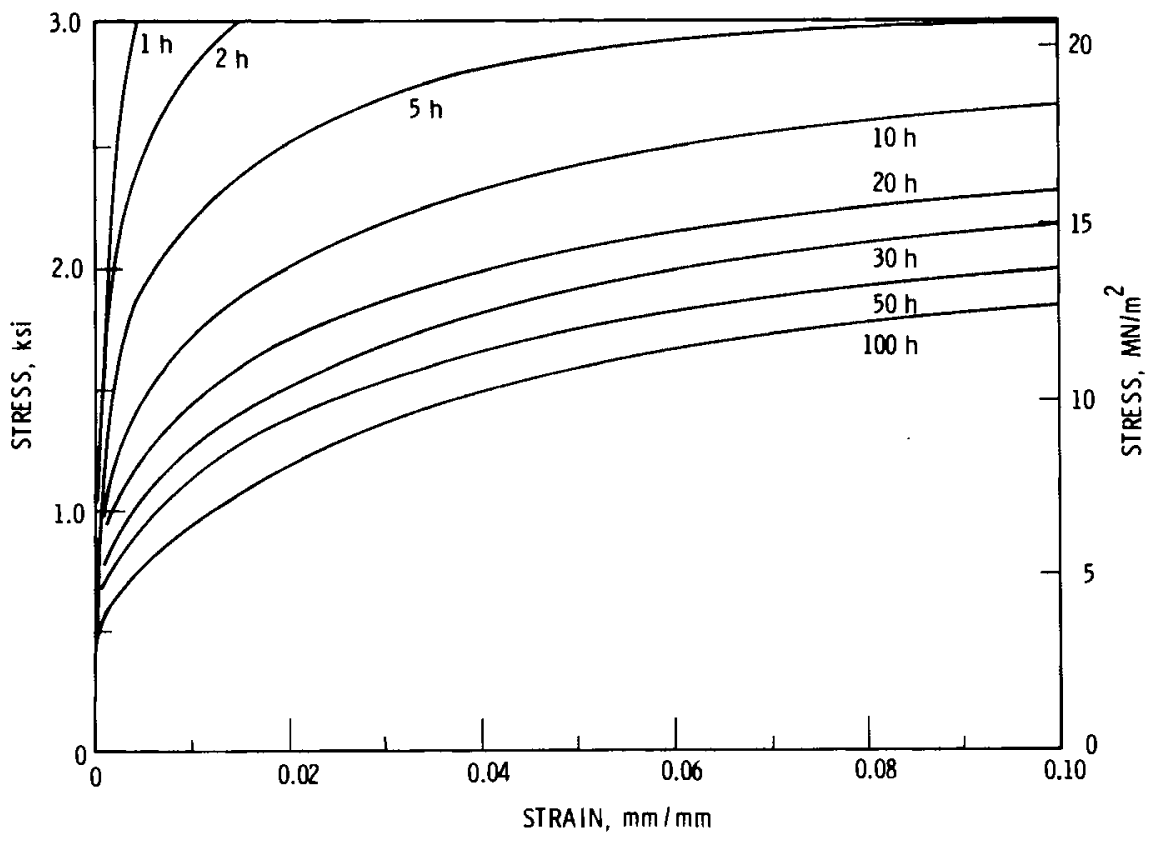

FIGURE D.27. Isochronous Stress-Strain Curves for Inconel Alloy 601 at $1050^{\circ} \mathrm{C}$ 


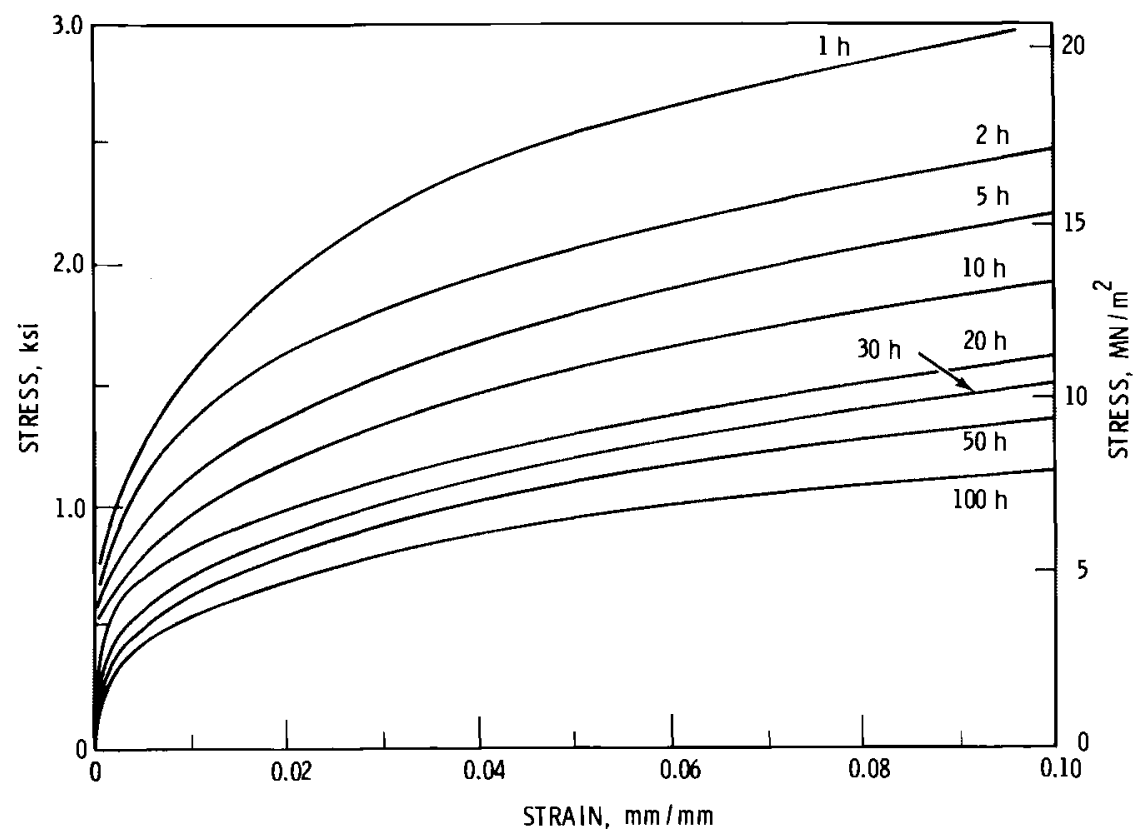

FIGURE 0.28 . Isochronous Stress-Strain Curves for Inconel Alloy 601 at $1100^{\circ} \mathrm{C}$

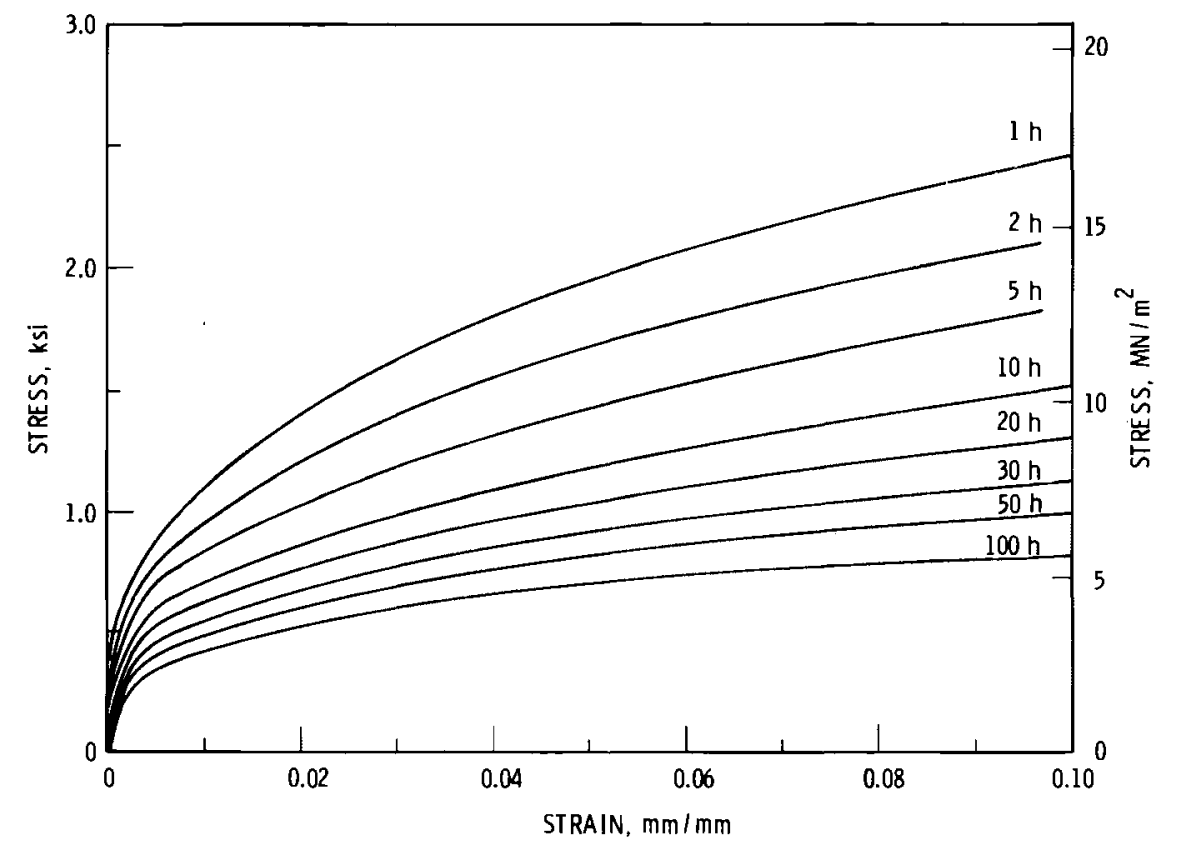

FIGURE D.29. Isochronous Stress-Strain Curves for Inconel Alloy 601 at $1150^{\circ} \mathrm{C}$ 


\section{REFERENCES}

Allegheny Ludlum Steel Corporation. 1956. Stainless Steel Handbook. Pittsburgh, Pennsylvania.

ASME. 1972. The Generation of Isochronous Stress-Strain Curves. New York, New York.

Brickner, K. S., G. A. Ratz, and R. F. Dorngala. 1965. Creep-Rupture Properties of Stainless Steels at $1600^{\circ}$, $1800^{\circ}$ and $2000^{\circ} \mathrm{F}$. ASTM STP-361, American Society for Testing and Materials, Philadelphia, Pennsylvania.

International Nickel Company, Inc. 1973. Huntington Alloys Bullet in on Inconel 601. New York, New York.

Simmons, W. F. 1968. Compilations of Chemical Compositions and Rupture Strengths of Superalloys. ASTM DS-9E, American Society for Testing and Materials, Philadelphia, Pennsylvania.
Simmons, W. F. and H. C. Cross. 1952. The Elevated Temperature Properties of Stainless Steels. ASTM STP-124, American Society for Testing and Materials, Philadelphia, Pennsylvania.

Simonen, F. A. and S. C. Slate. 1977. "Creep Analysis of Canisters for RadioActive Waste Vitrification." Trans. of the American Nuclear Society 27:259-260.

VanEcho, J. A., D. B. Roach, and A. M. Hall. 1967. "Short-Time Tensile and Long-Time Creep-Rupture Properties of the HK-40 Alloy and Type 310 Stainless Steel at Temperatures to $2000^{\circ} \mathrm{F}$." ASME Journal of Basic Engineering 89:465-479. 
APPENDIX E 
The closure system is one of the most challenging aspects of canister design. The final closure seals the glass inside the canister and must be a durable and reliable barrier to any interaction of the glass with the external environment. Closures should be designed so that they can be remotely welded and inspected. Closures must also allow connection to process equipment for filling; this connection must also be remotely operable. Thus, the closure opening in the canister top may require special configurations and features beyond those needed simply to secure and seal a lid to a canister top.

A special requirement of closure design, which is the main focus of this appendix, is that of lifting loads. In closure designs developed at PNL, it has been advantageous to include the lifting connection as an integral part of the closure system. A centrally positioned attachment point at the top of the canister adapts itself readily to remote connecting devices for lifting the canister.

The central theme of this appendix is a twist-lock closure that has been designed, fabricated, and utilized at PNL for canisters used with the ICM process. In Appendix F of this report, an analysis of the twist-lock closure for thermal stresses is described in connection with a fracture mechanics evaluation. Appendix $\mathrm{H}$ evaluates the twist-lock closure under severe internal pressure loadings that could develop under accident conditions.

Closures for use with the CM have been less extensively developed at PNL.. A flange type of closure has been used in the CM process. The final section of this appendix describes the design and stress analyses of a flange type of closure.

\section{TWIST-LOCK DESIGN}

Research at PNL has been extensively devoted to the development of a twist-lock closure for canisters used with ICM. This particular closure is described in detail here, both for its potential application for production waste canisters and as a vehicle to illustrate the various requirements any closure concept must meet.

The twist-lock design is shown schematically in Figure E.1, with prototype lids shown in Figure E.2. In this design, lifting loads are carried through lugs of the twist-lock rather than through the minimum section of the seal plate and closure weld. The 3.2-mm- (0.125-in.-) thick seal plate was selected as a convenient section limit for the GTA-type fusion weld and to provide required flexibility to the plate. For ultrasonic inspection, flat surfaces are present for positioning of transducers. The stud on the canister lid is designed to remotely connect to a lifting device. The twist-lock design has been integrated with process equipment to make the glass filling and off-gas connection. Twist-lock closures have been fabricated and tested at PNL.

Application of the lid to the filled canister and the seal-welding operation must be performed remotely. Closure designs developed at PNL have avoided filler metal in welding to simplify the design of equipment for remote welding. If a fusion weld without filler metal is used, the weld cross section will tend to be relatively small. Careful configuring of the closure weld ensures that the weld is not stressed excessively during handling of the canister.

The remote welder developed at PNL is shown in Figure E.3. The GTA process was selected since it most closely matches proposed design criteria. The GTA process is the most common method in use today for 


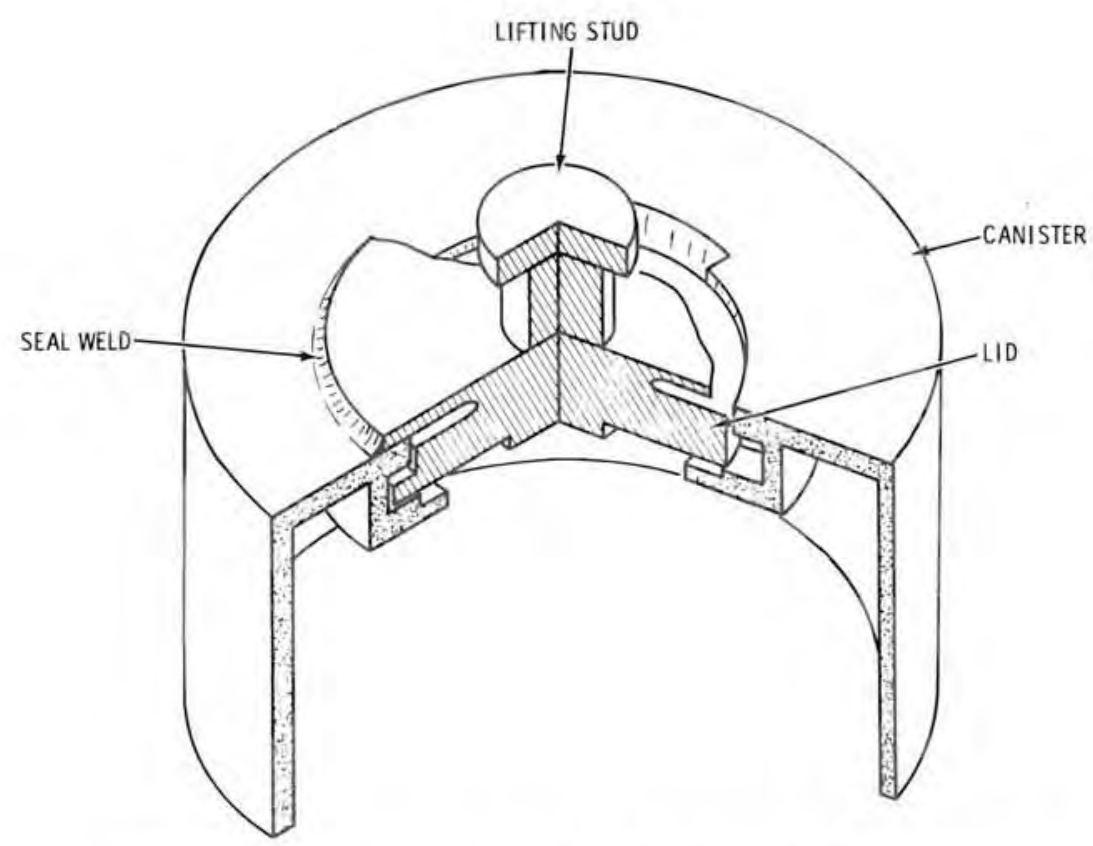

FIGURE E.1. Schematic Drawing of the Twist-Lock Closure

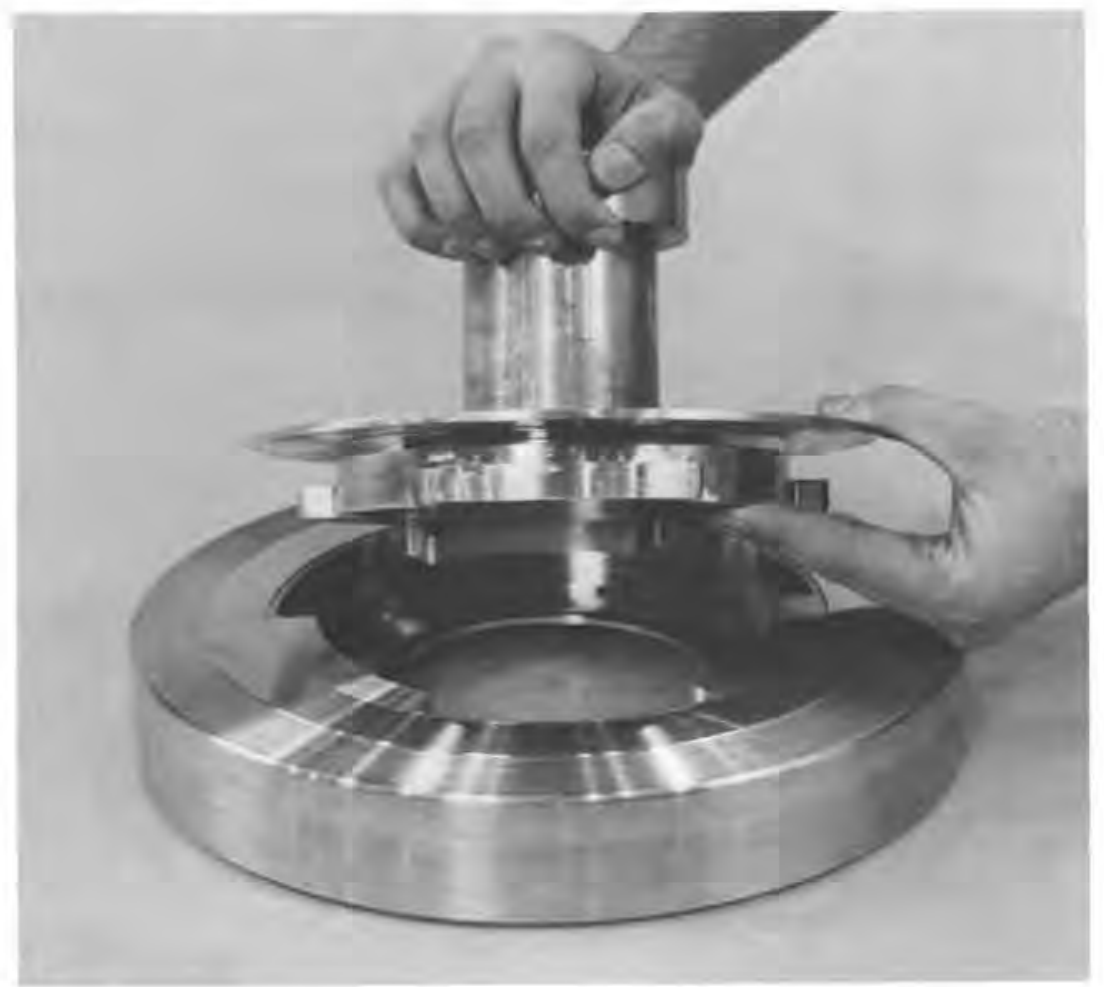

FIGURE E.2. Prototype Twist-Lock Closure 


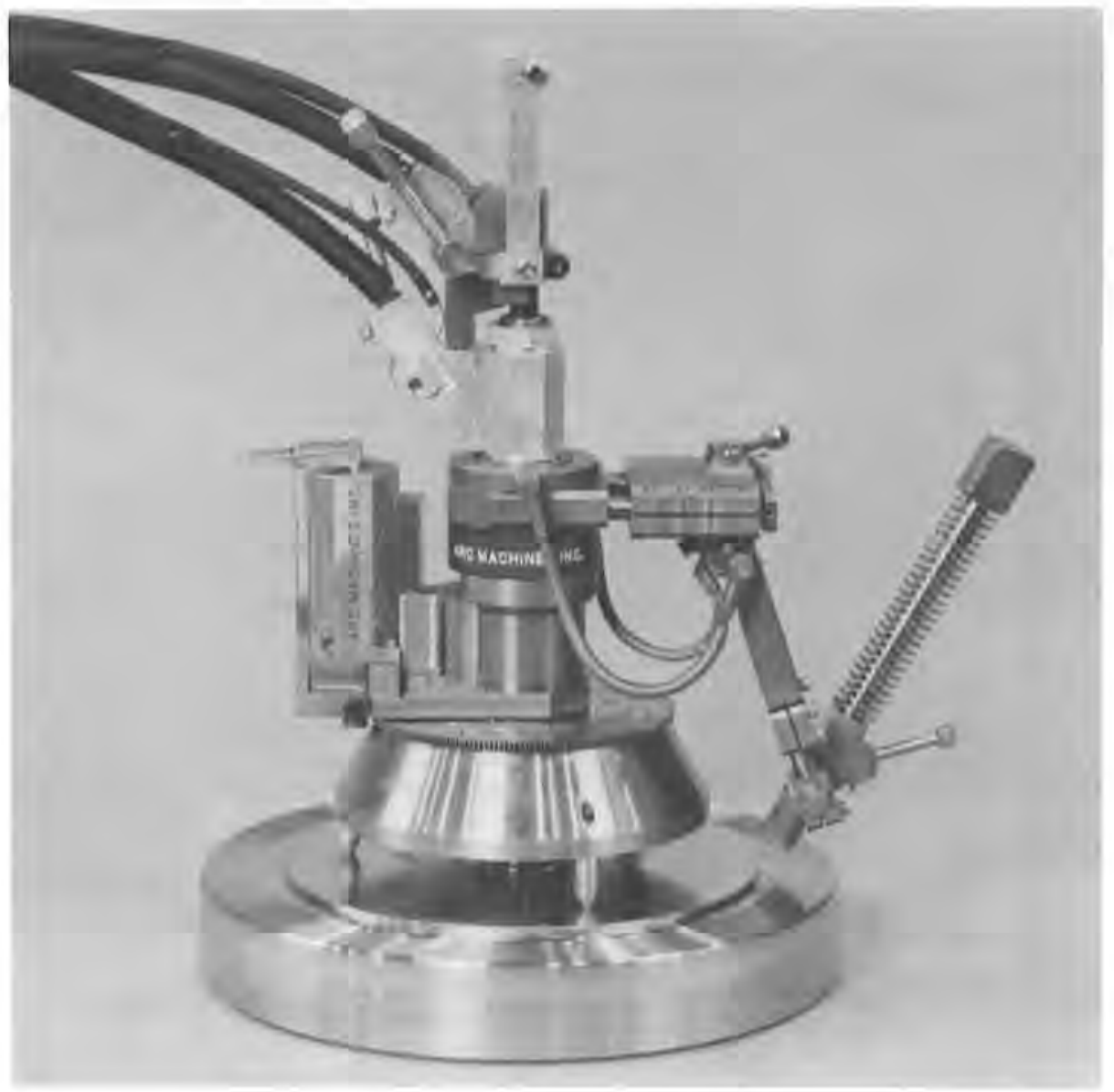

FIGURE E.3. PNL Prototype Canister Closure Welder Using the GTA Welding Process

welding nuclear equipment. It has been carefully studied and the techniques for making high quality welds are well understood. The welder shown makes an autogenous fillet that can range from 3.2 to $6.4 \mathrm{~mm}$ ( $1 / 8$ to $1 / 4$ in.) thick. Tight tolerances are maintained on the lid dimensions to maintain the appropriate gap between the welding tip and the lid. The welder is positioned off a hole in the center of the lid, so that the only fit-up requirement is to minimize the gap between the lid and the canister top. The welding device itself was designed for ease of maintenance. The device is relatively low in cost and in event of major damage can be easily replaced.

Operation of the welder is quite simple. The device is removed from a storage location and set on top of the canister lid. The lid is then tack-welded in four locations and the automatic welding sequence is initiated. The welding head rotates around the lid, making the weld, then automatically slows to a stop.

Before the closure is welded, any contaminants must be removed from the welding surface and the parts must be properly fitted. The entire ICM canister will have experienced the $1050^{\circ} \mathrm{C}$ ( $1922^{\circ} \mathrm{F}$ ) processing temperature so that the weld area will be heavily oxidized. The weld area must be free of oxidation, oils and dirt. The oxidized base material will be the most difficult to remove. Various procedures have been considered at PNL, including machining, grit blasting, chemical removal and ultrasonics.

After the weld has cooled, it will be inspected to assure that it is sound and leak-tight. While various techniques have been considered at. PNL, the most suitable techniques for this purpose are leaktesting, using helium and uttrasonic inspection. Canisters contain only waste glass 
and some nonradioactive gases. The major material leaking from the outside into the canister is water. Water should be kept out of the canister primarily to prevent possible canister pressurization if the canister is ever heated during normal or accident conditions. Studies at PNL have determined that a helium leak rate of $10^{-4} \mathrm{~atm} \mathrm{cc} / \mathrm{s}$ would be suitable for leaktightness, both for water into the canister and for solids, powders or slurries out of the canister. other investigations at PNL have concluded that a leak rate in the range of $10^{-5}$ to $10^{-6} \mathrm{~atm} \mathrm{cc} / \mathrm{s}$ would be practical and reliable under the expected hot-cell operating conditions; this rate would still provide a conservative measure of leaktightness.

The PNL concept for a leak test is illustrated in Figure E.4. Helium is placed inside the canister before welding. After welding, a bell jar is placed on the top of the canister and evacuated. A commercial leak detector will then check for helium and measure the rate of leakage, if any.

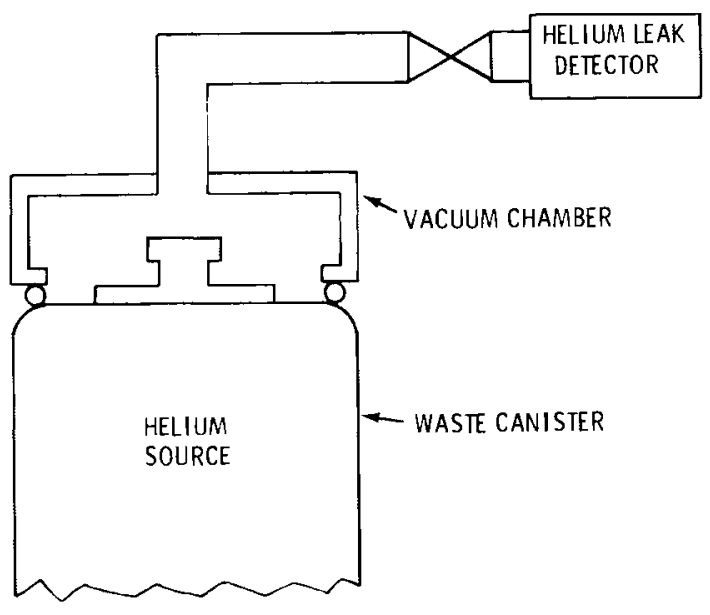

FIGURE E.4. Schematic Diagram of the Equipment for Helium Leak Checking a Canister

The twist-lock closure is also designed so that it can be inspected by ultrasonic techniques. Ultrasonic inspection will detect internal defects in the weld, which may increase in size as a result of cyclic loads on the lid. Appendix $F$ of this report shows that a defect one-half the thickness of the weld or larger must be detected. This is well within the range of most ultrasonic equipment.
PNL is developing the equipment to demonstrate the ultrasonic inspection of the closure weld. The ultrasonic test will use an immersion, through-transmission technique that relies on loss of signal for flaw detection and sizing. Two transducers in the configuration, shown in Figure E.5, will be rotated around the weld. Any flaws will be detected and recorded on a permanent file in a conventional C-scan format. The coolant for the transducers will be water. The canister will either be in water, if it is high-heat waste, or water will be injected under the transducers. Before each inspection the equipment will be calibrated on a standard weld with known defects.

After the closure seal is welded and inspected, the canister must be decontaminated. The canister and closure configuration should avoid features like recesses or pockets that are difficult to decontaminate. Also, allowance must be made to overpack each canister if this should prove necessary or desirable. Thus, projections from the canister that would prevent a convenient fit of a canister into an overpack should be avoided.

\section{LIFTING STRESSES ON TWIST-LOCK CLOSURES}

After the waste canisters are filled, they will be subjected to lifting stresses from special-purpose, remote-connecting devices. It is the objective here to illustrate methods that can ensure that overstress conditions do not occur during handling. The rules given in the cask designer's guide (Shappert 1978) were found to be appropriate for HLW canisters. The main requirement of this guide is that there be a safety factor of 3.0 with respect to yield for static $1.0-\mathrm{g}$ loads. This safety factor evidently provides suitable provision to account for dynamic contributions to lifting loads during handling.

In this study, canisters of 12-, 16-, 20and 24-in. dia were analyzed for stresses after they were lifted from the center of the lid. In analyses of preliminary designs the lids were first found to be understressed; further stress analyses showed that section sizes could be substantially reduced. Minimum member sizes are given below for the four canister designs, and stress levels in the optimal closure designs are reported.

The closures were designed for lifting loads at $400^{\circ} \mathrm{C}\left(750^{\circ} \mathrm{F}\right)$. A one-time lift of 


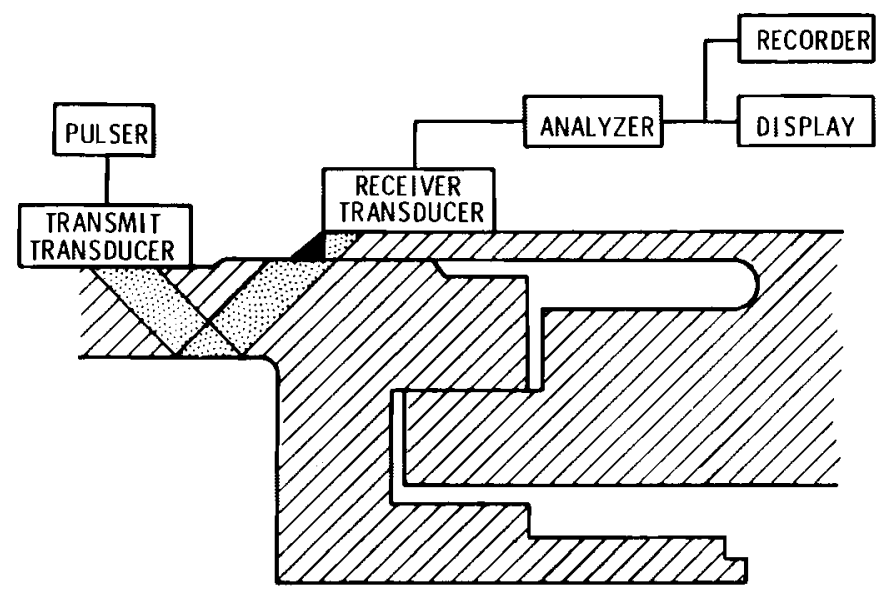

FIGURE E.5. Schematic Diagram Showing Transducers and Instrumentation for Ultrasonic Inspection

the canister from the ICM furnace at a temperature as high as $700^{\circ}$ to $800^{\circ} \mathrm{C}\left(1290^{\circ}\right.$ to $1470^{\circ} \mathrm{F}$ ) was also considered. A safety factor of 3.0 with respect to yield during normal handling at $400^{\circ} \mathrm{C}\left(750^{\circ} \mathrm{F}\right)$ was adopted as a design criterion. This safety factor is in accordance with recommendations of the cask designers guide (Shappert 1978) for lifting loads applied to shipping containers for nuclear applications. With this safety factor, the design stresses were $50.5 \mathrm{MN} / \mathrm{m}^{2}$ (7320 psi) and $73.0 \mathrm{MN} / \mathrm{m}^{2}(10,590 \mathrm{psi})$, respectively, for $304 \mathrm{~L}$ stainless steel and Inconel 601.

The computer program MONSASTIFF (Lestingi 1970) was used for the stress calculations. Figure E.6 shows how the configuration was modeled as shell segments in the computer stress analyses. The lugs were assumed to support no stress in the circumferential direction, with a zero value of elastic modulus assigned to this direction. Also, the lugs were assumed to extend around $50 \%$ of the circumference of the twist-lock configuration, with a $10 \%$ clearance for assembly. Thus, calculated lug stresses from the axisymmetric analyses were multiplied by a factor of 2.22 to account for the threedimensional nature of the twist-lock configuration. It was believed that this was a reasonable approximation, provided that a minimum of four lugs are employed in the twist-lock design. The three-dimensional, finite-element calculations described below show that the approximation is reasonable even for a three-lug configuration.

Vertical lifting loads equal to the estimated canister weights were applied to the center of the canister lids. The weights for the four canister sizes were $840 \mathrm{~kg}$, $1316 \mathrm{~kg}, 2130 \mathrm{~kg}$ and $3090 \mathrm{~kg}(1850 \mathrm{lb}$, $3000 \mathrm{lb}, 4700 \mathrm{lb}$ and $6800 \mathrm{lb})$. Because of possible lateral loads applied to the canister lifting device, the closure was analyzed for downward, as well as upward, loading. Upward and downward loads from canister handling are indicated as $F_{1}$ and $F_{2}$, respectively, on Figure E.6.

The load $\mathrm{F}_{3}$ indicated in Figure $\mathrm{E} .6$ is a $3430 \mathrm{~N} / \mathrm{m}$ (20 lb/in.) seal compression load. This seal is a ring with a C-shaped cross section, which is used when the canister is connected to the spray calciner. Bending stresses in the lug loaded by the seal are much below yield strength levels for the design temperature of $400^{\circ} \mathrm{C}\left(750^{\circ} \mathrm{F}\right)$. At canister fill temperatures of $1050^{\circ} \mathrm{C}$ $\left(1922^{\circ} \mathrm{F}\right)$, creep deformation would occur in the lug at the calculated stress levels. However, in actual practice, it is expected that any relaxation in sealing preload would occur by plastic deformation or creep in the metallic seal rather than in the canister lug.

The dimensions given in Figures E.6 through E.11 are for optimal designs and are intended to serve as a basis for selecting minimum dimensions consistent with structural integrity requirements. Dimensions are given only for $304 \mathrm{~L}$ stainless stee 1. The thickness for Inconel 601 can be reduced by about $17 \%$ due to its higher yield strength compared to $304 \mathrm{~L}$. The designs for all but the 24-in.-dia canister were developed for a flat-ended top closure. For the 24-in.-dia canister both a flat-ended and a 


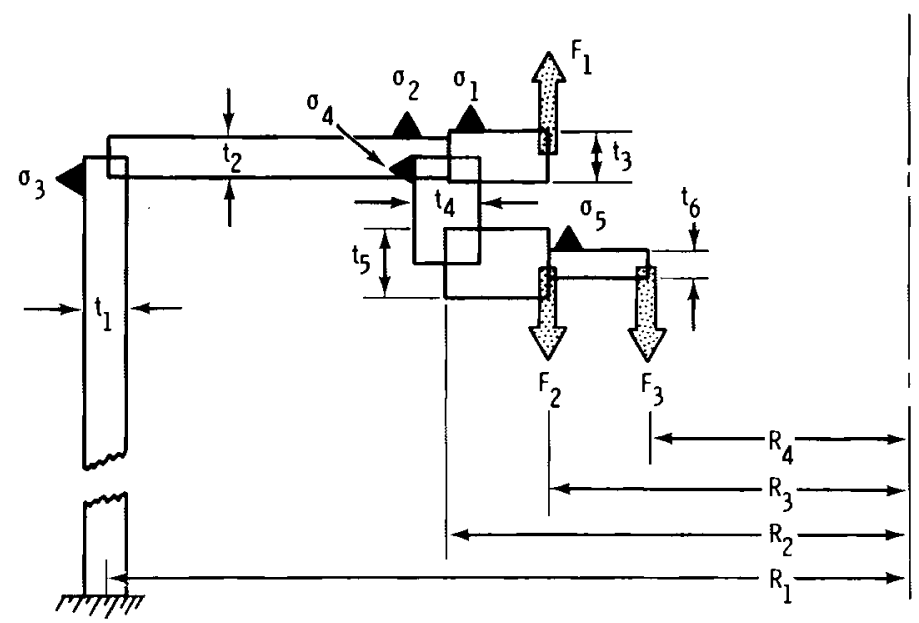

(a) MODEL OF TWIST-LOCK CLOSURE FOR MONSASTIFF STRESS ANALYSIS

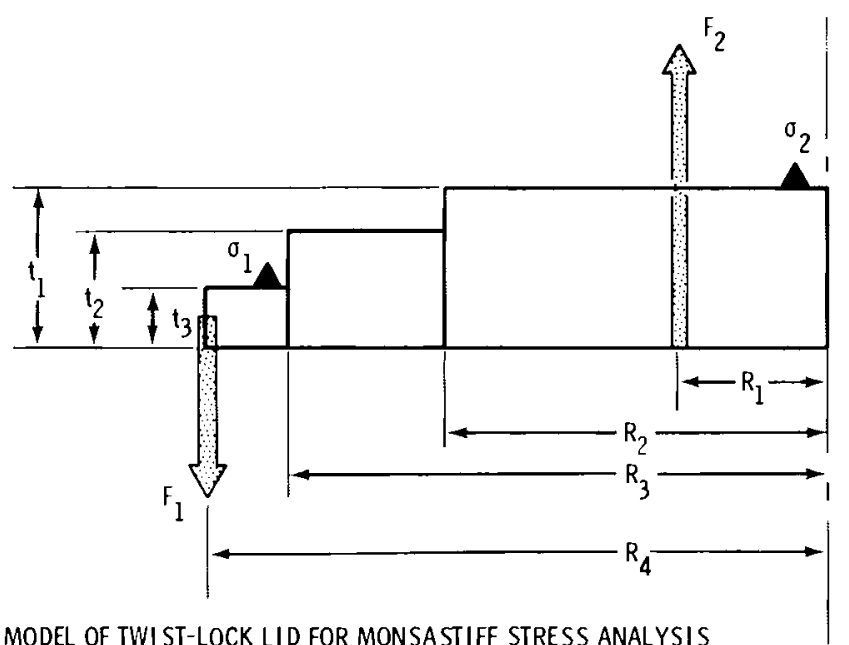

(b) MODEL OF TWI ST-LOCK LID FOR MONSASTIFF STRESS ANALYSIS

FIGURE E.6. Shell Segment Model of Twist-Lock Closure

contoured-ended closure were designed. A comparison of Figures E.10 and E.11 shows that wall thickness can be considerably reduced by the more structurally efficient contoured-end. However, structural eff $i-$ ciency and weight reduction are relatively low priority considerations compared to ease of assembly, ease of closure welding, and the ability to perform nondestructive inspection. These other factors tend to favor the flat-ended configuration. The stresses shown in Figures E.6 through E.11 are the maximum values calculated at each of the indicated locations for all three loading conditions $\left(F_{1}, F_{2}\right.$ and $\left.F_{3}\right)$. Stress levels at the various locations are at or near the design stress of $50.5 \mathrm{MN} / 2$ (7320 psi) for the optimal designs. The dimensions of these optimal designs were determined by adjusting member thicknesses and performing stress analyses in an iterative manner. The actual dimensions used in the fabrication of prototype canisters at PNL were rounded up slightly from the minimum dimensions given in Figures E.6 through E.11.

\section{THREE-DIMENSIONAL ANALYSIS OF LID}

In the design analyses described above, the calculation of stresses in the twistlock closure was based on simplified assumptions. In particular, the twist lock was treated as an axisymmetric shell structure using linear shell-bending theory. As such, aspects of stress distributions in 


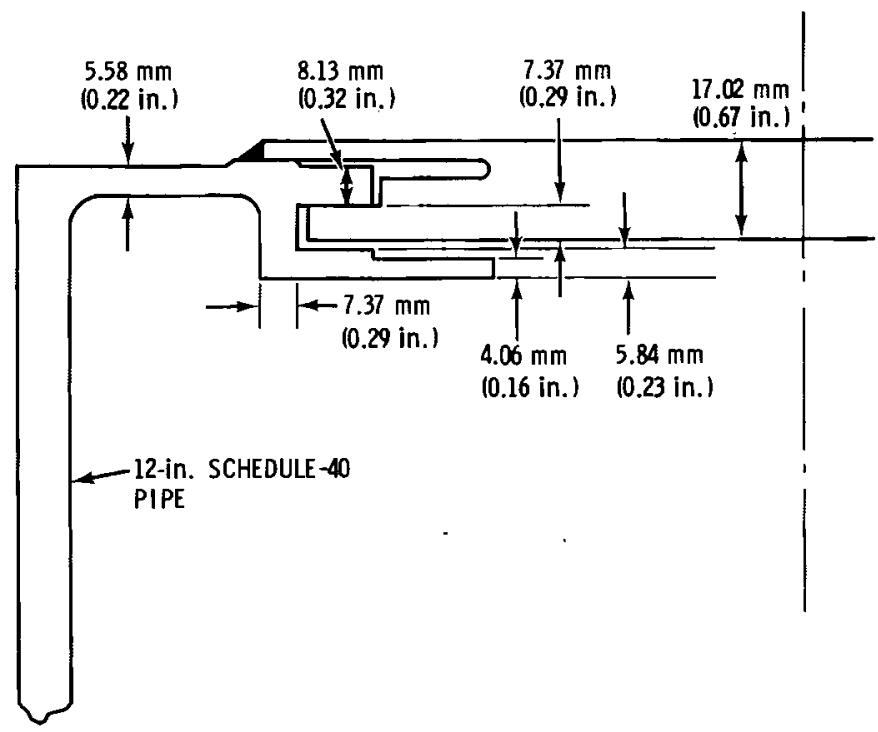

(a) CLOSURE DIMENSIONS

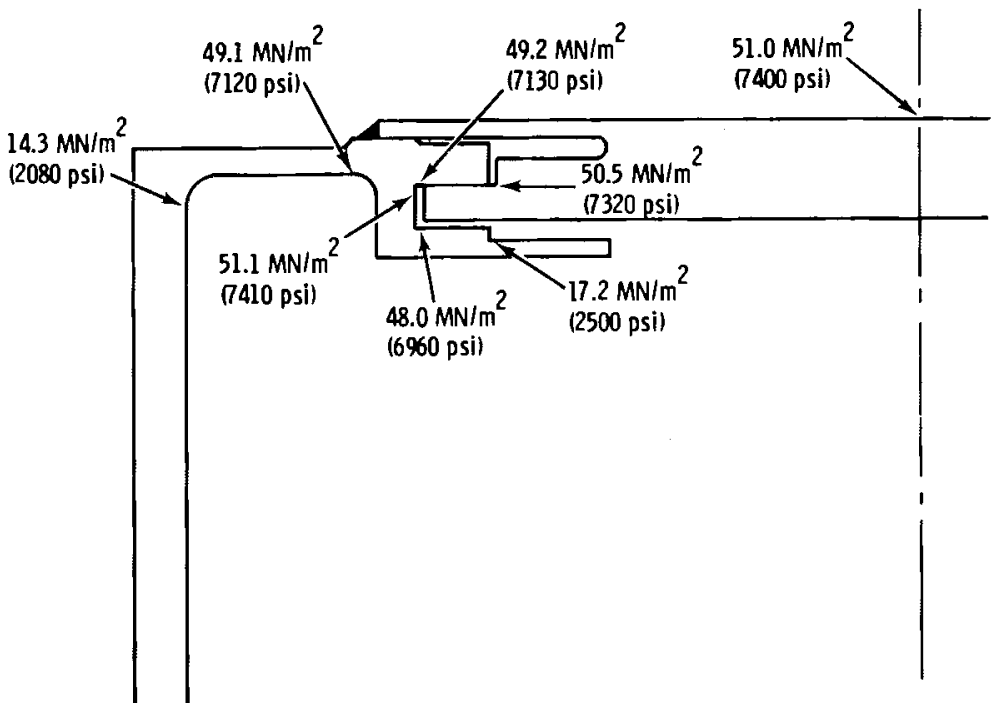

(b) CLOSURE STRESSES

FIGURE E.7. Dimensions and Lifting Stresses for Twist-Lock Closure for 12-in.-Dia Canister

the individual lugs of the twist lock were ignored. For more realistic stress data, the twist-lock lid was analyzed with threedimensional, solid-type elements. For comparison purposes, one set of analyses will retain the assumption of axisymmetry. To consider circumferential variations in stress, a finite-element model was designed to use the eight node isoparametric element in the computer program ANSYS (DeSalvo and
Swanson 1975) for treating general threedimensional solids.

Figure E.12 shows the finite-element model of the twist-lock lid used for analysis of stresses from lifting loads. Threedimensional solid or brick-type elements are used to model a three-lug design. Due to geometric symmetry, only one-sixth or a $60^{\circ}$ sector of the lid was included in the 


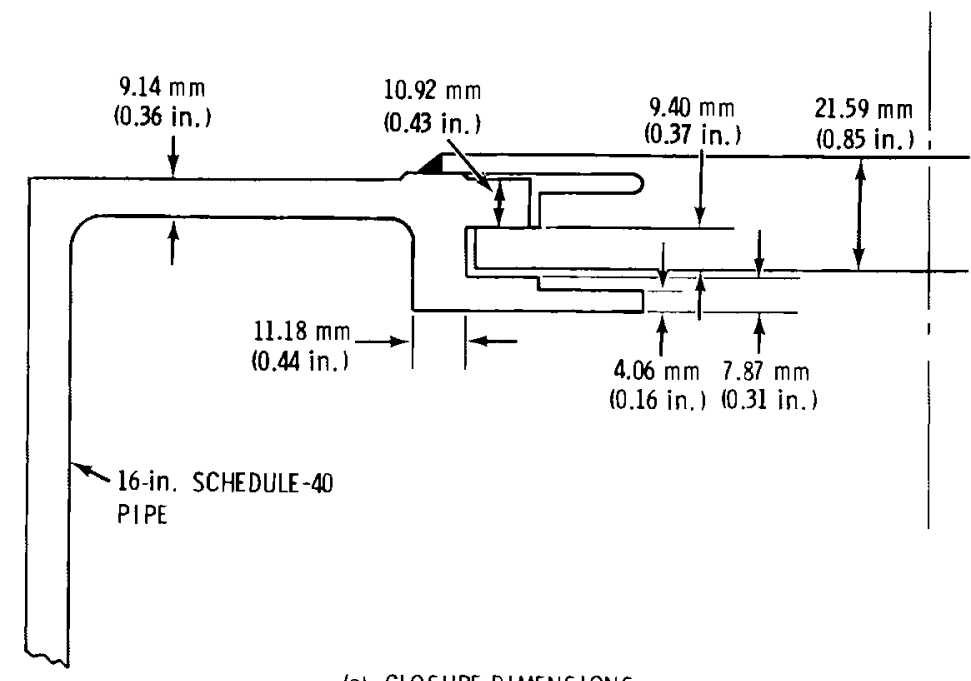

(a) CLOSURE DIMENSIONS

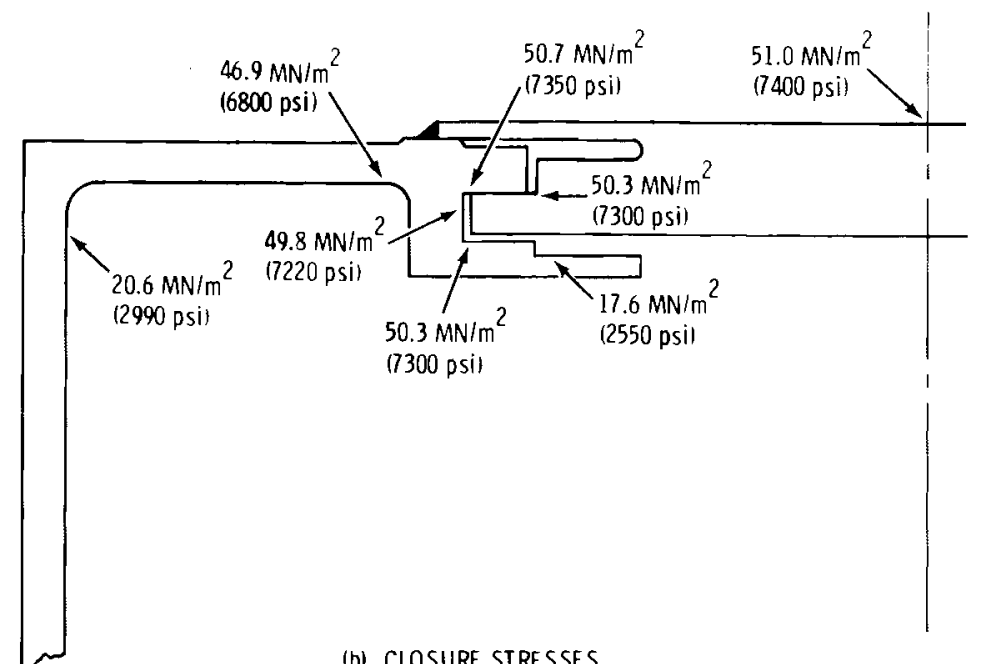

(b) CLOSURE STRESSES

FIGURE E.8. Dimensions and Lifting Stress for Twist-Lock Closure for 16-In.-Dia Canister

model. In the model, the gaps between the lugs were filled with elements that will be deleted during the stress solution.

Figure E.13 shows the calculated variation in deflection around the circumference of the lid, as would be produced by a $1316-\mathrm{kg}(3000-1 \mathrm{~b})$ lifting load. The results show that the deflection at the lugs is over twice that at locations midway between the lugs.

Figures E.14 to E.16 show contours of stress (two times maximum shear stress) at the upper and lower surfaces of the lid and at the midplane of the lid. The dashed contours correspond to the axisymetric solution (neglecting lugs) for the same geometry. Calculated stresses are clearly higher for the nonsymmetric loading and geometry. The design stress for the lid was $50.5 \mathrm{MN} / \mathrm{m}^{2}$ (7320 psi), whereas the maximum stress shown in Figures E.14 to E.16 is about $27.6 \mathrm{MN} / \mathrm{m}^{2}$ (4000 psi). As has been stated, approximate methods were used to calculate stress levels for lid design, and it was concluded that these methods were conservative. Also, the actual 


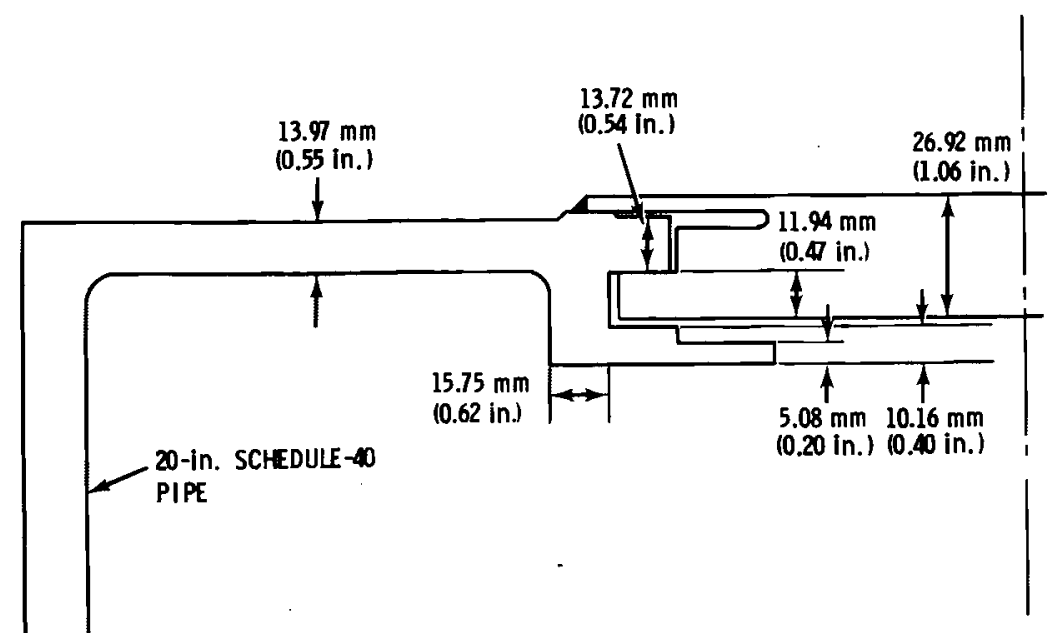

(a) CLOSURE DIMENSIONS

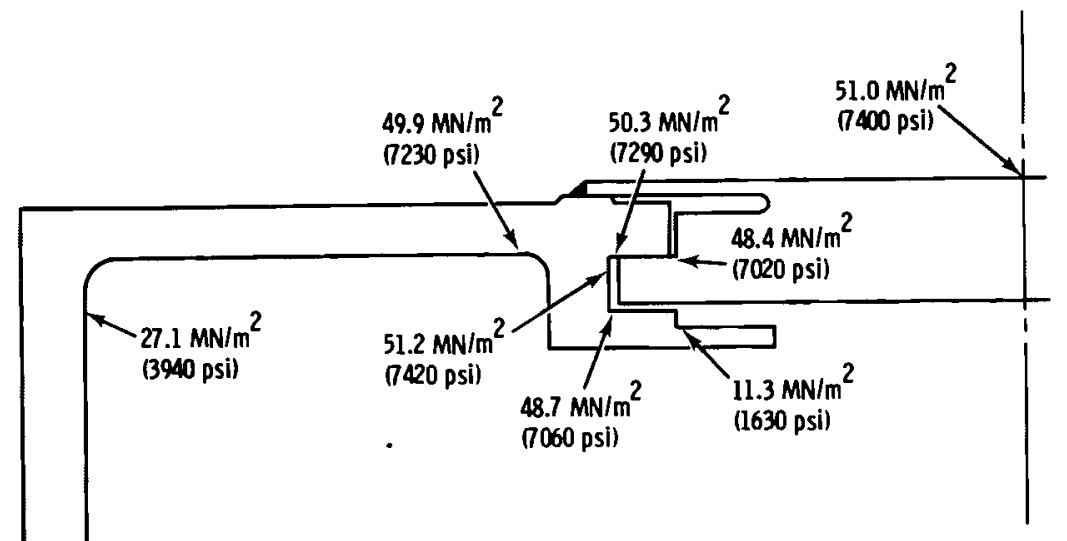

(b) CLOSURE STRESSES

FIGURE E.9. Dimensions and Lifting Stresses for Twist-Lock Closure for 20-in.-Dia Canister

lid and twist-lock thickness of a prototype canister were used in the three-dimensional analyses. These values were greater than the minimum values established by the design calculations.

\section{CLOSURE FOR CM CANISTER}

A flange type of closure has been proposed for use with canisters filled by the CM process. In the CM process, the molten glass is poured directly into the canister and the special features of the twist-lock arrangement are not required to connect the canister to process equipment.

Figure E.17 shows a schematic of a proposed flange type of closure. The canister can be lifted either from a central connector on the closure plate or by gripping the flange externally. The opening diameter of the flange can be selected on the basis of canister size and process connection requirements. Two plates are used to close the opening of the flange after the canister is filled. An internal plate is relatively thin but is readily seal-welded. The thick 


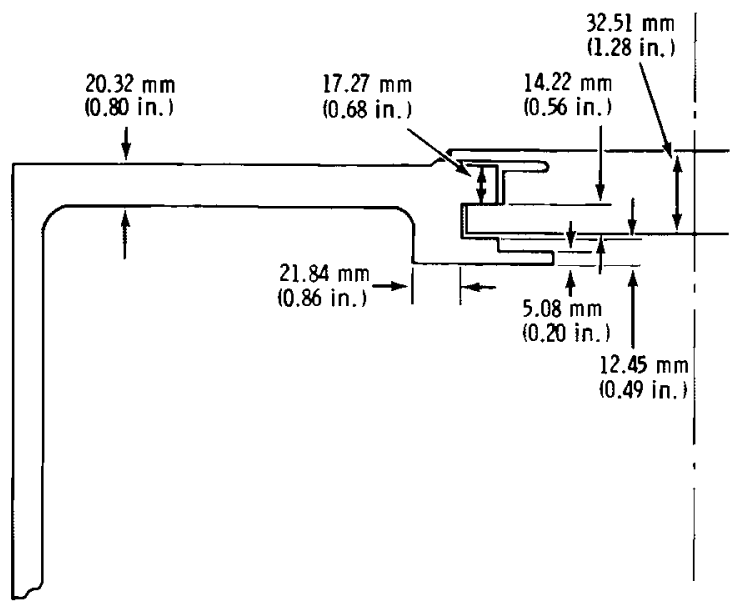

(a) CLOSURE DIMENSIONS

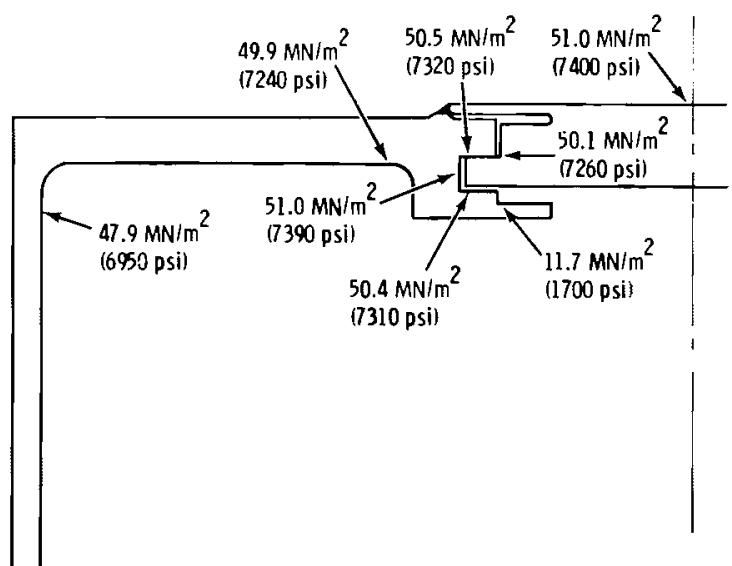

(b) CLOSURE STRESSES

FIGURE E.10. Dimensions and Lifting Stresses for Twist-Lock Closure for 24-in.-Dia Canister of Flat-Ended Configuration

external plate is secured by bolts, which makes the design rugged. This plate must sustain impact loadings and provide secondary support to the seal plate in the event of an internal pressure rise from accidental heating.

Stresses from lifting loads were evaluated for the proposed closure concept. The configuration of the canister top is shown in Figure E.18. The design has a flat top with a 152-mm- (6.0-in.-) dia opening to which a flange is attached. The overall canister diameter was $610 \mathrm{~mm}$ (24 in.), and the weight of the canister was $2840 \mathrm{~kg}$ $(6260 \mathrm{lb})$. Stresses were calculated for
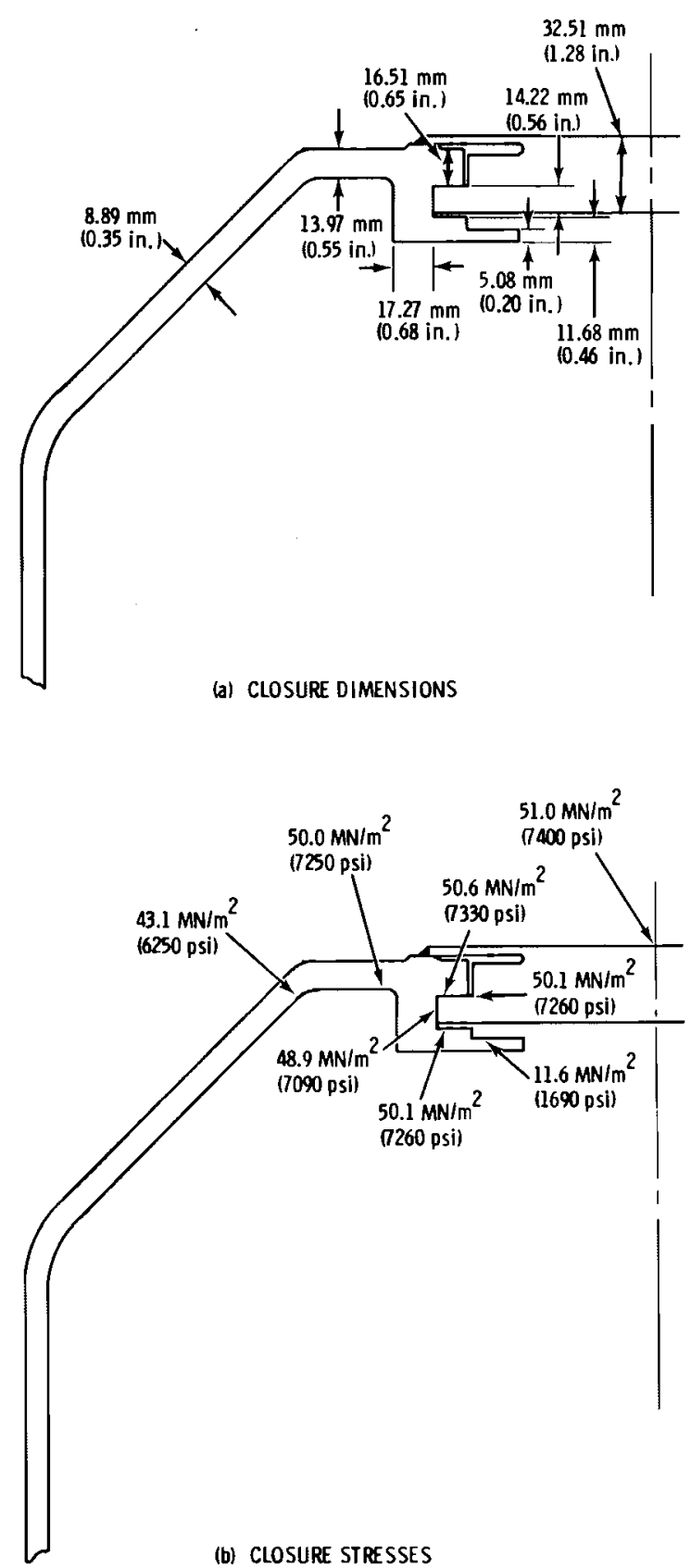

FIGURE E.11. Dimensions and Lifting Stresses for Twist-Lock Closure for 24-in.-Dia Canister of ContouredEnded Configuration

various combinations of flange and top thickness, $t_{1}$ and $t_{2}$ as indicated in Figure E.18. 


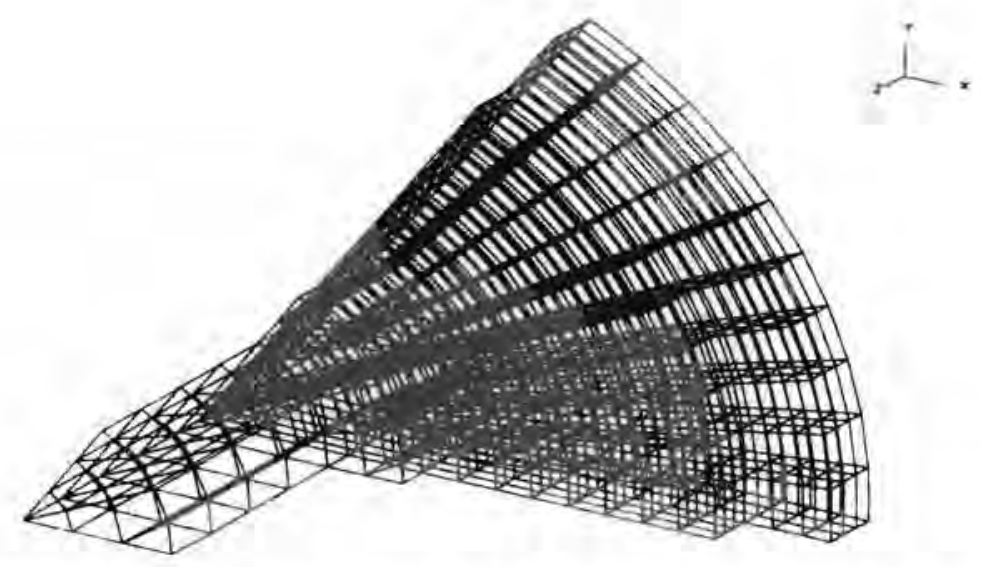

FIGURE E.12. Finite-Element ModeT of Twist-Lock Canister Lid

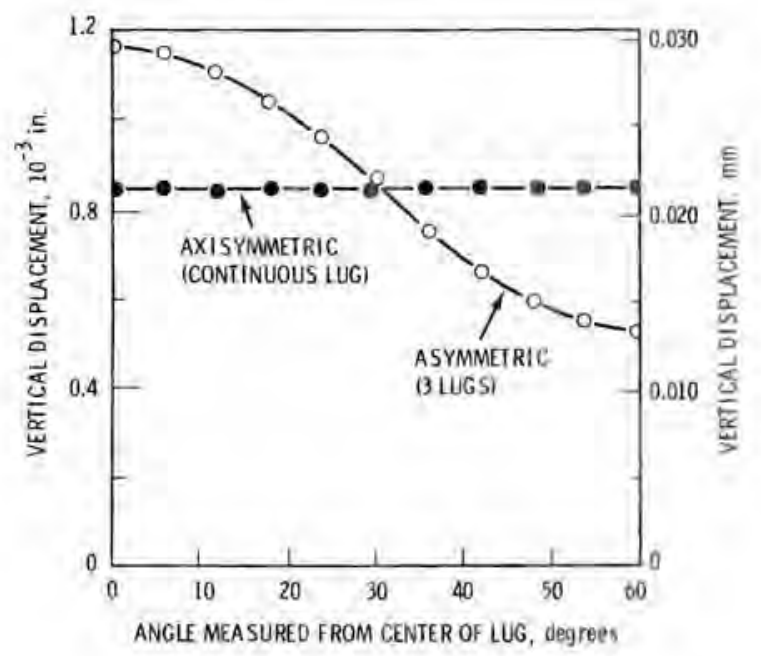

FIGURE E.13. Calculated Rim Displacement for Canister Lid

For the parametric analysis, the structural behavior of the closure area was approximated by thin-shell theory and calculations were performed using the computer program MONSASTIFF (Lestingi 1970). It was conservatively assumed that the canister weight was supported on the outer diameter of the flange, and no structural contribution from the closure plate was considered. The 610-mm- (24-in.-) dia by $3.05-\mathrm{mm}-(10-\mathrm{f}-)$ long canister was assumed to be fabricated from schedule-40, low-carbon steel pipe, A nonheating glass was assumed, and the stress was evaluated for room-temperature conditions. At room temperature, carbon stee 1 has a minimum yield strength of about $207 \mathrm{mN} / \mathrm{m}^{2}(30,000 \mathrm{psi})$. Using a safety factor of 3,0 on yield for canister lifting, an allowable stress of about $69 \mathrm{MN} / \mathrm{m}^{2}$ $(10,000 \mathrm{psi})$ was assumed for the analysis of stresses due to static weight.

Table E.1 summarizes the results of the parametric study in terms of the stress output locations identified in Figure E.18. The results show the tradeoff between the flange neck thickness, $t_{2}$, and the canister top thickness, $t_{1}$. In the first five design configurations of Table E.1, the neck thickness, $\mathrm{t}_{1}$, was taken as $7.1 \mathrm{~mm}$ ( $0.28 \mathrm{in.})$, which corresponded to a standard piping flange thickness. It was determined that a corresponding canister top thickness of $38 \mathrm{~mm}(1.5 \mathrm{in}$.$) is required to maintain$ stresses within allowable levels. For the final two cases, the neck thickness was increased to 19 min ( $0.75 \mathrm{in.}$ ) and $25.4 \mathrm{~mm}$ (1.0 in.) and, as indicated, significant reductions in the required top thickness resuited.

It was concluded that a flange type of closure can readily support lifting loads imposed at the outer edge of the flange. The calculated results show that different combinations of closure dimensions can be selected to meet structural requirements. Also, the results suggest that the use of tapers could vary the thickness to obtain maximuin structural efficiency. However, such designs would probably increase fabrication costs. 


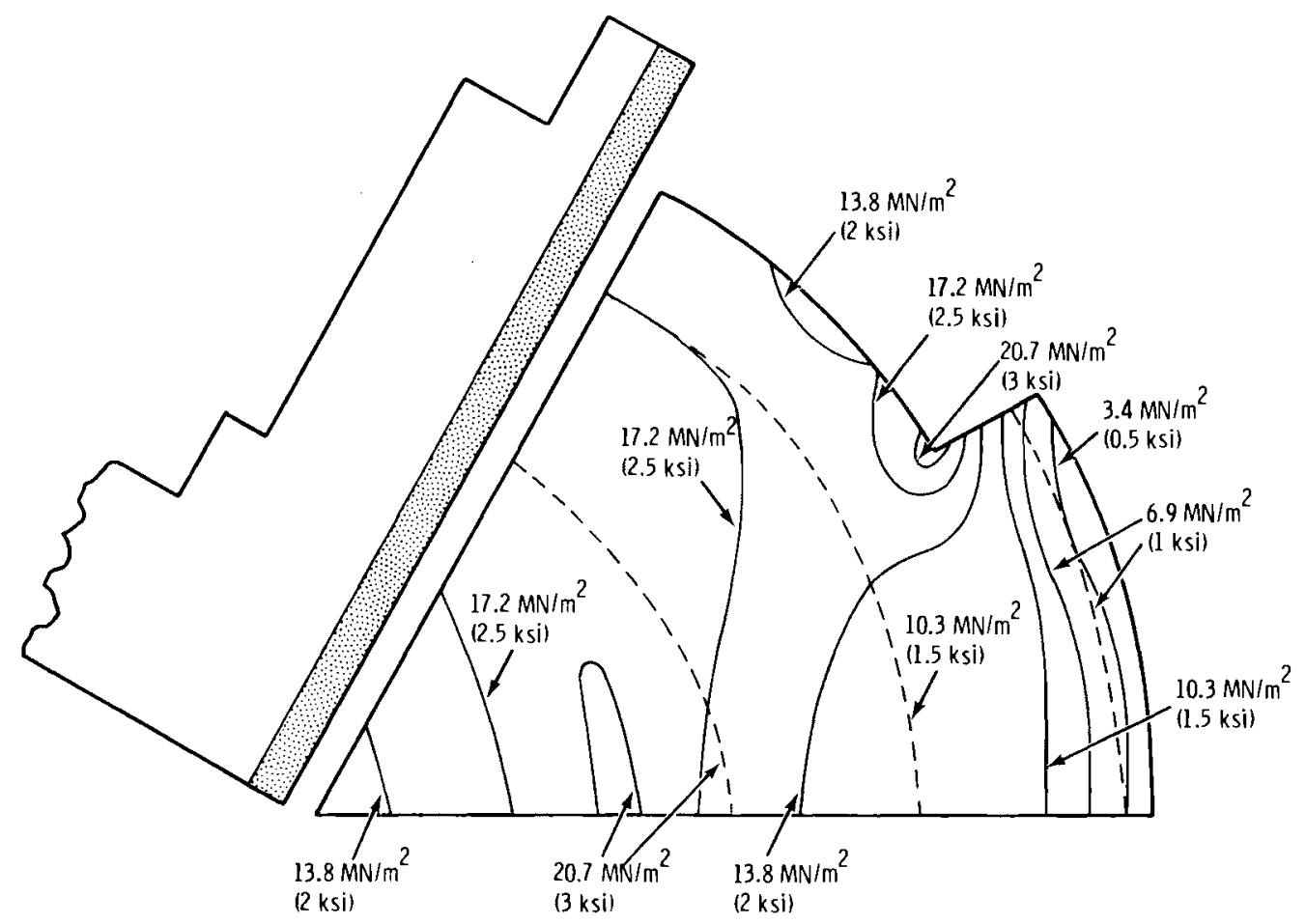

FIGURE E.14. Calculated Stress Contours (2x Max. Shear) on Lower Surface of Lid

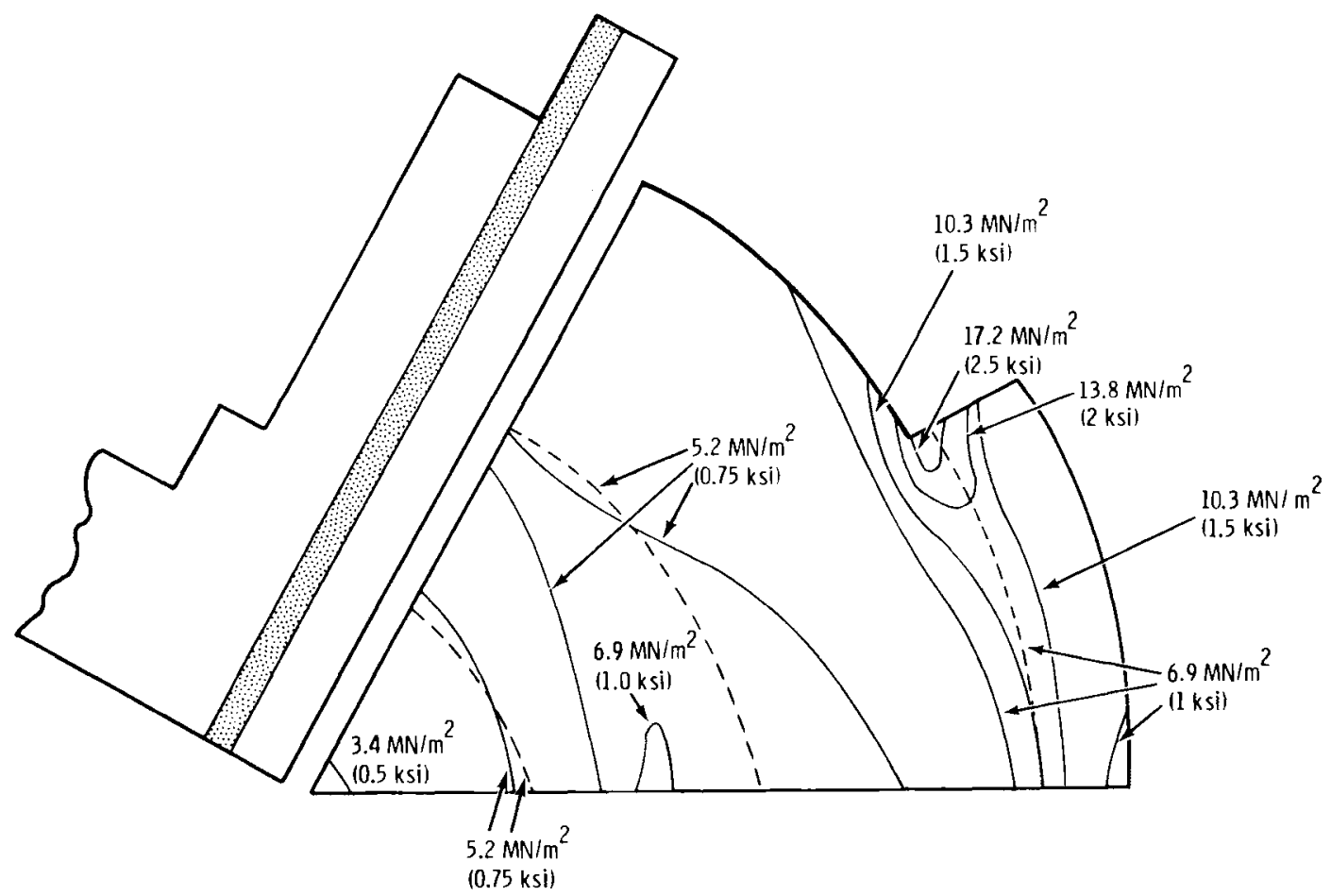

FIGURE E.15. Calculated Stress Contours $(2 \times$ Max. Shear $)$ on Midplane of Lid 


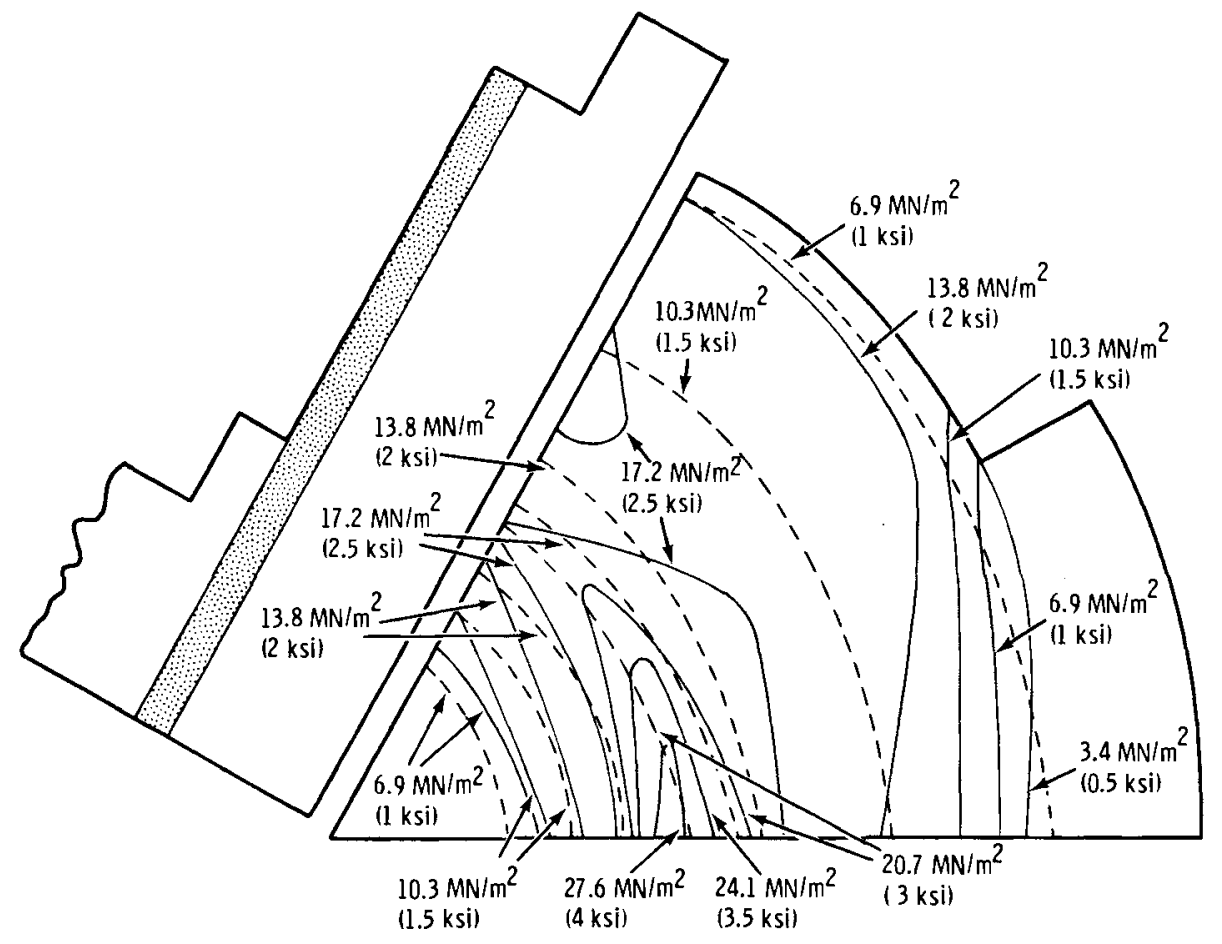

FIGURE E.16. Calculated Stress Contours $(2 \times$ Max. Shear $)$ on Upper Surface of Lid

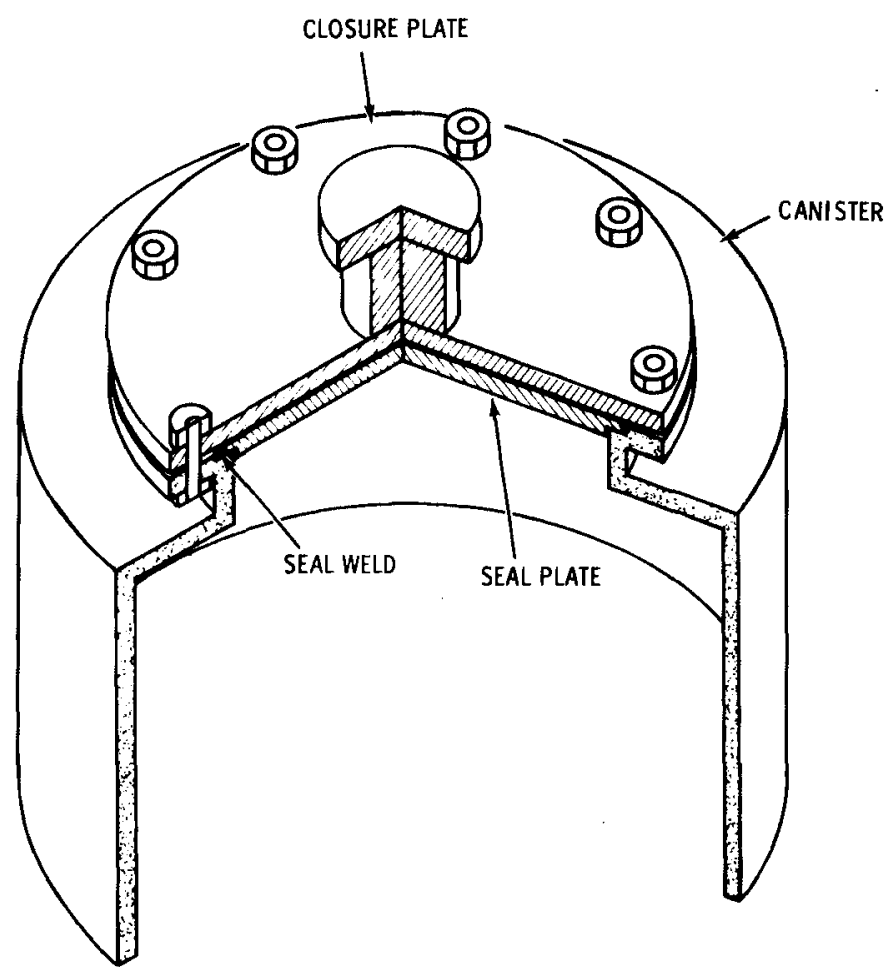

FIGURE E.17. Schematic Drawing of Flange Closure 


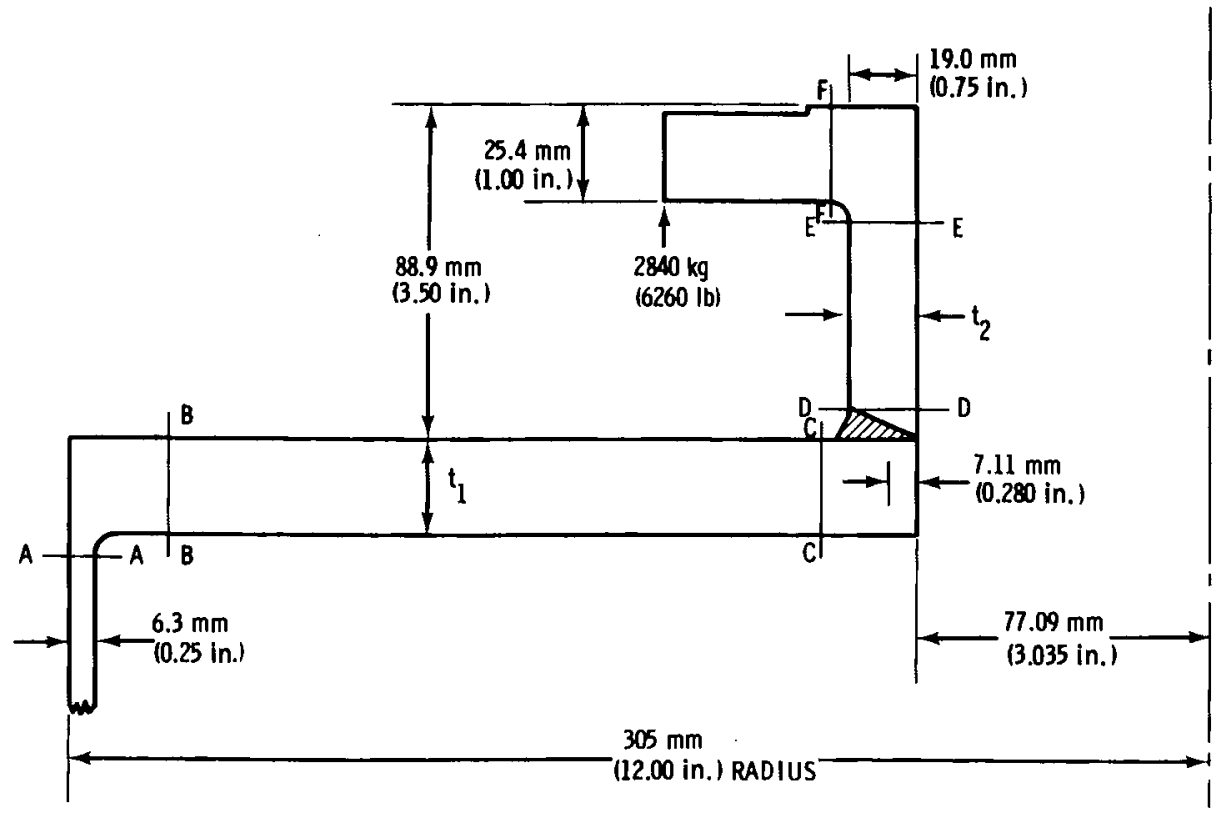

FIGURE E.18. Dimensions of Flange Closure and Stress Output Locations

TABLE E.1. Results of Stress Analyses for Various Design Parameters

\begin{tabular}{|c|c|c|c|c|c|c|}
\hline \multirow{2}{*}{$\begin{array}{c}\text { Design Configuration } \\
\mathrm{mm} \text { (in.) }\end{array}$} & \multicolumn{6}{|c|}{ Stress Output, $M N / \mathrm{m}^{2}$ (psi) } \\
\hline & $\mathrm{AA}$ & $\mathrm{BB}$ & $\mathrm{CC}$ & $\mathrm{DD}$ & $\mathrm{EE}$ & $\overrightarrow{F F}$ \\
\hline$t_{1}=12.7(0.5), \quad t_{2}=7.1(0.28)$ & $\begin{array}{c}192 \\
(27,800)\end{array}$ & $\begin{array}{l}50 \\
(7,300)\end{array}$ & $\begin{array}{c}139 \\
(20,100)\end{array}$ & $\begin{array}{c}406 \\
(58,900)\end{array}$ & $(4,300)$ & $\begin{array}{c}29 \\
(4,200)\end{array}$ \\
\hline$t_{1}=19.0(0.75), t_{2}=7.1(0.28)$ & $\begin{array}{c}120 \\
(17,400)\end{array}$ & $\begin{array}{c}14 \\
(2,100)\end{array}$ & $\begin{array}{c}94 \\
(13,700)\end{array}$ & $\begin{array}{c}276 \\
(40,100)\end{array}$ & $\begin{array}{c}30 \\
(4,400)\end{array}$ & $\begin{array}{c}27 \\
(3,900)\end{array}$ \\
\hline$t_{1}=25.4(1.00), t_{2}=7.1(0.28)$ & $\begin{array}{c}70 \\
(10,200)\end{array}$ & $\begin{array}{c}13 \\
(1,900)\end{array}$ & $\begin{array}{c}69 \\
(10,000)\end{array}$ & $\begin{array}{c}169 \\
(24,500)\end{array}$ & $\begin{array}{c}31 \\
(4,500)\end{array}$ & $\begin{array}{c}26 \\
(3,800)\end{array}$ \\
\hline $\mathrm{t}_{1}=38.1(1.50), \mathrm{t}_{2}=7.1(0.28)$ & $\begin{array}{c}27 \\
(3,900)\end{array}$ & $(1,100)$ & $\begin{array}{c}37 \\
(5,400)\end{array}$ & $\begin{array}{c}66 \\
(9,500)\end{array}$ & $\begin{array}{c}32 \\
(4,700)\end{array}$ & $\begin{array}{c}28 \\
(4,000)\end{array}$ \\
\hline $\mathrm{t}_{1}=50.8(2.00), \mathrm{t}_{2}=7.0(0.28)$ & $\begin{array}{c}12 \\
(1,800)\end{array}$ & $\begin{array}{l}5 \\
(700)\end{array}$ & $\begin{array}{c}22 \\
(3,200)\end{array}$ & $\begin{array}{c}48 \\
(7,000)\end{array}$ & $\begin{array}{c}34 \\
(4,900)\end{array}$ & $\begin{array}{c}22 \\
(3,200)\end{array}$ \\
\hline $\mathrm{t}_{1}=25.4(1.00), \mathrm{t}_{2}=19.0(0.75)$ & $\begin{array}{c}52 \\
(7,600)\end{array}$ & $\begin{array}{c}10 \\
(1,400)\end{array}$ & $\begin{array}{c}48 \\
(7,000)\end{array}$ & $\begin{array}{c}74 \\
(10,800)\end{array}$ & $\begin{array}{c}33 \\
(4,800)\end{array}$ & $\begin{array}{c}22 \\
(3,200)\end{array}$ \\
\hline$t_{1}=19.0(0.75), t_{2}=25.4(1.00)$ & $\begin{array}{c}88 \\
(12,700)\end{array}$ & $\begin{array}{c}10 \\
(1,500)\end{array}$ & $\begin{array}{c}96 \\
(13,900)\end{array}$ & $\begin{array}{c}48 \\
(7,000)\end{array}$ & $\begin{array}{c}20 \\
(2,900)\end{array}$ & $\begin{array}{c}23 \\
(3,400)\end{array}$ \\
\hline
\end{tabular}




\section{REFERENCES}

Desalvo, G. J. and J. A. Swanson. 1975. ANSYS Engineering Analys is User's Manual. Swanson Analys is Systems, Elizabeth, Pennsylvania.

Lestingi, J. R. 1970. Direct Stiffness Analys is of Branch Shells of Revolution Using Numerical Integration ProdeduresVol. II - MONSASTIFF User's Manual. Report Number 70-1, The Institute of Science and Engineering Research, Department of Civil Engineering, The University of Akron, Akron, Ohio.
Shappert, L. B. 1978. A Guide for the Design, Fabricaion and Operation of Shipping Casks for Nuclear Application. ORNL-NSIC-68, 0ak Ridge National Laboratory, Oak Ridge, Tennessee. 


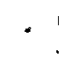

-

, 
APPENDIX $F$ 
APPENDIX $F$

\section{ANALYSIS OF CLOSURE BY DAMAGE-TOLERANCE CONCEPTS}

At the conclusion of the vitrification process the canister is sealed with a lid and the final closure weld is made. This final closure must be welded in a hot-cell environment. The weld must also be inspected by remote means. This section is concerned with the twist-lock closure design, which has been developed at PNL for use with the ICM process. The structural integrity of a weld under projected service conditions is studied, based on damage tolerance concepts. Admissible defect sizes and inspection requirements are thereby established. These sizes witl provide the acceptance criteria for preservice and in-service ultrasonic inspection.

The method of damage-tolerance analysis has been developed extensively within the aerospace industry, and detailed design procedures based on the method have been formulated (Military Specification MIL-A-8344). Such methods utilize fracture mechanics concepts and involve the prediction of in-service crack extension. Various forms of structural damage, are considered, such as material flaws, manufacturing defects, and in-service cracks from such mechanisms as fatigue. Initial defect sizes are established by estimates of the size of the largest crack that could go undetected during inspection of the component. It is then required that this crack will not grow to a critical size in-service. Alternative$1 y$, in-service inspection intervals may be established so that the component can be replaced or repaired before a defect can grow to critical size.

In the present application, the defects of concern were in a seal weld of a canister closure system. The proposed inspection method was thought to be capable of detecting cracks that extended through one-half or more of the net section of the weld. The purpose of this study was to consider the growth of various postulated defects and to determine by analysis if such defects would grow in-service to a size that would result in a leakage path or lead to a gross fracture through the closure weld.

\section{DESCRIPTION OF THE DESIGN}

Figure F.1 shows the particular canister and closure design that was the focus of this study. The body of the 304L stainless steel canister was nominally $406 \mathrm{~mm}$ (16 in.) in dia, with a 9.52-mim (0.375-in.) wall thickness. The canister top was flat and
$14.22 \mathrm{~mm}$ (0.560 in.) thick. A twist-lock design with three lugs on the lid and a matching configuration of the canister top was used to secure the lid to the canister. The twist-lock configuration at the opening in the canister top was chosen primarily because of a requirement to connect a filling apparatus to the canister by remote means. The same twist-lock action serves as a convenient means to secure the 1id. In handling, the canister is lifted by an attachment to the center of the 1id. Lifting loads are transmitted through the lugs of the twist-lock closure. The $3.18-\mathrm{mm}-$ $(0.125-i n .-)$ thick seal plate is sufficientiy compliant so that it experiences little or no stress during handling and, in this sense, is a nonstructural part of the closure.

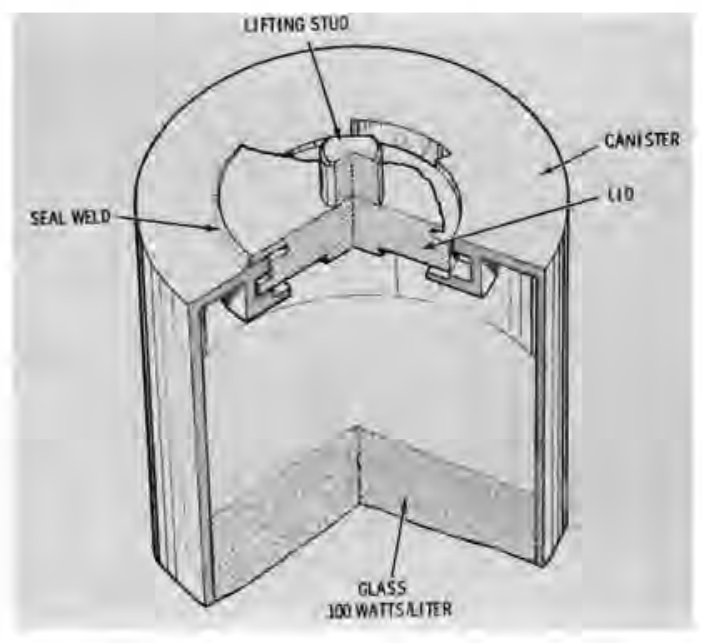

FIGURE F.1. Full-Scale Canister 
Once the lid is engaged through the twist-lock connection, the edge of the seal plate is welded to the top of the canister by a tungsten arc, inert gas, fusion weld that is remotely controlled. This weld must then be inspected remotely using an ultrasonic procedure developed for this purpose. The integrity of this critical weld and its sensitivity to welding defects is the focus of this study.

A review of the canister service conditions was conducted to identify sources of stress in the weld. Stresses due to lifting were insignificant. However, the canister was expected to suddenly change in temperature during service. It is expected that a water basin will be used for interim storage. Also, to decontaminate the outer surface of the canister, a water spray may be used. As indicated in Figure F.1, the vitrified radioactive waste will produce internally generated heat, possibly at a rate as high as $100 \mathrm{~W} / \mathrm{L}$. For analys is purposes, this level of heat generation was assumed. When stored in air, the heat from the vitrified waste will cause the temperature to rise in the top and lid of the canister. When immersed in water, the temperature of the top will approach that of the water. During the thermal transient, it was evident that the potential existed for substantial thermal stress. The review of service conditions concluded that such transient thermal stresses would govern the structural integrity of the closure weld. Subsequently, detailed heat-transfer and stress analyses of the canister closure design were undertaken.

\section{HEAT TRANSFER}

The computer codes HEATING4 (Turner and Simon-Tov 1971) and ANSYS (DeSalvo and Swanson 1975) were used to analyze steadystate and transient temperatures in the canister top region. The canister material was assumed to be $304 \mathrm{~L}$ stainless steel. Due to ease of input data preparation, the HEATING4 code was used in preliminary scoping studies. Once heat-transfer conditions and thermal-solution trends were established, the canister was modeled with the finiteelement computer program ANSYS. This code permitted a unified thermal and stress analysis to be performed with automated transfer of thermal solution data to the stress analysis phase of the calculation.

Two steady-state and two transient temperature states were considered. The steady-state conditions were radiation and free convection in $49^{\circ} \mathrm{C}\left(120^{\circ} \mathrm{F}\right)$ ambient air, and submersion in $21^{\circ} \mathrm{C}\left(70^{\circ} \mathrm{F}\right)$ water. The transients corresponded to an instantaneous transfer of the canister from one medium to the other. By far the most severe thermal gradients resulted from the quench of the hot canister at a temperature of about $260^{\circ} \mathrm{C}$ $\left(500^{\circ} \mathrm{F}\right)$ into the water.

Figure F.2 shows the finite-element model used in the ANSYS thermal and stress analysis. Only the upper $305 \mathrm{~mm}$ (12 in.) of the canister that extended above the glass level were modeled. Previous HEATING4 analyses included the heat-emitting glass, and results of these analyses provided glass surface temperatures for use as boundary conditions to the ANSYS thermal analyses. Calculated glass surface temperatures ranged from $482^{\circ} \mathrm{C}\left(900^{\circ} \mathrm{F}\right)$ at the centerline of the canister to $205^{\circ} \mathrm{C}\left(400^{\circ} \mathrm{F}\right)$ at the outer surface. Using these temperatures as boundary conditions, heat transfer from the glass surface to the top and sides of the canister was accounted for by the mechanism of radiation. A form factor of 1.0 was assumed for radiation to the top of the canister, and a factor of 0.2 for radiation to the side walls of the canister. A factor of 1.0 for the top was assumed to be conservative since this would maximize top temperatures and thus overestimate the severity of the conditions for the water quench. Emissivities within the range of 0.6 to 0.8 were used for the radiation calculations. A form factor of 1.0 was assumed for radiation from the

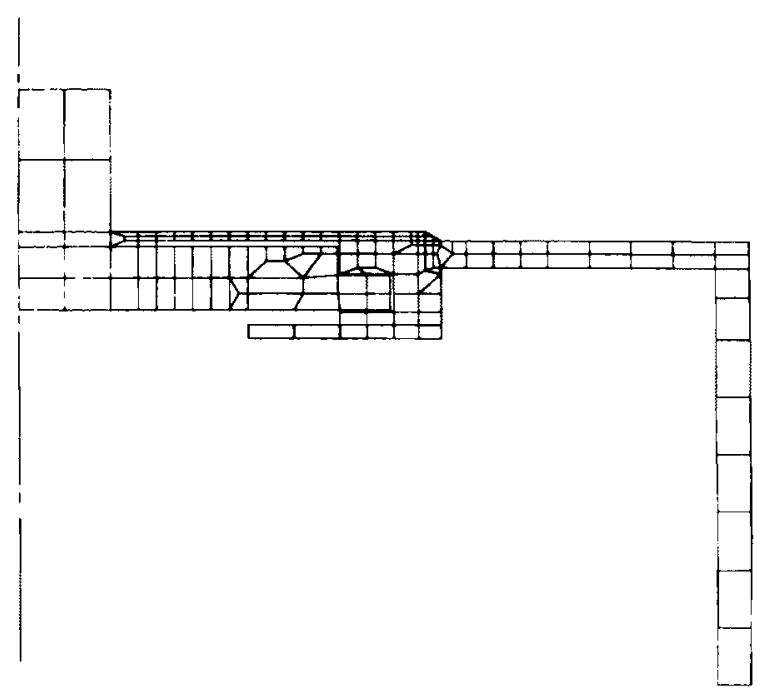

FIGURE F.2. Finite-Element Model for Thermal Structural Analysis 
outer surfaces of the canister to the environment.

During the water quench, the heat transfer will be governed by complex phenomena, as discussed by Chen (1963). The film coefficient for pool boiling conditions reported by Forster and Zuber (1955, pp 531-535) was used in the present calculations. This coefficient was a strong function of $f i l m$ temperature, giving very high cooling rates early in the quench, and then showing a rapid decrease with film temperature as the quench proceeded.

Gaps between parts of the twist-lock lid were modeled in detail for the thermal analysis. However, the geometry of the twist lock was idealized to be axisymmetric. Heat transferred across the gaps by the combined mechanisms of radiation and heat conduction through air.

During the water quench, the most significant aspect of the transient thermal solutions was the rapid cooling of the thin seal-plate relative to the more massive parts of the canister top and 1id. Thermal contraction of this plate induced tensile stresses that were transmitted through the closure weld. Figure F.3 indicates temperatures at selected nodes of the finiteelement model for a time of $4.6 \mathrm{~s}$ into the water quench, which corresponded to the maximum tensile stresses adjacent to the weld.

\section{STRESS ANALYSIS}

The finite-element model of Figure F.2 was utilized to calculate transient thermal stresses. Of critical concern were the stresses in the seal plate at the location of the closure weld. Figure F.4 shows the calculated variation in these stresses during transient heating and cooling.

During rapid cooling, two critical times were identified. At $0.39 \mathrm{~s}$ into the water quench, the thermal differential through the thickness of the seal plate resulted in a maximum tensile stress at the outer surface location. At a much later time $(4.6 \mathrm{~s})$, the temperature differential between the thin seal-plate and the more slowly cooling portions of the canister top resulted in the predicted maximum tensile stresses, which were adjacent to the weld at the inner surface of the seal plate.

Transient heating of the canister top upon removal from the water-cooling environment resulted in no critical stresses of interest. Rather, it was the steady-state condition of air cooling for which stresses at the closure weld attained their maximum compressive values.

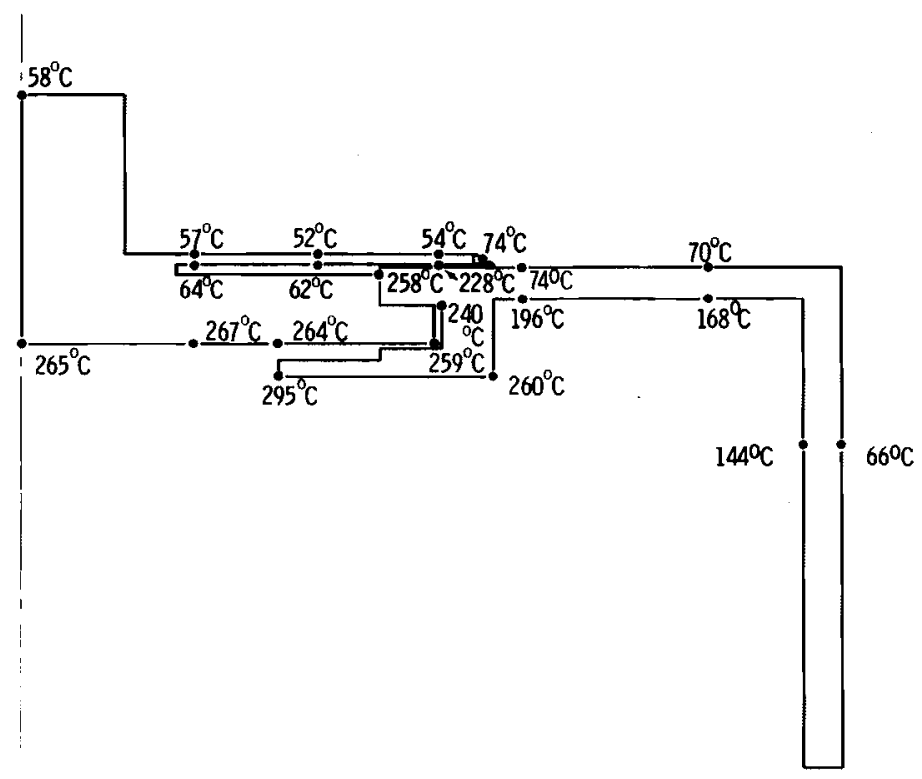

FIGURE F.3. Temperature Distribution at $4.6 \mathrm{~s}$ into Water Quench 
The nominal stresses shown in Figure $F .4$ were not used directly in evaluating the integrity of the closure weld. Rather, these results were used to identify the specific times for evaluating stress intensity factors for postulated weld defects. For stress intensity factor evaluations, more refined finite-element models of the closure weld were used. These stress intensities were calculated for equivalent, purely mechanical loading states, which were determined from solutions for the first-level finiteelement model shown in Figure F.2. This model had a provision to introduce a cut adjacent to the closure weld. In this way, a complete fracture across the seal plate could be simulated and the relative displacement of the parts across the fracture plane were determined. Stress intensity factors were determined on the basis of the mechanical loadings required to eliminate the calculated displacement discontinuity across the artificial cut in the thermal structural model. With this procedure, it was not necessary to transpose the temperature distributions onto the refined model used in the fracture mechanics analysis.
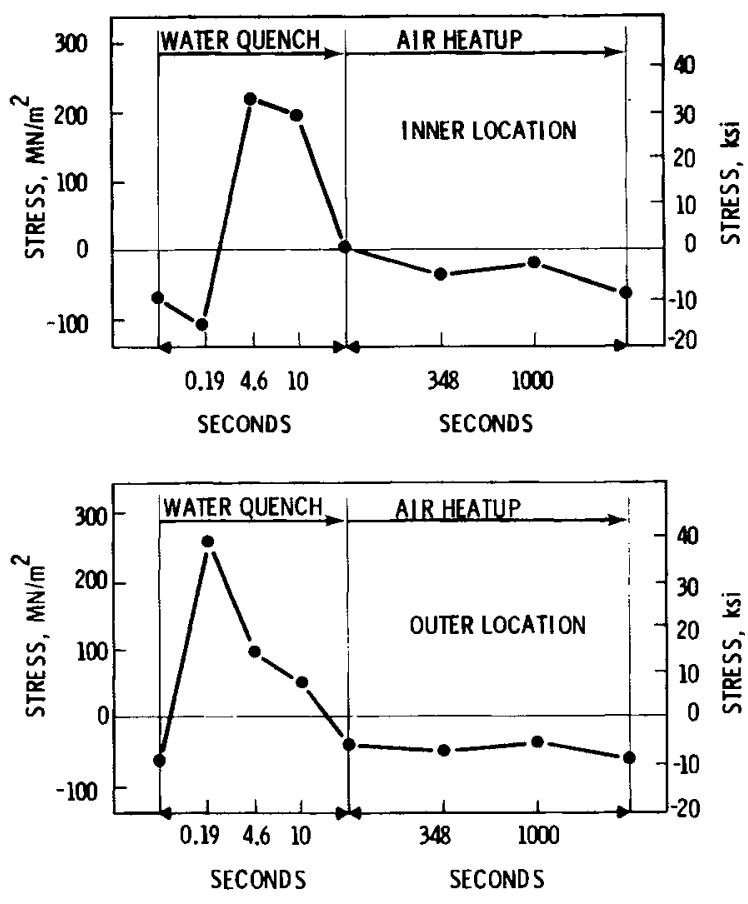

FIGURE F.4. Transient Thermal Stress in Seal Plates Adjacent to Closure Weld

\section{CALCULATION OF STRESS INTENSITY FACTORS}

In considering the weld-joint integrity, it was necessary to postulate locations and orientations of defects in the weld. For this purpose, the set of weld crack types shown in Figure F.5 was selected to span the range of possible defects from fabrication. At the time of this study, no information was available to suggest which of these modes would most closely approximate defects encountered during fabrication. The postulated defects were taken to be in planes extending from the end of the notch-like configuration of the joint. As shown in Figure F.5, crack or ientations of $0^{\circ}, 45^{\circ}$ and $90^{\circ}$ were considered, with the crack beginning either at the internal or external location; thus, a total of six basic crack types were considered. Detailed finite-element models of the closure weld geometry were generated for the specific case of the $45^{\circ}$ defect, as shown in Figure F.6. The weld bead shape was based on an observed configuration of a trial weld specimen. Along the plane of the postulated crack, a double set of nodes allowed simulation of cracking. Adjoining nodes on opposite sides of the crack plane were either coupled with linear stiffness elements to simulate the uncracked condition or were uncoupled to allow relative nodal displacements across the stressfree crack plane.
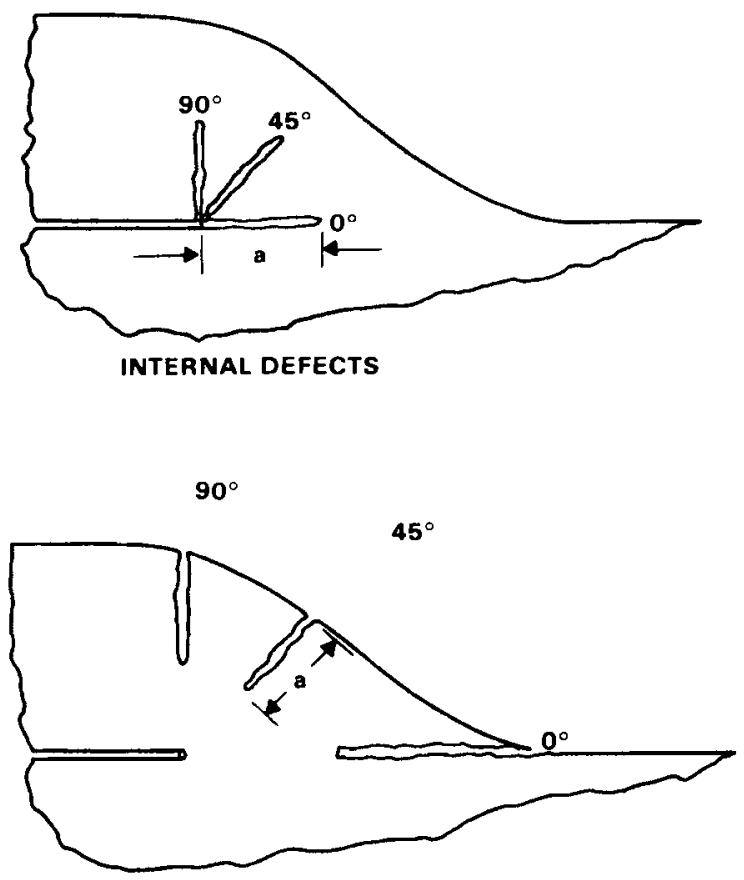

EXTERNAL DEFECTS

FIGURE F.5. Postulated Weld Defects 


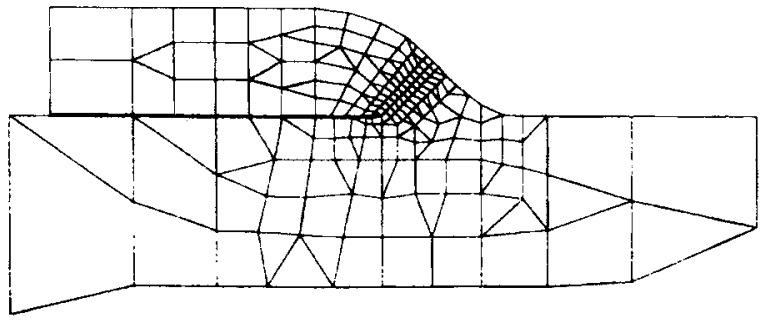

FIGURE F.6. Detailed Finite-Element Model for Fracture Mechanics Analysis

The PNL two-dimensional, finite-element program AXISOL was used for the stress intensity factor calculations. This program utilizes the constant-stress triangular element, either as single elements or merged as groups of four to form quadrilaterals in the manner of Wilson ( $W i l s o n$ and Jones 1967). The loading was the imposed displacement discontinuity at the location of the weld joint, as defined above.

The concept of crack closure work was used to evaluate stress intensity factors from the finite-element solutions. This concept can be viewed as an application of Irwin's (1958) equation. Its application in the present study is similar to the procedure discussed by Dixon and Pook (1969) and by Mowbary (1970). The crack closure work is calculated according to

$$
W=1 / 2\left(f_{x} \Delta u+f_{y} \Delta u_{y}\right),
$$

where $f_{x}$ and $f_{y}$ are the components of the reaction forces between adjacent nodes across the crack plane in the uncracked state. The displacement components $\Delta u_{x}$ and $\Delta u_{y}$ represent the relative displacement of the same nodes for a specific cracked state. The summation is for all nodes on the crack plane. In this study, the stress intensity factor for a given crack length was calculated from the crack closure work by

$$
K=\left(\frac{E}{1-v^{2}} \frac{a}{r} \frac{d W}{d a}\right)^{\frac{1}{2}}
$$

The derivative is evaluated in the numerical sense, with $r$ being the radial coordinate of the present position of the crack tip, $E$ the elastic modulus, and $v$ Poisson's ratio. No attempt was made to distinguish between mode I and mode II fractures, rather, the above equation was intended to evaluate an effective stress intensity factor. Detailed consideration was, however, given to the numerical values of the relative opening and sliding crack-tip displacements for the solutions generated in this study. The solutions all showed that the opening, or $\mathrm{K}_{\mathrm{I}}$ mode, dominated; the contributions from the sliding, or $\mathrm{K}_{\mathrm{II}}$ mode, were relatively small.

The accuracy of the numerical method of calculating stress intensity factors for the selected mesh refinement was evaluated. The mesh for the $90^{\circ}$ defect was exercised as a two-dimensional planar model for comparison with well-known solutions for an edge crack in a finite width strip. For this configuration, the numerical error was on the order of $10 \%$, with the stress intensities being underestimated. Similar levels of accuracy for the method are reported by Rybicki and Kanninen (1977) for relatively unrefined grids, like those used in the present work. It is believed that the stress intensity results reported here are more accurate than the $10 \%$ level of the edge-crack test case. In the present case, the calculated stress intensities were determined to be relatively weak functions of crack length in contrast to the relatively strong dependence on crack length for the edge-cracked strip.

Calculated stress intensity factors for the transient thermal loading are shown in Figures F.7 through F.12 for the six postulated modes of cracking and for the three critical times in the thermal transient. The positive or negative sense for the stress intensities were based on examination of the solutions for opening or closing at the crack tip. The stress intensities apparently do not approach zero for zero crack length for those cases in which cracking was assumed to start internally. Evidently, this is a reflection of the notch type configuration of the uncracked joint, which was, in fact, modeled as a sharp crack. For external cracking, the stress intensity approached zero for a zero crack length in a characteristic fashion. The zero degree crack orientations gave relatively low stress intensities and, surprisingly, exhibited a dominate mode I opening type of behavior, rather than a mode II sliding behavior. Stress intensity factors for the $45^{\circ}$ and $90^{\circ}$ crack orientations were roughly comparable. Also, there appeared to be no clear-cut difference in severity between internal and external cracking. In general, under steady-state conditions of air cooling, cracks tended to close. On the other 
CRACK LENGTH, in. .

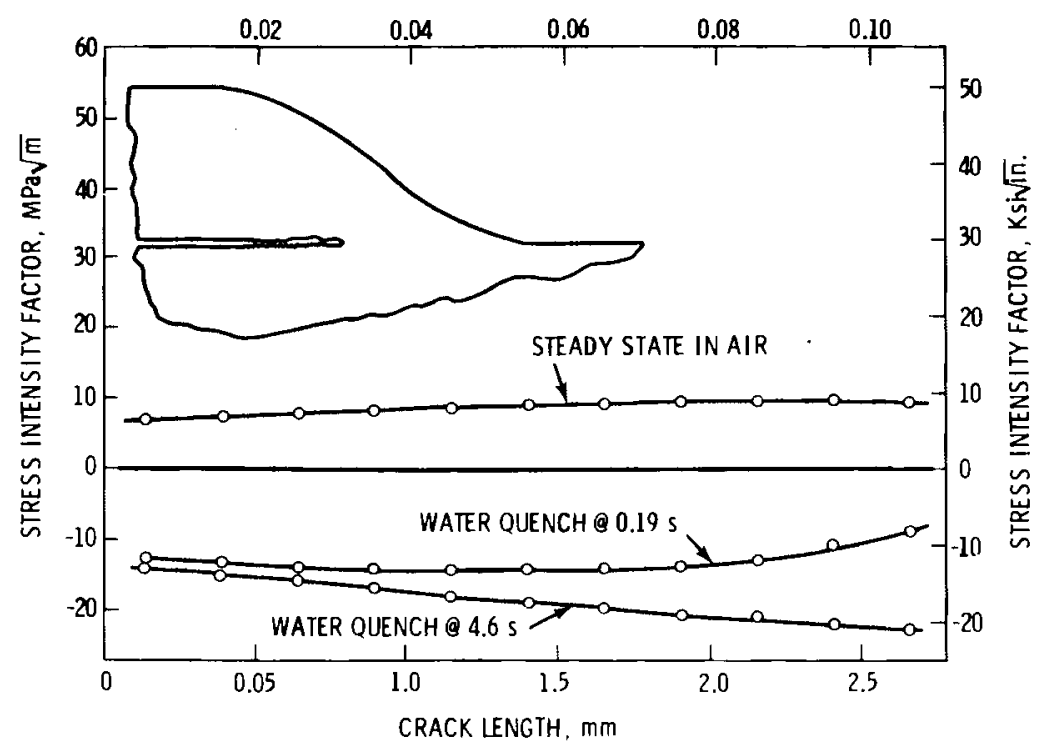

FIGURE F.7. Stress Intensity Factors for Internal Zero Degree Defect

CRACK LENGTH, in.

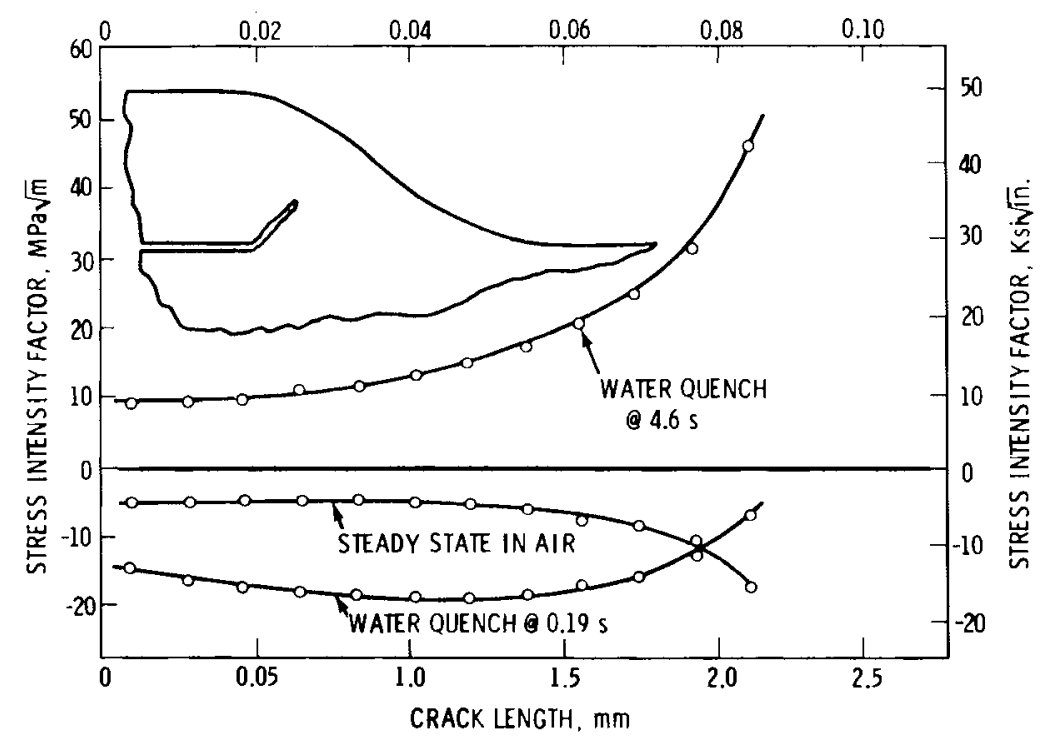

FIGURE F.8. Stress Intensity Factors for Internal $45^{\circ}$ Defect

hand, cracks were predicted to open the greatest during the transient cooling of a water quench.

\section{CRACK GROWTH CALCULATIONS}

Fatigue crack growth was predicted for $304 \mathrm{~L}$ stainless stee 1 , which was thought to be representative of materials being considered for canisters. Inconel 601 is also a candidate for waste canister use. Available data on crack growth and fracture indicated that similar conclusions would hold for either of these alloys, regarding the limits on crack size and the structural integrity of the closure weld. 
CRACK LENGTH, in.

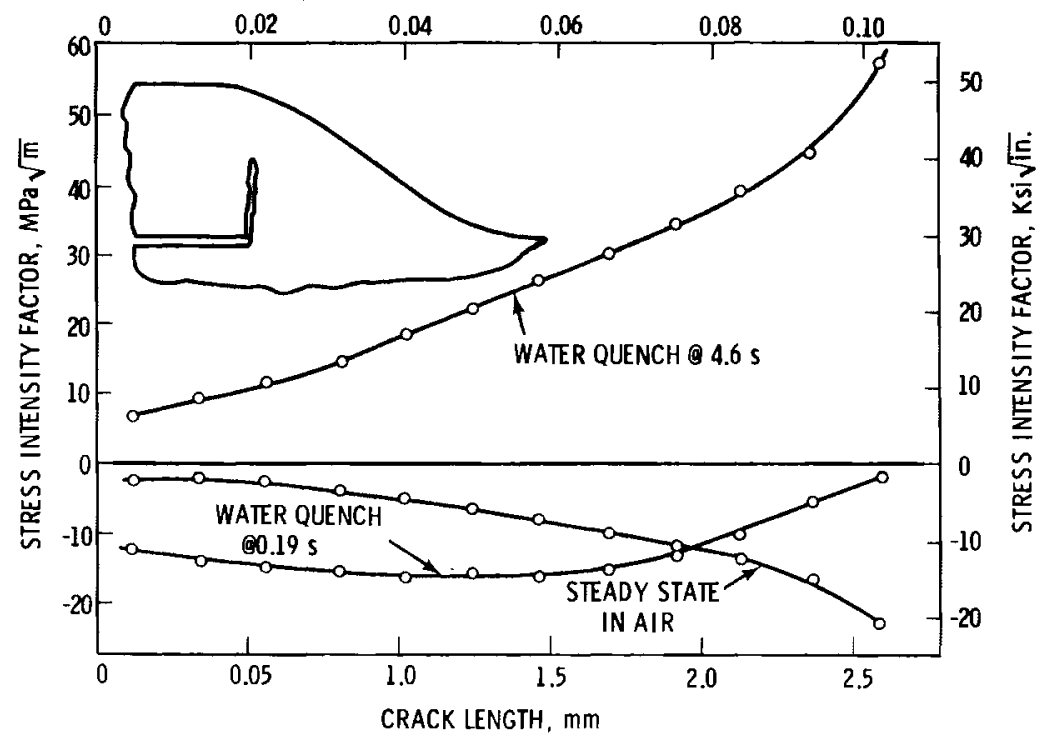

FIGURE F.9. Stress Intensity Factors for Internal $90^{\circ}$ Defect

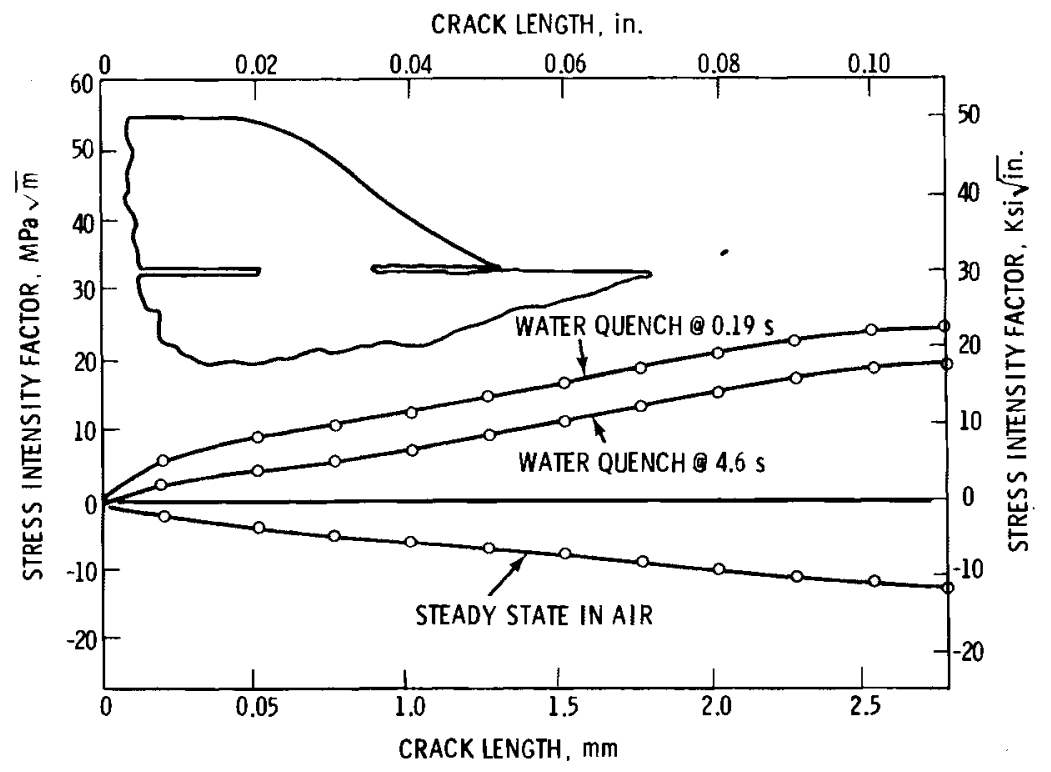

FIGURE F.10. Stress Intensity Factors for External Zero Degree Defect

Stable or unstable crack growth due to exceeding the fracture toughness parameters was ruled out. The displacement discontinuity at the closure weld due to a complete break at this location was calculated as described above. This calculated displacement discontinuity did not exceed $0.25 \mathrm{~mm}$ (about 0.010 in.). This discontinuity can serve as an upper bound for estimating crack opening displacement. Fracture tests on $304 \mathrm{~L}$ stainless steel plates as reported by Kanninen et al. (1976) showed that crack opening displacements of about ten times this level are required to initiate a 


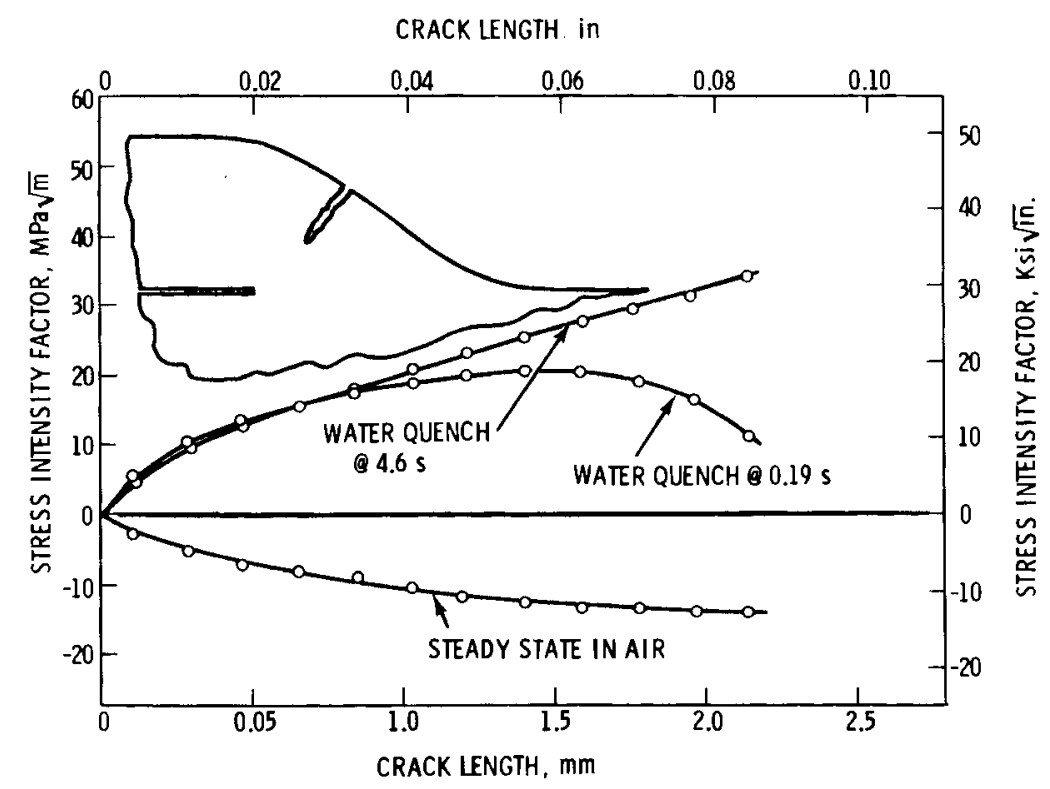

FIGURE F.11. Stress Intensity Factors for Externa $145^{\circ}$ Defect

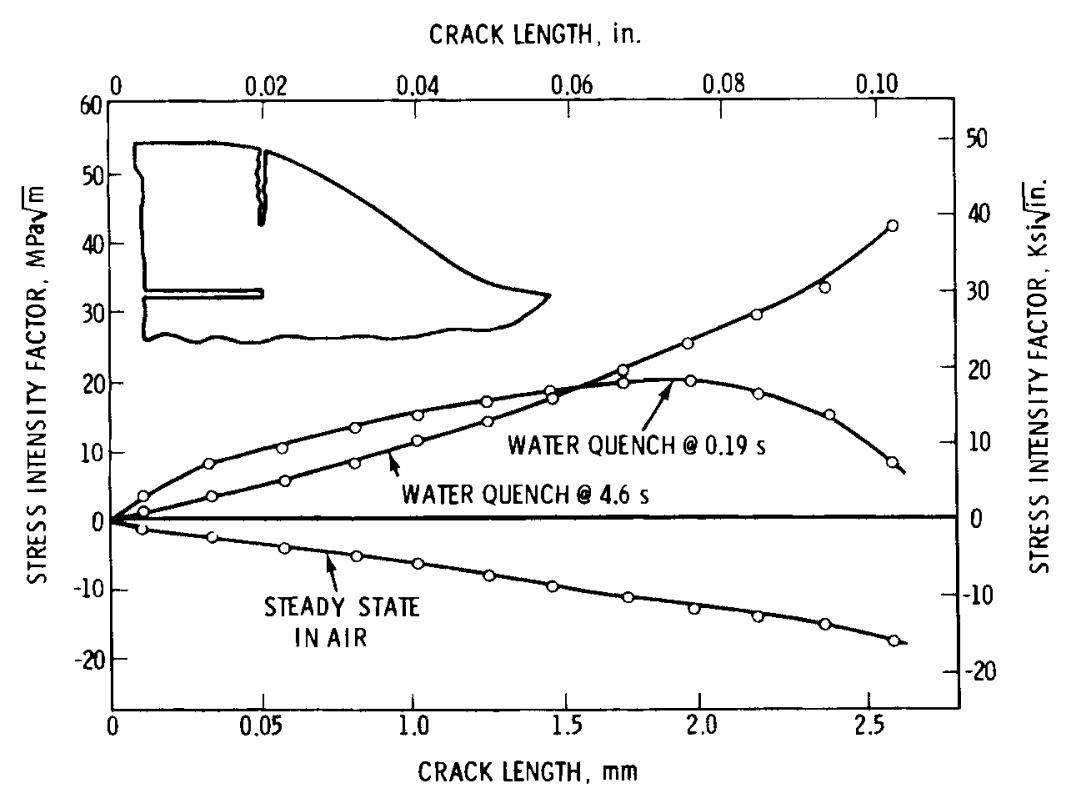

FIGURE F.12. Stress Intensity Factors for External $90^{\circ}$ Defect

stable mode of crack growth. Test results show that continued loading is required to produce catastrophic fracture. For materials as tough as $304 \mathrm{~L}$ stainless steel, fracture toughness values cannot be measured by conventional procedures. The calculated stress intensities in this study were below the level of $100 \mathrm{MPa} \sqrt{\mathrm{m}}$. It can be reasonably assumed that the material fracture toughness of interest is considerably greater than this. For example, data published by Loss (1976) indicate toughness values on the order of $300 \mathrm{Mpa} \sqrt{\mathrm{m}}$. 
Crack growth due to fatigue was evaluated on the basis of state-of-the-art prediction methods as discussed, for example, by Nelson (1977). In these methods, crack growth rates are described in terms of $\mathrm{da} / \mathrm{dN}$, with the parameter a being the crack length and $\mathrm{N}$ the number of fatigue cycles. This crack growth rate is related to the present value of a crack-tip stress intensity parameter. This parameter is usually the $k$, or the range in stress intensity over the fatigue cycle. Also, the parameter $K_{\max }$ or the maximum stress intensity during the cycle was utilized. In the present calculations, crack growth data reported by James (1974) were used for which the correlation parameter was $K_{\max }(1-R)^{0.6}$, where mean stress effects are included through the factor $R=$ $\mathrm{K}_{\min } / \mathrm{K}_{\max }$.

Figures $F .13$ and $F .14$ predict fatigue crack growth for various sizes of the postulated initial defects. In these calculations, it was assumed that $R=0$ and that $K_{\max }$ equals the $K$ values indicated in Figures F.7 through F.12. In effect, the $K$ versus crack-length curves were off-set in the positive direction so that the minimum $K$ values were zero. Such a procedure was followed because the stress analyses did not account for possible residual stresses in the canister lid assembly. To ensure conservative predictions of crack growth rates, it was necessary to assume that tensile residual stresses equal to the tensile yield strength of the material were present.
A review of stress levels in the present analyses indicated that taking $R=0$ was about equivalent to assuming a maximum residual stress at the tensile yield strength. During the thermal stress cycling, predicted elastic stresses could then exceed yield strength. However, in the present case, the predicted overall range in nominal stresses at the weld location were sufficiently low so that the cyclic stresses would shakedown to elastic behavior.

The crack growth curves shown in Figures F.13 and F.14 were plotted on ly to 100 cycles, since the total number of cycles to be experienced by a canister was placed at ten or fewer. For defects less than $1.5 \mathrm{~mm}$ (about $0.06 \mathrm{in.}$ ), the predicted crack growth was insignificant. This defect represents a crack that is nearly one-half the thickness of the seal plate. Cracks at the zero-degree orientation could be as large as $2.5 \mathrm{~mm}$ (about $0.10 \mathrm{in.}$ ) and not experience significant growth. Cracking at a $45^{\circ}$ orientation was found to represent the most severe condition, with growth rates becoming significant for crack sizes in excess of about $2.0 \mathrm{~mm}$ (about $0.08 \mathrm{in.}$ ). For the $90^{\circ}$ orientation, the significant defect was about the same size as for the $45^{\circ}$ orientation.

In the above considerations, it should be emphasized that the crack extended circumferentially around the entire weld. For the more common "thumb-nail" type of defect, the

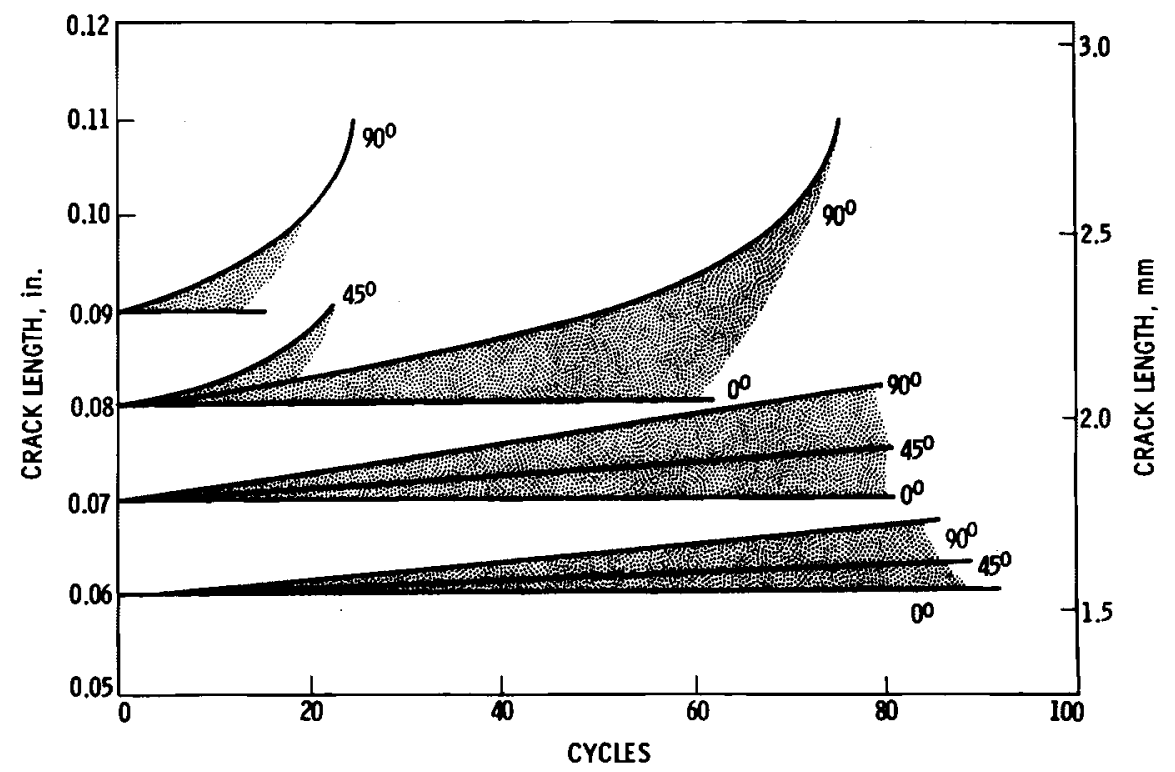

FIGURE F.13. Fatigue Crack Growth for Internal Defects 


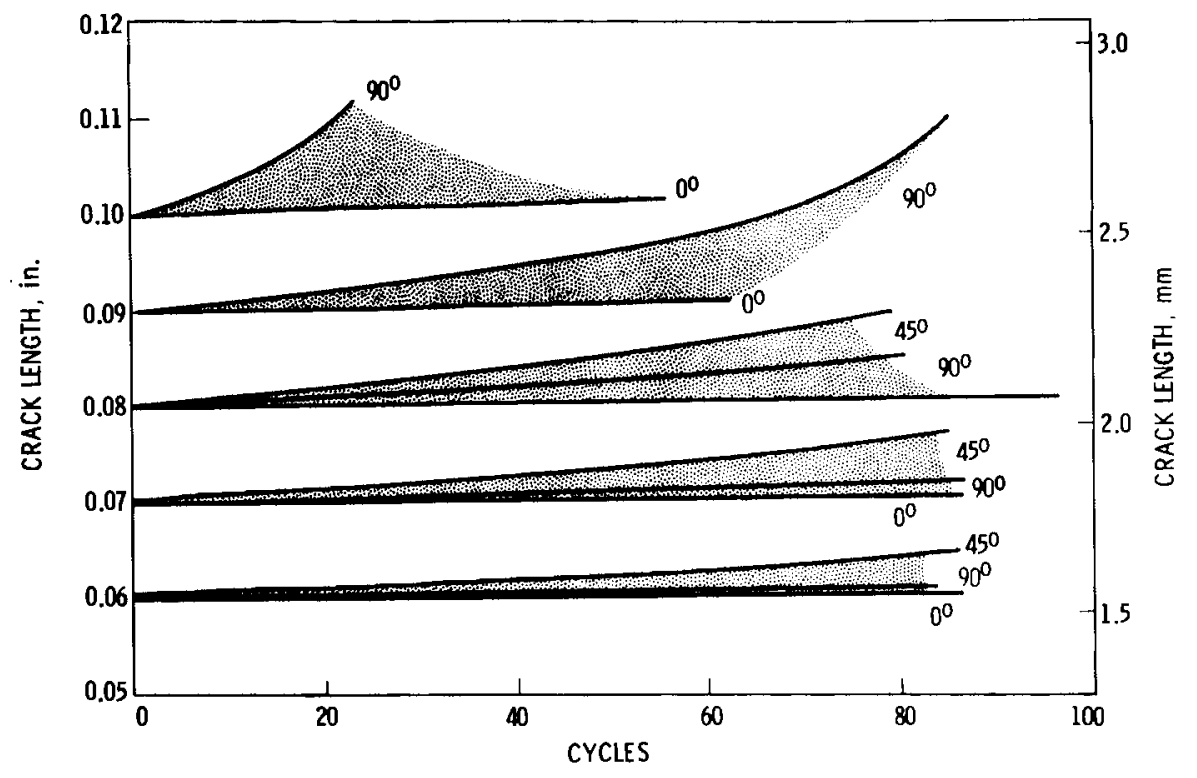

FIGURE F.14. Fatigue Crack Growth for External Defects

above estimates of significant defect depths may be quite conservative. An evaluation of the defect-aspect ratio (ratio of circumferential dimension to depth) was performed. This study indicated that for an aspect ratio of less than about 2.0 , a crack nearly through the section could be tolerated. On the other hand, cracks of large aspect ratio that extended approximately $13 \mathrm{~mm}$ (5 in.) could be considered to be as severe as a crack extending around the full circumference of the weld.

\section{ANALYSIS OF ACTUAL BEAD GEOMETRY}

The above calculations were based on an assumed we ld bead configuration, and were performed before data on actual weld bead configurations from welding trials were available. Figure F.15 shows a metalographic section of an actual weld bead, which differs in some respects from the configuration assumed in above analyses. Figure F.16 shows the finite-element model, which was based on a metalographic section of a weld. The model was developed to simulate cracking through the minimum section of the weld. Loadings to the weld were the same as in the previous analyses, those of repeated thermal cycling.

Figures $F .17$ and $F .18$ show calculated values of crack-tip, stress intensity factors and predicted fatigue crack growth rates for $304 \mathrm{~L}$ stainless steel. Both internal and external defects were considered, with crack growth rates slightly greater for internal defects. The results for the internal defects are shown here. The stress intensity and predicted crack growth rates for the actual bead configuration show the same trends as the predictions for the assumed weld configuration analyzed previous1y. The minimum cross section of the actual weld bead is less than that for the assumed weld bead initially considered. Thus, the absolute size of the critical defect is less (about 0.055 in. versus about 0.09 in.) than that estimated for the assumed weld bead. However, a defect can extend through a greater percentage of the weld cross section in the case of the actual weld bead geometry. In this respect, weld defects of critical size may be more readily detected in the weld of the smaller cross section.

\section{DISCUSSION AND CONCLUSIONS}

The structural integrity of an unconventional weld configuration was evaluated for a complex history of transient thermal loadings. Nominal stress levels and crack-tip stress intensity factors were evaluated with finite-element methodology. Fatigue crack growth rates were predicted and it was shown that initial defects of substantial and detectable size could be tolerated. The proposed weld inspection consists of a leak check followed by an ultrasonic evaluation. In the leak check, a gas source (helium or neon) is introduced into the canister just 


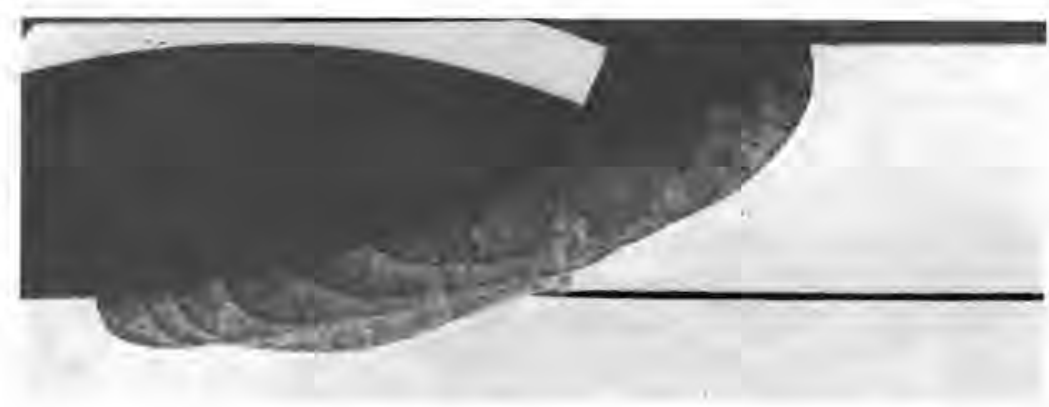

FIGURE F.15. Metalographic Section of Closure Weld

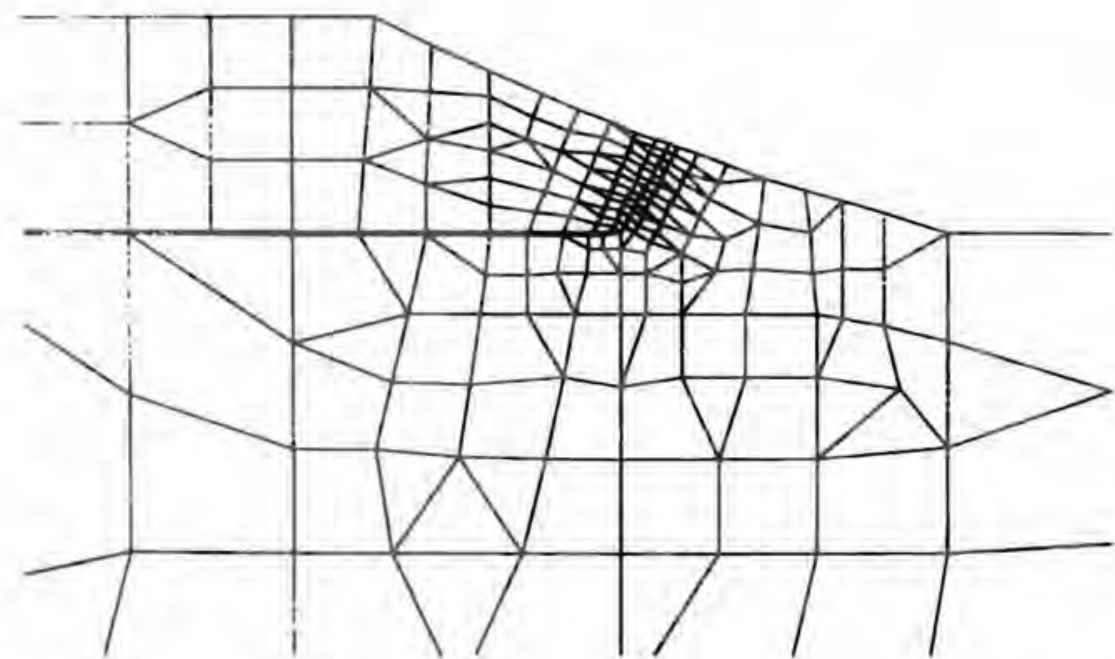

FIGURE F.16. Finite-Element Model Based on Metalographic Section of Weld Bead

before the lid is welded. After the lid is welded, leakage will be detected by placing a bell jar over the canister 1id, drawing a vacuum and checking to determine if leakage is within tolerable bounds. The proposed ultrasonic inspection will be by standard through-transmission techniques, with the transmitter on the canister top and the receiver on the lid. The presence of a defect will be assessed through a loss of signal. Evaluations of the proposed ultrasonic testing procedure indicated that defects extending through about one-half the weld cross section could be reliably detected. The fatigue crack growth calculations showed that defects well in excess of this detectable size can be tolerated; therefore, it was concluded that the development of more refined inspection methods was not warranted.

While this case study was for specific design and service conditions, the benefits gained from damage-tolerance analysis methods were well illustrated. Many of the benefits in the present situation came from application of the methods in the early stages of design and systems development. For the closure weld, the design concept emphasized simplification of assembiy and ease of welding, but appeared suspect from the standpoints of good design practice and structura) integrity. However, by an in-depth analysis, the structural integrity was established for a design concept that might otherwise have been rejected. 


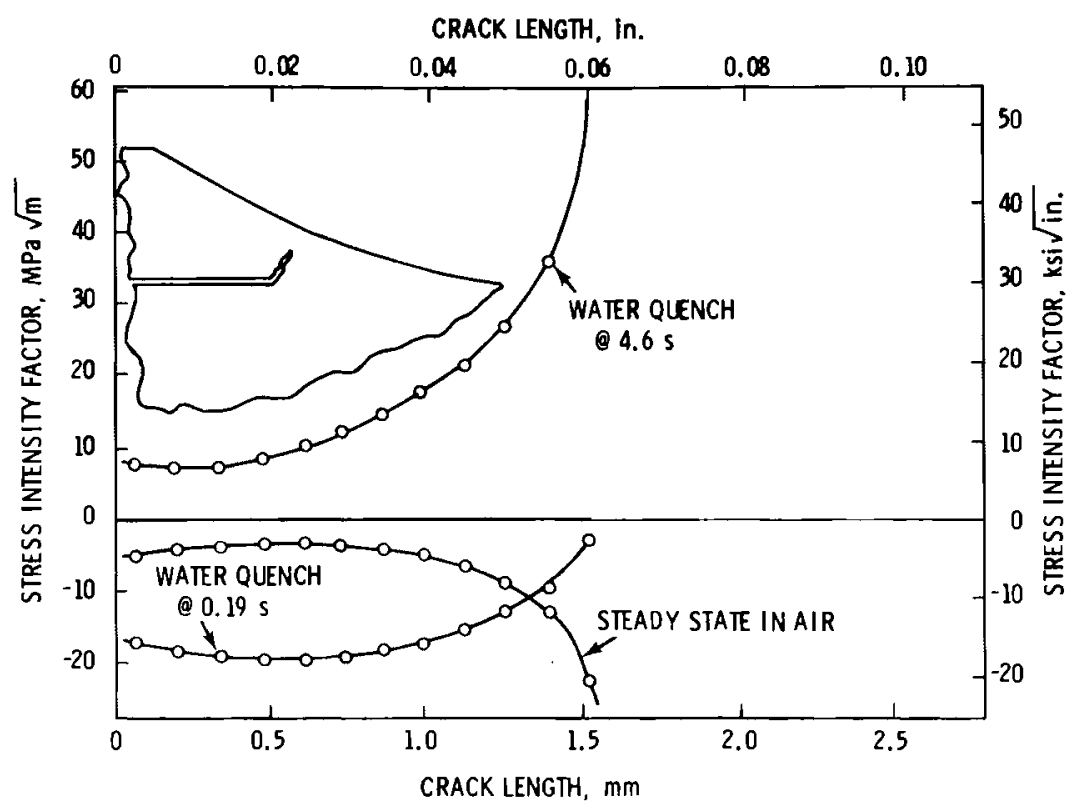

FIGURE F.17. Stress Intensity Factors for Internal Defects in Weld Bead of Metalographic Section

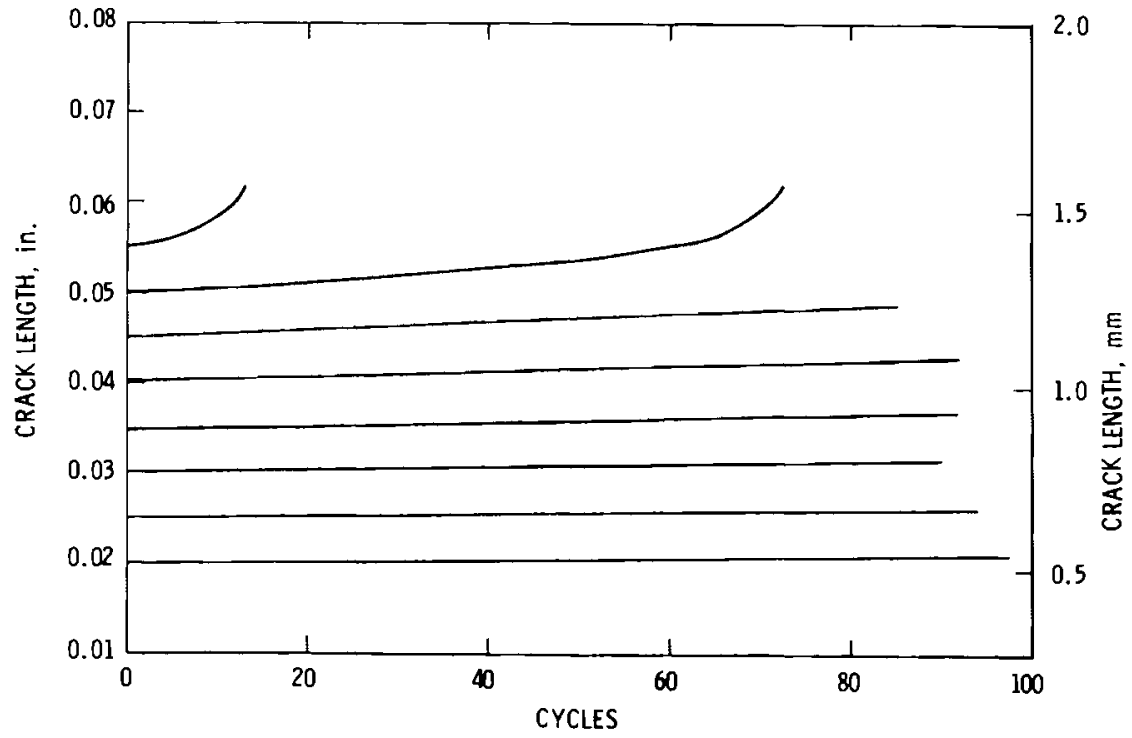

FIGURE F.18. Fatigue Crack Growth for Internal Defects in Weld Bead of Metalographic Section 


\section{REFERENCES}

Chen, J. C. 1955. A Correlation for Boiling Heat Transfer to Saturated Fluids in Convective Flow. ASME Paper No. 63-HT-34, American Society of Chemical Engineers, New York, New York.

DeSalvo, G. J., and J. A. Swanson. 1975. ANSYS Engineering Analys is User's Manual. Swanson Analysis Systems, Elizabeth, Pennsylvania.

Dixon, J. R., and L. P. Pook. 1969. "Stress Intensity Factors Calculated by the Finite-Element Technique." Nature 224. (166).

Forster, H. K., and N. Zuber. 1955. "Dynamics of Vapor Bubbles and Boiling Heat Transfer." AIChE Journal. $\underline{1}(4): 531-535$.

Irwin, G. R. 1958. "Fracture." Handbuck der Physik 6:551-590.

James, L. A. 1974. "Estimation of Crack Extension in a Piping Elbow Using Fracture Mechanics Techniques." $\mathrm{J}$. of Pressure Vessel Technology 96:273-278.

Kanninen, M. F., et al. 1976. Mechanical Fracture Predictions for Sensitized StainTess Steel Piping with Circumferential Cracks. EPRI NP-192. By Battelle Columbus Laboratories, prepared for Electric Power Research Institute, Columbus, Ohio.
Loss, F. J. 1976. J-Integral Characteristics of Type 316 Stainless Steel. Presented at the International Experts' Meeting on Elastic-Plastic Fracture Mechanics. San Francisco, California.

Military Specification MIL-A-8344, Airplane Damage-Tolerance Design Requirements.

Mowbary, D. F. 1970. "A Note on the Finite Element Method in Linear Fracture Mechanics." Journal of Engineering Fracture Mechanics 2:173-176.

Nelson, D. V. 1977. "Review of FatigueCrack Growth Prediction Methods." Experimental Mechanics 17(2):41-49.

Rybicki, E. F., and M. F. Kanninen. 1977. "A Finite-Element Calculation of Stress Intensity Factors by a Modified CrackClosure Integral." Journal of Engineering Fracture Mechanics 9:931-938.

Turner, W. D., and M. Simon-Tov. 1971. HEATING4 - In IBM 360 Heat Conduction Program, ORNL-TM-3208. Oak Ridge National Laboratory, Oak Ridge, Tennessee.

Wilson, E. L., and R. M. Jones. 1967. Finite Element Stress Analysis of Axisymmetric Solids with Orthotropic, Temperature Dependent Material Properties. Air Force Report No. BSD-TR-67-222 Aerospace Corporation, San Bernardino, California. 


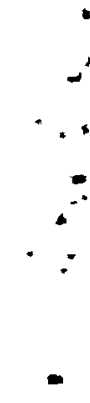


APPENDIX G 
APPENDIX G

\section{OVERPACK CONSIDERATIONS}

An overpack refers to any second container into which the primary canister is placed any time after filling with the waste glass product. This section of the report describes some of the important considerations that will govern decisions on if and when to overpack a primary canister. An account is then given of some computer simulations that predict residual stress levels in overpacks.

\section{EVALUATION OF OPTIONS}

An overpack may be used routinely or in special circumstances only. In usage under special circumstances the primary canister will be overpacked only if it does not meet quality standards. In routine usage, each canister will be overpacked after the primary canister is filled and sealed, as an inherent part of the packaging system design. Both operating modes have been considered at PNL to establish the advantages and disadvantages of each.

Arguments in favor of routine overpacking center on increasing the level of containment. The main arguments against routine overpacking are additional costs and degradation of heat removal.

For high-heat wastes, an overpack impedes heat removal, which may result in overheating of the glass composition or necessitate undesirably small canisters. For example, the temperature of a 12-in.-dia canister containing glass at $150 \mathrm{~W} / \mathrm{L}$ may increase $100^{\circ} \mathrm{C}$ (180 $\left.\mathrm{F}\right)$ when overpacked. This, in effect, requires smaller diameter canisters to meet the glass temperature limits; smaller canisters mean more canisters and thus, higher costs.

Current work at PNL is being conducted to demonstrate that a single canister will be able to meet all necessary requirements. The conclusions of an evaluation of overpack usage conducted by the Nuclear Services Corporation (1978, pp. 2-2) states ... "The use of an overpack, as an integral part of overall canister design, is undesirable, both from a design and economics standpoint" . . Under current industry guidelines and governmental regulations, the single canister concept appears acceptable. The argument for using an integral overpack as a second level of containment does not seem to be justified, since all facilities and shipping containers will contain any releases from a failed canister. Overpacks in this mode of operation would be used only on canisters that do not meet acceptance criteria for shipping or disposal.

Because there is a definite chance that some canisters will fail acceptance criteria, overpacks must be designed. One possible design is illustrated in Figure G.1. In general, overpacks should be designed so that minimal additional facilities will be

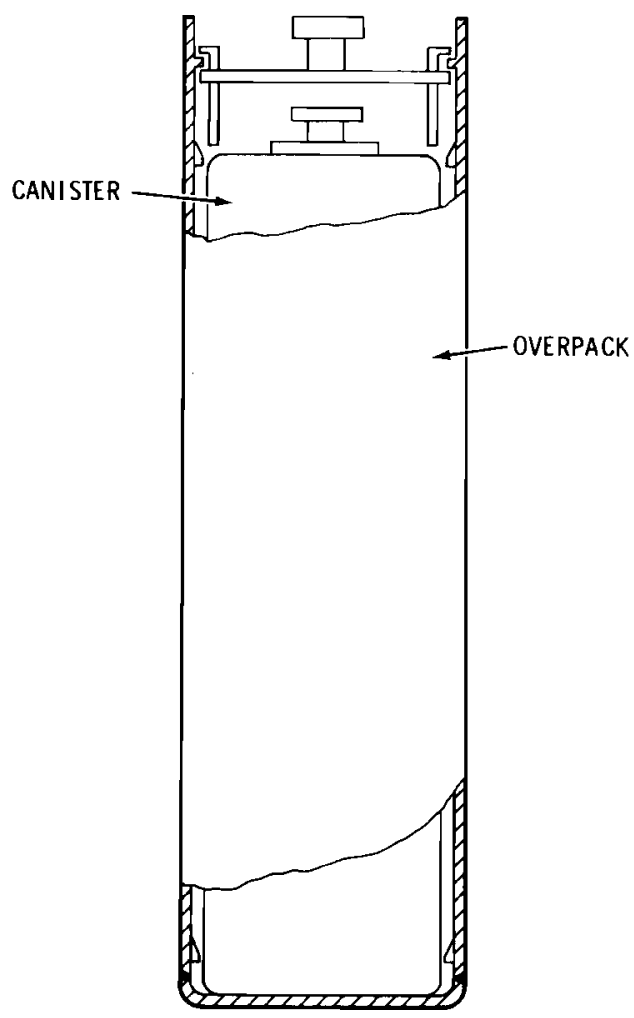

FIGURE G.1. Schematic Drawing of a Canister in an Overpack 
required to handle them. For example, the closure could be designed to use equipment similar to that for the canister closure. The overpack would preferably be emplaced in the second hot-cell, where only minor decontamination would be necessary.

The mode of routine overpacking has potential benefits, which are being invest $i-$ gated. The first is the additional level of containment the overpack provides. Two other benefits that have been considered are a possible reduction in quality verification requirements and easier decontamination. The overpack will not have endured the rigors of glass filling and cooldown, so its condition should be easier to predict when evaluating its integrity. In addition, the entire overpack could be checked by a helium leak test. The use of an overpack for decontamination would be achieved by placing a partially decontaminated canister into a clean overpack. This operation must be performed in a contamination-free cell, so that the clean overpack is not contaminated. Careful design and strict operating procedures would be needed to prevent contamination of the cell. The operational requirement and costs of this method will have to be compared to the other decontamination methods before a decision to use it is made.

A final potential benefit of routine overpack usage is a decreased susceptibility to stress-corrosion cracking in water storage, because levels of residual stresses in an overpack are lower than in a primary canister. Studies at PNL show that primary canisters typically have tensile residual stresses at the level of the yield strength of the canister wall material. The consequences of these residual stresses in the primary canister were discussed in Appendix I. In this appendix residual stresses that may exist in the wall of an overpack are evaluated.

\section{RESIDUAL STRESS IN OVERPACKS}

One of the major attractions of routine overpack usage is that an overpack could have very low residual stresses compared to a primary canister. If a nearly stress-free overpack could be produced, then water-basin storage could be used with little or no concern for stress-corrosion cracking of the overpack. In contrast, the wall of a primary canister will almost certainly have residual stresses on the order of the material yield strength; such stresses, in conjunction with suitable metallurgical conditions and water chemistry, can lead to stress-corrosion cracking during water storage.

The incentives for using overpacks on a routine basis hinge on two factors:

1) whether a stress-free canister is really required to avoid stress-corrosion cracking, and 2) whether water-bas in chemistry can be controlled, or crack-resistant alloys, such as Inconel 601, can be used. The first factor concerns whether one can ensure that an overpack will, in fact, be free of detrimental residual stresses after closure welding, and after mechanical and thermal stressing during handling. With regard to the second factor, the stress calculations below indicate that use of an overpack will certainly improve the residual stress situation. Elimination of the membrane residual tensile stress in the canister sidewall is certainly beneficial. However, residual stresses of lesser severity from fabrication, welding, and handling are likely to be present even in an overpack. These stresses are likely to be lower in magnitude and have a distribution characteristic of bending with a variation from tension to compression through the canister wall. In such stress fields, the growth of stresscorrosion cracks through the canister wall is less likely, since cracks may grow through zones of high tensile stress, but are then arrested as the regions of compressive stress are approached.

To indicate residual stress levels, canister overpack stresses resulting from rapid cooling were calculated. Residual stresses induced in canister walls and end closures were evaluated to determine whether an initially stress-free canister will develop residual stresses in service. The development of such stresses would increase the susceptibility of the overpack to stresscorrosion cracking and thus, would tend to outweigh one of the advantages of overpacks.

The finite-element computer program ANSYS (DeSalvo and Swanson 1975) was used for heat-transfer and stress calculations. Ranges of canister diameters, wall thicknesses and end closure configurations were analyzed to establish trends. In a series of one-dimensional analyses for a generic overpack cross section, a range of wall thicknesses and cooling conditions was considered. Figure G.2 shows the calculated values of peak surface-tensile stress during the cooling of a hot overpack by quenching it in water at various initial temperatures. For a yield strenth of $241 \mathrm{Mn} / \mathrm{m}^{2}$

$(35,000 \mathrm{psi})$, the cooling stresses would result in tensile plastic deformation during 
the rapid cooling. However, the resulting residual stresses from this tensile deforma$t i o n$ would be compressive at the outer surface of the overpack and this would not contribute to stress corrosion cracking.

$\therefore$

,. $\therefore$ $\therefore$

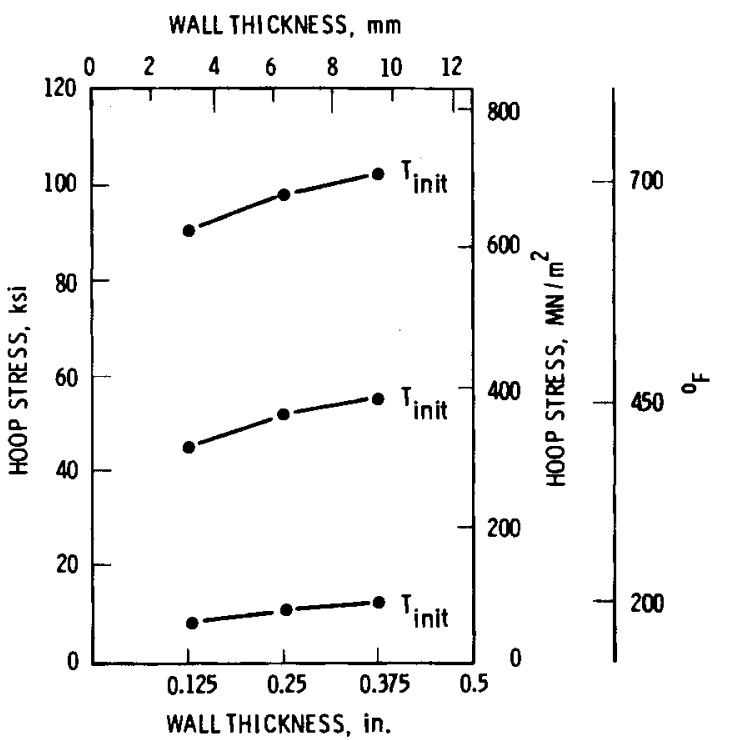

FIGURE G.2. Maximum Hoop Stress in Overpack Due to Water Quench - OneDimensional Cylindrical Model

A two-dimensional analysis of cooling stresses in a typical overpack bottom was also performed. This analysis evaluated local bending action, which could result in zones of tensile residual stresses at the outer surface of an overpack. The analysis considered an overpack with a flat bottom joined to a relatively thin-walled body. This difference in section thicknesses was selected to accentuate thermal stresses due to differential cooling rates. Initially, the overpack was at a temperature of $232^{\circ} \mathrm{C}$ $\left(450^{\circ} \mathrm{F}\right)$, corresponding to air storage of high-heat waste. The hot overpack was then cooled rapidly by quenching in water. Since the thicker bottom cooled nore slowly than the side walls, local thermal stresses built up in the overpack during transient cooling.

Figure G.3 shows predicted stresses for a 12.7-mm (0.500-in.) bottom joined to a 3.17-mm (0.125-in.) wal1. The time, $2.5 \mathrm{~s}$, corresponds to the maximum predicted stress. Outer surface stresses were primarily tensile during the water quench, which implies that subsequent residual stresses will be compressive. Elastic-plastic stress calculations that could predict residual stress patterns in detail were beyond the scope of the study. It should be noted that during the quench, one outer surface location is seen in Figure G.3 to be subjected to compressive stress. This location is in the side wall near the bottom corner jojnt, and the stress level is about $69.0 \mathrm{Mn} / \mathrm{m}^{2}$

$(10,000$ psi) in compression. Any subsequent tensile residual stresses at this location would, however be expected to be less than this $69.0 \mathrm{Mn} / \mathrm{m}^{2}(10,000 \mathrm{ps} i)$ level.

The analyses indicate that for a heatemitting glass, residual stresses will develop in an overpack when a hot overpack is transferred from air storage to water storage. However, these stresses are primarily compressive on the critical outer surface of the overpack. These stresses should be much less detrimental than the tensile stresses observed in primary canisters.

Besides residual stresses from rapid cooling, an overpack will be subject to other residual stresses. The major source of concern is the residual stress at the final closure weld in the overpack, a weld which probably cannot be stress-relieved in practice. The level of residual stresses in welds is governed by such factors as the joint design and details of the welding process. Determination of welding residual stresses either experimentally or analytically is a difficult task. Representative data on welding residual stresses are given by Rybicki and Stonesifer (1978). Surfacetensile stress levels at the material yield strength are typically observed at welds. However, the stresses vary through the weld section and are not uniformly tensile through the section.

Calculations indicate that no overpack will be free of residual stresses. Nevertheless, residual stresses in overpacks should be less severe than in primary canisters. Except at closure welds, residual stresses in overpacks should be primarily compressive at the critical outside surface that is exposed to corrosive media. The most severe residual stresses will probably be at closure welds in overpacks. It is recommended that welding stress be evaluated as part of the development effort of specific overpack designs. 


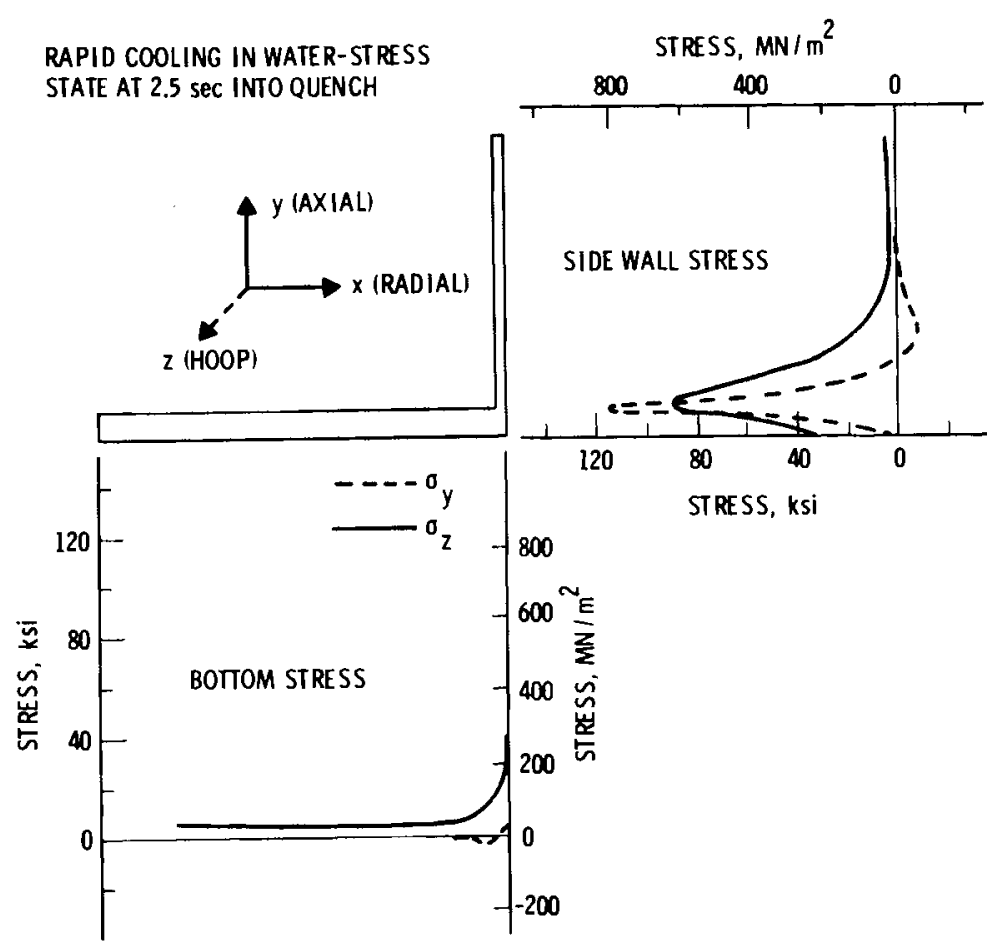

FIGURE G.3. Predicted Outer Surface Stress in Canister Overpack Due to Rapid Cooling in Water

\section{REFERENCES}

DeSalvo, G. J. and J. A. Swanson. 1975. ANSYS Engineering Analys is User's Manual. Swanson Analysis Systems. Elizabeth, Pennsylvania.

Nuclear Services Corporation. 1978. Recommendations for Codes and Standards to be Used for Design and Fabrication of High Level Waste Canister. Report No. NSC-1-78-004. Prepared for Rockwe 11 Hanford Operations (Rockwell Report RHO-C-13), Campbe11, California.
Rybicki, E. F. and R. B. Stonesifer. 1978. Computation of Residual Stresses Due to Multipass Welds in Piping Systems. ASME Paper No. 78-PVP-104, presented at the Joint ASME/CSME Pressure Vessels and Piping Conference, Montreal, Canada. 
$\therefore$

.

$\therefore$

$\therefore$

APPENDIX $\mathrm{H}$ 
APPENDIX H

\section{ACCIDENT PERFORMANCE}

Numerous accident scenarios can be proposed for HLW canisters. In this appendix two types of accidents are considered: impact and pressurization due to overheating (e.g., a fire). A stress analysis of a twist-lock closure shows the ability of the closure to sustain pressure loading. The results of a series of drop tests using glass-filled canisters are described, and factors that govern the impact strength of canisters are identified.

\section{IMPACT STRENGTH OF CANISTERS}

Canisters for vitrified high-level nuclear waste must be rugged to sustain loads of handling and transportation. Under normal conditions, such loads will be relatively modest and will not tax the integrity of the canister. However, under accident conditions (dropping during handling, collision accidents during shipment, etc.) loadings can be severe, and breaching of the canister must be considered a possibility.

Specific design criteria for accident conditions have not yet been adopted for waste canisters. However, it is expected that future criteria will be similar to the highly developed rules presently in force for the transportation of radioactive materials. These rules are outlined below. The approach at PNL to the design of canisters for impact loadings has been to follow, as much as possible, the design practices recormended for shipping containers for radioactive materials. These recommended practices cover materials selection, joint design, welding techniques, and quality assurance. Due to the difficulty of predicting the structural response of containers under impact conditions, stress calculations have been minimal. Rather, efforts have been directed to evaluation of designs using fullscale drop tests. Full-scale testing has been a particularly attractive alternative since canisters are readily available from the extensive PNL research in the area of glass melting.

Evidence to date, both from PNL impact tests and data reported in the literature, indicates no inherent technical problems relative to bottom and side impact of filled canisters. In fact, data suggests that waste canisters could be designed to sustain bottom and side impact velocities in the 20 to $90 \mathrm{~m} / \mathrm{s}(100$ to $300 \mathrm{f} / \mathrm{s})$ range (Teledyne Isotopes 1974; General Electric
Space Division 1975), which is well above any of the present criteria for transportation of radioactive materials. In contrast, little is known of the consequences of an impact on a canister top and the subsequent integrity of the canister closure system. The impact capabilities of specific closure concepts are expected to vary greatly. Depending on details of the design, the closure could fail in an impact from a drop of a few feet, or could sustain impacts approaching the canister capability under bottom and side impact. Future impact evaluations at PNL will focus on the closure integrity problem.

\section{Design Criteria}

Lacking specific design criteria for HLW canisters, PNL and other research laboratories (Nuclear Services Corporation 1978; Kaiser Engineers 1977) have applied the Federal criteria of 10 CFR 71.64. These requirements apply to containers for the transport of radioactive materials. For impact, engineering analyses or actual tests must show that the containers can be subjected to the following hypothetical accident conditions without releasing radioactive materials:

- Free Drop: Free drop through a distance of $(9 \mathrm{~m}) 30 \mathrm{f}$ onto a flat, essentially unyielding surface, striking the surface in a position for which maximum damage is expected.

- Puncture: Free drop through a distance of $102 \mathrm{~cm}$ (40 in.) onto the top end of a vertical, cylindrical, mild steel bar mounted on and perpendicular to an essentially unyielding horizontal surface. The bar shall be $15 \mathrm{~cm}$ (6 in.) in diameter, with its top horizontal and its edge rounded to a radius of not more than $0.64 \mathrm{~cm}(1 / 4 \mathrm{in.})$. It shall be of a length that causes maximum damage to the 
package, but shall not be less than $20.3 \mathrm{~cm}$ ( 8 in.) long. The container striking the bar shall be in a position

for which maximum damage is expected.

The practice has been to impose these impact requirements on the waste package itself, even though in transport the canister will necessarily be within a massive shielded cask to meet radiation requirements. Neglect of the impact protection provided by the cask insures a conservative approach to canister design and also dictates a measure of ruggedness to the canister against accidents that may occur in handling the canister outside a shipping cask. Handling of exposed canisters will occur within the processing plant and at the geological disposal site. The question has not been resolved whether impact accident criteria from the general transportation field should be applied to handling operations conducted within the controlled environment of the processing plant or disposal site.

Other accident scenarios have been proposed by Kaiser Engineers (1977). The most severe of these is probably a canister drop of several thousand feet down a mine shaft at the geological disposal site. As in the case of a shielded transportation cask, impact requirements on the canister could be greatly decreased if energy absorption is provided as part of the mine shaft handling system.

In addition to or as a replacement for the Federal criteria of 10 CFR 71.64 , a detailed evaluation of accident possibilities in the life cycle of a canister should be performed. For specific canisters and processing facilities, maximum drop heights can be determined. Also, items could be established in the plant that could act as penetrators if struck by a falling canister. Evaluations of this type would more realistically govern canister impact strength requirements. The consequences of a canister breach could also be factored into such evaluations, although in the controlled environment of the processing plant such breaches could be of minor significance.

\section{IMPACT TESTS}

Two series of impact tests on glassfilled canisters have been conducted at PNL. These test series were performed in 1975 and 1977, and additional testing is anticipated. The main objective of the 1975 series was to evaluate the extent of glass fracturing as a result of impact (Smith and Ross 1975). The quantity of respirable glass fines produced and the increase in glass surface area were measured. As a secondary factor, the impact resistance of the filled canisters was considered. Breaches of certain canisters were observed only at relatively high velocities of 20 and $36 \mathrm{~m} / \mathrm{s}(66$ and $117 \mathrm{f} / \mathrm{s}$ ) and not at a $13.4 \mathrm{~m} / \mathrm{s}$ (44 f/s) velocity corresponding to a $9.1 \mathrm{~m}$ drop $(30 \mathrm{f})$. Both full-scale and subsized canisters were tested.

The more recent 1977 test series were all on full-scale canisters and the focus was on canister integrity. Figures $\mathrm{H} .1$ and $\mathrm{H} .2$ show the mobile crane and the test pad used for the drop test. The specially constructed test pad consisted of a $178-\mathrm{mm}-$ (7-in.-) thick steel plate set into a $1.2 \times 1.2 \times 3-\mathrm{m}(10 \times 10 \times 4-\mathrm{f})$ reinforced concrete mass. At the maximum crane height, a drop from $32 \mathrm{~m}$ (104 f) above the pad could be achieved. A quick-release hook allowed canisters to be dropped without imparting an impulse at the time of release. By suitable positioning of the cable sling along the length of the canister, the canister could be dropped with a corner impact point in line with the canister's center of gravity. This impact results in maximum damage to the canister.

Table H.1 lists the results of impacts on canisters of various designs. Some canisters were filled with simulated waste of nonradioactive borosilicate glass. Some canisters were partially filled with glass and then topped off with concrete, while others were filled entirely with concrete. The latter were used primarily for practice drops. All tests were conducted during the month of December, with near freezing temperatures prevailing.

Canisters selected for these tests included some that potentially could meet criteria for packaging of HLW in terms of design characteristics and fabrication quality. On the other hand, a number of canisters had been fabricated to meet short-term needs of nonradioactive process development trials at PNL. The design and fabrication quality of these canisters did not meet the criteria for HLW packaging. The drop test results for these canisters nevertheless provided valuable data on failure thresholds.

Table H.2 summarizes the drop heights and observed condition of the canisters after the impacts. Figure $\mathrm{H} .3$ shows the result of a typical bottom impact test. Canister condition after impact was evaluated on the basis of visual inspection and in several 


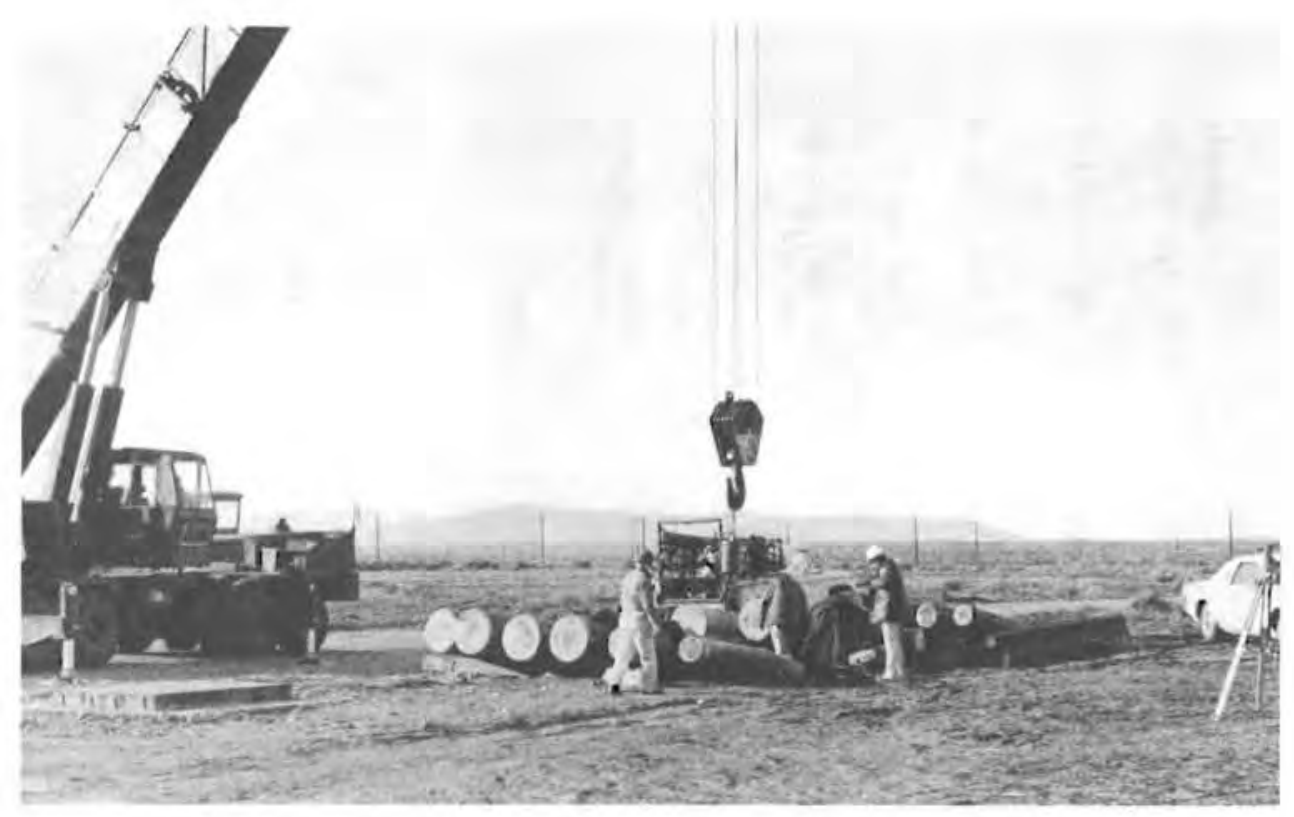

FIGURE H.1. Mobile Crane and Canisters in Position for Impact Testing

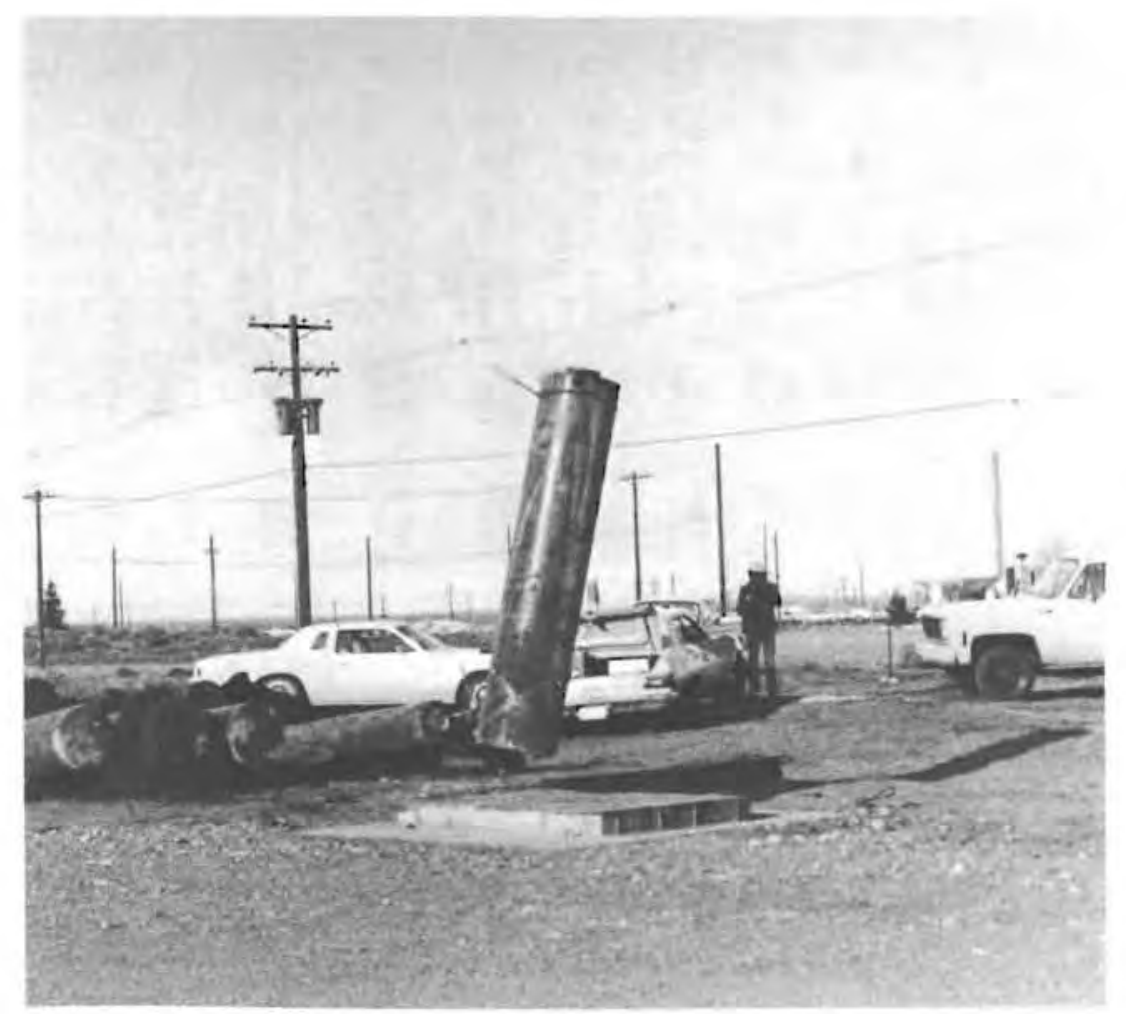

FIGURE H.2. View of Impact Pad with Canister Number 5 About to Impact 
TABLE H.1. Description of Canisters Impacted in 1977 Series Drop Tests

\begin{tabular}{|c|c|c|c|c|c|c|c|c|}
\hline $\begin{array}{l}\text { Canister } \\
\text { Number } \\
\end{array}$ & $\begin{array}{l}\text { Diameter } \\
\text { in. } \\
\end{array}$ & $\begin{array}{l}\text { Length, } \\
\text { m(in.) }\end{array}$ & $\begin{array}{l}\text { Wall } \\
\text { Thickness, } \\
\text { mm (in.) } \\
\end{array}$ & Material & $\begin{array}{l}\text { Weight, } \\
\mathrm{kg}(1 \mathrm{~b})\end{array}$ & Bottom Design & Top Design & Contents \\
\hline 8 & 12.75 & $\begin{array}{l}2.13 \\
(84)\end{array}$ & $\begin{array}{c}6.3 \\
(0.25)\end{array}$ & $304 \mathrm{~L}$ & $\begin{array}{c}592 \\
(1305)\end{array}$ & $\begin{array}{l}\text { Formed head with flat end; weld } \\
\text { about } 50 \mathrm{~mm}(2 \mathrm{in.}) \text { from end }\end{array}$ & Twist lock & $\begin{array}{l}\text { Nearly } 2.13 \text { m (84 in.) } \\
\text { glass }\end{array}$ \\
\hline 45 & 16 & $\begin{array}{l}2.13 \\
(84)\end{array}$ & $(0.312)$ & $304 \mathrm{~L}$ & $\begin{array}{c}917 \\
(2020)\end{array}$ & $\begin{array}{l}\text { Formed head with flat end; weld } \\
50 \text { to } 75 \mathrm{~mm}(2 \text { to } 3 \text { in.) } \\
\text { from end }\end{array}$ & Twist lock & 1.93 (76 in.) glass \\
\hline 3 & 12.75 & $\begin{array}{l}2.95 \\
(116)\end{array}$ & $(0.375)$ & $\begin{array}{l}\text { Carbon } \\
\text { Steel }\end{array}$ & $\begin{array}{c}754 \\
(1660)\end{array}$ & $\begin{array}{l}\text { Flat plate welded to end } \\
\text { of pipe }\end{array}$ & Pipe flange & $\begin{array}{l}\text { Filled to top with } \\
\text { concrete }\end{array}$ \\
\hline 4 & 18 & $\begin{array}{l}2.95 \\
(116)\end{array}$ & $\begin{array}{l}14.3 \\
(0.562)\end{array}$ & $\begin{array}{l}\text { Carbon } \\
\text { Steel }\end{array}$ & $\begin{array}{c}1507 \\
(3320)\end{array}$ & $\begin{array}{l}\text { Flat plate welded to end } \\
\text { of pipe }\end{array}$ & Pipe flange & $\begin{array}{l}\text { Filled to top with } \\
\text { concrete }\end{array}$ \\
\hline 7 & 24 & $\begin{array}{l}2.95 \\
(116)\end{array}$ & $\begin{array}{c}6.3 \\
(0.25)\end{array}$ & $\begin{array}{l}\text { Carbon } \\
\text { Steel }\end{array}$ & $\begin{array}{c}2165 \\
(4770)\end{array}$ & $\begin{array}{l}\text { Formed head with flat end; } \\
\text { weld about } 75 \mathrm{~mm}(3 \mathrm{in.}) \\
\text { from end }\end{array}$ & $\begin{array}{l}\text { Pipe flange; flat plate bolted } \\
\text { to flange }\end{array}$ & $\begin{array}{l}\text { Filled to top with } \\
\text { concrete }\end{array}$ \\
\hline 18 & 24 & $\begin{array}{l}2.95 \\
(116)\end{array}$ & $\left(\begin{array}{c}6.3 \\
(0.25)\end{array}\right.$ & $\begin{array}{l}\text { Carbon } \\
\text { Steel }\end{array}$ & $\begin{array}{c}2192 \\
(4830)\end{array}$ & $\begin{array}{l}\text { Flat plate welded to end } \\
\text { of pipe }\end{array}$ & Pipe flange & $\begin{array}{l}\text { Filled to top with } \\
\text { concrete }\end{array}$ \\
\hline 1 & 24 & $\begin{array}{l}2.84 \\
(112)\end{array}$ & $(0.25)$ & $\begin{array}{l}\text { Carbon } \\
\text { Steel }\end{array}$ & $\begin{array}{c}2176 \\
(4795)\end{array}$ & $\begin{array}{l}\text { Formed head with } \mathrm{fl} \text { at end; } \\
\text { weld about } 75 \mathrm{~mm}(3 \mathrm{in.}) \\
\text { from end }\end{array}$ & $\begin{array}{l}\text { Formed head of dished shape; } \\
\text { pipe flange welded to head }\end{array}$ & $\begin{array}{l}\text { Filled to top with } \\
\text { concrete }\end{array}$ \\
\hline 29 & 24 & $\begin{array}{l}1.52 \\
(60)\end{array}$ & $\begin{array}{c}9.5 \\
(0.375)\end{array}$ & $\begin{array}{l}\text { Carbon } \\
\text { Steel }\end{array}$ & $\begin{array}{c}944 \\
(2080)\end{array}$ & $\begin{array}{l}\text { Formed head of dished shape; } \\
\text { cylindrical skirt welded } \\
\text { to head }\end{array}$ & $\begin{array}{l}\text { Formed head of dished shape; pro- } \\
\text { jection of } 150 \text { to } 200 \mathrm{~mm} \\
\text { (6 to } 8 \text { in.) dia welded to top }\end{array}$ & Glass \\
\hline 30 & 24 & $\begin{array}{l}2.84 \\
\text { (112) }\end{array}$ & $\begin{array}{c}6.3 \\
(0.25)\end{array}$ & $\begin{array}{l}\text { Carbon } \\
\text { Steel }\end{array}$ & $\begin{array}{l}2176 \\
(4795)\end{array}$ & $\begin{array}{l}\text { Formed head with } \mathrm{fl} \text { at end; } \\
\text { weld about } 50 \mathrm{~mm}(2 \mathrm{in.}) \\
\text { from end }\end{array}$ & $\begin{array}{l}\text { Formed head of dished shape; } \\
\text { pipe flange welded to head }\end{array}$ & Glass \\
\hline 46 & 20 & $\begin{array}{l}2.13 \\
(84)\end{array}$ & $(1.00)$ & $304 \mathrm{~L}$ & $\begin{array}{c}1725 \\
(3800)\end{array}$ & $\begin{array}{l}\text { Flat plate welded to pipe } \\
\text { with mult ipass fillet weld }\end{array}$ & Twist lock & Glass \\
\hline 5 & 24 & $\begin{array}{l}2.84 \\
\text { (112) }\end{array}$ & $(0.375)$ & $\begin{array}{l}\text { Carbon } \\
\text { Steel }\end{array}$ & $\begin{array}{c}2365 \\
(5210)\end{array}$ & $\begin{array}{l}\text { Flat plate welded to end } \\
\text { of pipe }\end{array}$ & Flat plate with 6 -in. pipe flange & $\begin{array}{l}0.46-m(18-i n .) \text { glass; } \\
2.39-m(94-i n .) \text { concrete }\end{array}$ \\
\hline 42 & 24 & $\begin{array}{l}2.45 \\
(116)\end{array}$ & $\begin{array}{c}9.5 \\
(0.375)\end{array}$ & $\begin{array}{l}\text { Carbon } \\
\text { Steel }\end{array}$ & $\begin{array}{c}2431 \\
(5355)\end{array}$ & $\begin{array}{l}\text { Flat plate welded to end } \\
\text { of pipe }\end{array}$ & Flat plate with 6 -in. pipe flange & $\begin{array}{l}\text { Filled to top with } \\
\text { concrete }\end{array}$ \\
\hline 2 & 24 & $\begin{array}{l}2.84 \\
(112)\end{array}$ & $\begin{array}{c}9.5 \\
(0.375)\end{array}$ & $\begin{array}{l}\text { Carbon } \\
\text { Steel }\end{array}$ & $\begin{array}{c}2406 \\
(5300)\end{array}$ & $\begin{array}{l}\text { Flat plate welded to end } \\
\text { of pipe }\end{array}$ & Flat plate with 6 -in. pipe flange & $\begin{array}{l}1.32-m(52-i n .) \text { glass; } \\
1.52-m(60-i n .) \text { concrete }\end{array}$ \\
\hline
\end{tabular}


TABLE H.2. Results of 1977 Series of Canister Impact Tests

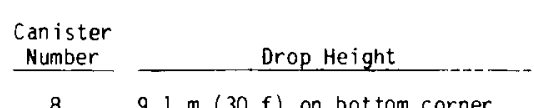

$9.1 \mathrm{~m}(30 \mathrm{f})$ on bot tom corner

$4531.7 \mathrm{~m}(104 \mathrm{f})$ on bottom corner

$36.1 \mathrm{~m}(20 \mathrm{f})$ on bottom corner

$49.1 \mathrm{~m}(30 \mathrm{f})$ on bottom corner

$79.1 \mathrm{~m}(30 \mathrm{f})$ on bottom corner

$9.1 \mathrm{~m}(30 \mathrm{f})$ on (opposite)

$9.1 \mathrm{~m}(30 \mathrm{f})$ on top flange

I

\section{$18 \quad$ Not dropped}

$15.2 \mathrm{~m}(50 \mathrm{f})$ on bottom corner

$29 \quad 15.2 \mathrm{~m}(50 \mathrm{f})$ on bot tom corner

$$
12.2 \mathrm{~m}(40 \mathrm{f}) \text { on top }
$$

$30 \quad 7.6 \mathrm{~m}(25 \mathrm{f})$ on bot tom corner

\section{$6.1 \mathrm{~m}(23 \mathrm{f})$ on top}

$9.1 \mathrm{~m}(30 \mathrm{f})$ on bottom corner

$59.1 \mathrm{~m}(30 \mathrm{f})$ on bottom corner

$9.1 \mathrm{~m}(30 \mathrm{f})$ on (opposite) bot tom corner

$426.1 \mathrm{~m}(20 \mathrm{f})$ on bottom corner

$29.1 \mathrm{~m}(30 \mathrm{f})$ on bot tom corner
Damage No visible cracks; minimum deformation of bottom with no buckling

No visible cracks; extensive corner deformation; slight buckling canister wall near bottom.

No visible external cracks; metallography showed no breach of canis ter, but some cracking starting at root of partial penetration weld.

Cracked part through, but no breach of can ister; metal lography showed poor weld penetration with some cracking starting from internal surface.

No visible external cracks; metallography showed no breach of canis. ter, but some cracking starting at root of partial penetration weld. No visible external cracks; metallography showed no breach of canister, but some cracking starting at root of partial penetration weld. Cracking of flange to head weld; canister breached; bolts dented head, but did not penetrate.

No visible external cracks; metallography showed good welds with full penetration; no evidence of crack growth from inside surface.

No breach of canister; cracking of welds joining skirt to bottom no metallography performed.

Cracking of joint between top and welded projection.

Canister breached; cracks in both weld and base metal; metallography showed good weld quality, but large grain size in heat affected zone.

Cracking of flange to head weld; canister breached.

No visible external cracks; minimal deformation; no metallography.

Corner probably cracked and canister breached; weld cracking and canister breach evident during sectioning; metallography showed poor weld with lack of penetration.

cracking and breach of impacted corner; gross opening of opposite corner, which had been cracked in previous impact.

Cracking of corner weld through full thickness; metallography showed poor weld penetration resulting in weld cracking along heat affected zone.

Cracking of corner weid through full thickness; metallography showed poor fit up at joint leading to incomplete weld penetration.
Comments

Severe local buckle of side wall probably due to lack of full curing

Severe local buck 1 ing of side wall probably due to lack of full curing of concrete.

Damage at two impacted bottom corners appears to be independent of each other.

Corner flattening extended into weld.

corner flattening extended into weld.

A dent near the bottom appears as if the canister struck the corrier of the
impact pad.

Massive canister but with less than opt imum bottom corner joint design.

Glass fragments ejected from crack during second drop.

Buckling of side wall near bottom.
Concrete flowed plastically due to Concrete flowed plastically due to
incomplete curing; more extensive bot tom incomplete curing; more extensive bot
deformation seen on concrete filled deformat ion seen on concrete filed
canister than glass filled canister. 


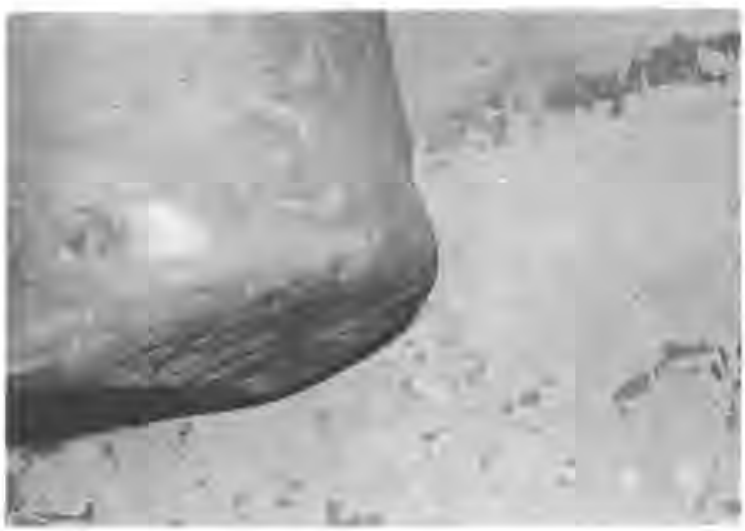

FIGURE H.3. Canister 45 Showing Bottom Deformation Following 31.7-m (104-f) Drop onto Corner

cases by metallographic sectioning to check for cracks. No cracks were observed in bottom impacts for canisters that followed accepted design and fabrication practices. Cracking was observed in carbon steel canisters with flat plate bottoms welded to a length of pipe that served as the canister body. Of these, only canister No. 5 exhibited a gross breach that resulted in visible ejection of glass, and in this case the glass was ejected after two 30-f drops. Later, metallographic inspection of the bottom welds in canister 5 and other cracked canisters showed a lack of weld penetration. A bottom corner joint of the design used on canister 5 is not recommended for low-carbon steel and partial penetration welds are to be avoided at all joints subject to impact damage.

Top impacts for some of the canisters were performed with typical results shown in Figure H.4. The consequences of top impact were expected to be more severe than for bottom impact. The void at the top of the canisters does not provide the restraining effect that glass provides at the canister bottom. The observed impact performance in the top drops was not satisfactory since cracking occurred at welds. It is believed, however, that optimization of the weld joint configurations can correct the deficiencies in impact performance. Impact strengths could be increased by reinforcement of the critical weld-joint region to force plastic deformation to be distributed into the head, rather than be localized in the joint area. Also, alternative closure designs can eliminate the projection associated with the flange-type closure by bringing the closure flush with the top (as in the case of the twist-lock closure designed at PNL).

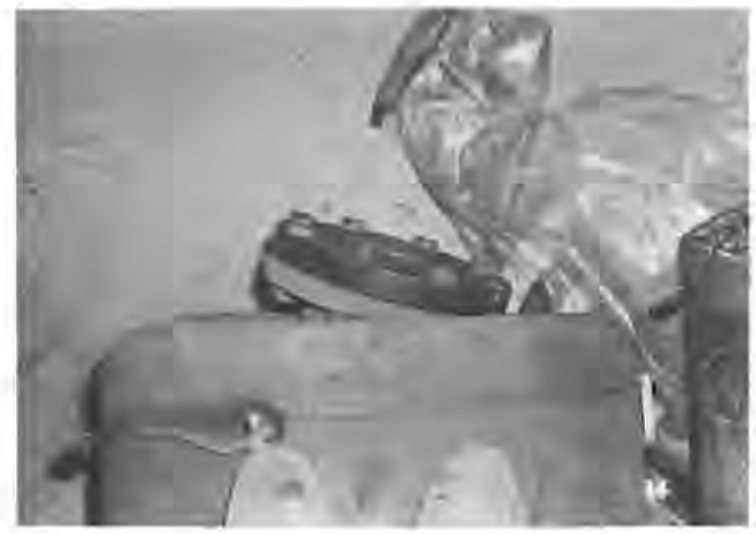

FIGURE H.4. Top of Canister Number 30 Following Drop from $6.1 \mathrm{~m}(20 \mathrm{f})$

The parameters of the canister wall thickness and drop height were not varied sufficiently in the test matrix to clearly identify trends in impact performance relative to these parameters. However, the results are consistent with evidence presented, for example, by Shappert (1970). This evidence suggests that bottom impact performance is strongly influenced by material toughness and joint design. Wall thickness and drop height are less important.

PNL has not tested canister puncture resistance as defined by the above criteria. Performance data from shielded shipping casks shows a clear relationship between puncture resistance (as measured by allowable drop height) and wall thickness. It is likely that puncture resistance criteria will impose definite limits on minimum canister wall thicknesses.

It was concluded that HLW canisters can sustain severe bottom impacts and that no unusual design features are required. Further canister design studies and impact tests should focus on top impact performance and puncture performance, for which test data are more limited.

\section{INTERNAL PRESSURE STRESSES}

In the design of HLW canisters, stresses due to internal pressure have been viewed as being of secondary importance. Nevertheless, PNL has identified possible sources of internal pressure, and has evaluated the consequences of pressurization of the canister closure after seal welding. 
After closure welding there will be a volume of gas within the top cavity of the canister. It was estimated that heating of contained gases will result in a pressure increase of $0.012 \mathrm{MN} / \mathrm{m}^{2}$ (1.79 psi) for each $56^{\circ} \mathrm{C}\left(100^{\circ} \mathrm{F}\right)$ change in temperature. A typical temperature rise was est imated to be $177^{\circ} \mathrm{C}\left(350^{\circ} \mathrm{F}\right)$ for which the increase in pressure would be $0.043 \mathrm{MN} / \mathrm{m}^{2}(6.26 \mathrm{ps} i)$. This normal internal pressure increase is of negligible significance.

Heating of any water entrapped in the top cavity of the canister can have far more serious consequences. If water were present in sufficient quantity, the pressure during heating would equal the vapor pressure of the water at the temperature in question. For example, heating to $371^{\circ} \mathrm{C}\left(700^{\circ} \mathrm{F}\right)$ would result in a pressure of $22 \mathrm{MN} / \mathrm{m}^{2}$
(3200 psi). The most likely source of water is thought to be leakage through a defect in the closure weld during periods of waterbasin storage. In the event of relatively slow heating, it is likely that vapor pressure would vent itself through the same defect that permitted entry of water into the canister in the first place. Catastrophic pressurization is anticipated primarily in connection with very rapid heating, if, for example, a canister were exposed to a fire.

Stress calculations have helped to establish the pressure capability of the twistlock closure system. Figure H.5 shows the results of a finite-element stress analys is of a top and twist-lock closure of a 406-mm(16-in.-) dia canister. An internal pressure of $0.69 \mathrm{MN} / \mathrm{m}^{2}$ (100 psi) was selected for purposes of calculating relative stress
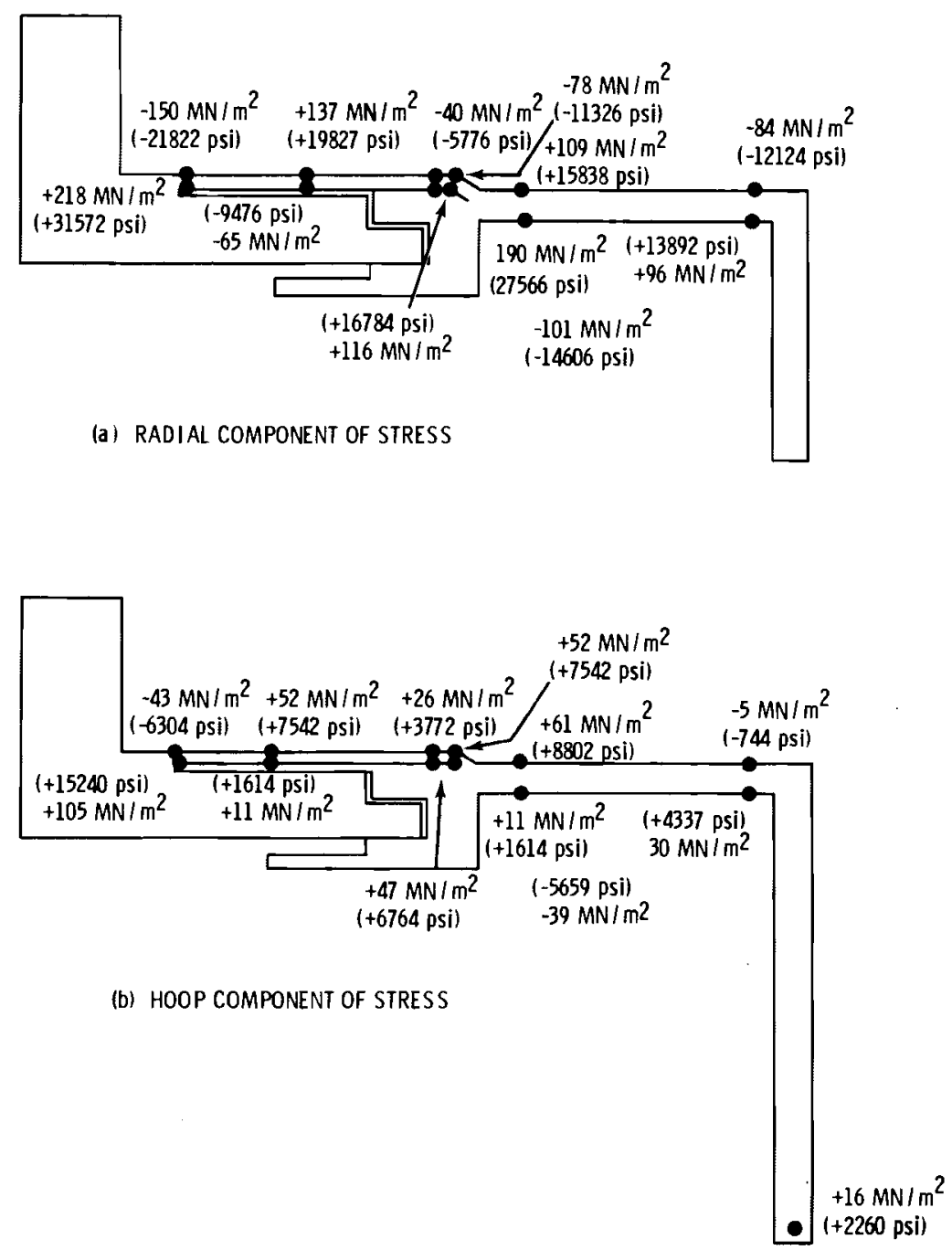

FIGURE H.5. Calculated Stresses in Canister Closure System for Internal Pressure of $0.69 \mathrm{MN} / \mathrm{m}^{2}$ (100 psi) 
levels in different components of the canister. The innner hub of the 3.2-mm-

$(1 / 8$-in.-) thick seal plate is the most highly stressed location. The outer portion of the canister top has stresses at levels of approximately one-half of the stress levels in the seal plate. Stresses in the canister sidewall are relatively low.

For design purposes, a material yield strength of $207 \mathrm{MN} / \mathrm{m}^{2}(30,000 \mathrm{psi})$ and an ultimate strength of $414 \mathrm{MN} / \mathrm{m}^{2}(60,000 \mathrm{psi})$ were assumed. Pressure ratings were estimated for: 1) initial yielding, 2) gross plastic deformation, and 3) bursting. At sufficiently high pressures the canister top and seal plate will burst like a ruptured disc. This bursting pressure (as given in Table H.3) was estimated to be twice that which produced gross plastic deformation.
The seal plate was clearly the weak link in the twist-lock design, However, it has more than adequate strength to sustain pressure increases during normal heating cycles. On the other hand, if large amounts of entrapped water are heated rapidly (such as during a fire), even the relatively high pressure rating of the canister sidewall would be exceeded. In this event, the seal plate would perform like a ruptured disk and vent the pressure once a level of about $2.48 \mathrm{MN} / \mathrm{m}^{2}$ (360 psi) was reached. It would be preferable if the canister top failed at this lower pressure. The release of energy would be less at the lower pressure, and there would be less dispersion of contamination.

TABLE H.3. Pressure Ratings of Canister Top

\begin{tabular}{|c|c|c|c|}
\hline & $\begin{array}{r}\text { Canister } \\
\text { Side Wall } \\
\end{array}$ & $\begin{array}{c}\text { Canister } \\
\text { Top }\end{array}$ & $\begin{array}{r}\text { Seal } \\
\text { Plate } \\
\end{array}$ \\
\hline Initial Yield & $\begin{array}{r}9.2 \mathrm{Mn} / \mathrm{m}^{2} \\
(1330 \mathrm{psi})\end{array}$ & $\begin{array}{l}1.31 \mathrm{MN} / \mathrm{m}^{2} \\
(190 \mathrm{psi})\end{array}$ & $\begin{array}{c}0.60 \mathrm{MN} / \mathrm{m}^{2} \\
(87 \mathrm{psi})\end{array}$ \\
\hline $\begin{array}{c}\text { Gross Plastic } \\
\text { Deformation }\end{array}$ & $\begin{array}{l}9.2 \mathrm{MN} / \mathrm{m}^{2} \\
(1330 \mathrm{psi})\end{array}$ & $\begin{array}{l}2.76 \mathrm{MN} / \mathrm{m}^{2} \\
(400 \mathrm{psi})\end{array}$ & $\begin{array}{l}1.24 \mathrm{MN} / \mathrm{m}^{2} \\
(180 \mathrm{psi})\end{array}$ \\
\hline Burst & $\begin{array}{l}18.3 \mathrm{MN} / \mathrm{m}^{2} \\
(2650 \mathrm{psi})\end{array}$ & $\begin{array}{l}5.52 \mathrm{MN} / \mathrm{m}^{2} \\
(800 \mathrm{psi})\end{array}$ & $\begin{array}{l}2.48 \mathrm{MN} / \mathrm{m}^{2} \\
(360 \mathrm{psi})\end{array}$ \\
\hline
\end{tabular}




\section{REFERENCES}

Code of Federal Regulations, Title 10, part 71, section 64, Appendix $B$.

General Electric Space Division. 1975. Multi-Hundred Watt Radioisotope Thermoelectric Generator Program Final Safety Analys is Report, Vol. II, Accident Model Document for LES 8/9. For U.S. Energy Research and Development Administration, Philadelphia, Pennsylvania.

Kaiser Engineers. 1977. High-Level Waste Canister Envelope Study Structural Analysis. By Kaiser Engineers for Rockwell Hanford Operations (Rockwell Report RHO-C-8), Oakland, California.

Nuclear Services Corp. 1978. Recommendations for Codes and Standards to be Used for Design and Fabrication of High-Level Waste Canister. NSC-1-78-004, by Nuclear Services Corporation for Rockwe 11 Hanford Operations (Rockwe 11 Report RHO-C-13), Campbel1, California.

Shappert, L. B., ed. 1970. A Guide for the Design, Fabrication and Operation of Shipping Casks for Nuclear Application. ORNL-NSIC-68, Oak Ridge National Laboratory, Oak Ridge, Tennessee.

Smith, T. H., and W. A. Ross. 1975. Impact Testing of Vitreous Simulated High-Level Waste in Canisters. BNWL-1903, Pacific Northwest Laboratory, Richland, Washington.

Teledyne Isotopes. 1974. SNAP-19 Viking Final Safety Analys is Report, Vol. III, Safety Analys is Document. ESO-3069-15-3, for U.S. Atomic Energy Commission, Timon ium, Maryland. 


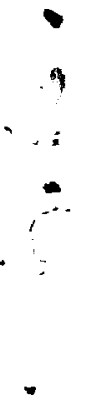


APPENDIX I 
APPENDIX I

\section{RESIDUAL STRESSES AND GLASS FRACTURING}

Residual stresses and their consequences on canister integrity have been an important concern of work at PNL. Canister residual stresses are attributed to the differential thermal expansion coefficients of the metal canister and the glass within the canister. Since the interaction between the canister and glass is the primary source of stress, a unified analysis procedure was used to treat both the glass and canister components. This appendix begins with a discussion of the effect of residual stresses on possible failure modes for canisters. Then two analytical models for predicting residual stresses and glass fracturing are described. The first utilizes a one-dimensional model, focusing on the canister and the factors that govern residual stresses in the canister wall. The second approach is a two-dimensional model focusing on the glass and factors that govern the development of cracks in the glass matrix.

\section{EFFECT OF RESIDUAL STRESSES ON CANISTER INTEGRITY}

The effect of residual stresses on structural integrity has been the subject of much concern. The following discussion summarizes the consensus of work as reported in the literature on residual stresses. A special effort is made to interpret known trends in the context of canister residual stresses.

\section{Existence of Residual Stresses}

The existence of some level of residual stresses in engineering structures is usually a known and an accepted condition. Even after stress relief, the presence of stress at some low value is frequently assumed and is often factored into the design of the structure. However, the role of stresses on the serviceability of structures must be evaluated on a case-by-case basis.

Very high tensile residual stresses have been measured in walls of waste canisters. They are attributed to the differential thermal expansion coefficients of the metal canister and the glass within the canister. During the cooling of a canister of molten glass, the stress in the canister can build up to the extent that the canister material yields. Subsequently, the level of residual stress is limited by the material yield strength. The presence of residual stresses in canisters is not questioned. Rather, the focus has been on determining if there are possible detrimental effects of these residual stresses on the structural integrity of the canister.

\section{Gross Distortion}

Much of the literature on residual stresses relates to welding technology. Residual stresses in this context are associated with welding distortion, which can degrade the function of the component or make subsequent fit-up and welding of the structure impossible. In waste canisters, measurable changes in diameter have been observed at PNL as a result of the filling process. Typical data are given in Appendix $C$ of this report. For ICM diameter in_- 0 creases have not exceeded $1.27 \mathrm{~mm}$ (0/50 in.); they have consistently been less for the $C M$. No significant deviations from straightness have been observed in canister filling trials. In no cases have dimensional changes been sufficient to affect the function of the canister to any extent. Also, observed dimensional changes per se are not believed to result in any loss of canister structural integrity.

\section{Static Fracture}

The effect of residual stresses on the static strength of structures has been subject to different interpretations in the literature. Since the residual stresses in canisters can be at the material yield strength, first order considerations would suggest that the canister wall is in a condition of incipient fracture. Such considerations do not recognize the importance of yielding and material ductility on the 
occurrence of fracture and that residual stresses are of a self-limiting nature. In ductile metals, residual stresses generally cannot result in sufficient plastic deformation to cause catastrophic fracture.

Residual stresses will affect fracture under static or dynamic loadings only if the material has a low fracture toughness and if the structure has particularly large crack-like defects. However, the materials of interest to the canister application are noted for their high fracture toughness. Also, in the context of fracture mechanics, the crack-like defects that could occur in canisters are relatively small; those types of brittle fracture propagation that are of concern to large-diameter and thick-walled pressure vessels are not believed relevant to waste canisters.

At PNL, a brittle fracture of a canister due to residual stresses or imposed mechanical loadings has never been observed. In drop tests of prototypical canisters, as reported in Appendix $H$, many canisters known to have high residual stresses have sustained severe impact loadings and gross plastic deformation without loss of integrity. Canisters have occasionally failed in such drop tests when they were not designed and fabricated to accepted standards. These canisters had severe plastic deformation in corner weld joints; however, even for these canisters, there is no reason to believe that residual stresses had any effect on the weld failures.

\section{Fatigue Cracking}

Residual stresses are known to have an important effect on fatigue life. Tensile residual stresses reduce fatigue life, while compressive residual stresses have been demonstrated to increase fatigue life. However, the stress cycles in the life of waste canisters are projected to be minimal. Thus, the potential for fatigue failure of waste canisters is remote, and residual stresses will have little or no potential to affect the fatigue life of canisters. Glass-filled PNL canisters have never failed because of fatigue cracking.

\section{Stress-Corrosion Cracking}

For stress-corrosion cracking to occur, canisters having residual stresses must be associated with two other conditions: 1) the material must be susceptible to cracking (e.g., sensitized 304 stainless stee 1), and 2) it must be exposed to specific corrosive conditions.
Stress-corrosion cracking should not be a factor for low-carbon or low-alloy steel canisters, or for canisters stored in air rather than in water basins. The greatest concern at PNL has been for stainless steel canisters that are to be stored for long periods in water basins.

Stress-corrosion cracking of a stored glass-filled canister has occurred at PNL (Bradley 1977). Studies have shown that an adverse combination of stress, material characteristics, and corrosive conditions caused the cracking. It is currently recognized that material, processing, and storage conditions must be controlled to prevent stress-corrosion cracking of canisters. It is believed that the potential for cracking can be eliminated through canister alloy selection, residual stress reduction, control of processing conditions, and control of water chemistry during water-basin storage.

Conclusions on Residual Stress Effects

Concern about residual stresses appears limited to stress-corrosion cracking. For this failure mode, the potential damaging effect of residual stresses can be eliminated, if suitable restrictions are placed on canister materials and usage. The potential for stress-corrosion cracking is essentially nonexistant for low-carbon and low-alloy steel canisters stored in an air environment. The potential is greatest for stainless steel canisters subject to waterbasin storage.

ONE-DIMENSIONAL ANALYSIS OF RESIDUAL STRESSES

It has long been recognized that stresses originate in both the glass and canister during cooling of the molten glass. Such stresses have been manifested as cracking of the glass and as tensile residual stresses in the walls of the canister. This discussion deals with the development of an analytical model to simulate the process of glass solidification and cooling, which is designed to predict time histories of stress in the glass canister system. This analytical model is based on the adaptation of finite-element computer programs. Details of this model and a collection of case studies will be described. The case studies include conditions approximating present canister experience with simulated waste, which can serve as baseline checks to evaluate the validity of the analysis. Other case studies consider internal heat 
generation in the radioactive waste materials. In such cases, extrapolation of experience from nonradioactive glasses can be mis leading.

\section{Thermal Analysis Model}

Since all stresses of importance to the canister system are thermally induced, heat transfer is an important component of the stress analysis procedure. The thermal model is shown in Figure I.I and has been implemented with the ANSYS finite-element computer program (DeSalvo and Swanson 1975). The computer code ANSYS performs both steady-state and transient heat-transfer calculations using an implicit time-step scheme. Figure I.1 illustrates an axial slice, representative of the canister, at locations removed from the ends of the canister. The glass and the metal of the canister wall were assigned individual thermal properties that are temperature dependent; in addition, the glass could be assigned a level of internal heat generation (W/L). Tables I.1 and I.2 list the thermal properties for glass and $304 \mathrm{~L}$ stainless steel that were used in the numerical studies. The glass properties should be viewed as only representative of borosilicate wastecontaining glasses and not specific to any particular composition. An ideal bond was assumed at the glass-metal interface so that the thermal impedance across this interface could be taken to be zero. Heat was transferred from the outside surface of the canister by convection and radiation.
TABLE I.1. Thermal and Physical Properties of Glass [Density $=3.2 \mathrm{gm} / \mathrm{cc}\left(0.115 \mathrm{lb} / \mathrm{in}^{3}\right)$ ]

\begin{tabular}{|c|c|c|c|c|c|}
\hline \multirow{2}{*}{\multicolumn{2}{|c|}{$\frac{\text { Temper ature }}{{ }^{\circ} \mathrm{C}}$}} & \multicolumn{2}{|c|}{ Conductivity } & \multicolumn{2}{|c|}{ Specific Heat } \\
\hline & & D & $\begin{array}{l}\mathrm{BTU} / \mathrm{h}- \\
\text { in.- }{ }^{\circ} \mathrm{F}\end{array}$ & $\begin{array}{l}\text { Calo- } \\
\text { ries/g }\end{array}$ & B \\
\hline & & & & 0.084 & 0.1 \\
\hline 63 & & & & -- & -- \\
\hline 72 & & & & -- & - \\
\hline & & & & -- & 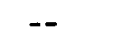 \\
\hline & & 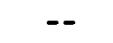 & & 0.171 & 0.309 \\
\hline
\end{tabular}

TABLE I.2. Thermal and Physical Properties of 304L Stainless Steel [Density $=7.8 \mathrm{gm} / \mathrm{cc}$ $\left.\left(0.28 \mathrm{lb} / \mathrm{in.}{ }^{3}\right)\right]$

\begin{tabular}{|c|c|c|c|c|c|}
\hline \multirow{2}{*}{\multicolumn{2}{|c|}{$\frac{\text { Temperature }}{\text { of }}$}} & \multicolumn{2}{|c|}{ Conductivity } & \multicolumn{2}{|c|}{ Specific Heat } \\
\hline & & $\mathrm{W} / \mathrm{M}-{ }^{\circ} \mathrm{C}$ & $\begin{array}{l}\text { BTU/h- } \\
\text { in. - OF }\end{array}$ & $\begin{array}{l}\text { Calo- } \\
\text { ries/g }\end{array}$ & BTU/1b \\
\hline-18 & 0 & 13.0 & 0.625 & -- & - \\
\hline 204 & 400 & 17.9 & 0.861 & -- & -- \\
\hline 427 & 800 & 20.2 & 0.972 & -- & -- \\
\hline 649 & 1200 & 23.5 & 1.131 & -- & -- \\
\hline 871 & 1600 & 26.0 & 1.250 & -- & -- \\
\hline 1093 & 2000 & 27.4 & 1.319 & -- & -- \\
\hline 21 & 70 & -- & -- & 0.060 & 0.108 \\
\hline 982 & 1800 & -- & -- & 0.092 & 0.165 \\
\hline
\end{tabular}

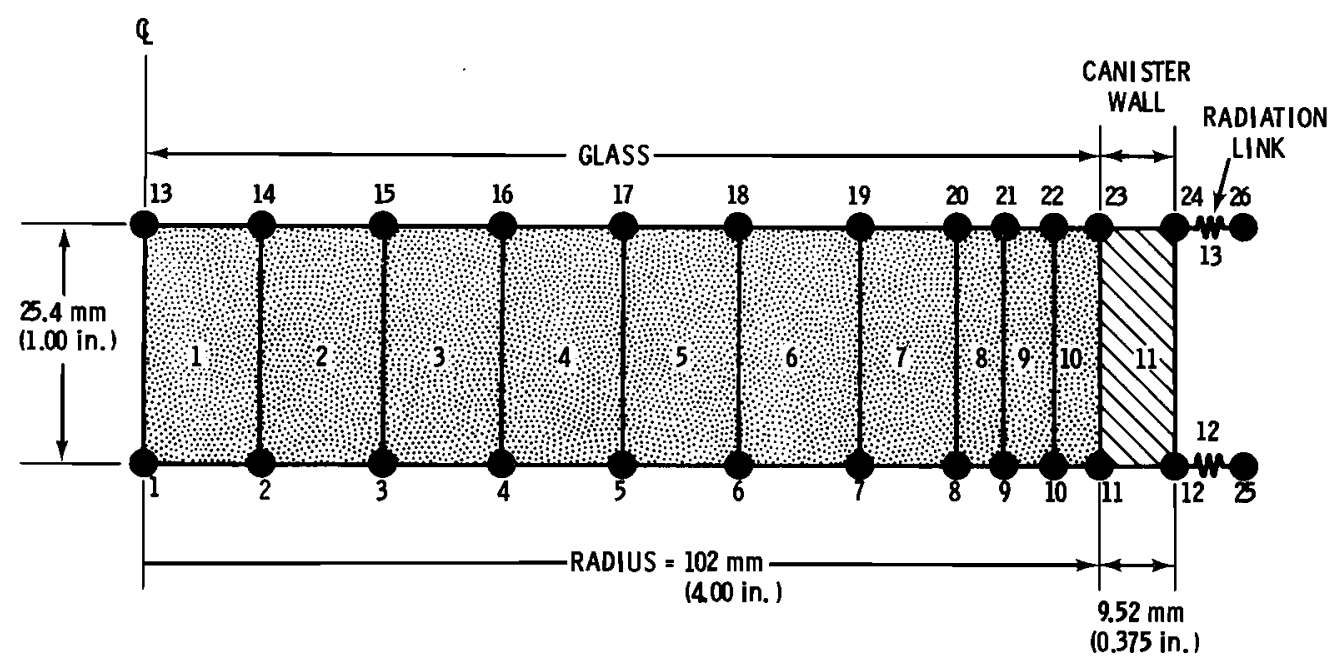

FIGURE I.1. Thermal Analysis Model for ANSYS Finite-Element Code 


\section{Stress Analysis Model}

Stresses were calculated with the finiteelement computer program AXISOL (Wilson and Jones 1967). The element break down of the glass-canister structure, shown in Figure I.2, matches that used in the thermal analysis that provided temperature data to the stress analysis. Detailed consideration was given to the boundary conditions imposed on the upper and lower faces of the axial slice treated in the analysis. On the lower $f$ ace, nodes were constrained to remain on a plane (i.e., zero axial displacement). On the upper surface, it was necessary to use a double set of nodes so that the column of the liquid glass could rise or fall in response to thermal expansion effects. Once the glass solidified, the upper surface of the solidified mass was then constrained to displace as a plane. Within both the liquid and solid glass, radial compatibility was enforced between adjacent nodes.

The solidification of glass was treated on the basis of the instant-freezing model, which is described below. Above the freezing temperature, the elements of the liquid glass were assigned a negligible value of elastic modulus. Stresses were calculated for a sequence of temperature states during the cooling process. After the glass passed the solidification temperature, the last recorded mechanical-strain state in the glass element was then fixed as a "lockedin" state of permanent deformation. Upon final cooling, the distribution of stress in the glass was largely determined by the distribution of such locked-in strains.
The canister was treated as an elasticplastic solid. At each time step, the stresses were adjusted to satisfy plastic yield and flow criteria. The accumulated plastic strain at the end of each solution time step was carried over as a permanent or an initial strain to the next time step. Effects of strain reversals and residual stresses were thus taken into account. The specific mechanical properties used in the numerical studies are listed in Tables $I .3$ and I.4. Below the solidifcation temperature (taken as $575^{\circ} \mathrm{C}$ or $1067^{\circ} \mathrm{F}$ ), variations in glass properties with temperature were neglected.

\section{Glass-Hardening Behavior}

The hardening behavior of glass has been discussed in the literature, particularly as it relates to the prediction of residual stresses associated with tempering of commercial plate glass. The assumption used in our numerical studies is the instantfreezing model, first proposed by Bartenev (1949). In this approach, the complex phenomena of a glass transition range is replaced by the simple concept of an instant freezing temperature, $\mathrm{T}_{\mathrm{g}}$. Above this temperature, the glass is considered incapable of sustaining shear stresses, while below this temperature the glass is treated as a perfectly elastic solid. The instantfreezing concept has been successfully applied to predict residual stresses in tempered plate glass; the predicted stresses have generally been in remarkable agreement with measured stresses.

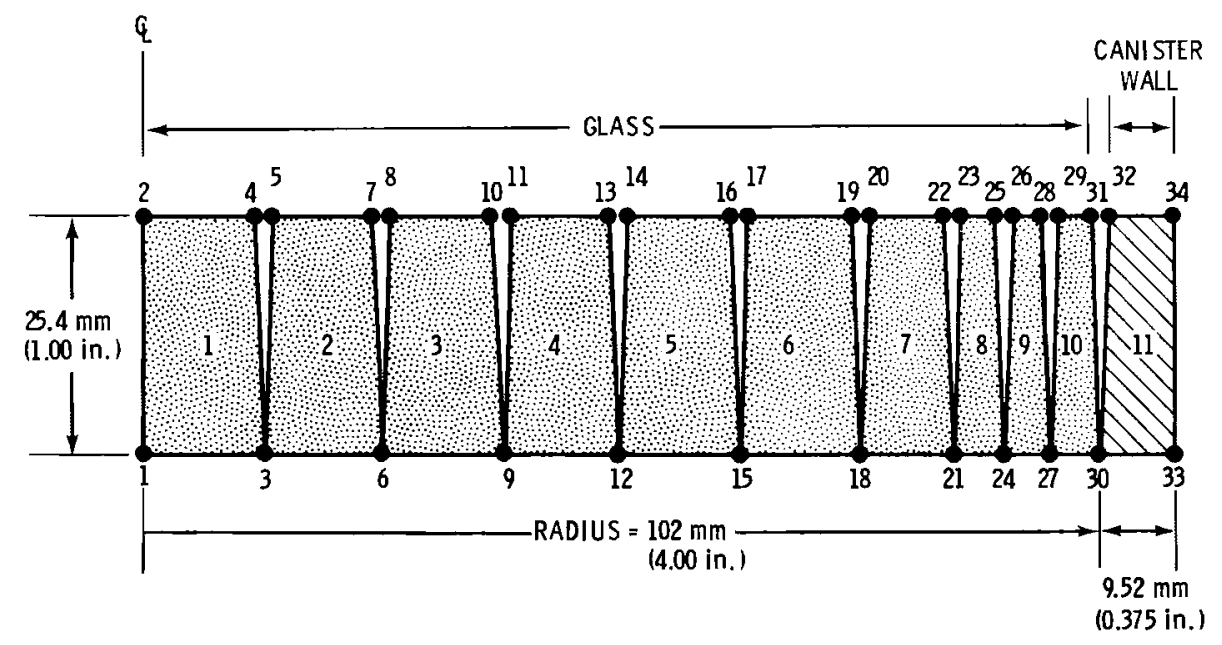

FIGURE I.2. Stress Analysis Model for Finite-Element Code AXISOL 
TABLE I.3. Mechanical Properties of Glass

\begin{tabular}{|c|c|c|c|c|c|c|}
\hline \multirow[b]{2}{*}{ Temperature } & \multicolumn{2}{|c|}{ Elastic Modulus } & \multirow{2}{*}{$\begin{array}{l}\text { Poisson's } \\
\text { Ratio } \\
\end{array}$} & Thermal & \multirow{2}{*}{$\frac{\text { Expansio }}{{ }^{0} c^{-1}}$} & \multirow{2}{*}{$\frac{n \text { Coefficient }}{\frac{{ }^{O} F^{-1}}{}}$} \\
\hline & $\mathrm{MN} / \mathrm{m}^{2}$ & psi & & & & \\
\hline $\begin{array}{l}\text { Below Solidification Temperature } \\
T_{T} 575^{\circ} \mathrm{C}\left(1067^{\circ} \mathrm{F}\right)\end{array}$ & 75,900 & $11 \times 10^{6}$ & 0.300 & & $\times 10^{-6}$ & $5 \times 10^{-6}$ \\
\hline $\begin{array}{c}\text { Above Solidification Temperature } \\
T \quad 575^{\circ} \mathrm{C}\left(1067^{\circ} \mathrm{F}\right)\end{array}$ & 0.0067 & 1.0 & 0.49999 & 2.8 & $\times 10^{-6}$ & $5 \times 10^{-6}$ \\
\hline
\end{tabular}

TABLE I.4. Mechanical Properties of 304L Stainless Stee 1

\begin{tabular}{|c|c|c|c|c|c|c|c|}
\hline \multicolumn{2}{|c|}{ Temperature } & \multicolumn{2}{|c|}{ Modulus } & \multicolumn{2}{|c|}{ Expansion } & \multicolumn{2}{|c|}{ Yield Strength } \\
\hline${ }^{{ }^{0} \mathrm{C}}$ & $o_{F}$ & $\mathrm{MN} / \mathrm{m}^{2}$ & psi & ${ }^{0} c^{-1}$ & $o_{F}-1$ & $\mathrm{MN} / \mathrm{m}^{2}$ & psi \\
\hline 38 & 100 & $0.193 \times 10^{6}$ & $28.0 \times 10^{6}$ & $4.4 \times 10^{-6}$ & $8.0 \times 10^{-6}$ & 241 & 35,000 \\
\hline 427 & 800 & $0.166 \times 10^{6}$ & $24.1 \times 10^{6}$ & $5.2 \times 10^{-6}$ & $9.3 \times 10^{-6}$ & 138 & 20,000 \\
\hline 649 & 1200 & $0.145 \times 10^{6}$ & $21.2 \times 10^{6}$ & $5.4 \times 10^{-6}$ & $9.7 \times 10^{-6}$ & 103 & 15,000 \\
\hline 871 & 1600 & $0.116 \times 10^{6}$ & $16.8 \times 10^{6}$ & $5.7 \times 10^{-6}$ & $10.2 \times 10^{-6}$ & 69 & 10,000 \\
\hline
\end{tabular}

It is believed that canister-stress calculations are much less influenced by the limitations of the instant-freezing concept than calculations for plate-glass tempering. The canister and glass-tempering problems differ significantly in two ways. First, stresses in the glass-canister assembly result primarily from differences in the thermal expansion coefficients of the glass and canister material. Second, the section thicknesses in canister glass are much greater than those of interest in plate-glass tempering. Thus, temperatures can differ greatly in the interior of the canister glass relative to the softening temperature range. This is not true for tempering of plate glass.

Although the instant-freezing model appears to be an excellent approximation for canister analyses, the more complex rheological models reported in the 1 iterature have a lso been investigated. The application of such models to glass residual-stress predictions has been the subject of several papers (Narayanaswamy and Gordon 1969; Wayman 1962; and Lee, Rogers and Woo 1965).

The rheological behavior of glass has been treated by the theory of thermoviscoelastic stress analysis (Morland and Lee
1960; Muki and Steinberg 1961; Lee and Rogers 1963; Lee, Rogers and Woo 1964). Temperature is taken to affect the stressrelaxation process by a contraction in the time scale so that an equivalent time can be defined as

$$
\zeta=t \Phi(T)
$$

Such material behavior is termed thermorheologically simple and is equivalent to a temperature change causing a shift, without a change in the shape of stress-relaxation curves. Stress-relaxation studies by Van Zee and Noritake (1963) show that glass at elevated temperatures obeys such a law to a good approximation. For commercial sodalime glass, the shift function can be represented as

$$
\log _{10}\{\Phi(T)\}=0.03861(T-538),
$$

where $\mathrm{T}$ is the temperature in ${ }^{\circ} \mathrm{C}$. Lee, Rogers and Woo (1965) have reported the relaxation modulus for this glass. The equations of the above rheological scheme 
were incorporated into our stress analys is model in a simplified manner to establish the sensitivity of glass and canister-stress predictions to viscoelastic effects. The results of these numerical studies at PNL indicated that the rheological behavior has little effect on stresses for the glasscanister situation.

\section{Parameters for Case Study}

An 8-in.-dia canister was used in our initial case studies. The canister was made of 304L stainless steel, with a 203-mm (8.00-in.) ID and a wall thickness of $7.94 \mathrm{~mm}(0.3125 \mathrm{in.})$. For simplicity, there were no fins within the canister. The 8-in.-dia canister was selected partly because a larger size requires internal fins to maintain glass centerline temperatures at acceptable levels and partly because it matched the size of many existing developmental ICM canisters. These can isters have been the subject of glasscharacterization and experimental residual- stress studies, and thus offered an opportunity to compare predictions with service experience.

Glass and canister stresses were calculated with two varying parameters: the internal heat-generation rate in the glass and the history of heating and cooling. Heat-generation rates from 0 to $100 \mathrm{~W} / \mathrm{L}$ were considered. Thermal conditions were those of ambient air cooling, water cooling, and furnace heating. Various sequences of these conditions were analyzed so that transientstress states and residual stress levels under steady-state conditions could be determined.

\section{Thermal Solutions}

In our calculations, a canister of molten glass was assumed to be removed from an ICM furnace at a temperature of $1050^{\circ} \mathrm{C}$ (1922 $\mathrm{F}$ ) and cooled to an equilibrium temperature in air. This cooling process is shown in Figure $I .3$ for an internal heat-generation rate

RADIUS, mm

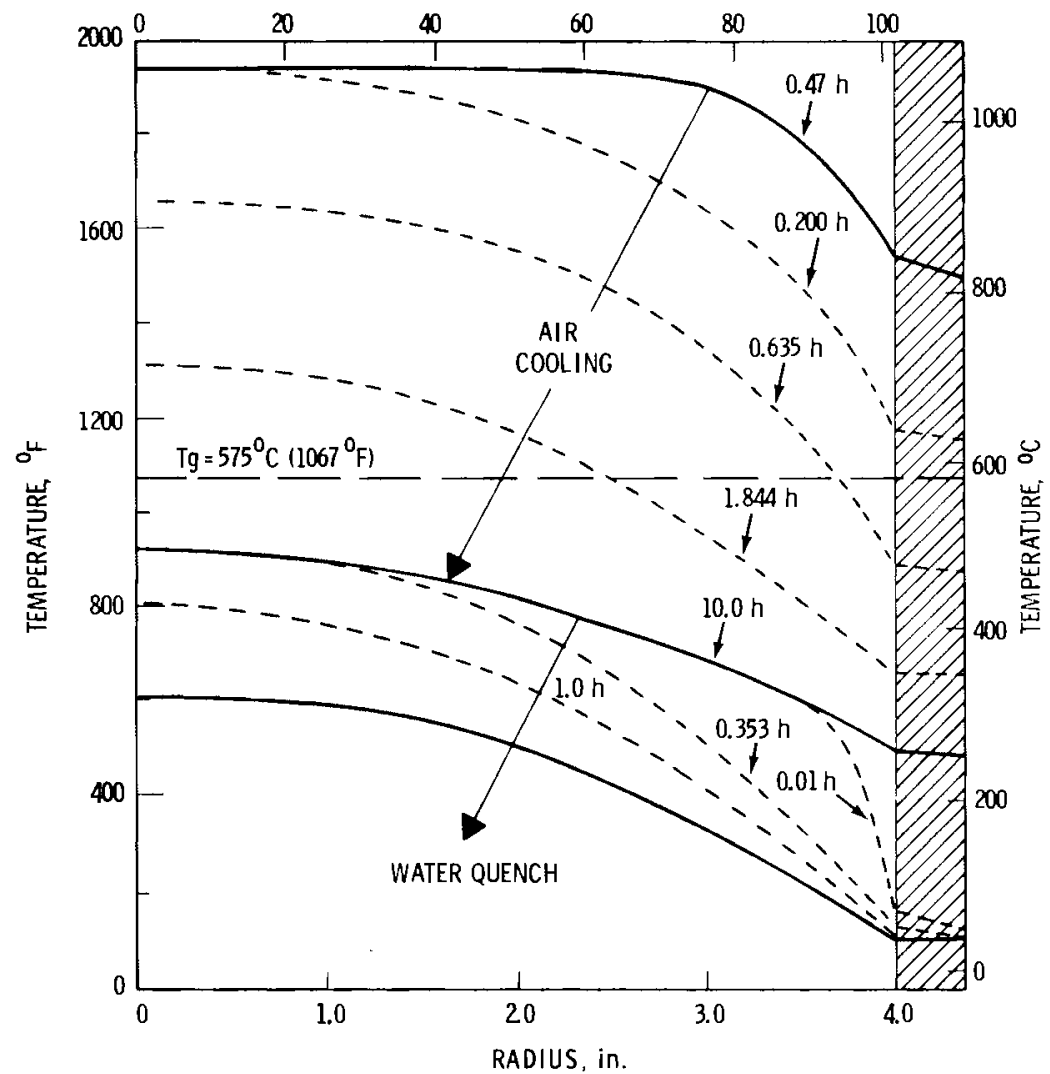

FIGURE I.3. Temperature Profiles in Canister of Glass for Air Cooling from $1050^{\circ} \mathrm{C}\left(1922^{\circ} \mathrm{F}\right)-100 \mathrm{~W} / \mathrm{L}$ 
in the glass of $100 \mathrm{~W} / \mathrm{L}$. Heat rates of 0 and $50 \mathrm{~W} / \mathrm{L}$ were also analyzed. The initial part of the cooling process was similar for all cases; the cooling primarily differed in the equilibrium temperature distribution. With no heat generation, the temperature eventually reached the ambient level. For $50 \mathrm{~W} / \mathrm{L}$, the final canister wall temperature was $170^{\circ} \mathrm{C}\left(340^{\circ} \mathrm{F}\right)$, and the glass center line temperature was $304^{\circ} \mathrm{C}\left(580^{\circ} \mathrm{F}\right)$. For $100 \mathrm{~W} / \mathrm{L}$, the corresponding temperatures were $255^{\circ} \mathrm{C}$ $\left(490^{\circ} \mathrm{F}\right)$ and $493^{\circ} \mathrm{C}\left(920^{\circ} \mathrm{F}\right)$.

For the heat-generating glass, thermal analyses were also performed for cooling by water immersion. As shown in Figure I.3, the canister wall cools very rapidly. The canister temperature reaches a terminal level near the water temperature before the glass as a whole is able to exhibit any cooling response. Eventually, however, the glass centerline temperature reaches a reduced equilibrium temperature, which is compatible with the reduced outer wall temperature. A third transient occurs when the heat-generating canister of glass is removed from water immersion into an air-cooling environment, and this transient was also analyzed.

\section{Canister Stresses}

Canister stresses were calculated for the thermal transient conditions described above. Figure I.4 shows the stress-time behavior for internal heat-generation rates in the glass, ranging from 0 to $100 \mathrm{~W} / \mathrm{L}$. For all cases, the initial air cooling of the canister of molten glass from $1050^{\circ} \mathrm{C}$ $\left(1922^{\circ} \mathrm{F}\right)$ resulted in tensile residual stress in the wall of the canister; however, the heat generation tends to reduce the level of this tensile stress. The tensile stress in the canister wall is due to the higher thermal expansion coefficient of the steel canister relative to the glass. With internal heat generation, the glass and canister never cool to ambient temperatures. As a result, the full effect of the differential thermal contraction of the metal and glass never develops.

The consequences of water cooling on canister stress levels are dramatically shown in Figure I.4. With no heat generation, the canister is initially at room temperature, and placing the canister in room temperature water has no effect on either temperature or stress. However, when a hot canister is first placed in the water, the metal wall of the canister cools rapidly to the water temperature. The canister is thus prevented from contracting by the still hot glass; as a result, the tensile stress in the canister increases sharply deforming the canister plastically. Eventually, as the glass also cools, the thermal differential between the metal and the glass decreases, and in response, the tensile stress in the canister wall
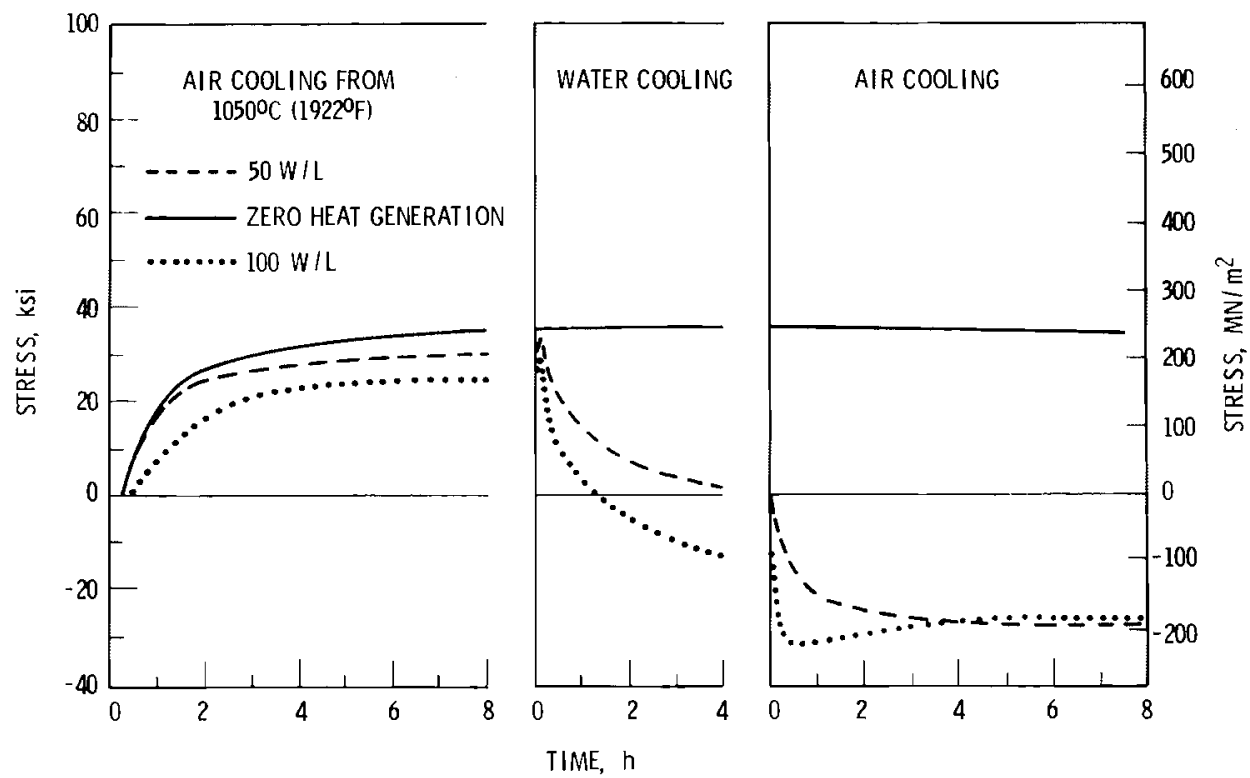

FIGURE I.4. Stress in Wall of Canister Showing Effect of Heat Generation 
decreases. For a heat rate of $100 \mathrm{~W} / \mathrm{L}$, the canister wall stress actually is predicted to become compressive. When removed from water storage, the canister wall stress tends to become even more compressive, and compressive yielding of the canister wall is predicted because both the canister and glass temperatures increase. For increasing temperatures, the higher expansion coefficient of the metal relative to the glass causes the canister stress to become compressive.

Figure I. 5 shows the results of calculations that include more than one cycle of the air-to-water thermal transient. The first cycle is representative of subsequent cycles, and thus, an analysis of one cycle is sufficient to characterize the cyclic stress behavior.

The consequences of heat treatment on a canister with a zero heat-generation glass are shown in Figure I.6. The glass is reheated to a temperature of $427^{\circ} \mathrm{C}\left(800^{\circ} \mathrm{F}\right)$, short of its softening temperature of $575^{\circ} \mathrm{C}$ $\left(1067^{\circ} \mathrm{F}\right)$. The hot canister is quenched in water, and at the end of the quench a compressive canister-wall stress equal to the yield strength is predicted. However, this predicted compressive stress in the canister wall may not be realistic. If stresses in the wall of the canister are to become compressive, the glass-metal bond must support tensile stresses. Examinations of experimental canisters show evidence of fracture at or near the bond. Such bondline fractures would relieve compressive residual stresses that might develop in the canister wall.

Fractures at the bond line will affect both the thermal response and the stress response of the glass-canister system. Such fractures are normal to the path of the heat flow and will introduce gap-type resistances to heat transfer. A bond-line gap could significantly affect the temperatures in the system, in addition to eliminating compressive stress regime from the curves of predicted canister wall stresses. To a first approximation, the canister wall would be stress-free during the periods of predicted compressive stress, while the tensile stress regimes should be relatively unaffected by the presence of bond-line fractures.

\section{Glass Stresses}

Stresses in the glass arise from two sources. The first source is the differential thermal expansion of the glass relative to the canister, which results in a radial loading to the glass at the glass-metal interface. Stresses from this source cannot exceed about $19 \mathrm{MN} / \mathrm{m}^{2}$ (2700 psi), since greater stresses in the glass would imply a stress in the canister wall greater than the material yield strength of $241 \mathrm{MN} / \mathrm{m}^{2}$ $(35,000 \mathrm{psi})$. The second source of stress

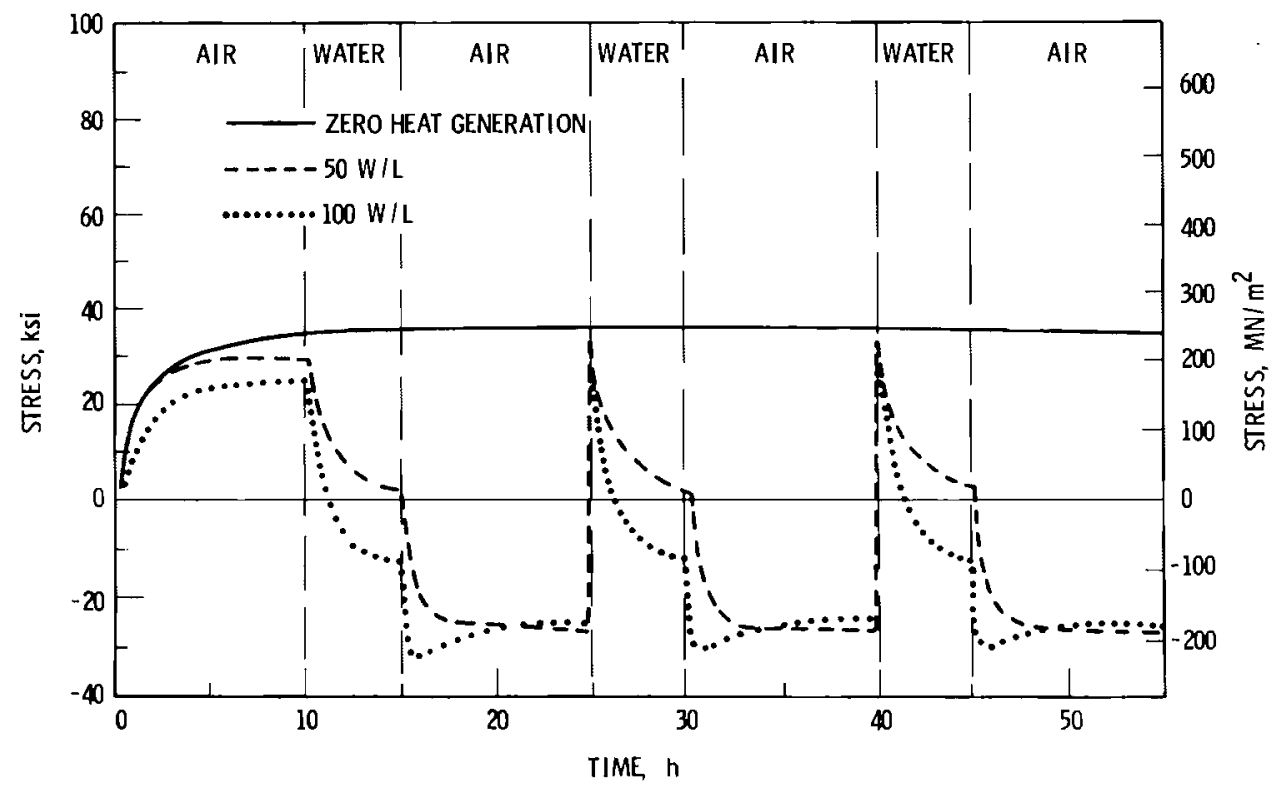

FIGURE 1.5. Stress in Canister Wall Showing Effect of Thermal Cycling 

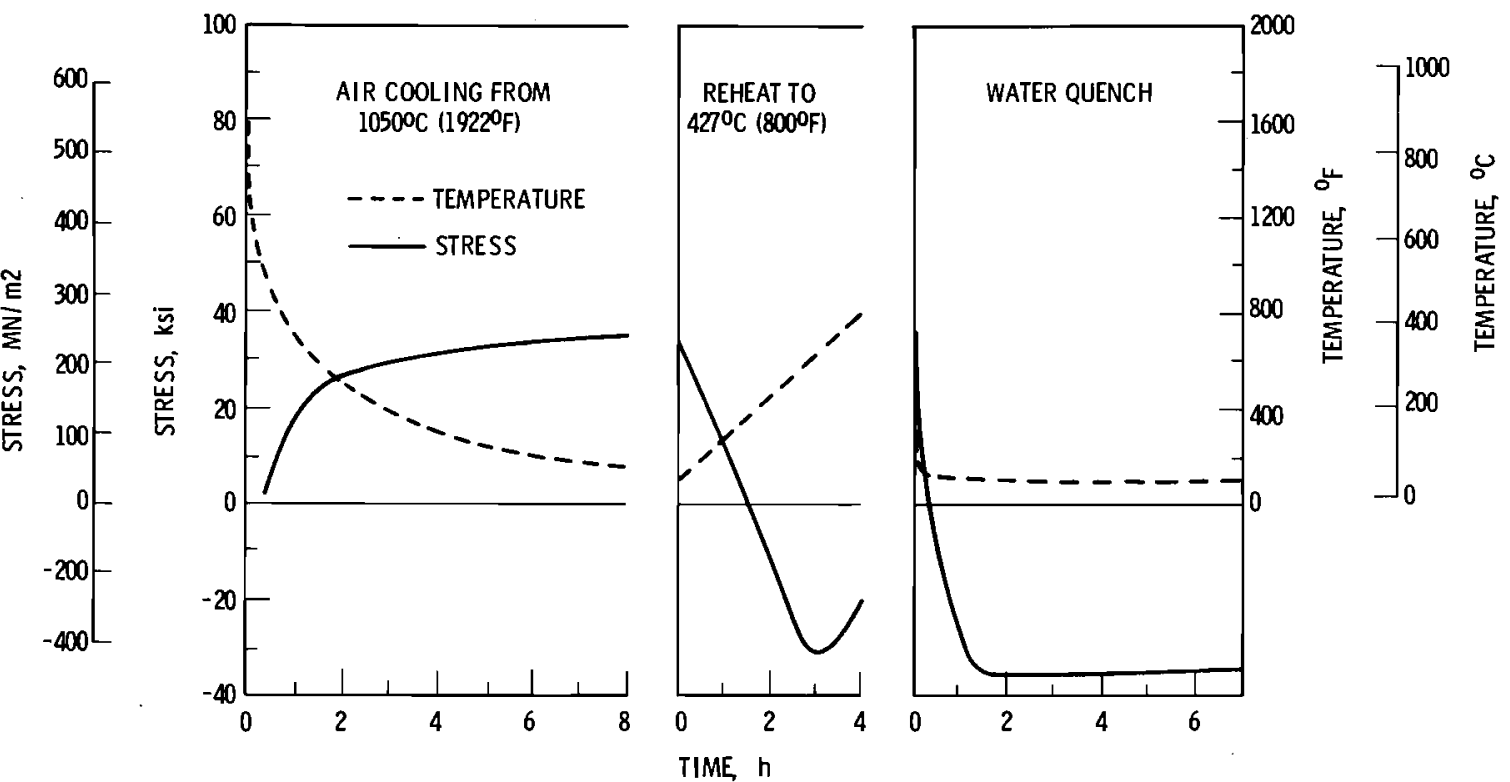

FIGURE I.6. Effect of Water Quench on Stress in Canister Wall is the glass monolith itself, which develops residual stresses because of temperature differentials in the glass as it cools through its softening temperature range. For glass with internal hect generation, thermal stress patterns (from steady-state cooling) are superimposed on these locked in stresses.

Three components describe the state of stress in the glass: stresses in the radial, axial, and hoop (or circumferential) directions. The predicted axial and hoop stress components have been found to have roughly equivalent distrtibutions, which are - greater in magnitude than the corresponding radial component of stress. In general, the central portion of the glass is in a state of tension while the outer region is in a state of compression. Maximum tensile and compressive stresses were calculated to be on the order of $207 \mathrm{MN} / \mathrm{m}^{2}(30,000 \mathrm{psi})$. The following figures show the significant trends of the predicted axial-stress components.

Figure I.7 shows the effect of heat content of the glass ( 0 and $100 \mathrm{~W} / \mathrm{L})$ on the stress in the glass. The calculated stress is lower for the heat-generating glass. Changes in stress as the heat-emitting glass is transferred from air storage to water storage are also indicated. Stresses are lowest following the initial air cooling of the molten glass from the melting temperature of $1050^{\circ} \mathrm{C}\left(1922^{\circ} \mathrm{F}\right)$. Glass stress level increases when the canister is quenched during transfer to water storage. The glass stress increases even further when the canister is later removed from the water; it again attains a steady-state thermal condition in the air-cooling environment.

Figure I.8 shows the change in glass stress predicted over a long period, as the level of radioactive decay heat decreased from $100 \mathrm{~W} / \mathrm{L}$ to a level of zero heat-generation. The stress for the self-heating glass tends to increase with time and eventually exceeds the level predicted for a nonheating glass.

Figure I.9 indicates that process conditions can have an important effect on the stress level in the glass. In this study, a nonheating glass was considered. In one case, the glass was simply air-cooled from a molten state at $1050^{\circ} \mathrm{C}\left(1922^{\circ} \mathrm{F}\right)$. In the other case, the glass was water-quenched from a temperature of $650^{\circ} \mathrm{C}\left(1200^{\circ} \mathrm{F}\right)$ which is above its softening point. The development of stress during the cooling period of the quench was indicated. It was also shown that the rapidly cooled glass has significantly higher stresses than the air-cooled glass.

It should be emphasized that the results shown in Figures I.7 to I.9 do not consider glass fracture. The estimated tensile fracture strength of the glass of interest 


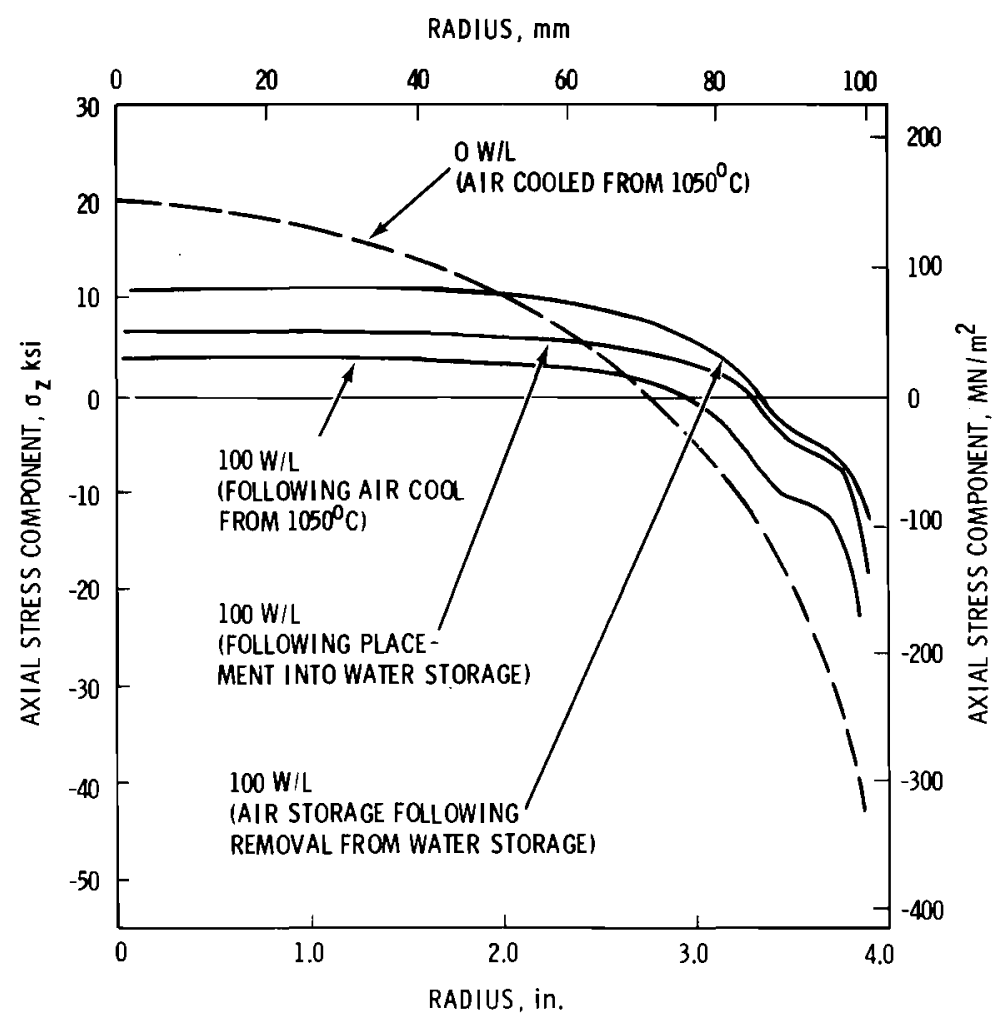

FIGURE I.7. Effect of Heat Content on Glass Stress

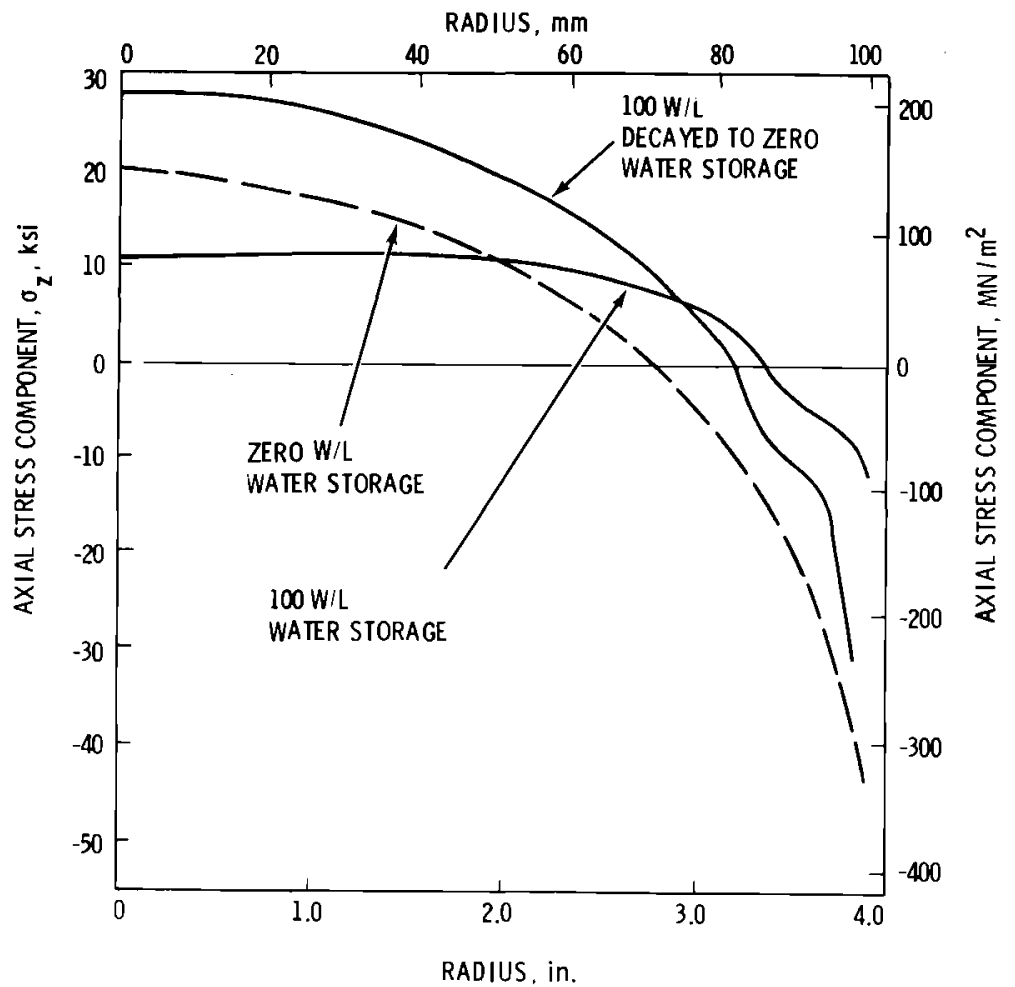

FIGURE I.8. Change in Glass Stress as Heat Content of Glass Decreases During Period of Storage 


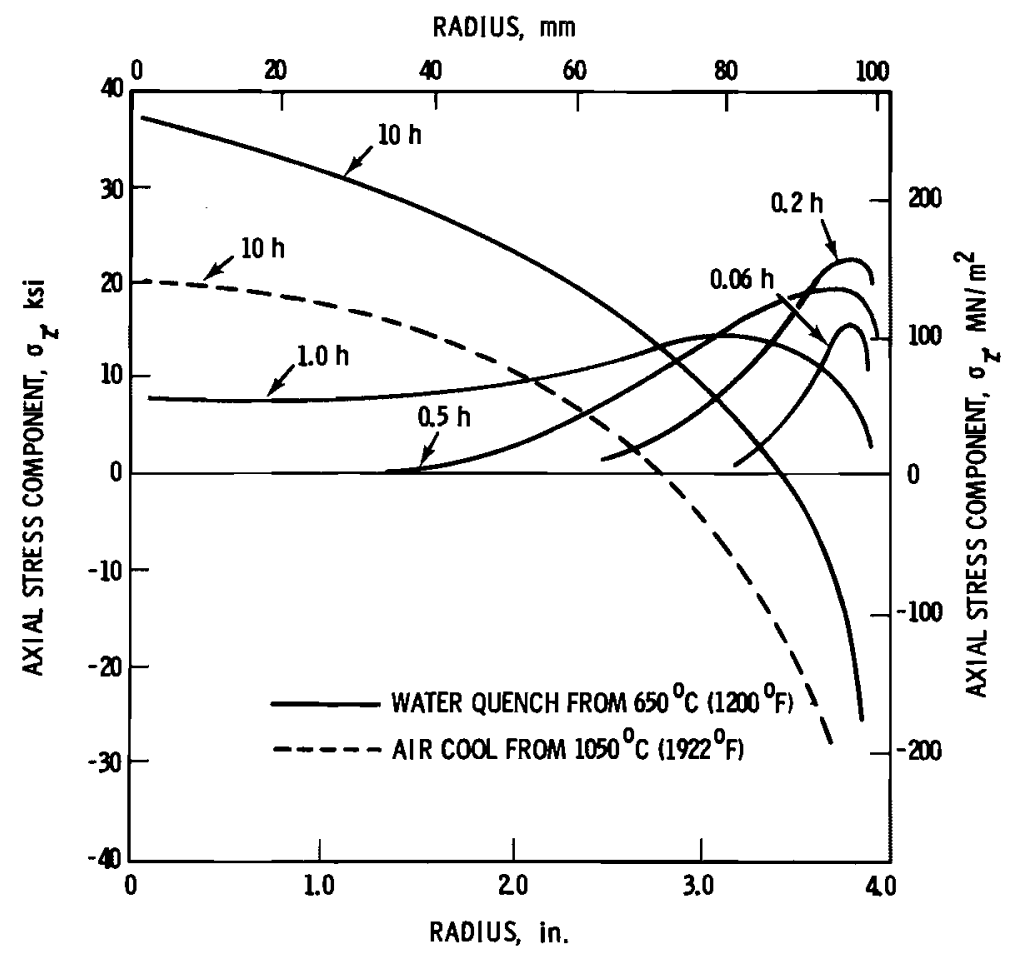

FIGURE I.9. Effect of Cooling Rate on Glass Stress (Zero Heat-Generation Glass)

will be on the order of $35 \mathrm{MN} / \mathrm{m}^{2}$ (5000 psi) or lower. It is clear for the heating and cooling conditions considered here that the glass in the canisters will crack. After the glass has cracked, the stress will be redistributed in both the glass and canister wall.

\section{TWO-DIMENSIONAL ANALYSIS OF RESIDUAL} STRESSES

The one-dimensional analysis model described above neglected the presence of fins within the glass matrix. Also, cracking of the glass due to high tensile stresses was not considered. This section of the report describes results obtained from a two-dimensional, finite-element stress analysis in which the interaction between the glass and fins, and prediction of glass cracking were the focal points.

\section{Stress-Analysis Model}

So that the glass stress and fracturing problem could be studied, a cross section of a canister with eight internal fins was modeled, as shown in Figure I.10. It was assumed that a glass with no internal heat generation was cooled at a very slow rate, so that the resulting stresses were due solely to the differential expansion coefficients of the fin and canister materials relative to the glass. Since the assumed temperature conditions were isothermal, there was no need for heat-transfer calculations for the complex geometry.

An automatic grid generator was developed to produce finite-element meshes of the type shown in Figure I.11. In this case, a onesixteenth symmetry element was used to model the canister with eight internal fins. The finite-element program allowed elements to crack at high tensile stress points. It was assumed that after cracking, elements could no longer support stress on the planes of maximum tensile stress. Planes parallel to the direction of cracking were, however, capable of supporting stress.

The glass behavior was that of the "instant-freezing" concept described previously. During cooling the glasscanister-fin assembly was assumed to be stress-free at the freezing temperature. The strain state in the glass was then taken 


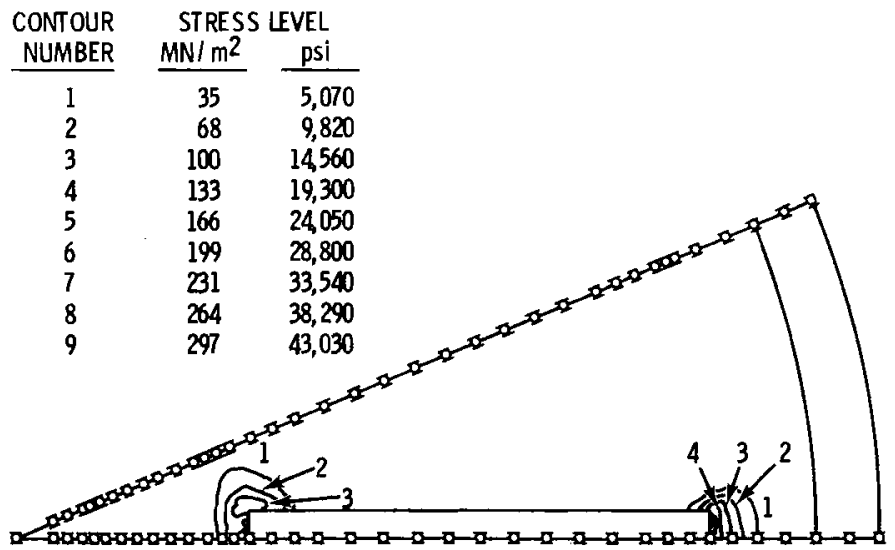

FIGURE 1.12. Calculated Contours of Maximum Tensile Stresses in Glass Due to Differential Thermal Expansion Coefficients of Glass and Metal

$69 \mathrm{MN} / \mathrm{m}^{2}(10,000 \mathrm{psi})$ FRACTURE STRESS

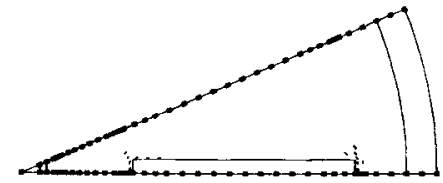

$17 \mathrm{MN} / \mathrm{m}^{2}(2,500 \mathrm{psi})$ FRACTURE STRESS

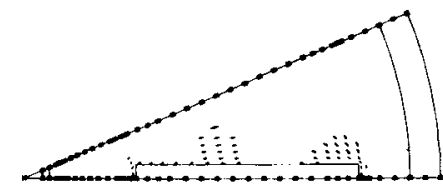

$35 \mathrm{MN} / \mathrm{m}^{2}$ (5000 psi) FRACTURE STRESS

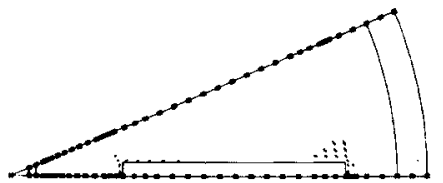

$0.0 \mathrm{MN} / \mathrm{m}^{2}$ FRACTURE STRESS

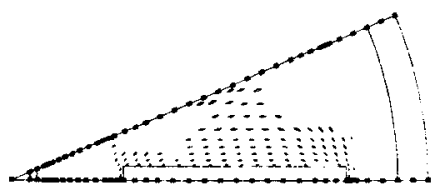

FIGURE I.13. Predicted Cracking Patterns in Glass Filled 8-in.-Dia Canister with 8 Internal Fins

Figure I.14 shows the observed crack pattern in an actual canister of the same configuration and dimensions as that considered in the computer analysis. The crack pattern was revealed in a polished section of a glass sample from a canister filled by the ICM process. Both similarities and differences are seen between the predicted and observed cracking. Much of the difference is no doubt due to differences between the actual and assumed cooling rates and thermal transients. The experimental canister was exposed to more severe thermal stressing than that considered in the analysis. The experimental cracking shows a pattern extending around the fins like that predicted in the analysis. The actual cracks tend to be fewer in number, but connected in a fashion which the simplified assumptions of the analys is did not consider. In addition, the experimental pattern shows cracks with a circumferential orientation. These are probably due to a high radial component of stress because of radial temperature gradients. Such temperature gradients were not considered in the analysis. The experimental crack pattern also shows a fine array of cracks at the interface between the glass and inside surface of the canister. There also appears to be a gap between the canister and glass. The one-dimensional analys is indicated that such a gap was a result of rapid cooling. Shear stresses at the glasscanister interface due to differential axial-thermal expansion are also thought to be key causes of the outside-diameter surface cracking. These shear stresses are not calculated by the two-dimensional axial slice model. Consideration of the interfacial shear stresses is the subject of continuing work at PNL. 

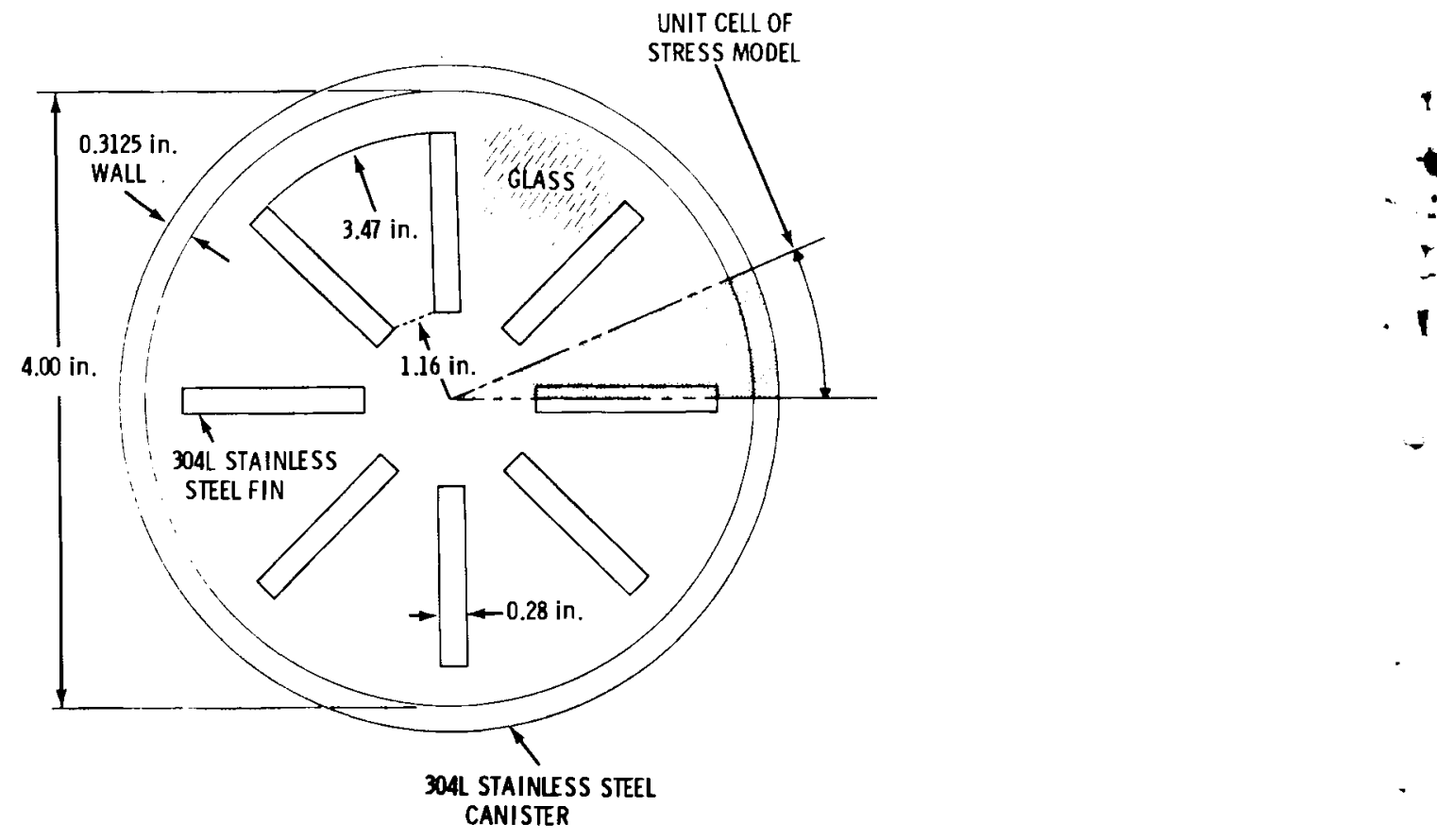

FIGURE I.10. Glass Filled 8-in.-Dia Canister with 8 Internal Fins

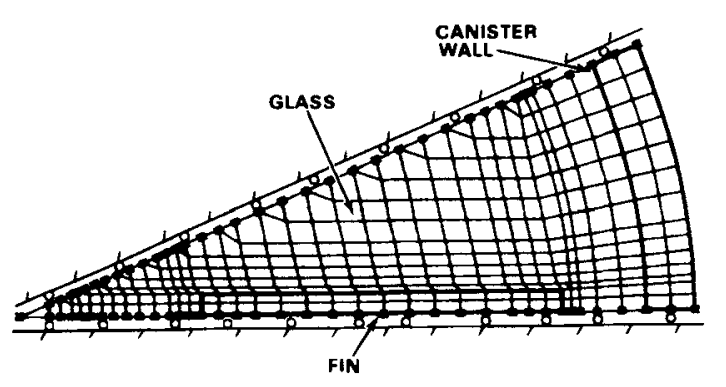

FIGURE I.11. Stress Analysis Mode1 for Glass Fracturing

to be permanently set, and stresses in the assembly increased as cooling proceeded. The analys is was programmed for sequential cracking, so that the highest stressed regions cracked first, allowing stresses to redistribute. The next highest stressed region in the redistributed stress field was then allowed to crack, and this process was repeated for successively higher levels of imposed stress. At each step it was assumed that cracks in itiated in one element propagated only across that element, rather than extending into adjacent elements, as might be the case in actual practice.

\section{Predicted Crack Patterns}

The stresses resulting from the differential thermal expansion coefficients of the 304L stainless steel canister and fins relative to the glass are shown in Figure $I-12$. Contours of equal levels of tensile stress in the glass are illustrated. The contours are numbered by values of 1 through 10 , with a value of 10 corresponding to about $275 \mathrm{MN} / \mathrm{m}^{2}(40,000 \mathrm{psi})$. High tensile stresses are concentrated near the ends of the fins, The calculated stress level of $275 \mathrm{MN} / \mathrm{m}^{2}(40,000 \mathrm{ps} i)$ is well above the tensile strength of the glass of interest, and it was clear that fracturing of the glass will occur.

A graphical interpretation of the predicted cracking process is shown in $\mathrm{Fig-}$ ure I.13, as prepared by computer graphics. The actual strength of the glass is likely to vary, both from one melt to another and with respect to location within a single canister. The final cracking patterns after a slow cooling of a canister of glass are shown for assumed glass strengths of 0 to $69 \mathrm{MN} / \mathrm{m}^{2}(0$ to $10,000 \mathrm{psi})$. For the simulated cooling conditions, the glass cracks first near the ends of the fins. The expanding array of cracks then extends along the length of the fins, and eventually well into the glass matrix. 


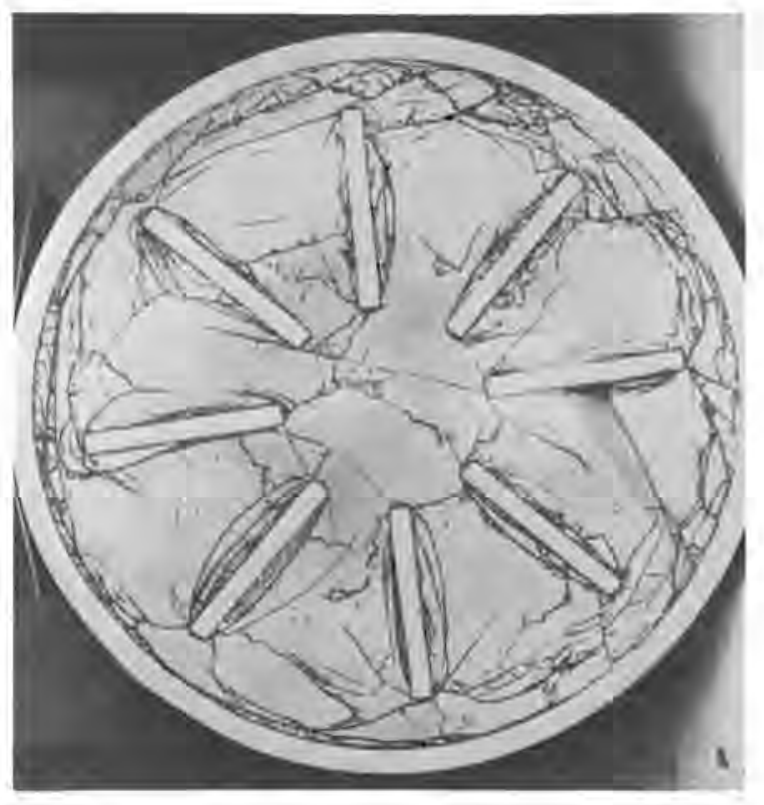

FIGURE I.14. Glass Cracking Pattern as Seen in Sectioned Canister Outside Diameter $=219 \mathrm{~mm}(8.625$ in.) , Wall Thickness $=8.18 \mathrm{~mm}(0.322 \mathrm{in.})$

\section{CONCLUSIONS AND RECOMMENDATIONS}

Analytical models of residual stresses and glass cracking have proven useful in the interpretation of experimental trends and as a guide to process improvements. The predictions of canister residual stress. calculations agree with experimental data, which show residual stresses of the material yield strength in the walls of canisters. Predictions of glass stresses and cracking patterns are consistent with the types of cracking observed in experimental canisters. A long-term goal is to predict the extent of glass cracking in a quantitative manner (e.g., net increase in surface area and particle size). However, present analytical methods do not permit realistic quantitative predictions.

Slate et al. (1979) have addressed the causes and consequences of glass cracking in depth. They concluded that thermal and residual stresses are the major causes of cracking in glass waste. The major consequences of cracking are the increase in surface area, which may result in more leaching, and the production of respirable-size particles. Slate et al. (1979) concluded, however, that the amount of cracking in HLW glass can be controlled within acceptable limits. In most situations, the amount of cracking typically observed in simulated waste glass should have no significant effect on the safety of surface operations. Also, recent work on glass behavior in disposal environments does not indicate that cracking causes any significant adverse effects.

Further studies are in progress at PNL to refine the existing analytical models and to consider different process conditions. Studies of residual stresses in canisters and cracking in glass are continuing with evaluations of fu11-scale canisters. In particular, attention is being directed to large-diameter canisters in the 24-in.-dia range and to the conditions of the $\mathrm{CM}$ process. Analytical models are being developed to evaluate interfacial shear stresses due to longitudinal differential shrinkage of the glass and canister. The model of glassfracture behavior is being extended to permit modelling shear-cracking, in addition to tensile cracking. 


\section{REFERENCES}

Bartenev, G. H. 1949. "Tempering of Gl ass." Zh. Tekkn. Fiz. 19(12):1423-1433.

Bradley, D. J. 1977. History of Prototype High-Level Waste Canister SS-9 While in Air and Water Storage. PNL-2278, Pac if ic Northwest Laboratory, Richland, Washington.

DeSalvo, G. J., and J. A. Swanson. 1975. ANSYS Engineering Analys is User's Manual. Swanson Analysis Systems, Elizabeth, Pennsylvania.

Lee, E. H., and T. G. Rogers. 1963. "Nonlinear Effects of Temperature Variation in Stress Analysis of I sothermally Linear $V$ is coelastic Materials." In Proceedings of IUTAM Symposium on Second-Order Effects in Elasticity, Plasticity, and Fluid Dynamics, Pergamon Press, Haif a, Israel.

Lee, E. H., T. G. Rogers, and T. C. Woo. 1965. "Residual Stresses in a Glass Plate Cooled Symmetrically From Both Surfaces." J. of American Ceramic Society $48(9): 480-487$.

Morland, L. W., and E. H. Lee. 1960. Transactions of the Society of Rheology. Vol. VI, edited by E. H. Lee, International Publishers, Inc., New York, New York, pp. 233-263.

Muki, R., and E. Ste inberg. 1961. "Transient Thermal Stresses in Viscoelast ic Materials with Temperature-Dependent Properties." J.Appl. Mech. 28(2):193-207.
Narayanaswamy, 0. S., and R. Gordon. 1969. "Calculation of Residual Stresses in Glass." J. of American Ceramic Society $56(1): 554-558$.

Slate, S. C., et al. 1979. "Stresses and Cracking in High-Level Waste Glass." Proceedings of the Conference on High-LeveT Radioactive Solid Waste Forms. NUREG/CP-0005, Nuc7ear Regu7atory Commission, Washington, D.C.

Van Zee, A. F., and H. M. Noritake. 1963. "Measurement of Stress-Optical Coefficient and Rate of Stress Release in Commercial Soda-L ime Glasses." J. American Ceramic Society 30(1):127-133.

Waymann, H. D. 1962. "A Thermoviscoelastic Description of the Tempering of Glass." J. of American Ceramic Society $\underline{45}(11): 517-522$.

Wilson, E. L., and R. M. Jones. 1967. Finite Element Stress Analys is of Axisymmetric Solids With Orthotropic, Temperature Dependent Material Properties. Air Force Report No. BSD-TR-67-222, Aerospace Corporation, San Bernardino, California. 
1
$\vdots$
$\vdots$
1
- 


\section{$\underline{\text { DISTRIBUTION }}$}

$1 \quad$ No. of

- Copies

$\therefore$

\section{UNITED STATES}

A. A. Churm

DOE Chicago Patent Division

9800 South Cass Avenue

Argonne, IL 60439

R. E. Cunn ingham

Deputy Director for Fuels and Materials

Nuclear Regulatory Commission

Silver Springs, MD 20910

T. C. Chee

DOE Office of Nuclear Waste Management

Washington, DC 20545

C. R, Cooley

DOE Office of Nuclear Waste Management Washington, DC 20545

Sheldon Meyers

DOE Office of Nuclear Waste Management Washington, DC 20545

R. G. Romatowski

DOE Office of Nuclear Waste Management Washington, DC 20545

D. M. Rohrer

United States Nuclear Regulatory

Commission

Washington, DC 20555

C. A. Heath

DOE Office of Nuclear Waste Management Washington, DC 20545

G. Oertel

DOE Office of Nuclear Waste Management Washington, DC 20545

A. F. Perge

DOE Office of Nuclear Waste Management Washington, DC 20545

R. D. Walton

DOE Office of Nuclear Waste Management Washington, DC 20545

W. E. Mott

DOE Division of Environmental Control Technology

Washington, DC 20545
No. of

Copies

\author{
J. Neff, Program Manager \\ Department of Energy \\ Columbus Program Office \\ $505 \mathrm{King}$ Avenue \\ Columbus, $\mathrm{OH} 43201$ \\ John $V$ an Cleve \\ DOE 0ak Ridge Operations Office \\ P.0. Box X \\ Oak Ridge, TN 37830 \\ J. B. Whitsett \\ DOE Idaho Operations Office \\ P.0. Box 2108 \\ Idaho Falls, ID 83401 \\ E. S. Goldberg \\ DOE Savannah River Operations Office \\ P.0. Box A \\ Aiken, SC 29801 \\ 27 DOE Technical Information Center \\ J. R. Berreth \\ Allied Chemical Corporation \\ 550 2nd Street \\ Idaho Falls, ID 83401 \\ Allied Chemical Corporation \\ (File Copy) \\ 550 2nd Street \\ Idaho Falls, ID 83401
}

A. Williams

Allied-General Nuclear Service

P.0. Box 847

Barnwe11, SC 29812

J. L. Jardine

Argonne National Laboratory

9700 South Cass Avenue

Argonne, IL 60439

M. M. Steindler/L. E. Trevorrow

Argonne National Laboratory

9700 South Cass Avenue

Argonne, IL 60439

Wayne Carbiener

Battelle Memorial Institute

505 King Ave.

Columbus, $\mathrm{OH} 43201$

J. Kircher

Office of Nuclear Waste I solation

Battelle Memorial Institute

505 King Ave.

Columbus, $\mathrm{OH} 43201$ 
No. of

Copies

Bever ly Rawles

Office of Nuclear Waste I solation

Battelle Memorial Institute

505 King Ave.

Columbus, $\mathrm{OH} 43201$

Brookhaven National Laboratory

Reference Section

Information Division

Upton, NY 11973

J. L. Crandall

E. I. duPont DeNemours and Company

Savannah River Laboratory

Aiken, SC 29801

T. B. Hindman

E. I. duPont DeNemours and Company

Savannah River Laboratory

Aiken, SC 29801

H. L. Hull

E. I. duPont DeNemours and Company

Savannah River Laboratory

Aiken, SC 29801

R. G. Garvin

E. I. duPont DeNemours and Company

Savannah River Laboratory

Aiken, SC 29801

Jim Howe 1

E. I. duPont DeNemours and Company

Savannah River Laboratory

Aiken, SC 29801

D. L. McIntosh

E. I. duPont DeNemours and Company

Savannah River Laboratory

Aiken, SC 29801

J. A. Kelley

E. I. duPont DeNemours and Company

Savannah River Laboratory

Aiken, SC 29801

M. D. Boersma

E. I. duPont DeNemours and Company

Savannah River Laboratory

Aiken, SC 29801

S. Mirshak

E. I. duPont DeNemours and Company

Savannah River Laboratory

Aiken, SC 29801

A. S. Jennings

E. I. duPont DeNemours and Company

Savannah River Laboratory

Aiken, SC 29801
No. of

Copies

H. Henning

Electric Power Research Institute

$3412 \mathrm{Hillview}$ Avenue

P.0. Box 10412

Palo Alto, CA 94301

Environmental Protection Agency

Technology Assessment Division

(AW-559)

Office of Radiation Programs

Washington, DC 20460

R. G. Barnes

General Electric Company

175 Curtner Avenue (M/C 858)

San Jose, CA 95125

Los Alamos Scientific Laboratory (DOE)

P.0. Box 1663

Los Alamos, NM 87544

J. P. Duckworth

Plant Manager

Nuclear Fuel Services, Inc.

P.0. Box 124

West Valley, NY 14171

J. G. Cline, General Manager

NYS Energy Research and Development Authority

230 Park Avenue, Rm 2425

New York, NY 10017

Oak Ridge National Laboratory (DOE)

Central Research Library

Document Reference Section

P.0. Box $X$

Oak Ridge, TN 37830

E. H. Kobisk

Solid State Division

Oak Ridge National Laboratory

Oak Ridge, TN 37830

R. Roy

Pennsylvania State University

Materials Research Laboratory

University Park, PA 16802

J. Braithwaite

ORG 5831

Sandia Laboratories

P.0. Box 5800

A1buquerque, NM 87185

W. Weart

Sandia Laboratories

Albuquerque, NM 87107 
No. of

Copies

J. 0. Blomeke

Union Carbide Corporation (ORNL)

Chemical Technology Division

P.0. Box Y

Oak Ridge, TN 37830

R. E. Blanco

Union Carbide Corporation (ORNL)

Chemical Technology Division

P.0. Box $Y$

Oak Ridge, TN 37830

D. E. Ferguson

Union Carbide Corporation (ORNL)

Chemical Technology Division

P.0. Box Y

0ak Ridge, TN 37830

H. W. Godbee

Union Carbide Corporation (ORNL)

Chemical Technology Division

P.0. Box $Y$

Oak Ridge, TN 37830

\section{FOREIGN}

2 International Atomic Energy Agency

Kartner Ring 11

P.0. Box 590

A-1011, Vienna, AUSTRIA

B. Morris

Atomic Energy Research Establishment, Harwe 11, Didcot,

Berks, ENGLAND

D. W. Clelland

United Kingdom Atomic Energy Authority

Risley, ENGLAND

E. R. Merz

Institut fur Chemische

Technologie

Kernforschungsan loge Julich

GmbH

$\overline{D 517}$ JuTich

Postfach 365

Federal Republic

WEST GERMANY

R. Bonniaud

Center de Marcoule

B.P. 170

30200 Baguols-Sur-Ceze

FRANCE

C. Sombret

Centre de Marcoule

B.P. 170

30200 Baguols-Sur-Ceze

FRANCE
No. of

Copies

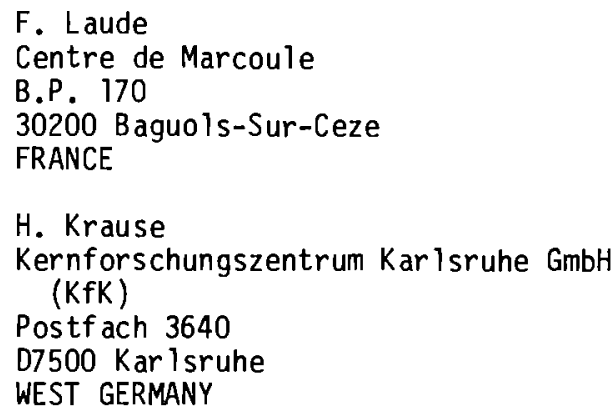

H. Krause

Kernforschungszentrum Karlsruhe GmbH (KfK)

Postfach 3640

D7500 Kar lsruhe

WEST GERMANY

S. Tashiro

Japan Atomic Energy Research Institute

Environmental Safety Research

Laboratory

1-1-13, Shibashi

Minatop $k u$, Tokyo

JAPAN

3 DOE Richland Operations Office

P. A. Craig

H. E. Ransom

M. J. Zamorsk i

5 Rockwell Hanford Operations

L. Brown

M. J. Kupfer

G. Reep

D. D. Wodrich

File copy

Exxon Nuclear Company

S. J. Beard

Westinghouse Hanford Company

A. G. Blasewitz

81 Pacific Northwest Laboratory

S. M. Barnes

W. J. Bjorklund

H. T. Blair

W. F. Bonner

R. A. Brouns

J. L. Buelt

L. A. Chick

R. D. Dierks

M. S. Hanson

A. J. Haverfield

L. K. Holton

J. H. Jarrett

D. E. Knowlton

W. L. Kuhn 
No. of

Copies

D. E. Larson

S. A. McCullough (3)

J. L. McElroy

G. B. Mellinger

J. E. Mendel

F. A. Miller

R. E. Nightingale

D. E. Olesen

K. H. Oma

C. R. Palmer

A. M. Platt

D. L. Prezbindowski (2)

W. A. Ross

J. M. Rusin

D. H. Siemens

F. A. Simonen (10)

S. C. Slate (30)

C. L. T immerman

R. T. Treat

R. E. Westerman

Technical Information (5)

Publishing Coordination YO(2) 